\title{
THE USE OF L1 AND THE TL IN FOCUS ON FORM AND ITS IMPACT ON UPTAKE, NOTICING AND LANGUAGE DEVELOPMENT
}

\section{TRUONG HONG HUE MINH}

A THESIS SUBMITTED TO THE VICTORIA UNIVERSITY OF WELLINGTON IN FULFILMENT OF THE REQUIREMENTS FOR THE DEGREE OF DOCTOR OF PHILOSOPHY IN APPLIED LINGUISTICS

VICTORIA UNIVERSITY OF WELLINGTON

2010 



\begin{abstract}
Since Long's (1991) coinage of the term focus on form (FonF)* to refer to brief attention to form in a meaning-oriented classroom, a substantial amount of research has been conducted on the role of FonF in second language learning. Evidence from this research supports the beneficial effects of FonF on learner noticing and language development (e.g. Doughty \& Varela, 1998; Ellis, Basturkmen, \& Loewen, 2001a; Loewen, 2005; Lyster \& Ranta, 1997; Mackey, 2006). However, some other aspects of FonF, especially in an English-as-a-foreign-language (EFL) setting, have received less attention. For example, it has been widely observed that in EFL settings where the teacher and learners usually share the first language (L1), teacher use of L1 to correct learners' errors is frequent (Anton \& DiCamilla, 1999; Crawford, 2004; Gabrielatos, 2001; Macaro, 2001; Turnbull \& Arnett, 2002). The effect of L1 versus the target language (TL) use on second language learning in the language classroom has long been an issue of concern for both teachers and researchers (Anton \& DiCamilla, 1999; E. Chau, 2007; Crawford, 2004; Gabrielatos, 2001; Swain \& Lapkin, 2000; Turnbull \& Arnett, 2002). However, choice of the language of form-focused episodes (FFEs) by EFL teachers has received little attention in the FonF research literature.
\end{abstract}

This research study investigates teacher use of L1 and the TL in FonF in an EFL setting in Vietnam and its impact on learner uptake, noticing and language development. The research consists of two studies: an observational/descriptive study followed by an experimental study. The observational study sought to identify general patterns of teacher use of L1 and the TL during FFEs in EFL classes through a close analysis of FFEs occurring in EFL classes in two private language institutions in Vietnam. Twelve class sessions across two proficiency levels with six Vietnamese EFL teachers were observed, audio-recorded and analysed. The results revealed that the amount of FonF and uptake in this setting was similar to amounts reported in other research although there was wide variation across the six class groups and the two proficiency levels. Over $18 \%$ of the teacher feedback moves were in L1, although again there was wide variety across classes and proficiency levels. When the L1 Vietnamese teachers gave explicit information to learners in multi-move FFEs, particularly on morphosyntax and lexical FFEs, they were more likely to use L1. 
These findings informed the experimental study which explored the relationship between the use of L1 and the TL in FFEs and learner uptake, noticing and language development. In this study, three interactive dyadic tasks were performed by individuals from two groups of learner participants with the researcher as interlocutor. Learners from one group received feedback in L1 $(n=20)$, learners from the other group in the TL $(n=23)$. The analysis revealed that, overall, the amount of uptake was similar between the two groups, suggesting that choice of the language of FonF does not influence learner uptake. Furthermore, the results for noticing and learning suggest that the language of FonF ( $\mathrm{L} 1$ or the TL) does not strongly influence learning outcomes.

By shedding light on teacher use of L1 and the TL in FonF and how this affects uptake, noticing, and learning, this research increases our understanding of the efficacy of FonF in the under-researched setting of non-native English teachers teaching in an EFL context.

* For abbreviated items, please go to Appendix 1. 


\section{ACKNOWLEDGEMENTS}

The road has been long and difficult, and it would have been impossible for me to get through if I were not supported in many different ways by the following people.

First and foremost, I would like to thank my supervisors, Dr. Jonathan Newton and Dr. Rebecca Adams for their invaluable guidance, encouragement, support and patience. I am deeply grateful for the research experiences shared through our casual talks which have inspired and motivated me in the least stressful way.

I would like to thank New Zealand Development Scholarships for granting me the award which gave me the opportunity to concentrate on my study. Without this grant, I could never have managed to be a breadwinner and a researcher at the same time.

My great thanks also go to the staff of the School of Linguistics and Applied Language Studies and the Student Learning Support Service (SLSS) of Victoria University of Wellington for their support and their smiles. My special thanks are to Kirsten Reid of SLSS for her patient listening and tailored help, and to Dalice Sim of the School of Mathematics, Statistics and Operations Research for her magic solutions to any statistic problems I encountered.

I am also grateful to my colleagues and the staff at the two private language centres which provided the setting for my study, and the research participants for joining me throughout the complicated process of data collection. I would like to offer my great thanks are for my two dear friends and colleagues, Nguyen Thi Hong Nhan and Tran Thai Phuong Boi for their ongoing support and care during the busy time of data collection. My special thanks also go to my friend, Le Nguyen, and her family for their support since my family and I first came to Welington, and their friendship throughout the time we have been here.

Last but not least, I would never thank my family enough for their support. My heartfelt thanks go to my extended families, my own parents and siblings as well as my in-laws, 
who have always supported our decision to go overseas to study. My special thanks are for my husband, Vien Dang, and my children, Vinh Dang and Mien Dang, for accompanying, supporting, understanding and enduring me with unconditional care and love. 


\section{TABLE OF CONTENTS}

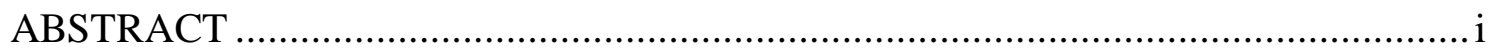

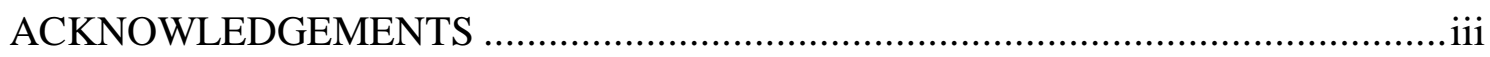

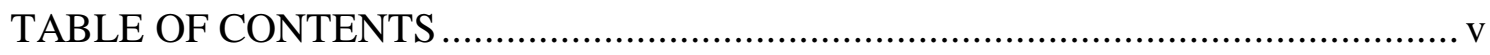

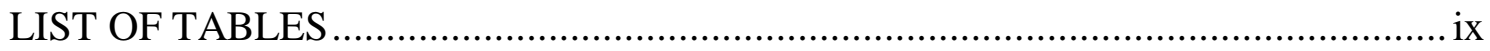

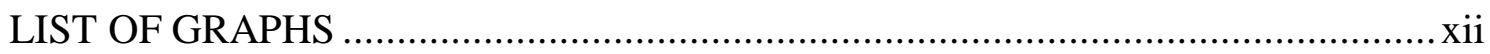

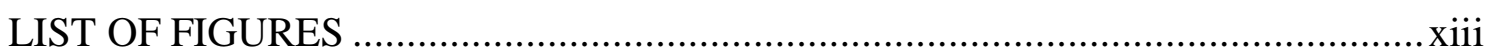

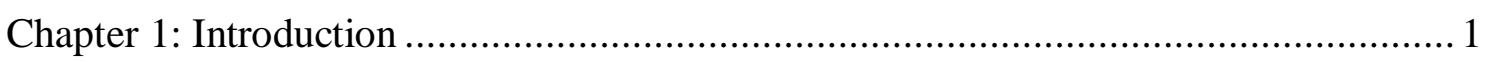

1.1. The purpose of the study...................................................................... 1

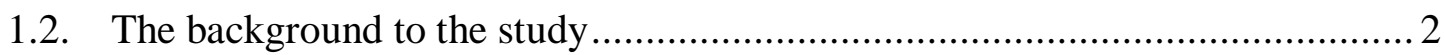

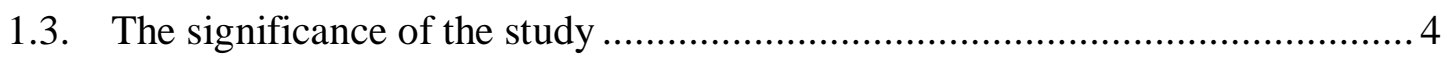

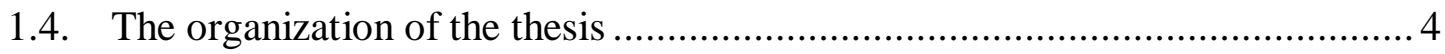

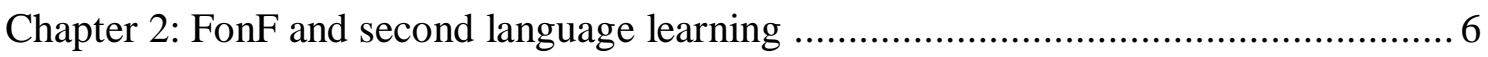

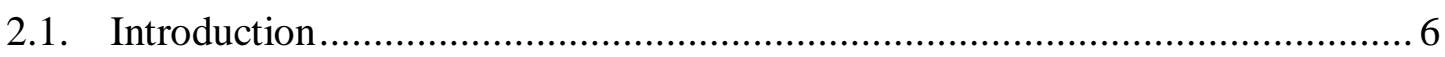

2.2. FonF definition and its related features .................................................. 6

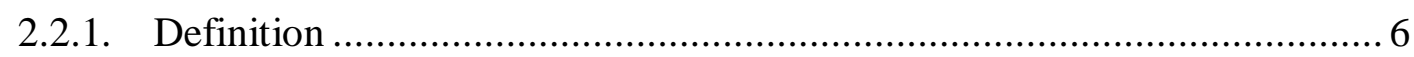

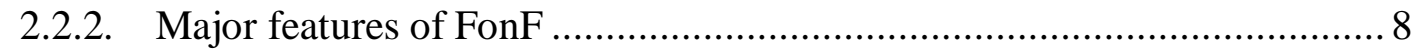

2.3. Psycholinguistic rationale underlying FonF ............................................. 13

2.3.1. The Input Hypothesis ............................................................................. 14

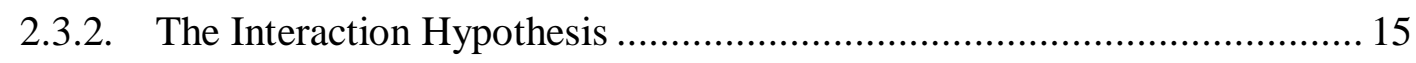

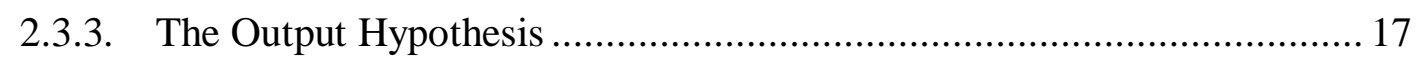

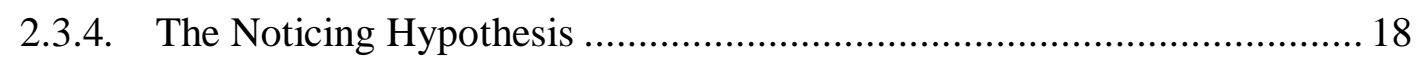

2.4. Main findings in FonF research ................................................................ 20

2.4.1. FonF occurrence in second language/foreign language classroom ...........20

2.4.2. Uptake in FonF ............................................................................... 21

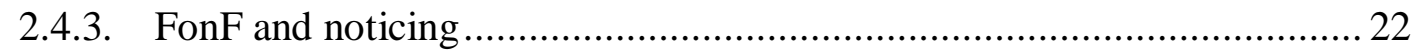

2.4.4. FonF and language development................................................... 23

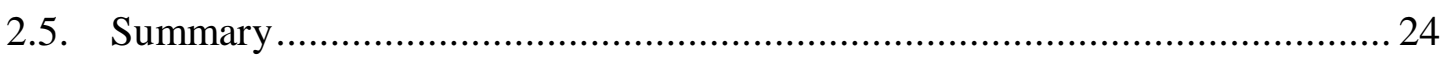

Chapter 3: The use of L1 in second language/foreign language classrooms ................ 26

3.1. L1 use across instructional settings and teaching methods .......................... 26

3.1.1. L1 use in different instructional settings ............................................ 26

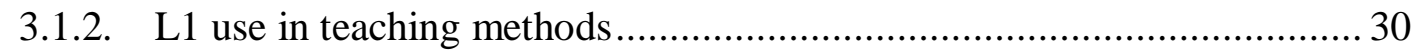


3.2. The arguments for and against L1 use in second language/foreign language classrooms

3.2.1. The roles of L1 use in second language/foreign language classrooms ...... 31

3.2.2. The virtual position on the TL use ....................................................... 35

3.3. The amount of L1 use across the instructional settings ................................ 36

3.3.1. The amount of learner use of L1 _....................................................... 36

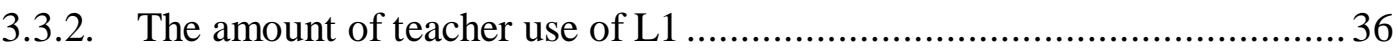

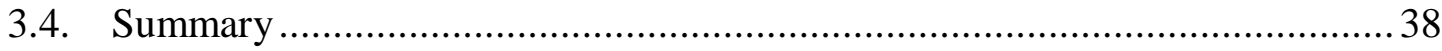

Chapter 4: Methodology for the descriptive study ................................................ 40

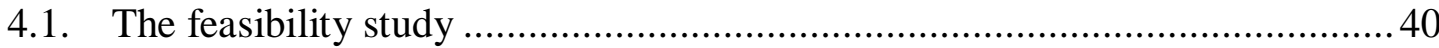

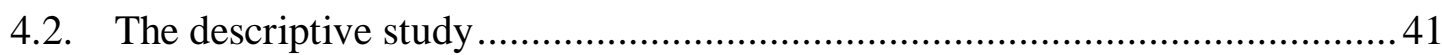

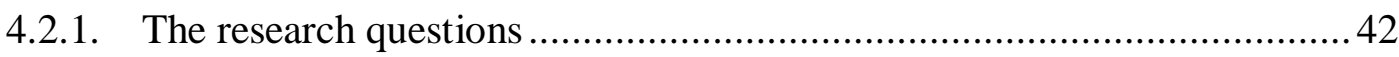

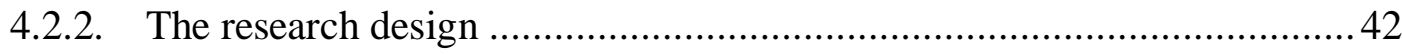

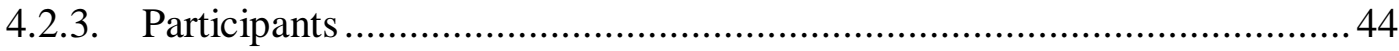

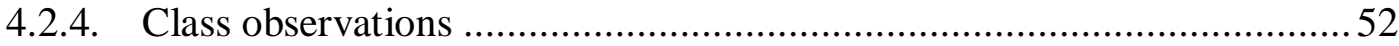

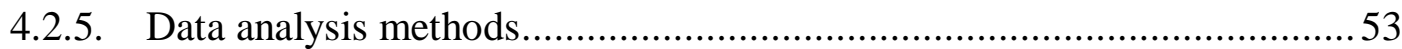

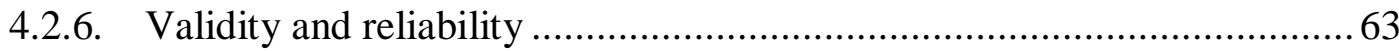

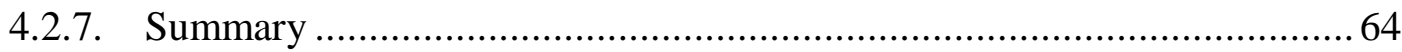

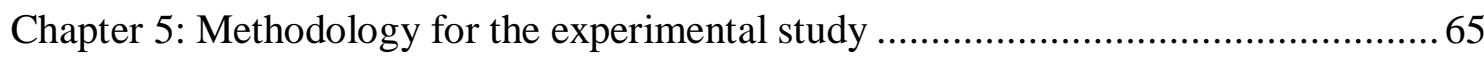

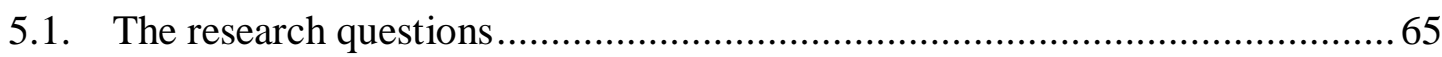

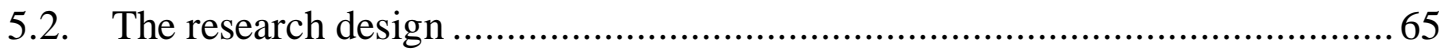

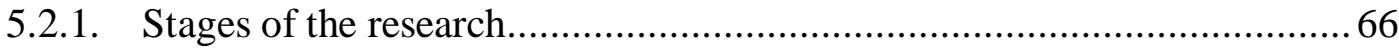

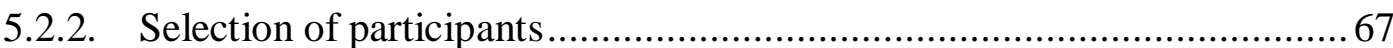

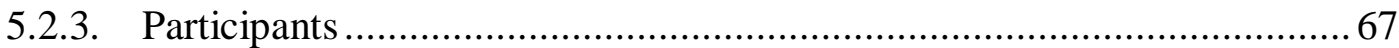

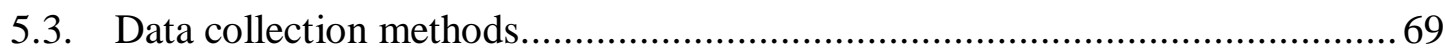

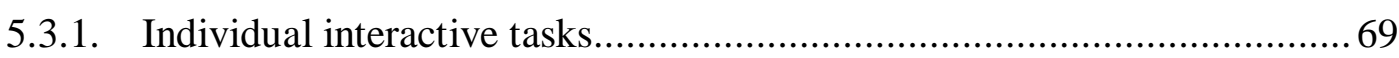

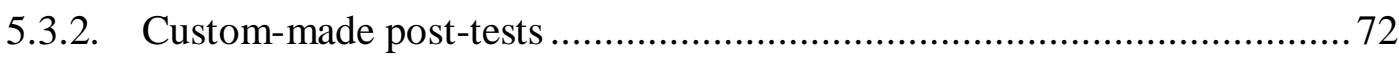

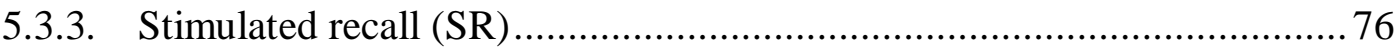

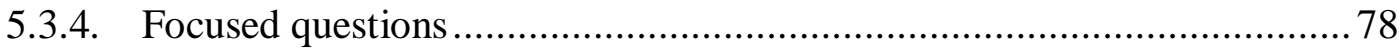

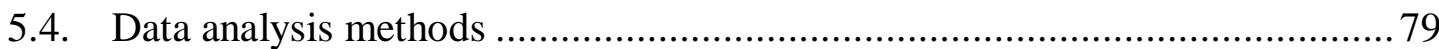

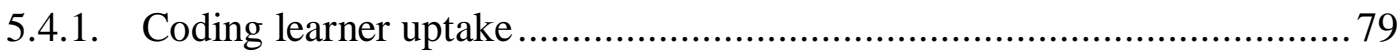

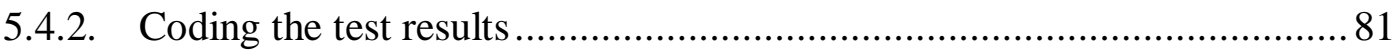

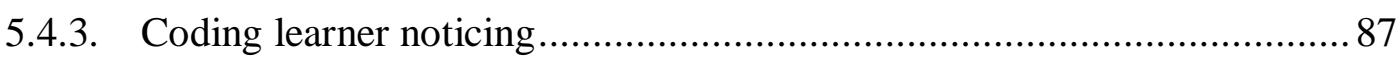

5.4.4. Statistic tools used for data analysis .................................................... 91

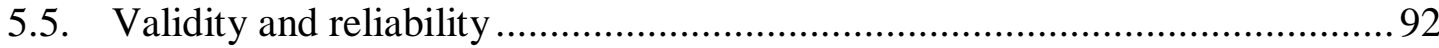




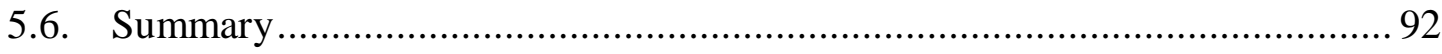

Chapter 6: FonF in an EFL context and its characteristics ..................................... 94

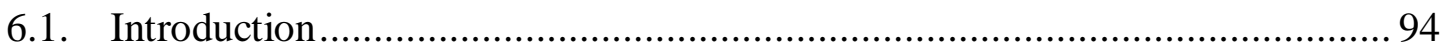

6.2. The amount of FonF in EFL classrooms .................................................... 94

6.2.1. Frequency of FFEs and teacher feedback moves ................................. 94

6.2.2. Occurence of FonF in EFL classrooms................................................ 98

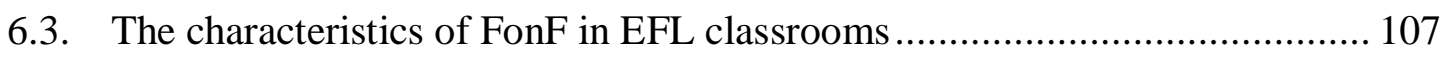

6.3.1. Types, sources and linguistic foci of FonF in EFL classrooms .............. 107

6.3.2. Pattern and variation of FonF characteristics in EFL classrooms .......... 117

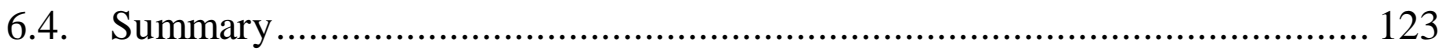

Chapter 7: Teacher use of L1 and TL in FonF and learner uptake............................ 126

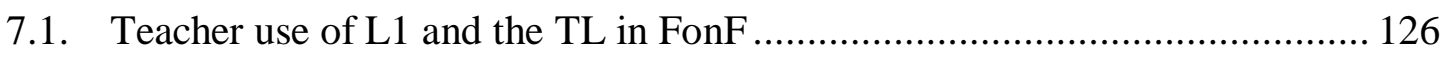

7.1.1. The amount of feedback in L1 and the TL....................................... 126

7.1.2. The use of L1 and the TL across the types of teacher feedback ............ 129

7.1.3. The use of L1 and the TL across the source of FonF ......................... 134

7.1.4. The use of $\mathrm{L} 1$ and the TL across the linguistic foci ............................ 138

7.1.5. Discussion: Factors influencing the use of L1 and the TL in FonF ........ 143

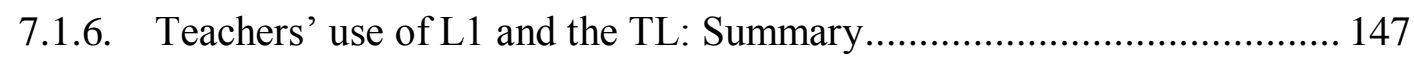

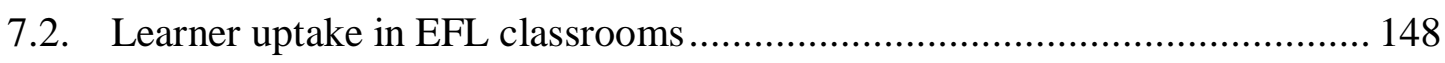

7.2.1. Learner uptake types across class groups ....................................... 149

7.2.2. Pattern of uptake types and teacher use of L1 and the TL.................... 156

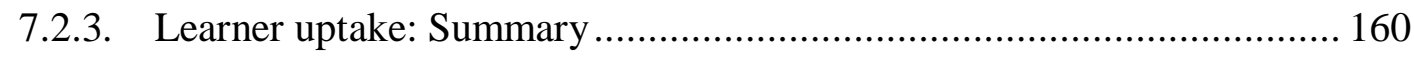

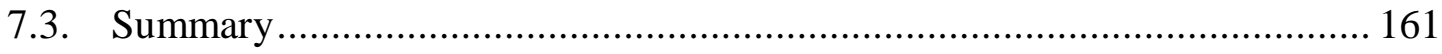

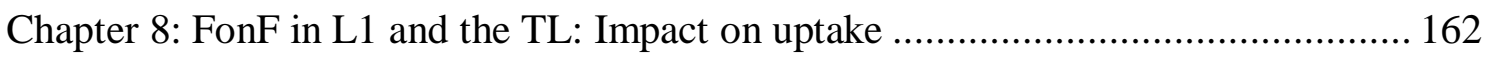

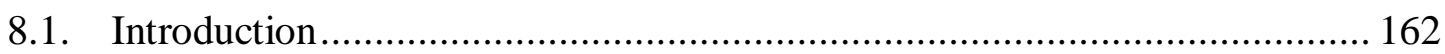

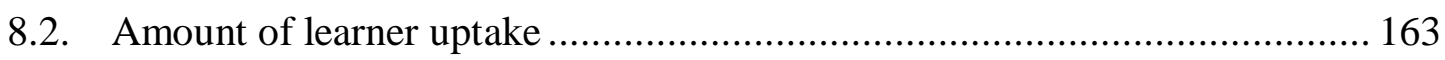

8.2.1. Amount of uptake types across the use of L1 and the TL ................... 164

8.2.2. Amount of "camouflaged uptake" across the use of L1 and the TL ....... 171

8.3. Teacher use of L1 and the TL and its impact on learner uptake and note-taking 174

8.3.1. The frequency and types of uptake in an experimental study ................ 174

8.3.2. The use of L1 and the TL and its impact on learner uptake ................. 177

8.3.3. The use of L1 and the TL and its impact on "camouflaged uptake"...... 179

8.4. The neglected aspects of the construct of uptake in FonF .......................... 181

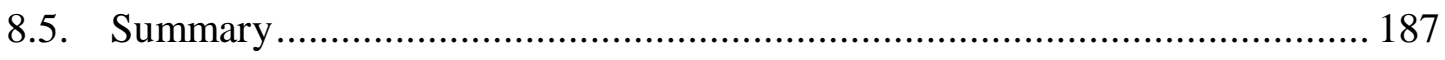


Chapter 9: FonF in L1 and the TL: Impact on learner noticing and language

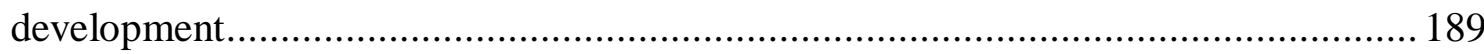

9.1. FonF in L1 and the TL: Impact on learner noticing ….............................. 189

9.1.1. The levels of learner noticing across the use of L1 and the TL in FonF . 189

9.1.2. Teacher use of L1 and the TL and its impact on learner noticing ........... 195

9.1.3. The use of L1 and the TL and its impact on learner noticing: Summary 197

9.2. FonF in L1 and the TL: Impact on language development ......................... 197

9.2.1. Learners' test results across the teacher use of L1 and the TL in FonF .. 197

9.2.2. Teacher use of L1 and the TL and its impact on language development 205

9.2.3. The use of $\mathrm{L} 1$ and the $\mathrm{TL}$ in FonF and its impact on language development:

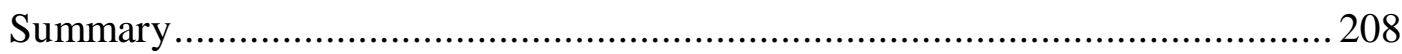

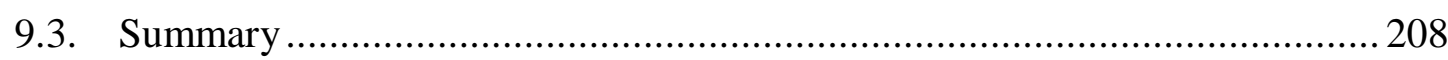

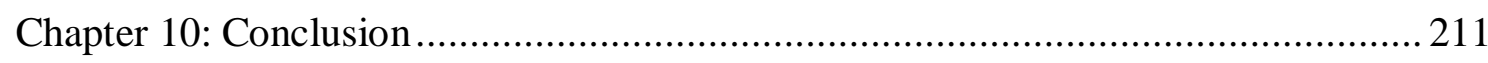

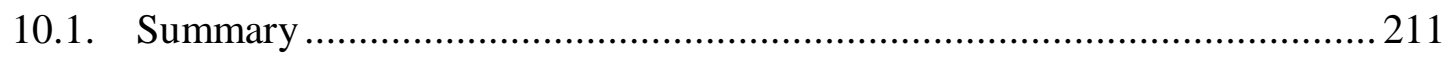

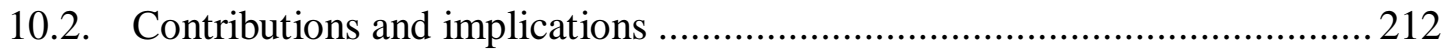

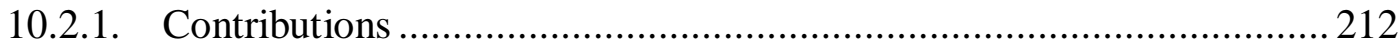

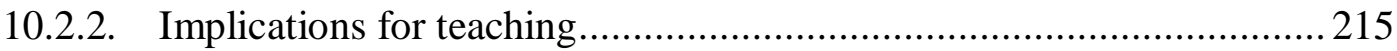

10.3. Limitations and further research........................................................ 216

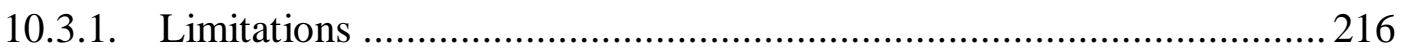

10.3.2. Further research ....................................................................... 217

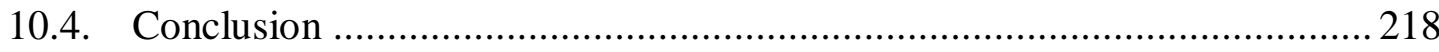

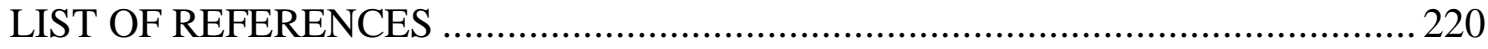

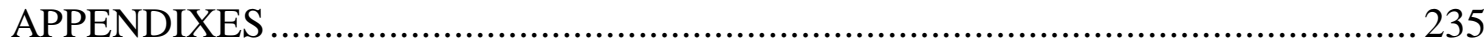




\section{LIST OF TABLES}

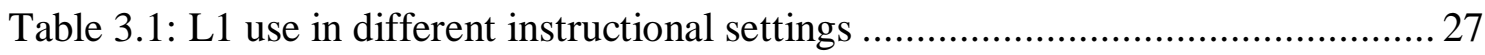

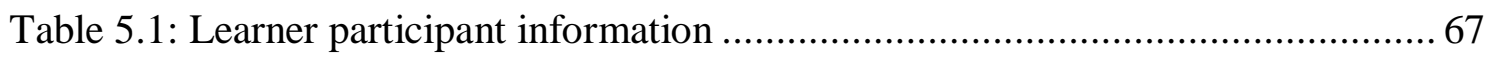

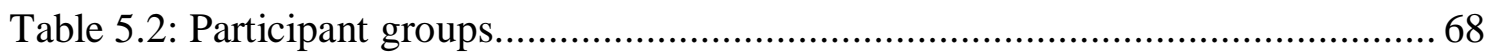

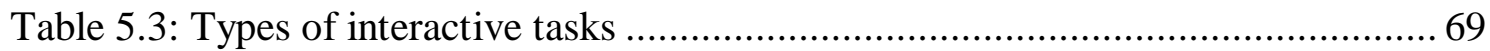

Table 5.4: Coding learner uptake and other characteristics of FFEs (adapted from

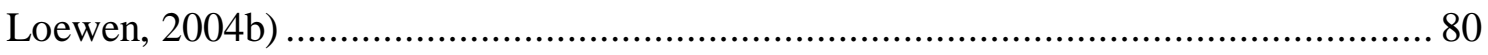

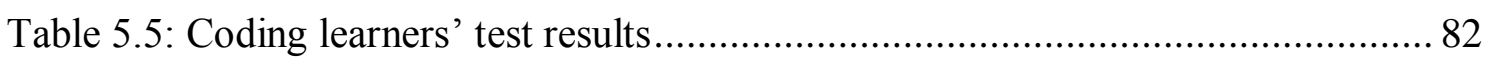

Table 6.1: Frequency of FFEs and teacher feedback moves ................................... 95

Table 6.2: Frequency of FFEs across class groups and proficiency levels ................... 95

Table 6.3: Frequency of feedback moves across class groups and proficiency levels ... 96

Table 6.4: Complexity of FFEs across class groups and proficiency levels .................. 97

Table 6.5: Types of teacher feedback across class groups....................................... 108

Table 6.6: ASRs for teacher feedback types .......................................................... 109

Table 6.7: Source of FFEs across class groups and proficiencies ............................ 110

Table 6.8: Source of teacher feedback moves across class groups and proficiencies, and

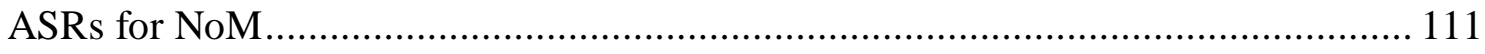

Table 6.9: Linguistic foci of FFEs across class groups and proficiencies .................. 112

Table 6.10: ASRs of linguistic foci of FFEs across class groups .............................. 114

Table 6.11: Linguistic foci of feedback moves across class groups and proficiencies 115

Table 6.12: ASRs of linguistic foci of feedback moves across class groups ............... 116

Table 6.13: Linguistic foci of FFEs across FonF studies...................................... 119

Table 7.1: Teacher feedback moves in L1 and the TL across class groups and

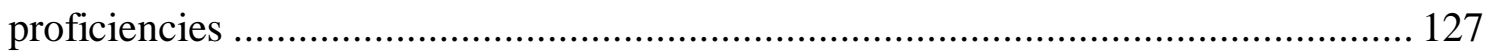

Table 7.2: ASRs of teacher use of L1 and the TL in feedback moves across class groups 128

Table 7.3: Teacher use of L1 and the TL across types of teacher feedback ............... 130

Table 7.4: ASRs of the use of L1 and the TL across the teacher feedback types ......... 132

Table 7.5: ASRs of teacher use of L1 and the TL in different types of teacher feedback

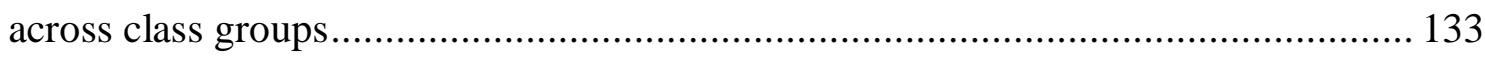

Table 7.6: Teacher use of L1 and the TL across types of teacher feedback ................ 135 Table 7.7: ASRs of the teacher use of L1 and the TL in NoF-triggered feedback across classes. 
Table 7.8: Teacher use of L1 and the TL across linguistic foci of feedback moves across

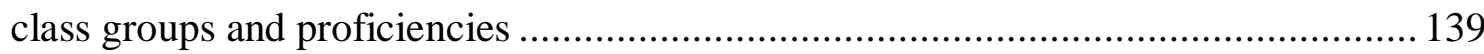

Table 7.9: ASRs of the use of L1 and the TL across the FonF source ........................ 141

Table 7.10: ASRs of language foci across the teacher use of L1 and the TL .............. 142

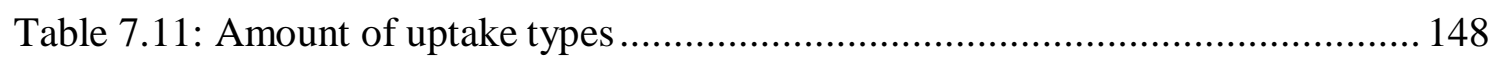

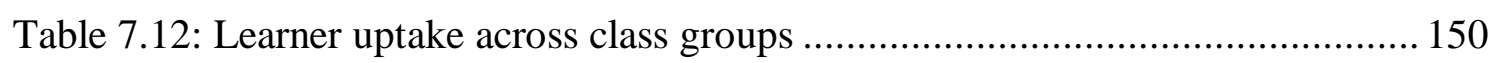

Table 7.13: ASRs of the uptake types across class groups ....................................... 151

Table 7.14: Learner uptake types across the use of L1 and the TL ......................... 152

Table 7.15: ASRs of learner uptake types across the use of L1 and the TL ................ 153

Table 7.16: Uptake types across the use of L1 and the TL layered by proficiency levels

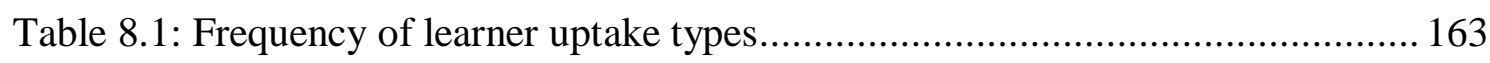

Table 8.2: Types of uptake across the use of L1 and the TL..................................... 164

Table 8.3: ASRs for uptake types across the use of L1 and the TL........................... 165

Table 8.4: Odds ratios of the occurrences of uptake types with the use of L1 versus the TL 166

Table 8.5: Frequency of uptake types across proficiency levels layered by the use of L1 and the TL.

Table 8.6: Frequency of uptake types across the use of L1 and the TL layered by the proficiency levels

Table 8.7: ASRs of the uptake types across the use of the TL and L1 layered by the proficiency levels

Table 8.8: Note-taking or "Camouflaged uptake" across the use of L1 and the TL .... 172

Table 8.9: Note-taking or "camouflaged uptake" practice across uptake types ........... 173

Table 8.10: Rate of repair and no uptake across the studies.................................... 175

Table 9.1: Amount of learner noticing across the use of L1 and the TL ................... 189

Table 9.2: Learner noticing across the teacher use of L1 and the TL layered by the

proficiency levels.

Table 9.3: Learner noticing across the proficiency levels layered by the teacher use of

L1 and the TL. 192

Table 9.4: Learners' note-taking practice and learner noticing ................................ 194

Table 9.5: Results for custom-made post-tests across the use of L1 and the TL ......... 198

Table 9.6: ASRs of learners' test results across the use of L1 and the TL ................. 199

Table 9.7: Odds ratios of the occurrences of targetlike answer with the use L1 of versus

the TL 200 
Table 9.8: Results for custom-made post-tests across the use of L1 and the TL layered by proficiency levels 200

Table 9.9: ASRs of test result across the use of L1 and the TL, layered by proficiency levels 202

Table 9.10: Test result across proficiency levels layered by the use of L1 and the TL 203 Table 9.11: ASRs of test result across proficiency levels layered by the use of L1 and the TL 204 


\section{LIST OF GRAPHS}

Graph 7.1: FonF moves in L1 and the TL across classes...................................... 127

Graph 7.2: Teachers' use of L1 and the TL in Provide......................................... 131

Graph 7.3: Teachers' use of L1 and the TL in Elicit .......................................... 131

Graph 7.4: Teachers' use of L1 and the TL in Reformulate .................................. 132

Graph 7.5: Teacher use of L1 and the TL in NoM .......................................... 135

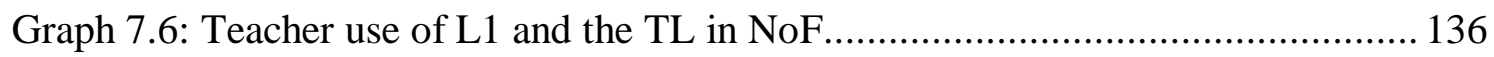

Graph 7.7: Teacher use of L1 and the TL in spelling-focused moves ...................... 138

Graph 7.8: Teacher use of L1 and the TL in pronunciation-focused moves............... 138

Graph 7.9: Teacher use of L1 and the TL in morphosyntax-focused moves .............. 140

Graph 7.10: Teacher use of L1 and the TL in vocabulary-focused moves ................. 140

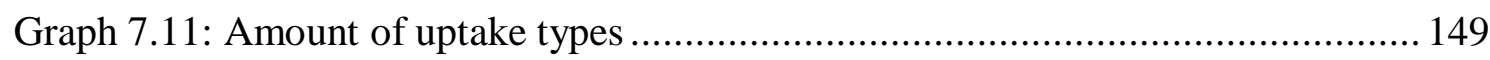

Graph 7.12: Learner uptake types across the use of L1 and the TL ........................ 152

Graph 7.13: Beginning learners' uptake types across the use of L1 and the TL......... 155

Graph 7.14: Advanced learners' uptake types across the use of L1 and the TL .......... 155

Graph 8.1: Frequency of types of learner uptake .............................................. 163

Graph 8.2: Types of uptake across the use of L1 and the TL.................................. 164

Graph 8.3: Frequency of uptake types across proficiency levels layered by the use of L1

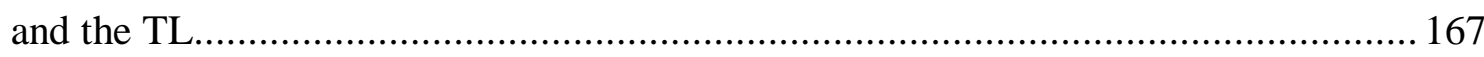

Graph 8.4: Uptake types across the use of L1 and the TL layered by the proficiency levels 169

Graph 8.5: Note-taking or "Camouflaged uptake" across the use of L1 and the TL.... 172

Graph 8.6: Note-taking practice across uptake types......................................... 173

Graph 9.1: Amount of learner noticing across the use of L1 and the TL ................... 190

Graph 9.2: Learner noticing across the teacher use of L1 and the TL layered by the proficiency levels.

Graph 9.3: Learner noticing across the proficiency levels layered by the teacher use of

L1 and the TL. 193

Graph 9.4: Learners' note-taking practice and learner noticing ................................ 194

Graph 9.5: Results for custom-made post-tests across the use of L1 and the TL ........ 198

Graph 9.6: Results for custom-made post-tests across the use of L1 and the TL layered

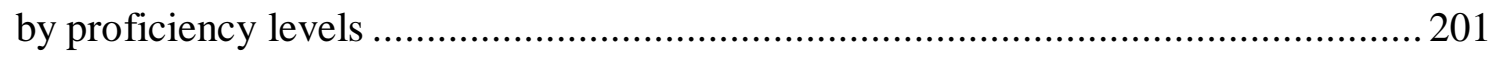

Graph 9.7: Test result across proficiency levels layered by the use of L1 and the TL. 203 


\section{LIST OF FIGURES}

Figure 2.1: Options in language teaching (Long \& Robinson, 1998).......................... 7

Figure 2.2: FonF trigger (based on Williams, 2005) ........................................... 9

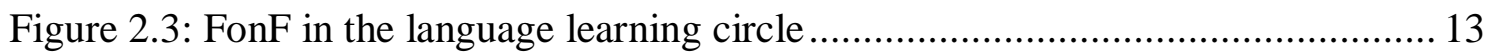

Figure 2.4: Data for SLA (Long \& Robinson, 1998).............................................. 15

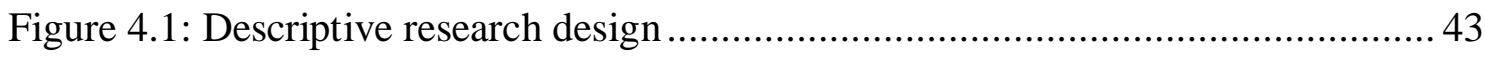

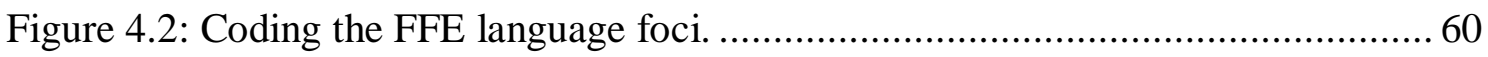

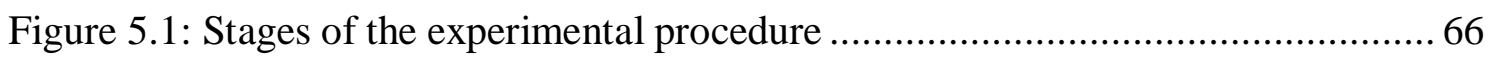

Figure 5.2: Coding scheme for acceptability judgment test items .............................. 85

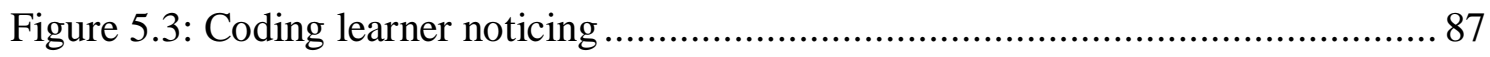





\section{Chapter 1: Introduction}

\subsection{The purpose of the study}

The role of focus-on-form (FonF) in the classroom in second language acquisition (SLA) is the subject of an extensive and growing body of research (e.g. Adams, 2007; Allwright, 1984; Anton \& DiCamilla, 1999; Ellis, Tanaka, \& Yamazaki, 1994; Gass, 1997; Loewen, 2005; Lyster, 2002; Mackey, 1999; McDonough \& Mackey, 2000). Several aspects of FonF such as what it involves and how it facilitates language learning have been researched. However, an aspect which has been left unattended is the impact of the language of FonF (i.e., the first language (L1) or the target language (TL)) on learning. From my 15-year experience in the profession, the use of L1 and the TL to address learners' linguistic problems has been a controversial topic among Vietnamese L1 teachers in Vietnam. Some teachers think that because they teach language classes, all instructional language including FonF has to be English to maximise exposure to English in the foreign language classroom. Other teachers believe that selective use of L1 may be helpful in FonF, but that English use should still be prioritised in the EFL classroom. Other teachers advocate the use of L1 in FonF, arguing that L1 is the best choice for FonF, especially for long explanations during FonF as it saves time and effort, and that $\mathrm{L} 1$ is a neglected resource in the EFL classroom.

There are two main reasons for me to choose the use of L1 and the TL in FonF among Vietnamese L1 teachers as the topic for my thesis. First of all, while FonF has been a pedagogical approach for the last two decades, and has attracted a considerable amount of research (e.g. Ellis, Basturkmen, \& Loewen, 2001b, 2002; Loewen, 2005; Long, 1991; Long \& Robinson, 1998; Lyster \& Ranta, 1997; Panova \& Lyster, 2002), little is known about this practice in EFL settings like the one in Vietnam, where language classes are taught by L1 teachers who share the mother tongue with their learners. Secondly, though the use of L1 and the TL in the language classroom has been largely documented (e.g. Anton \& DiCamilla, 1999; Atkinson, 1993; Macaro, 2001; Turnbull \& Arnett, 2002), little research has been carried out on L1 and TL use in FonF and its impact on learning. This study, therefore, aims to investigate this practice in the Vietnamese context where English is considered an important foreign language, and teachers who share L1 with their learners are not certain whether this sharing is a curse or blessing. 
This thesis aims to answer six research questions in two different studies: a descriptive study and an experimental study. The descriptive part of the study addresses the three following questions:

In EFL classes taught by Vietnamese L1 teachers in Vietnam:

1. How much and what kinds of FonF take place during teacher-student interaction in EFL classrooms in Vietnam?

2. What types of FonF during teacher-student interaction are given in the first language (Vietnamese) and in the target language (English)?

3. How much and what kinds of uptake take place during teacher-student interaction in EFL classrooms in Vietnam in relation to the teacher use of L1 and the TL?

The experimental study aims to answer the three following research questions:

In an EFL setting instructed by a Vietnamese L1 teacher in Vietnam:

1. Does the teacher use of L1 in FonF during teacher-student interaction lead to more noticing than the use of the TL?

2. Does the teacher use of L1 in FonF during teacher-student interaction lead to more uptake than the use of the TL?

3. Does the teacher use of L1 in FonF during teacher-student interaction lead to more language development than the use of the TL?

\subsection{The background to the study}

Despite some dramatic social and political changes in Vietnam since English first became a foreign language taught at school in the 1960s, English remains the major foreign language taught at schools and universities in Vietnam. At schools and universities, English is usually a compulsory subject. Graduation examinations of secondary and tertiary education usually include a compulsory English test. Since Doi Moi (Renovation) policy took off in the early 1990s with the aim of openly connecting Vietnam with the rest of the world, English has an even more important foreign language (Nunan, 2003; Do, 2006). A certificate of a specific level of English is usually required at work and for higher education. Certificates of English are issued at three 
different levels: A (beginning), B (intermediate) and C (advanced), and tests required to get these certificates examine four skills: listening, speaking, reading and writing. Because English classes in Vietnamese schools and universities usually give lessons in grammar, reading and writing only, hundreds of thousands of private English language centres came into being all over the country teaching English to prepare learners for these tests, especially concentrating on speaking and listening skills. However, classes at these language centres are quite crowded, which results in poor teaching quality, and the procedure of issuing certificates is usually criticised for a lack of efficiency and reliability.

Since the Doi Moi policy took effect, while the English teaching system at school and university in Vietnam has remained virtually unchanged, private education has developed dramatically to stay in tune with the changing needs for English learning in Vietnam. Over the last decade, the number of Vietnamese students going overseas to study has grown quickly (IIE, 2010; Austrade, 2010). In addition, many foreign enterprises are coming to Vietnam to do business. Private English teaching, therefore, has changed to meet these new needs. Several private English language centres came into being, aiming to provide English courses for learners preparing to study abroad or work in international companies. In the private study environment, courses and syllabuses are designed to help learners obtain internationally acknowledged English certificates such as IELTS, TOEFL or TOEIC. Classes at these centres are small in size, while teaching methods are communication-oriented. Accordingly, school fees are high. Teachers at these centres are carefully recruited, and learners are committed and motivated with high expectations from the centres.

This study took place in two of the private English language centres which are supposed ${ }^{1}$ to teach "English for communication" for learners who want to communicate in English and to acquire international certificates of English such as IELTS, TOEFL or TOEIC. One may argue that this setting may not provide the most representative view of the English teaching panorama of Vietnam. However, this study relies on meaningcentred classrooms and these private English language centres are where these

\footnotetext{
${ }^{1}$ The practice of teaching "English for communication" varies widely across these private English centres, ranging from classes with a main focus on speaking skills only to classes using newly designed teaching materials covering the four skills of speaking, listening, reading and writing with a communicative purpose.
} 
classrooms are most prevalent. In addition, trends in economics and education in Vietnam are driving a growing need for these types of classes.

\subsection{The significance of the study}

This study is significant for two main reasons. First, it addresses the existing gaps in FonF research: how teachers use $\mathrm{L} 1$ and the $\mathrm{TL}$ in FonF and how this practice influences learner uptake, noticing and language development. This is the only study on FonF so far of which I am aware that focuses on the use of L1 and the TL in FonF in foreign language classes where teachers and learners share their L1. This issue has thus far been controversial due to lack of research evidence.

Second, by combining both descriptive and experimental approaches, this study both examines the teacher use of $\mathrm{L} 1$ and the TL in FonF and measures its impact on learning. As a result, this study does not only provide observational findings about the practice, but also experimental results which measure its effectiveness.

\subsection{The organization of the thesis}

This thesis contains seven chapters. Chapter 1 introduces the thesis. Chapter 2 reviews research into FonF including the definition of FonF and its features, in turn including the trigger of FonF, the meaning-centred setting in which it takes place, and some dimensions of FonF features such as explicit-implicit, intensive-extensive, and plannedincidental. SLA theories underlying FonF such as the Input Hypothesis, the Interaction Hypothesis, the Output Hypothesis and the Noticing Hypothesis are also discussed in relation to how FonF facilitates acquisition. Chapter 2 also reviews the main findings in FonF research, including the occurrence of FonF in the language classroom, the occurrence of learner uptake and noticing in FonF, and the relationship between FonF and learning.

Chapter 3 continues the literature review by focusing on previous research into the use of L1 and the TL in the language classroom. This chapter gives a summary of the possibility of the use of L1 in teacher-learner and learner-learner interaction across different instructional settings as well as the position of L1 across different teaching methodology. The reasons for the use of L1 and the TL are also reviewed and discussed. 
This chapter ends with a summary of the research results of the amount of L1 used by teachers and learners in different instructional settings.

Chapter 4 and Chapter 5 describe the research design and methodology used in the descriptive study and the experimental study of this research, respectively. Each of these chapters includes a description of data collection and data analysis processes, a discussion of the validity and reliability of the research procedure, and a description of the statistical tools used for data analysis.

Chapter 6 presents and discusses the findings of the descriptive study dealing with the amount and types of FonF taking place in natural EFL classes taught by the Vietnamese L1 teachers. Chapter 7 continues to describe and analyse the results of the descriptive study, focusing on the amount and types of FonF across the teacher use of L1 and the $\mathrm{TL}$ in FonF, and the relationship of this practice with learner uptake.

Chapter 8 presents and discusses the results of the experimental study involving the impact of the teacher use of L1 and the TL in FonF on learner uptake. This chapter reports how much learner uptake takes place in the experimental study and how learner uptake is associated with the teacher use of L1 and the TL in FonF. This chapter also takes into account the learners' note-taking habit in FonF and its relation to uptake. Chapter 9 continues to describe the results of the experimental study which focuses on teacher use of L1 and the TL and its impact on learner noticing and language development.

Chapter 10 contains contributions and implications of the research in FonF instruction as well as in future research. This chapter also points out the limitations of the research and gives a conclusion to the thesis. 


\section{Chapter 2: FonF and second language learning}

\subsection{Introduction}

This chapter will first present definitions of widely used terms in the research on FonF. It will then discuss the psycholinguistic rationale underlying FonF. Finally, the chapter will review the findings of the research which has examined the relationship between FonF and second language learning.

\subsection{FonF definition and its related features}

As pointed out by researchers such as Lyster \& Ranta (1997) and Williams (2005), the various terms in the research of FonF have been quite confusing and potentially discouraging to English-as-a-second-language (ESL) and EFL teachers who are supposed to be among the most direct beneficiaries from the research findings. This part of the chapter aims to clarify the term focus on form (FonF) in relation to its definition and its major features.

\subsubsection{Definition}

Form is a multi-meaning and ambiguous term in the literature of SLA. In the research on vocabulary acquisition, form is one of the two dimensions of a word, defined as the way a word is written or pronounced as opposed to meaning, the other side of a word referring to its semantic aspect (Nation, 2001; Thornbury, 2006). In the literature of SLA, form has long been used to refer grammar (e.g. Ellis, 1984, 1990). However, as pointed out by R. Ellis (2001) and R. Ellis, Basturkmen, \& Loewen (2002), form in the term FonF covers any aspect of linguistic form including phonological, lexical, graphological, grammatical and even the meaning/function conveyed by a particular form. Each particular aspect of form is usually referred to as a linguistic (code) feature in the FonF literature.

The original definition of FonF by Long $(1988,1991)$ and revised by Long \& Robinson (1998) presents FonF as an eclectic teaching option which is positioned in the middle of the continuum with Option 1, focus on formS (FonFS), and Option 2, focus on meaning as the two extremes (see Figure 2.1). By FonFS, they refer to synthetic syllabi such as 
Grammar Translation in which language learning is assumed to be a process of learners' accumulating linguistic entities to build up their own interlanguage. Focus on meaning is the teaching option based on analytic syllabi like immersion or natural approach. Immersion refers to a method of teaching a second language by using the TL as the language of instruction to "immerse" learners in a TL surrounding such as the French immersion program in Canada (Swain \& Lapkin, 1989). Similarly, the natural approach promotes language learning through learners' exposure to the TL during meaning-focused communicative activities in the class (Krashen \& Terrell, 1983). According to the teaching methods that reflect this option, second language learning is most efficient when being modelled to be acquisition-like: implicit and non-obtrusive, and with only comprehensible input deemed essential for acquisition (Krashen, 1980).

Figure 0.1: Options in language teaching (Long \& Robinson, 1998)

\begin{tabular}{|c|c|c|}
\hline Option 2 & Option 3 & Option 1 \\
\hline $\begin{array}{l}\text { analytic } \\
\text { focus on meaning }\end{array}$ & $\begin{array}{l}\text { analytic } \\
\text { focus on form }\end{array}$ & $\begin{array}{l}\text { synthetic } \\
\text { focus on forms }\end{array}$ \\
\hline Natural Approach & TBLT & GT, ALM, Silent Way, TPR \\
\hline Immersion & Content-Based LT(?) & \\
\hline $\begin{array}{l}\text { Procedural Syllabus } \\
\text { etc. }\end{array}$ & $\begin{array}{l}\text { Process Syllabus(?) } \\
\text { etc. }\end{array}$ & $\begin{array}{l}\text { Structural/N-F Syllabuses } \\
\text { etc. }\end{array}$ \\
\hline
\end{tabular}

As pointed out by Long and Robinson (1998), research conducted in this field has revealed shortcomings of the first two teaching options (Option 1 and Option 2). Language learning has been shown to be more complex than a process of accumulating linguistic entities as implied in the Option 1 teaching methods. And providing learners with comprehensible input as in Option 2 cannot guarantee learning since learning a second language is different from acquiring an $\mathrm{L} 1$ in several aspects. FonF, as the third option, is envisioned to combine the strengths of the two other options by maintaining the communicativeness of a meaning-focused classroom while briefly drawing learners' attention to form 'triggered by perceived problems with comprehension or production' (Long \& Robinson, 1998, p. 23). An example of a FonF approach is task-based language teaching in which learners perform meaningful tasks using the TL while receiving feedback on linguistic features from their classmates and their teacher. The 
completion of tasks and maintaining the communicative flow of the class are prioritised within which shifts of attention to linguistic forms occur as necessary for successful task completion. Long argues that these embedded form-focused episodes are optimal for leading learners to notice new linguistic forms and to test hypotheses about the language, both of which are claimed to promote language acquisition.

Since the coinage of the term FonF by Long $(1988,1991)$, it has been widely used to refer to similar concepts with different scopes. Lightbrown \& Spada (1990) use FonF as another term for form-focused instruction. Lyster and Ranta (1997) refer to FonF as a new term for corrective feedback (CF). In other studies such as Sheen (2004) and Farrokhi \& Gholami (2007), the scopes of FonF differ. The difference in the scopes of this term across the studies is reflected in the variation of the major features of FonF discussed in the following .

\subsubsection{Major features of FonF}

The two major features of FonF according to Long \& Robinson (1998, p. 23) should be: (1) it takes place in a 'meaning-focused classroom lesson', and (2) consists of 'an occasional shift of attention to linguistic code features'. Thus, they argue that focus on meaning and FonFS are not necessarily mutually exclusive. These two features have been the core of most interpretations of the term FonF in the research studies that followed its birth. However, different studies have defined how the 'shift of attention to linguistic code features' is triggered in different ways. This has resulted in diverse uses of the term FonF in different studies as discussed below.

\subsubsection{FonF trigger: Problematicity and learner interlanguage gap}

Figure 2.2 shows the taxonomy of FonF trigger which comes from either the teacher or the learner across different scopes of FonF studies. 
Figure 0.2: FonF trigger (based on Williams, 2005)

FonF trigger

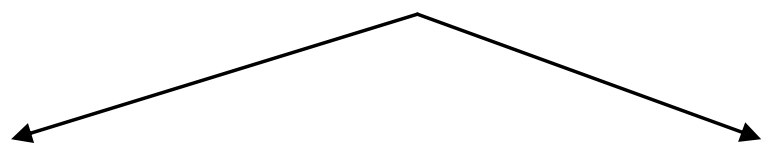

Learner problem/difficulty

Teacher-anticipated problem/difficulty

(error, communication breakdown, learner inquiry)

(teacher question, eliciting)

- need-based/problem-based

- anticipated need

- actual gap

- no problem-based

- perceived gap

- possibly not actual gap
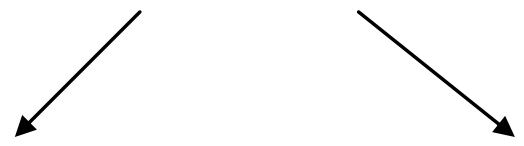

Real-time problem

Pre-planned problem

- reactive

- pro-active

- incidental

- planned

- extensive

- intensive

Research on FonF has identified two main views on what constitutes a legitimate FonF trigger and therefore on what are the parameters of a FonF approach: problematicity and learner interlanguage gap. The view defining FonF trigger as problematicity claims that FonF is only triggered by a problem or difficulty learners encounter when they are using a language communicatively. Thus, some early studies equated FonF with $\mathrm{CF}$ in which a learner problem is in the form of an error, and FonF is error treatment, (e.g. Lyster \& Ranta, 1997). This treatment may be incidental and extensive (e.g. Lyster \& Ranta, 1997), or planned and intensive (e.g. Doughty \& Varela, 1998), but it must be reactive to a learner problem in conveying a message.

Long \& Robinson's (1998, p. 23) later extended the definition of FonF trigger to cover learner queries about linguistic items, that is to say, problems of production as well as comprehension. Several studies now typically distinguish these two main categories of FonF: reactive FonF (i.e., CF) and pre-emptive FonF (i.e., learner-initiated FonF) (e.g. Loewen, 2004a, 2004b; Loewen, 2005). Both types of trigger are actually learner- 
initiated and emerge from the conversational interaction in which learners' pushed output is enabled (Swain, 1995, 2005). According to Williams (2005) these two problem-oriented categories address real learner problems. On the other hand, she casts a doubt on what is called teacher-initiated FonF by Ellis, et al. (2001a, 2001b).

In their studies, Ellis and his colleagues have had a different view at the trigger of FonF; this view addresses a FonF trigger as the learner's interlanguage gap. Ellis et al. (2001; 2004; 2001b, 2002) consider the learner interlanguage gap as one of the central features of FonF. Learner interlanguage gaps can typically be revealed in two cases. First, these gaps can be observable through their errors in interaction which may or may not cause communication breakdown. When communication breakdown occurs, attention to form is obviously necessary to clarify any miscommunication between interlocutors by a process of locating the problem and providing treatment. However, in a lot of cases, no miscommunication occurs despite the perceived errors, and it is usually the teacher's choice to address or ignore them. FonF in the former circumstances aims at negotiation of meaning, while in the latter situations, it simply draws learners' attention to linguistic items per se. Whether miscommunication exists, this case of learner interlanguage gaps is problem-instigated, and the learner interlanguage gap is real and well-perceived (Williams, 2005); the treatment, therefore, is necessary and well-expected.

Second, it is widely observed that in many classroom situations, learners initiate attention to form by asking the teacher questions about some linguistic forms they are interested in. No miscommunication or errors occur, but it can be argued that the gap in learner interlanguage exists (Williams, 2005), and learners pre-empt their future linguistic problems (Ellis et al, 2001) and get prepared by filling their interlanguage gaps when possible. Nevertheless, the gaps in learner interlanguage are not necessarily that observable and evident. In many cases, the learner interlanguage gaps can be preempted by the teacher through some well-used strategies in classroom such as asking whether learners know a word (Ellis et al, 2001).

Learner interlanguage gap has been a key concept in the literature of SLA. The Noticing Hypothesis (R. W. Schmidt, 2001) emphasizes the importance of learners' noticing the gap in their interlanguage. The Output Hypothesis (Swain, 2005) establishes the role of learner output production as a chance for learners to process syntactically and reveal their interlanguage gaps to FonF. While more theory-driven than problematicity, learner 
interlanguage gap may raise two concerns. First, as pointed out by Williams (2005), the teacher's guess can be inaccurate, which may lead to a fake gap. Williams (2005) argues that since a linguistic problem may not exist, whether this is FonF is questionable. A second concern is that the boundary between FonF and the teacher instruction may become more blurred than ever, since the range of learner interlanguage gaps seems limitless, and the boundary can thus be extended to cover most teacher instruction in classroom.

Despite the concerns, Ellis et al (2001a, 2001b, 2002) argue and show that learner interlanguage gaps in teacher-initiated FonF can be verified from analysis of the data. When identifying form-focused episodes (FFEs), they consider the context of the data and eliminate episodes initiated by the teacher in which the learner interlanguage gap does not exist. They also argue that while teacher-initiated FonF may address learner interlanguage gaps, and hence contribute to language learning, little is known about this type of FonF (Ellis, et al., 2001a).

\subsubsection{A meaning-centred setting}

Another feature that differentiates FonF from FonFS is the setting where FonF takes place. One of the prerequisites for FonF to occur is a setting in which the flow of communication is a priority. This explains why the types of syllabus defined for FonF are task-based (Ellis, et al., 2002; Long \& Robinson, 1998) or possibly content-based (Long \& Robinson, 1998) since both types of syllabuses involve meaningful communication, interaction and negotiation. To ensure the setting is meaning-centred, researchers emphasize that FonF should be transitory and occasional, and the teachers and the learners can "navigate in and out of FonF" smoothly (e.g. Doughty \& Varela, 1998; Ellis, et al., 2001a; Farrokhi \& Gholami, 2007; Loewen, 2005). However, while the amount of FonF taking place in the studies can be quantified through various coding systems, the question whether a meaning-centred setting exists is usually answered by the subjective observation of the researchers (Ellis, et al., 2001a; Loewen, 2003, 2004a, 2004b, 2005). In task-based language teaching, task completion is usually cited as a criterion for the existence of a meaning-centred setting. 


\subsubsection{Some distinguishing types of FonF}

FonF has been distinguished as: incidental and extensive versus planned and intensive FonF, and explicit versus implicit FonF.

Long (1991) and R. Ellis, et al. (2001a) emphasize one of the features of FonF as being incidental and hence extensive. The consideration of excluding planned and intensive attention to form from FonF may originate from the need to promote FonF as an analytic approach, distinct from a synthetic approach (Long \& Robinson, 1998). While FonFS treats language learning as a process of accumulating linguistic entities taught in pre-planned lessons, FonF in Long \& Robinson's (1998) definition rejects planned and intensive attention to form as this feature is typical of a FonFS approach. Similarly, studies on incidental FonF like Basturkmen, et al. (2004) or Loewen (2003, 2004b, 2005) also consider planned FonF an undesirable feature. However, in Doughty \& Varela's (1998) study, planned and intensive attention to form is still taken into account because the purpose of this experimental study is to examine the effectiveness of recasts when learners learn a targeted grammatical feature. The researchers argue that since FonF in their study takes place in a meaning-centred setting where the class successfully performs the interactive task, and FonF opportunities occur naturally, FonF in their study is "reasonably incidental" (Doughty \& Varela, 1998, p. 135).

Another distingusing type of FonF is explicit-implicit FonF. As pointed out by Doughty \& Williams (1998), the explicitness of FonF is one of the pedagogical choices teachers need to make when doing FonF. They argue that implicit FonF is unobtrusive and aims to attract learner attention, while explicit teaching is overt, obtrusive and metalinguistic, which aims to direct learner attention. The implicit-explicit continuum of FonF addresses the tension between the need for FonF to be unobtrusive enough to maintain the communication flow while also salient enough to draw the learner's attention. While too much attention to form results in deliberate rather than automatic language use, a feature distinguishing FonF from FonFS (Doughty \& Williams, 1998), the explicitness of FonF has been researched. FonF studies show that implicit FonF like recasts often leads to less attention, less learner uptake and repair and hence less learning than explicit FonF such as metalinguistic explanations (e.g. Ellis, Loewen, \& Erlam, 2006; Loewen, 2005; Lyster \& Ranta, 1997; Radwan, 2005). 
In the study to come, as learner uptake, noticing and language development are adopted as indexes for learning, learner attention, uptake and repair are the key aspects to be examined and discussed in order to address the research questions on the relationship between the teacher use of L1 and the TL and its impact on learning.

\subsection{Psycholinguistic rationale underlying FonF}

FonF takes place in the circle of language learning characterized by a meaningful communicative and interactive setting (see Figure 2.3). In this circle, learning takes place when comprehended input (Gass, 1997) is noticed and becomes intake. Intake fuels output and is incorporated in pushed output. The pushed and modified output, in turn, participates in the interaction flow to become new input and possibly receives new negative evidence. FonF in this circle involves learners' process of receiving feedback, noticing their interlanguage gaps, and incorporating feedback in their pushed output.

Figure 0.3: FonF in the language learning circle

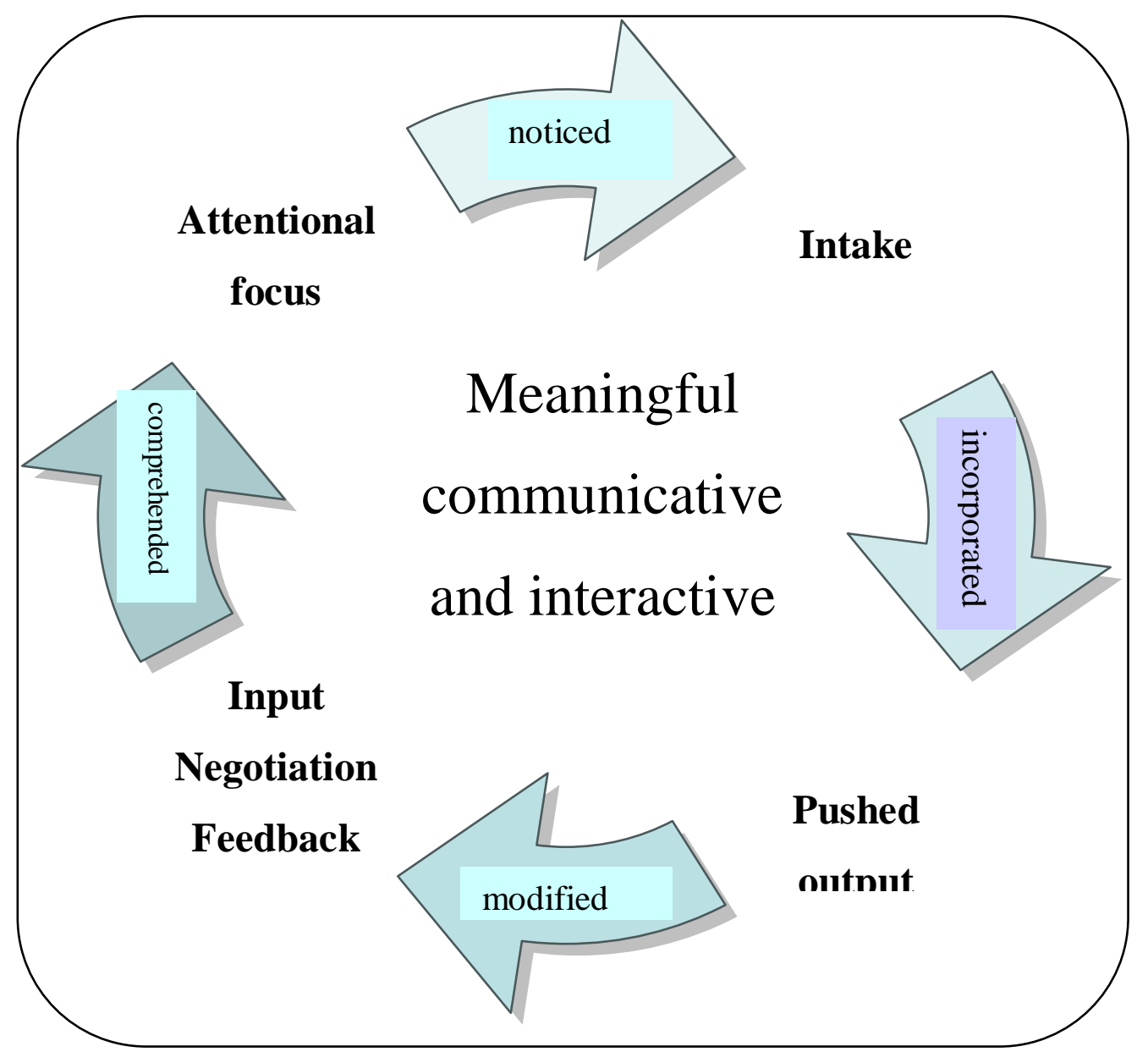


The theoretical rationale for FonF draws from a series of claims concerning the underlying machenism for second language acquisition. These claims have been presented in a series of related hypotheses, namely, the Input Hypothesis (Krashen, 1980; 1985), the Interaction Hypothesis (Long 1983; 1996), the Output Hypothesis (Swain, 1985; 1995; 2005) and the Noticing Hypothesis (R. W. Schmidt, 1990, 2001). The interactive process of FonF takes place in a meaningful communicative setting, in which learning is explained by the Interaction Hypothesis. The question how input leads to learning is answered in the Input Hypothesis. The process of input becoming intake can be explained by the Noticing Hypothesis. Another hypothesis which helps to clarify the procedure of intake becoming output and output resulting in language development is the Output Hypothesis.

\subsubsection{The Input Hypothesis}

The Input Hypothesis as proposed by Krashen $(1980,1985)$ emphasizes the role of comprehensible input in second language learning. According to Krashen, comprehensible input provided to the learner in accordance with the formula of natural acquisition order $i+1$ is necessary for acquisition. This hypothesis claims that when the learner is exposed to positive evidence as models, s/he will acquire the language the way a child learns his/her mother tongue (Krashen \& Terrell, 1983). This hypothesis stresses the role of input simplification to make input comprehensible and the role of affective filters to accept the comprehensible input. However, it rejects the role of output since the productive opportunity is marginal for learners in the language classrooms, and being pushed to produce output may cause anxiety in learners (Krashen, 1985). This hypothesis lays the foundation for teaching approaches such as immersion or natural approach (Long \& Robinson, 1998).

However, claims for the sufficiency of comprehensible input have been widely criticised (e.g. Izumi, 2003; Izumi, Bigelow, Fujiwara, \& Fearnow, 1999; Mackey \& Oliver, 2002; McDonough, 2005; Swain, 2005). First, young L1 learners are different from post-childhood second language/foreign language learners in learning ability and in a range of affective, cognitive, maturational and social dimensions. Thus, the assumption that L2 learning will proceed in a similar way to L1 learning is not sustainable. Secondly, some research has shown that aspects of second 
language/foreign language are unlearnable when the learners are exposed to positive evidence only (L. White, 1989, 1991). Finally, many studies have pointed out the considerable advantage of formal instruction with a focus on output over the naturalist approach (see Ellis, 2008).

As can be seen from Figure 2.4, Long \& Robinson (1998) claim that data for SLA includes not only positive evidence but also negative evidence. In this framework of data for SLA, FonF contributes to input in the forms of CF, negotiation of meaning (when there is miscommunication) and preemtive feedback. Research on FonF has shown the effectiveness of these types of input in inducing learning. For example, studies on $\mathrm{CF}$ find that learners receiving $\mathrm{CF}$ outperform those who did not (e.g. Lightbrown \& Spada, 1990; Lyster \& Ranta, 1997; Panova \& Lyster, 2002). Recent studies on preemptive FonF also report the occurrence of this type of FonF and its effectiveness in facilitating learning (e.g. Ellis, et al., 2001a; Loewen, 2003, 2004a).

\section{Figure 0.4: Data for SLA (Long \& Robinson, 1998)}

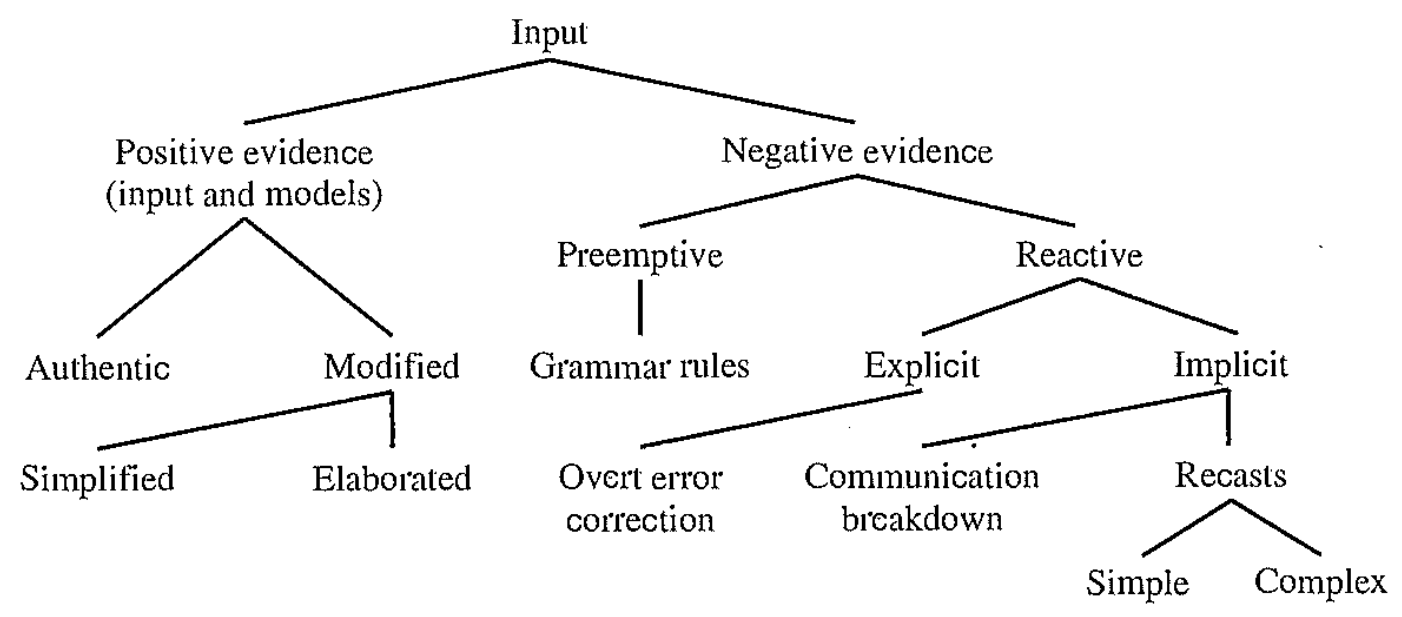

\subsubsection{The Interaction Hypothesis}

The Interaction Hypothesis as originally proposed by Long (1983), claims that interaction can facilitate acquisition by making input comprehensible. This version of the Interaction Hypothesis is criticised for failing to explain how comprehensible input leads to acquisition (Ellis, 2008). Long's (1996) later version of this hypothesis acknowledges the role of interaction in inducing learners' output when learners seek to clarify input or when an interlocutor seeks clarification of their own output. Through negotiation for meaning that takes place during interaction, second language/foreign 
language learners can become aware of their interlanguage gaps when they try to comprehend input or express meanings. This "facilitates acquisition because it connects input, internal learner capacities, particularly selective attention, and output in productive ways" (Long, 1996, pp. 451-452).

The Interaction Hypothesis highlights the role of negative evidence and modified output in language learning (Ellis, 2008). While positive evidence mainly requires learners' top-down semantic knowledge to comprehend the input, negative evidence stimulates learners to use their bottom-up syntactic knowledge to produce the output (Swain, 1985, 1995, 2005). The process of negotiating for meaning not only exposes learners to positive evidence but also involves them in the productive process through their attempt to express themselves, their attention to the CF from the NS or the more proficient interlocutor in the form of recasts, and their corporation of the intake in making adjustments to their interlanguage accordingly. The modified output, in turn, may be rejected or confirmed by their interlocutor during the interaction flow to possibly initiate new feedback from the interlocutor and new modified output from learners to form a circle of learning (Gass, Mackey, \& Pica, 1998).

Research on the role of interaction has confirmed the effectiveness of interaction in facilitating learning. For example, Ellis, et al.(1994) examining classroom interaction and its impact on comprehension and vocabulary acquisition in Japanese EFL classroom found that interactionally modified input results in better comprehension and more vocabulary acquisition than premodified input. Van Lier (1998) argues that interaction with others is likely to provide learners with learning opportunities. Mackey \& Oliver (2002) find that child ESL learners receiving interactional feedback were morelikely to improve their question formation than those who did not. Bitchener (2004) reports a positive relationship between negotiation of meaning and language learning. Not only teacher-learner and classroom interaction is beneficial to language learners, Adams (2007) found that learners also benefit from interacting with each other. As FonF takes place in a meaningful communicative and interactive setting, it contributes to the interaction flow of the classroom and hence, to inducing language learning. 


\subsubsection{The Output Hypothesis}

The Output Hypothesis as proposed by Swain $(1985,1995,2005)$ highlights the roles of learner language production in language learning. According to Swain (1995, p. 160), the learner's process of producing pushed output requires him/her a deeper level of cognitive work than that of the process of receiving comprehensible input. When receiving comprehensible input, the learner's cognitive level is more likely to end at the comprehensive level. Meanwhile, producing pushed output requires him/her to reflect on whether his/her output is comprehensible to his/her interlocutor, appropriate for the context and accurate at the morphosyntactic level. As it is demanding to produce comprehensible, appropriate and accurate output, the learner needs to make the best use of his linguistic ability and resources, and if he fails, he may need to modify his output until he succeeds. Many studies so far have supported the importance of output in the learning process (e.g. Izumi, 2002; Izumi, et al., 1999; Loewen, 2003, 2005; McDonough, 2005).

Pushed output and modified output play many important roles in language learning as pointed out by Swain (1995, 2005), Skehan (1998) and R. Ellis (2008). First, output triggers the learner's attention to form. While attempting to produce the language rather than just receiving it, the learner may notice the gap between what he wants to say and what he can say (Izumi, 2002), and works toward filling the gap. Second, producing output gives the learner the opportunity to practise the language, and this process helps the learner with automatization of his existing second language/foreign language language (Skehan, 1998). Thirdly, the process of producing pushed output requires the learner to reflect on the language metalinguistically in order to succeed in using his second language/foreign language knowledge at the syntactic level (Ellis, 2008). Finally, when providing output, the learner is simultaneously testing his language hypotheses (Swain, 2005). The hypothesis testing process may lead to the learner modifying output to respond to confirmation checks or clarification requests from his interlocutor.

In the framework of FonF, learner language production in the forms of pushed output and modified output is represented in learner uptake. A large amount of FonF research has focused on the learner's production of uptake in FonF (e.g. Egi, 2010; Ellis, et al., 2001a; Loewen, 2004b; Lyster \& Ranta, 1997; Panova \& Lyster, 2002; Sheen, 2004; Tsang, 2004a). The term uptake refers to the learner's response to feedback on a particular linguistic form in the ESL/EFL classroom. It involves learner pushed output 
and modified output triggered by FonF and so represents opportunities for the learner to practise the new linguistic item. Producing uptake is claimed to help the learner automatize retrieval of his/her second language/foreign language knowledge (Ellis, 2008; Lyster \& Ranta, 1997; Skehan, 1998). In addition, by producing uptake, the learner also tests his language hypotheses. Whether his hypotheses are confirmed or found faulty, the learner is actively involving in the productive process of negotiating meaning, understanding his interlocutor as well as making himself understood using the fullest of his linguistic knowledge (Swain, 1995, 2005). Uptake is, therefore, claimed to facilitate learning and, to some extent, can be used as a predictor for acquisition.

In contrast to the Input Hypothesis which emphasises subconscious implicit learning, the Output Hypothesis places greater emphasis on conscious learning. The role of the learner's consciousness in producing comprehensible output is elaborated in the Noticing Hypothesis.

\subsubsection{The Noticing Hypothesis}

A seminal article by (R. W. Schmidt, 1990) foregrounded the role of noticing in SLA. The Noticing Hypothesis (R. W. Schmidt, 1990, 2001) claims that noticing is necessary for SLA. He emphasizes that attention to form is a conscious process that occurs at three different levels: alertness, orientation and detection. Alertness is the learner's motivation and readiness to learn, which may occurs involuntarily. Orientation refers to the learner's general focus of attention which works as a filter to either facilitate or inhibit input in accordance with the oriented input flow. The level of detection enables the learner to cognitively register the new linguistic form or the form at odds with his interlanguage for a further input processing. These three levels suggest that noticing would rather be viewed along a continuum rather than a fixed event, especially when a researcher cannot get access to the learner's internal processing and data on noticing are completely based on the learner's report (Mackey, 2006).

The three levels of attention points out the need to include learners' individual differences in this research area. The learner's alertness depends on whether $\mathrm{s} / \mathrm{he}$ is motivated or whether his/her language level is developmentally ready enough. In addition, whether the learner's attention is form-oriented or meaning-oriented also contributes to what types of input are more likely to be noticed (van Patten, 1996). 
Since the learner's language ability influences whether form or meaning is priortised during input processing, learner proficiency levels are likely to have an impact on learner noticing (van Patten, 1989, 1990).

The role of noticing in SLA is the subject of many fairly recent studies (e.g. Adams, 2003; Izumi, 2002; Lapkin, Swain, \& Smith, 2002; Swain \& Lapkin, 2002). In most of these studies, tasks are designed to boost learner noticing of some linguistic features using different noticing-boosting techniques to create different levels of noticing such as task repetition, visual input enhancement, and comparing and discussing reformulated work. The results show that input enhancement may only lead to sensory detection in the receptive process, but pushed output may lead to incorporating new forms in the productive process (Izumi, 2002). As a result, noticing through visually detecting a particular form does not induce as much learning as noticing through producing pushed output and reflecting on learning.

Research on FonF shows that the salience of FonF is related to learner noticing and uptake (e.g. Loewen, 2004b). As a result, noticing plays an important role because when learners notice their interlanguage gaps during FonF, they are more likely to modify their output accordingly in their uptake (Mackey, 2006). This is where negative evidence provided by FonF makes a difference compared with positive evidence only in a focus-on-meaning approach (Long \& Robinson, 1998). In a FonF approach, negative evidence juxtaposes learners' interlanguage gaps and the targetlike forms so that the gaps are noticed. The more salient FonF is, the more likely it is noticed and incorporated in learner uptake.

Among the noticing-boosting techniques promoted in the second language/foreign language classroom, the use of L1 is recommended as a "cognitive tool" to promote noticing (Ferrer, 2005a, 2005b; Swain \& Lapkin, 2000). Further empirical research on noticing is needed, however, to investigate these contextual aspects of the language classroom including the role of L1, to have a better understanding of the role of noticing and how to manipulate learner noticing in the second language/foreign language classroom. 


\subsection{Main findings in FonF research}

Research on FonF has focused on cognitive aspects of FonF involving the nature of learner modified output in the form of uptake, noticing and language development which follow the attention to form taking place in the second language/foreign language class. In this section, a review of the main findings in FonF research such as FonF occurrence, uptake in FonF, the relationships between FonF and noticing, and FonF and language development will be presented.

\subsubsection{FonF occurrence in second language/foreign language classroom}

Across the different research settings with different research taxonomies and measurements, the frequencies of FonF episodes and moves varied widely accordingly. However, a majority of the research studies on FonF report a frequent occurrence of FFEs (e.g. Basturkmen, et al., 2004; Ellis, et al., 2001b; Loewen, 2004b), or of language-related episodes (LREs) (e.g. Farrokhi \& Gholami, 2007; Leeser, 2004), or of teacher feedback turns usually followed by learner uptake turns (e.g. Lyster \& Ranta, 1997; Tsang, 2004a).

Across the different research studies, the frequency of FonF ranges from nearly one FFE every two minutes (Lyster \& Ranta, 1997) to one every 1.2 minutes (Oliver, 2000). A number of factors account for this variation. First, as Sheen (2004) and Ellis, et al. (2001a) explain in their studies, types of classrooms contributes an important part. In a classroom where language is the main focus and learners are motivated and committed, FonF is more likely to occur. In language-focused classes (e.g. Ellis, et al., 2001a; Loewen, 2005), the learners are fee-paying ESL learners who are highly committed to the course to meet their needs for university education or employment. Meanwhile, in immersion classes (e.g. Lyster \& Ranta, 1997), the learners are school children who take the classes mainly at their parents' will. This explains a higher frequency of FonF in the former type than the latter. Another reason for the difference in the frequency of FonF across the studies is different operationalisation systems of the data. While Lyster \& Ranta (1997) count only reactive FFEs, later studies like Ellis, et al.(2001a) or Loewen (2005) include pre-emptive FFEs.

Variation in the amount of FonF also occurs among the class groups in the same study. For example, Basturkmen, et al. (2004) report that the number of FFEs ranged from 
0.49 FFEs per minute to 1.25 FFEs per minutes across the three classes they observed. In Tsang's (2004a) study, the teachers' number of feedback turns varied from 0 to 39 across 18 classes. As pointed out by Basturkmen, et al.(2004), the relation between the teachers' stated beliefs and their FonF practice is rather weak. Another explanation for the difference in FonF practice across teachers can be attributed to the variation of their teaching and learning background, their own preferences and other differences in instructional settings such as learners and the pedagogical focus of the language program. Another suggestion from Loewen (2003) about the reason for this variation is that language teachers have no guidance about the optimal amount of FonF, and their FonF practice has long been an intuitively conducted part of the teacher work.

The following subsections review the main aspects of FonF which have been researched: uptake, learner noticing, and language development through FonF.

\subsubsection{Uptake in FonF}

Predictably, learner uptake in FonF depends on many factors including the explicitness of FonF and contextual factors. The more explicit the feedback is, the more likely the learner is to produce uptake. Recasts, which are an implicit reformulation of learners' erroneous utterances, have been found to receive the least uptake (Ellis, et al., 2001a; Farrokhi \& Gholami, 2007; Loewen, 2004b; Lyster \& Ranta, 1997; Panova \& Lyster, 2002; Sheen, 2004; Tsang, 2004a). More explicit FonF types like metalinguistic feedback or clarification requests are reported to be more likely to induce learner uptake (ibid.). The explicitness of FonF also depends on the complexity of FFEs. There is evidence that complex FFEs are more likely to draw learners' attention to form than simple ones and hence more likely to trigger learner uptake (Alcon-Soler, 2009; Ellis, et al., 2001a; Loewen, 2004b). Explicit FonF is also likely to increase learners' awareness ofinterlanguage gaps. By noticing the gaps, the learners are more likely to produce modified output (R. W. Schmidt, 2001).

Context is a second factor that influences the learner's production of uptake. For example, when comparing FonF taking place in four different instructional settings, Sheen (2004) found that learners in language-focused classes produced more uptake than those in the content-based or immersion classes. As R. Ellis, et al. (2001a) suggest, the difference may come from the learners' motivation and commitment. They argue 
that in fee-paying language-focused classes, the learners are more motivated and more committed to learning the language than those in the immersion setting.

Another learner-related factor is learner proficiency level. Several studies (e.g. Lyster \& Ranta, 1997; Mackey \& Philp, 1998; Panova \& Lyster, 2002; Philp, 2003; Williams, 2001) find that low level learners are less likely to notice feedback, especially implicit types like recasts, and hence, produce less uptake than more proficient learners.

Other factors that are likely to influence the occurrence of uptake include the teacher's and the learner's individual differences. For example, the occurrence of uptake may depend on the teacher's expectation for learner uptake as well as the opportunities for uptake s/he gives to the learner, which, in turn, may reflect the teacher's beliefs and attitudes to about feedback. In his study conducted in an ESL setting in New Zealand, Loewen (Loewen, 2004b) reports that students did not have a chance to respond to feedback in $9.5 \%$ of the FFEs identified from class observations. In addition, uptake only reflects the learner's vocal response to FonF, and thus, it is not related to the silent and hidden part of learners' response to feedback. In some contexts, learners may choose to take notes of the feedback or reflect on it instead of being vocal, due to contextual and cultural characteristics of the classroom such as large class size or respect for the teacher (Farrokhi \& Gholami, 2007; Sheen, 2004; Tan, 2007). Also, factors such as the learner's willingness to communicate, his learning preferences and various individual differences are likely to influence the production of uptake. However, research has not to date investigated these, and little is known about these aspects of uptake.

\subsubsection{FonF and noticing}

The success of FonF depends on learner noticing. Indeed, Long \& Robinson (1998) describe FonF as "attention to linguistic code features". Learner noticing is the main mechanism bu which FonF is claimed to push language learning. FonF research has explored learner noticing in relation to interactional feedback in the language classroom and how much the different levels of noticing induce learning.

Mackey's (2006) investigated the relationship between interactional feedback and reported noticing during classroom interaction. She used three noticing measures: 
learning journals, stimulated recall (SR) and focused L1 question. The study found that interactional feedback on a particular linguistic form resulted in higher levels of noticing. However, the levels of noticing also varied in the learners' reports, implying learners had different levels of noticing of a particular linguistic form. The study also found that learners' reports of noticing may be related to the types of feedback. For example, some grammatical points that induce negotiation may result in more noticing than those do not. Another study by Egi (2004) exploring the relationship between learners' immediate report of noticing and learning found that noticing had no significant influence on subsequent learning. Adams (2003) found that the learners who received both noticing and SR session outperformed those who received neither and those who received only a noticing session.

The results from these studies suggest an intricate relationship between FonF, noticing and learning. Understanding this relationship is difficult because learner noticing is an internal process to which researchers can have limited access. This explains the practice of simultaneously using various tools to examine noticing such as SR, journal writing, and focused questions (FQs) (e.g. Mackey, 2006).

\subsubsection{FonF and language development}

Since noticing and modified output are both components of FonF and both claimed to be facilitative of learning, FonF research also explores the relationship between FonF and language development. These studies measure the learner language development by comparing pre-tests and/or post-test and/or delayed post-tests results. Custom-made post-tests are usually used to include the particular linguistic items addressed in the FonF episodes or moves. Studies using this approach have found strong evidence for a causal relationship between FonF and learner language development.

Norris \& Ortega (2000) in their meta-analysis of 77 quasi-experimental and experimental studies on the effectiveness of second language instruction published between 1980 and 1998 found that instructed language learning outperformed naturalistic approaches. Among the approaches to instructed language learning, explicit FonF was the most effective type of instruction. Several studies on the effectiveness of CF (Carroll \& Swain, 1993; Lyster, 2004; Muranoi, 2000; Nagata, 1993; Rosa \& Leow, 2004) have found that groups receiving feedback treatment outdid control groups. 
Loewen's (2005) also found that learners receiving FonF were able to give correct or partially correct results for nearly $60 \%$ of the post-test items and $50 \%$ of the delayed post-test items. Mackey (2006) found that interactional feedback leads to learner noticing which, in turn, leads to language development. Other studies also report that interactional feedback lead to language development (R. Ellis, 2007; Loewen \& Nabei, 2007; McDonough, 2007; Sheen, 2007).

The effectiveness of FonF in inducing learning depends on a number of factors. First, many studies have reported that explicit FonF like metalinguistic feedback is more likely to lead to language development than implicit FonF like recasts (e.g. Carroll \& Swain, 1993; Ellis, et al., 2006; Loewen \& Nabei, 2007; Sheen, 2007). Second, some types of linguistic features are more susceptible to feedback than others, depending on the degree of salience of the targeted linguistic items. Feedback on non-salient linguistic items like articles (in Sheen, 2007) is less likely to be noticed and incorporated in the learner's output than salient items like lexis (Jeon, 2007). As pointed out by van Patten (1989, 1996), in a meaning-oriented setting, linguistic items with greater communicative values like lexical items usually attract more noticing from learners than morphosyntactical ones.

Another factor that may predict language development is types of learner uptake. Loewen (2005) discovered that repair is most likely to induce language development. To produce this type of uptake, learners not only notice their interlanguage gaps but also modify their output to become comprehensible and incorporate feedback into their output. This process pushes them make use of the language at both semantic and syntactic levels, giving them opportunities to practise their language knowledge for automatization and to test their language hypotheses. This explains how repair brings about language development.

\subsection{Summary}

FonF approach has been established as an eclectic teaching option in which occasional attention to form takes place in a meaning-focus setting (Long, 1988, 1991; Long \& Robinson, 1998). Research on FonF has found the theoretical foundation which justifies the roles of FonF. The roles of FonF include providing learners with opportunities for attention to form during interaction though which comprehensible input is created and 
pushed output is produced (Long \& Robinson, 1998). The process of learner output production, in turn, leads learners to noticing their interlanguage gaps, modifying their output accordingly (Swain, 1985, 1995, 2005).

Since the coinage of the term FonF, empirical research has been carried out across various instructional settings examining different aspects of FonF in the attempt to establish the roles of FonF in language learning. Evidence has been found that FonF facilitates learning (e.g. Mackey, 2006), and research findings consistently show an association between FonF and learner uptake, noticing and language development (e.g. Ellis, et al., 2001a; Loewen, 2004b, 2005; Lyster \& Ranta, 1997; Panova \& Lyster, 2002; Sheen, 2004).

Despite a large amount of FonF research conducted over the past 20 years, a majority of FonF research have been conducted mainly in two settings: immersion content-based classes and second language classes (e.g. Basturkmen, et al., 2004; Doughty \& Varela, 1998; Ellis, et al., 2001a, 2001b; Leeser, 2004; Loewen, 2004b, 2005; Mackey, 2006; Mackey \& Oliver, 2002; Mackey, Polio, \& McDonough, 2004; Panova \& Lyster, 2002). In the immersion setting, the teachers are usually bilinguals and the learners learn the language through the instruction in the TL only at school. In the second language classes, the learners usually have different mother tongues and the teachers are nativespeakers of the TLs. The foreign language setting also sets the scene for some studies but the teachers are NSs of the TL and the learners are speakers of the same L1 (e.g. Lyster \& Ranta, 1997; McDonough \& Mackey, 2006; Sheen, 2004). As a result, the framework for FonF research fails to include aspects which are characteristic of the EFL setting where teachers are non-native speakers (NNSs) of the TL (English) and share the mother tongue with their learners, which Borg (2005) considers more representative of language classrooms in a global sense. For example, while the teacher use of L1 in this foreign language setting is widely observed (see Turnbull \& Arnett, 2002), FonF research conducted in this setting fails to report this practice in FonF. The following chapter of the thesis will review research on a little known aspect of FonF in an EFL setting: choice of the language (that is, the TL or L1) is used in FonF, in this setting (e.g. Alcon-Soler, 2009; Farrokhi, Ansarin, \& Mohammadnia, 2008; Farrokhi \& Gholami, 2007; Fujii \& Mackey, 2009; Gass, Mackey, \& Ross-Feldman, 2005; Tsang, 2004a). 


\section{Chapter 3: The use of $L 1$ in second language/foreign language classrooms}

As can be seen from the previous chapter, FonF studies have been carried out in both second language and foreign language classrooms. However, while the language used this setting is very likely to be a mixture of second language/foreign language and the mother tongue, little is mentioned about the practice of using L1 and the TL in FonF in these studies. Therefore, another area of second language learning which focuses on the use of L1 in the language classroom is also reviewed to find out whether any aspect of FonF is related to the use of $\mathrm{L} 1$ in the language classroom.

This chapter reviews research on the use of L1 in second language/foreign language classrooms with a focus on factors affecting the use of L1. Throughout the literature on this topic, as pointed out by Turnbull \& Dailey-O'Cain (2009), two positions are usually taken by researchers: the virtual position promoting a TL-only classroom and the maximal position supporting a language class with a judicious use of L1. The review of these two positions will include the arguments for and against L1 use in accordance with what roles L1 can play in the language classroom and what barriers to the language learning process it may bring about. It also summarizes the findings of research on the frequency of L1 use and TL use in second language/foreign language classrooms.

\subsection{L1 use across instructional settings and teaching methods}

Research shows two factors that have a strong influence on how and how much L1 is used and should be used in the language classroom: instructional settings and language teaching methods.

\subsubsection{L1 use in different instructional settings}

Arguments for and against the use of L1 in the second language/foreign language classrooms vary according to the types of instructional settings in which the studies take place. In the research, three settings are distinguishable: the second language setting, the immersion setting and the foreign language setting. The second language (mainly ESL) 
setting is one in which teachers are NSs of the TL (mainly English) and learners are heterogeneous L1 speakers learning the TL as the language for survival in their second home country (e.g. Auerbach, 1993; E. Chau, 2007; Cook, 2001; E. M. Ellis, 2007). The immersion setting is one in which teachers are usually bilingual and learners are homogeneous L1 speakers (e.g. Swain \& Lapkin, 2000). The foreign language setting is one in which teachers may or may not share the L1 with learners (e.g. Al-Nofaie, 2010; Alegría de la Colina \& del Pilar García Mayo, 2009; Anton \& DiCamilla, 1999; Polio \& Duff, 1994b; Prodromou, 2000).

Table 3.1 shows the options for L1 use across different instructional settings.

Table 0.1: L1 use in different instructional settings

\begin{tabular}{|c|c|c|}
\hline & $\begin{array}{l}\text { L1 use in teacher- } \\
\text { learner interaction }\end{array}$ & $\begin{array}{l}\text { L1 use in learner- } \\
\text { learner interaction }\end{array}$ \\
\hline \multicolumn{3}{|l|}{ Second language setting: } \\
\hline $\begin{array}{l}\text { Homogeneous learners + } \\
\text { monolingual teacher }\end{array}$ & - & ++ \\
\hline $\begin{array}{l}\text { Homogeneous learners + } \\
\text { bilingual teacher }\end{array}$ & + & ++ \\
\hline $\begin{array}{l}\text { Heterogeneous learners }+ \\
\text { Monolingual/bilingual teacher }\end{array}$ & - & + \\
\hline \multicolumn{3}{|l|}{ Immersion setting: } \\
\hline $\begin{array}{l}\text { Homogeneous learners + } \\
\text { bilingual teacher }\end{array}$ & - & ++ \\
\hline \multicolumn{3}{|l|}{ Foreign language setting: } \\
\hline \multicolumn{3}{|l|}{ Homogeneous learners + } \\
\hline Monolingual teacher & - & ++ \\
\hline \multicolumn{3}{|l|}{ Homogeneous learners + } \\
\hline Bilingual teacher & + or ++ & ++ \\
\hline
\end{tabular}

Note: ++: very possible; +: possible; -: hardly possible 


\subsubsection{L1 use in the second language and immersion settings}

Much of the research in this setting has been carried out on the use of L1 in ESL classes (e.g. Auerbach, 1993; Mori, 2004). Learners in this setting are usually immigrants from different countries, learning the TL to integrate into the new home country. In these classes, the teachers are usually NSs of the TL and the learners are heterogeneous speakers of L1s. In this setting, the teachers' use of learners' L1 is out of the question, so the research on L1 use mainly focuses on L1 use between learners who share the same mother tongue. The advocacy of English-only classes, as pointed out by Auerbach (1993, p. 12), originates from some extreme ideological perspective equaling the use of English in American ESL classrooms with an act of patriotism for people who adopt a new nationality and with the norm of a second language class where it is believed that the use of L1 will limit opportunities for learners to develop their standard English.

On investigating a case of stay-in-English programs in an ESL setting, Mori (2004) argues that the use of L1 can be successfully excluded from the ESL language classroom as long as the teacher respects the learners and their languages and cultures, and the learners, in turn, desire to communicate. In this setting, as the TL plays an important role in the learners' everyday life, the learners are usually highly motivated to learn it for survival.

Some other researchers (Atkinson, 1993; Phillipson, 1992), however, oppose the exclusion of L1 from the ESL classroom, arguing that English-only policy in the classroom has promoted English hegemony. As a result, second language learners feel inferior, build a negative image of their own language and culture, and lose faith in their mother tongue and culture (Abbott, 1992; Barkhuizen, 2002). Phillipson (1992) is concerned about the consequent destruction of language diversity which may follows the hegemony of English. Auerbach (1993) emphasized that the use of English-only policy in the second language classrooms may even reinforce existing social inequities.

The immersion setting in language teaching research is characterized by the homogeneity of the learners who share L1 and the bilingualism of the teachers. In this setting, learners are immersed in content-based programmes given in the TL at school. This type of instruction has been reported as very successful thanks to the large amount of input in the TL provided to the learners. However, L1 use among the learners has been widely observed by the teachers. Studies report that teachers in fact avoid 
assigning group-work activities to prevent students from overusing L1 (Swain \& Lapkin, 2000). In CF research taking place in this setting (e.g. Lyster \& Ranta, 1997), learners' use of L1 is categorized as errors and teachers' response to this type of errors by translations is categorized as recasts.

In summary, in the second language and immersion settings, the role of the TL is important to the learners' survival (in the second language setting) or to the learners' academic life (in the immersion setting). L1 use in teacher-learner interaction is rare because teachers either do not share the L1 with learners or they avoid using the L1 due to institutional policy or their own beliefs (see Turnbull \& Arnett, 2002). As a result, research in these settings has focused mainly on the learners' use of L1.

\subsubsection{2. $\quad L 1$ use in the foreign language setting}

Research into L1 use in the foreign language setting focused on two types of classroom interaction: learner-learner interaction and teacher-learner interaction. Like in the immersion setting, L1 use in learner-learner interaction is largely inevitable due to the homogeneity of the learners. However, since the teachers in this setting could be bilingual or monolingual, teacher-learner interaction might or might not involve L1 use.

In the foreign language classrooms where the teachers are monolingual and NSs of the TL, the use of L1 in teacher-learner interaction is out of the question. The teacher's lack of L1 knowledge is even considered beneficial to learning since it creates the real need for negotiation of meaning between the teacher and the learners (Turnbull \& DaileyO'Cain, 2009). In the foreign language classrooms where the teachers and the learners share the mother tongue (which is, according to Borg (2005) more representative of the global language classroom), the option to use L1 is available in both teacher-learner and learner-learner interaction, and so the issue is an important one (Forman, 2007; Jenkins, 2010; K. Schmidt, 1995; Schweers, 1999). However, as pointed out by Macaro (2005), little empirical research has been conducted to bring about conclusive and practical results, and the use of L1 in the language classroom stays a "bone of contention" (Gabrielatos, 2001).

Moreover, a large part of the mainstream research on L1 use in the foreign language setting so far has mainly concentrated on the foreign language setting in the States 
where English is L1 and the TLs are Asian and European languages, and the teachers are the NSs of the TLs (Anton \& DiCamilla, 1999; Crawford, 2004; Duff \& Polio, 1990; Polio \& Duff, 1994a). Some teachers in Polio \& Auerbach's (1994) study were reported to be pleased to have a chance to practise a lot of English. Because of the powerful role of English as a lingua franca, the nature of teacher use of L1 and the TL in those studies, therefore, may not be comparable to that in the studies on EFL and the research results could hardly be generalizable to cover the EFL setting.

In summary, the use of L1 in the language classroom takes place across a wide range of instructional settings in which the teachers, the learners, the languages and the contexts involved are very different from each other. Most research in this area has been conducted in the second language setting, the immersion setting and the foreign language setting in English-speaking countries. In contrast, the use of L1 in the EFL setting where L1 is shared by the teachers and the learners has not been widely researched. As a result, the tenets for L1 use in the EFL classroom have generally mainly been exploited from the research findings of L1 use in other settings (e.g. Mangubhai, 2005). There is clearly a need to research L1 use in the EFL setting so that guidance on L1 use in this setting could be put forward.

\subsubsection{L1 use in teaching methods}

Another factor that affects views on L1 use has been the ascendency of various foreign language/second language teaching and learning methods. In the Grammar-Translation method, L1 played an essential role in the language classroom since L1 was the means for language transfer by which learners learned about the language instead of learning to communicate in the language (Rivers, 1981). However, when the Direct Method and other methods which superceded Grammar Translation emphasized the importance of using the language and so input was provided exclusively in the TL. As a result, in the classrooms using these methods, L1 hardly had any place.

In immersion programs and communicative language teaching (CLT) where the use of L1 is almost nonexistent in teacher-learner interaction and is reduced to minimum in learner-learner interaction, L1 is often considered interference and banned in the language classrooms. The use of L1 implies the trace of translation which has had bad reputation due to its relation to grammar-translation method strongly opposed by 
communicative language proponents (Cummins, 2009; Macaro, 2005; Turnbull \& Dailey-O'Cain, 2009). This places NNS teachers in monolingual classes in a difficult situation because their L1 is seen as an impediment to learning and yet is naturally drawn on as a resource. Thus, some teachers find L1 necessary but regrettable (Atkinson, 1987; Macaro, 2005), and some even report feeling guilty, which Macaro (2005) calls "an unhealthy outcome of a pedagogical debate".

Recently, in the context of the call for post-method or "beyond method" alternatives emerged (Kumaravadivelu, 1994, 2001, 2003; Larsen-Freeman, 1999; Long, 1991; Williams, 2005), the use of L1 in the second language/foreign language classrooms has returned as an issue for discussion and research.

In summary, the tenets of each teaching methods imply the likeliness of L1 use in the classroom. L1 use is inevitable in teaching methods that employ L1 as a language transfer tool, while this practice is considered interference to language learning in communicativeness-focused methods such as CLT, which may lead teachers and learners to a dilemma in L1 use. Recent emergence of post-method alternatives has once again brought L1 use back to discussion. The following will summarize all the arguments for and against L1 use in the language classroom.

\subsection{The arguments for and against $L 1$ use in second language/foreign language classrooms}

In this section, I consider arguments advocating for L1 use in second language/foreign language classrooms and those giving the TL a virtual position in the language classroom.

\subsubsection{The roles of $L 1$ use in second language/foreign language classrooms}

Codeswitching has been considered natural to bilinguals (Jenkins, 2010), which explains the fact that the use of L1 is inevitable in second language/foreign language classrooms, especially foreign language classrooms where teacher and learners share L1. Some studies consider the fact of sharing L1 and culture with learners as an advantage of NNS over NS teachers (e.g. Atkinson, 1987; Atkinson, 1993; Medgyes, 1992, 1994; 
Serdiukov \& Tarnopolsky, 1999). In the following, I will discuss the role of L1 in the language classroom on pedagogic, psycholinguist and sociolinguist perspectives.

\subsubsection{The pedagogical role of $\mathrm{L1}$ use in second language/foreign language classrooms}

Macaro (2000) and Schweers (1999) have explored teachers' and learners' beliefs on the use of L1 in the classroom and their practices in using L1 in the classroom. In their studies, teachers reported they used L1 to save time on some types of talk which would be less effective and lengthier in the TL such as giving complicated instructions about the class procedures, controlling learners' behaviour, translating and checking comprehension, and teaching grammar explicitly. Similar results are reported in Macaro (2005) and K. Schmidt (1995).

The use of L1 has also been documented as an effective way for class management. Some teachers and researchers find that when teachers recourse to L1, learners usually take it as an ominous signal to go back to order (Tracedreyer, n.d.). Cook (2001) also mentions the use of L1 by the teacher in organizing tasks and discipline the class.

Research also shows that teachers resort to L1 for long complicated talk as a communicative strategy to keep the interaction going, attract greater input, and avoid circumlocution and repetition (Macaro, 2005). The teacher choice of L1 in this case is also practical in the sense of reducing the amount of teacher talk, and thereby increasing the student talk to comply with the principles of the communicative language class (Turnbull \& Dailey-O'Cain, 2009). Both Cook (2001) and Swain \& Lapkin (2000) state that one of the main reasons for the L1 use of the learners in their studies is that they find it more efficient.

Atkinson (1987) Nation (1997) and many other researchers (Piasecka, 1988; K. Schmidt, 1995) argue for the use of L1 as a classroom resource. They call for the judicious use of L1 in the classroom for its advantages at different proficiency levels. L1 use is especially helpful at early levels giving instructions, discussing classroom methodology, and presenting and reinforcing language (Atkinson, 1987). Atkinson (1993) and Piasecka (1988) argue that monolingualism, especially in EFL low-level classrooms, is demotivating and discouraging since it inhibits learners' abilities and invalidates 
learners' lived experiences (Jenkins, 2010; K. Schmidt, 1995). Besides, Atkinson (1987) and Mercer (2001) claim that at all proficiency levels, the mother tongue can help with checking comprehension, eliciting language, checking for sense, testing and developing useful learning strategies.

In short, teachers' use of the mother tongue in the second language/foreign language classrooms can serve as a pedagogical strategy to reduce their dominant talk in giving lengthy and complicated class instructions and to manage the class. L1 can be exploited as a classroom resource that facilitates communication and thereby facilitates learning of the TL.

\subsubsection{The psycholinguistic roles of $\mathrm{L1}$ use in second language/foreign language classrooms}

Anton \& DiCamilla (1999) in their study of the collaborative interaction of adults learning Spanish as a foreign language found evidence that L1 can work as a cognitive tool to facilitate learning. They claim that L1 smooths learners' mutual work in defining various task elements. The learners in their study used L1 to provide each other scaffolded help as well as externalize their inner speech (Vygotsky, 1962) throughout the task. In another recent study, Alegría de la Colina \& del Pilar García Mayo (2009) also found that the use of L1 between learners at low proficiency level provided them with cognitive support, which helped them to work at a higher level better than the use of the TL only. Similarly, Cook (2001) claims that at low proficiency levels where learners' communicative priority is meaning, the use of L1 to convey meaning is countable in partly reducing their cognitive burden.

In his study in a college French class, Kern (1994) found that learners use L1 to reduce their cognitive load. L1 helped learners in his class reduce working memory constraints, avoid losing track of the meaning of the text, consolidate meaning in long-term memory, convert input into more familiar terms, and clarify the syntactic roles of certain lexical items (see Macaro, 2005; Turnbull \& Dailey-O'Cain, 2009). The use of L1 is also considered very helpful especially when a task is too demanding and the cognitive load therefore becomes excessively challenging and discouraging to learners. 
In conclusion, psycholinguistically, L1 use in the second language/foreign language class can be a cognitive tool to facilitate learning. In addition, it can make input comprehensible and enhance learners' noticing, which facilitates learning. In addition, it helps reduce the cognitive workload for learners, especially low-level ones, which, in turn, reduce their anxiety. The use of L1 also contributes to establishing rapport between teacher and learners and scaffolded help among learners.

\subsubsection{The sociolinguistic role of $\mathrm{L} 1$ use in second language/foreign language classrooms}

The sociolinguistic role of L1 has also been researched. Holmes (2008) argues that the use of L1 helps to create an atmosphere of solidarity between learners, and hence reduces anxiety. Learners also use L1 when they want to express their affections (Holmes, 2008), which explains the considerable amount of L1 use between learners in an immersion class observed by Swain \& Lapkin (2000).

The use of mother tongue in classroom is also considered humanistic since it allows learners (and sometimes the teacher) to say what they want to say (Harbord, 1992). Harbord also argues that since the tendency to rely on L1 to learn a new language is natural, the use of L1 should be encouraged since it is a learner-preferred strategy which will assist learning more than hindering it (Clanfield \& Foord, 2003; Gill, 2005). Butzkamm (1978) reported learners' preference for translations in word acquisition. Cook (2001) also argues that the learner's use of L1 is part of her main learning activity since no matter what the teacher expects from the learner, the process of resorting to L1 occurs naturally either explicitly or implicitly depending on the class policy, and hence cannot be banned.

No matter what roles research in this field claims the use of L1 holds in the second language/foreign language classrooms, a majority of researchers emphasize the necessity of using the TL judiciously in order not to "license" the teacher toward an overuse of L1. A great majority of researchers contend that there needs to be selective use of L1 in a second language or foreign language classroom. This position is termed as the optimal position by Macaro (2009) . Another position holding the exclusive use of the TL in the language classroom called the virtual position (Macaro, 2009; Turnbull 
\& Dailey-O'Cain, 2009) will be discussed in the following subsection. However, the question of how to use the TL judiciously is left unanswered.

\subsubsection{The virtual position on the TL use}

The virtual position on the TL use refers to the exclusive use of the TL in the language classroom as the optimal choice and seeing no pedagogical or communicative value in the use of L1 (Turnbull \& Dailey-O'Cain, 2009). Some researchers cited the Input Hypothesis as a rationale for the exclusion of L1 out of the second language/foreign language classrooms (see Turnbull \& Arnett, 2002). They argue that second language learning is equal to L1 acquisition, so when the input in the TL is comprehensible enough for learners in accordance with the $i+1$ formula, the use of L1 is unnecessary and distracting, which deprives learners of exposure to more TL (Krashen, 1985).

The Output Hypothesis is also used to explain the need to exclude L1 from the language classrooms (see Turnbull \& Arnett, 2002). This hypothesis emphasizes the importance of learners' production of output in the TL to practise new linguistic items for automating retrieval of the new language items as well as to test their interlanguage hypotheses (Swain, 2005). Following the logic of these claims, the permission for L1 use means reducing learners' TL production, which, therefore, negatively affects learning.

From the cognitive perspective, there have been different reasons for the exclusive use of the TL in the class. Some researchers argue that the use of the TL motivates learners by pushing them to "set instrumental goals", which enhances learning (Macaro, 1995). Constant exposure to the TL only in the classroom is thought to improve the quality of input, which in turn facilitates acquisition (Crawford, 2004). Another reason for this view is the belief about the need for language compartmentalisation. This view asserts that the use of L1 and the TL must be separated at all times so that separate language systems could be built, and learners can develop their L2 without being influenced by L1 (Cook, 2001).

In summary, the virtual position of the TL use finds support from the Input Hypothesis for the need to create an acquisition-like TL-only setting for language learners. This position also draws from the Output Hypothesis for the need to push learners' 
production of output in the TL to facilitate learning. Other arguments backing the use of the TL only in the language class include motivating learners to set goals for their learning, creating constant exposure to the TL only, and separating L1 from the TL, all of which are believed to facilitate learning.

\subsection{The amount of $\mathrm{L} 1$ use across the instructional settings}

This section reviews the results of several studies on how and how much L1/TL is used in the language classroom. Of the many studies on the amount of L1 and the TL use in the language classroom, most of the widely known and cited studies were carried out in the foreign language setting in English-speaking countries or the immersion setting (e.g. Macaro, 2001; Polio \& Duff, 1994b; Rolin-Ianziti, 2002; Swain \& Lapkin, 2000). Only a few studies were conducted in the ESOL setting such as Kharma \& Hajjaj (1989), Liu, Ahn, Baek, \& Han (2004) and Alegría de la Colina \& del Pilar García Mayo (2009). The foci of all these studies were on either the amount of L1 use by learners or the amount of L1 use by teachers.

\subsubsection{The amount of learner use of $L 1$}

In their study on how the low-level learners use L1 across different tasks in an EFL setting, Alegría de la Colina \& del Pilar García Mayo (2009) found that the number of L1 words used by the learners ranged from about $55 \%$ in jigsaw tasks to almost $78 \%$ in text construction tasks. The use of L1 is mainly for metacognitive talk and task management purposes.

Another study by Swain \& Lapkin (2000) carried out in an immersion setting found that around $25 \%$ of the learners' turns made use of some L1. However, only $12 \%$ of the L1 turns were off-task; the rest was found to help the process of learning the TL.

\subsubsection{The amount of teacher use of $\mathrm{L} 1$}

Duff \& Polio (1990) in their study on how much foreign language was used in 13 foreign language classrooms at universities in the States found that the amount of teacher use of L1 ranged from as little as $0 \%$ to as much as $90 \%$. Both Macaro (2001) and Rolin-Ianziti (2002) found a smaller range of L1 use in their studies: from $0 \%$ to $30 \%$ of L1 use in the French classes in Australia. A more recent study by de la Campa \& 
Nassaji (2009) taking place in a second-year German-as-a-foreign-language in an English-speaking Canadian university reported a rate of over $11 \%$ of L1 words used by the teachers with a small variation between the experienced instructor (over 9\%) and the novice instructor (over 13\%). This study also found that the teachers' rates of L1 use were the highest when they gave translation (32.3\% of the total L1 words), provided activity instruction (12.7\%) and made personal comments (11.8\%).

In the EFL setting, the amount of teacher use of L1 was reported in Kharma \& Hajjaj's (1989) study conducted in an EFL setting in Kuwait. The teachers in this setting spent about $20 \%$ of their time using L1. In their study on the use of the TL at Korean high schools, Liu, et al. (2004) found that the Korean teachers used up to $68 \%$ of L1 in the total number of words spoken, ranging widely from $40 \%$ to $90 \%$ across the individual teachers. The use of L1 as reported in this study was mainly for explaining vocabulary and grammar, giving background information and overcoming communication difficulties. In their study on TL use in an EFL setting in Hungary, Nagy \& Robertson (2009) counted the number of words of the TL (English) and L1 (Hungarian) spoken by the teachers and found that at the elementary level, one teacher used 9.4\% L1 while the other teacher used up to $27.7 \% \mathrm{~L} 1$. This rate, in contrast, was much higher in the two immediate classes at $40.9 \%$ and $47.5 \%$.

Some studies described how teachers resort to L1 for a particular instructional focus. Many studies reported that teachers tended to use L1 when they explained grammatical points $(66 \%$ of their grammar teaching time in Kharma \& Hajjaj's (1989) study, $88 \%$ in Franklin's (1990) study), and new vocabulary (71\% and $38 \%$ in Kharma \& Hajjaj's study (1989) and Franklin's (1990) study, respectively).

To explain the wide variety of L1 and TL use among teachers and learners, two groups of factors are often identified: external factors and interal factors. External factors include institutional policies such as curriculum, school language policy, social context or parents' expectations. Internal factors are either learner-related (such as motivation, age, and proficiency level), teacher-related (such as beliefs, training, and experience) or context-related factors (such as the type of tasks and lessons) (e.g. Crawford, 2004; Franklin, 1990; Nagy \& Robertson, 2009). 


\subsection{Summary}

In summary, the option for L1 use and TL use in the second language/foreign language classroom depends largely on the instructional settings and the teaching methods. In the instructional settings where L1 is not shared among learners or between learners and teachers, the option for L1 use is less likely, especially in teacher-learner interaction. In contrast, in the foreign language setting where learners and teachers share L1, the option for L1 use is more likely in both teacher-learner and learner-learner interaction. Research on the use of L1 and the TL in the language classroom, however, has been conducted mainly in second language setting, immersion setting and foreign language setting where English is L1. Teaching methods also influence L1 use in the language classroom; for example, the Grammar-Translation method uses L1 as a tool for language transfer, whereas CLT considers L1 as interference to language learning.

Research on L1 use in the language classroom shows two different positions about L1 use. One postion advocates the judicial use of L1, arguing that L1 is helpful to language learning in many ways: pedagogically, psycholinguistically and sociallinguistically. In contrast, the other position takes the TL only as the optimal approach. Emperical studies also show a wide range in the amount of L1 used by learner and teachers in the language classroom across different settings.

Despite the large amount of research on this topic, a few questions could be raised. First, the studies have one common point; that is, they are all observational or descriptive. While there are plenty of claims about various factors influencing the practice of L1 use, little has been done in the research designs of these studies to partition the influence of each factor. As a result, explanations and justifications for the practice tend to be speculative. The need is pressing for further research using a new research design such as an experimental study to control the variety of factors, and hence to have a thorough examination of this practice. Secondly, research on the use of L1 in the language classroom so far mainly focuses on L1 use during class talk. Little has been known about how L1 is manipulated in specific class activities. For example, there has been little research on the use of L1 and the TL in FonF and the impact of this practice on FonF. Given how common the practice is, this is surprising. In two studies by Farrokhi and his colleagues $(2008 ; 2007)$ on FonF in an EFL setting in Iran where the teachers and learners shared the mother tongue, the use of L1 was totally ignored as if it did not exist. In the research on FonF in the immersion setting, learners' use of L1 to the 
teacher is typically followed by a translation from the teacher, and is coded as errors for CF research (e.g. Panova \& Lyster, 2002). The purpose of the present study is to address this need, and in so doing, to address teachers' divergent views on the value of L1, and to identify whether the choice of FonF may have any impact on learner uptake, noticing and language learning. 


\section{Chapter 4: Methodology for the descriptive study}

The first phase of this research is a descriptive study that was carried out in EFL classrooms in Vietnam to investigate how much FonF and what kinds of FonF take place, how L1 and the TL are used in FonF, and how much uptake and what kinds of uptake take place across the teacher use of L1 and the TL in this context.

In this chapter of the thesis, the methodology and the techniques used to collect data for the descriptive study will be described and discussed. To begin with, the feasibility study which was conducted to investigate whether the data is available to be collected and analyzed will be described. The descriptive study will be discussed at length with respect to the research questions, the research design in specific stages, and the selection of participants. Data collection methods including class observations will also be described and discussed in detail. In addition, the methods of coding data and the validity and reliability of the coding methods will be presented.

\subsection{The feasibility study}

To investigate the feasibility of researching FonF in Vietnam EFL classrooms, I recorded three class periods. These class periods took place with first-year preintermediate English-major students in Vietnamese university classrooms. The three class periods consisted of a Speaking class, a Listening class and a Writing class. These classes are representative of the EFL classrooms at Vietnamese universities since they usually have more than 40 students and the teachers are NNSs of English. The administrators expected the teachers to use CLT in their classes; however, what happened in the classroom was very different. Observations for teacher development purposes are not done very often due to time constraints, limited budget and staff (see Truong, 2004), so in most cases, teachers are commonly left to decide on their classroom practices. The recordings showed frequent L1 use in these class periods. The Writing class and the Listening class were mostly in Vietnamese, and the class talk was mainly teacher talk. I chose the Speaking class to find data on FonF and found 15 FFEs during a class period of 42 minutes (2.8 minutes/each FFE), most of which were reactive and incidental. Four out of these 15 FFEs were in Vietnamese, and most the students' interaction with their peers and the teacher was in Vietnamese. In these 
instances, the teacher just accepted this practice without asking her students to try to use English. The recording suggests that FonF does take place in Vietnamese EFL classrooms and the use of L1 in FonF does happen, although sparingly in comparison to overall class talk.

I also conducted a mini-survey through interviews, email and e-conference with some colleagues (who are EFL or ESL teachers, both NSs of English (NSs) and NNSs of English (NNSs)) to collect their ideas about the need to use L1 in drawing learners' attention to linguistic items in EFL/ESL classroom and the specific classroom activities in which the use of L1 can be most helpful (see Appendix 2). Fifteen teachers were surveyed; 10 provided answers. All of the NNS teachers said they use L1 in their teaching when necessary, especially during error correction episodes. Two of them thought that L1 should not be used in an EFL class for any reason, and they try to avoid using it. Eight other teachers thought that L1 is helpful, especially for low-level and/or adult learners when they try to draw learners' attention to linguistic items so long as it is used selectively. The NS teachers who were asked indicated that knowing their students' L1 would help in giving explanations in error correction. They think it would save them a lot of time if they could give their explicit correction in L1 or translation, especially to low-level and new classes. I also found that an online debate among second language teachers (both NSs and NNSs) on this topic on a forum held by TESL-EJ at http://teslej.org/ej20/f1.html also showed similar answers from teachers all over the world.

\subsection{The descriptive study}

This study of the research aims to describe the types and amount of FonF taking place in EFL classrooms in Vietnam, the teachers' choice of the language (i.e., the TL or L1) in FonF, and the types and amount of uptake taking place in accordance with the teacher use of L1 and the TL in this setting.

The descriptive study reflects a focused description which falls in the middle of the qualitative-quantitative continuum of research methodologies described by LarsenFreeman \& Long (1991, p. 15). According to this continuum, this observational study is descriptive in nature with a scope narrowed to a specific aspect of the EFL classroom interaction: the use of the TL and L1 in FonF during teacher-student interaction. This 
type of research can include both qualitative and quantitative tools to fully describe the focused aspect of the study (Ellis, 2008, p. 777; Larsen-Freeman \& Long, 1991, p. 17).

The following sections of this chapter present the research questions of the descriptive study, the research design, the description of the participants and the class observations, and the data analysis methods. The validity and reliability of the research methodology are also discussed this part of the chapter.

\subsubsection{The research questions}

The descriptive part of the study addressed the following questions:

In EFL classes taught by Vietnamese NNS EFL teachers in Vietnam:

1. How much and what kinds of FonF take place during teacher-student interaction in EFL classrooms in Vietnam?

2. What types of FonF during teacher-student interaction are given in the first language (Vietnamese) and in the target language (English)?

3. How much and what kinds of uptake take place during teacher-student interaction in EFL classrooms in Vietnam in relation to the teacher use of L1 and the TL?

\subsubsection{The research design}

The observational study was designed to collect data on FonF taking place in intact classes in Vietnam. To collect data, I chose two private English language centres in Vietnam. Two separate institutions were selected to enhance the representativeness of the data. Private English language centres were chosen instead of public universities because their smaller class sizes (under 20 students per group) could make it easier for recording and transcribing teacher-learner interaction compared to the big groups at the Vietnamese university in my feasibility study where it was quite hard follow teacherstudent interaction in the recordings. Another important reason for the choice of these two private institutions was that they were established to meet the demand of the learners for a communication setting to practise speaking English. The classes at these institutions either taught "English for communication" courses or IELTS/TOEFL/ TOEIC-preparation courses. The classes chosen for this study, therefore, could allow for 
more data on teacher-student interaction and FonF for the purpose of this study than the setting of the feasibility study.

In addition to obtaining the approval from the Human Ethics Committee of Victoria University of Wellington to conduct the research, I obtained permission from the heads of the two private language institutions and the teachers in charge of beginning classes and advanced classes to observe and record their classes.

The data collection procedure was as follows.

\section{Figure 0.1: Descriptive research design}

\section{Preliminary sessions}

Institutions: Two private English language centres in Vietnam

Briefing and collecting participants' personal information

\begin{tabular}{l} 
Class observations \\
\begin{tabular}{|l|l|l|l|l|l|}
\hline \multicolumn{2}{|l|}{ Two consecutive 90-minute class sessions/class group(audio recorded) } \\
\hline \multicolumn{2}{|l|}{ English Language Centre 1 } & \multicolumn{3}{l|}{ English Language Centre 2 } \\
\hline $\begin{array}{l}\text { Advanced } \\
\text { Group 1 }\end{array}$ & Advanced & Beginning & Beginning & Beginning & Advanced \\
Group 3
\end{tabular} \\
\hline
\end{tabular}

As can be seen from Figure 4.1, before the first observation of each of the six class groups, I met with the teacher participants and learner participants of that group for briefing about the research collect their personal details. After that, I observed 12 class sessions (90 minutes/each) in 6 class groups ( 2 sessions/each class group) at two different levels of proficiency: elementary and advanced. I chose these two levels following arguments from teachers that students of higher proficiency level tend to favour second language use more than lower level students (see http://teslej.org/ej20/f1.html). Audio recordings were made to collect data on FFEs, teacher feedback moves in these FFEs and the teachers' language use (L1 and the TL) in their feedback moves. The observation sessions were conducted without revealing the focus 
of the observations to the participants in order to avoid contaminating the observation data.

The numbers of classes from each institution were balanced to make sure that similar amounts of data were collected from each. Two out of the three advanced class groups and one out of the three beginning class groups were from one English language institution and the other class groups were from the second institution (see Figure 4.1). The classes had three lessons a week every other day of the week (except Sundays). The two consecutive classes of the beginning classes took place during three or five days because in these classes, Vietnamese L1 teachers were in charge two sessions a week and native-speaker teachers in charge of one session. At the advanced level, Vietnamese L1 teachers had only one session a week, so two consecutive observations were one week away from each other.

\subsubsection{Participants}

The participants will be described in three groups: the research site, the teachers and the learners.

\subsubsection{Description of research site}

The two institutions where data was collected were both privately-owned English language centres in Vietnam. These institutions came into being at the start of the Doi Moi (Renovation) policy in Vietnam at the beginning of the 1990s, when the Vietnamese government started to "open door" diplomatically and economically to other countries. As a result, the demand for English education increased dramatically. In response to this demand, private education was legitimized, which, in turn, results in a rapid growth in the number of private English language centres.

The two private English language centres chosen for the descriptive study (English Language Centre 1 and English Language Centre 2) were two prestigious and popular centres which have branches in many large cities in Vietnam and were organized in similar ways. These institutions recruit learners regardless of their age or job. They do not have their own permanent teaching staff; their teachers have full-time day jobs elsewhere and take casual and part-time teaching jobs at these English language centres. 
The Vietnamese L1 teachers are recruited from high schools, colleges and universities in the local region, while the NS teachers are usually from international volunteer organizations. Both institutions have their own administrative staff who are responsible for curriculum development, and teaching and learning issues, including employing teaching staff and recruiting students.

Students are streamed into different classes according to their results in the placement tests taken in both written and oral forms. Most students go to general English classes, and a smaller number of the students go to test-preparation classes to prepare for international tests of English such as IELTS, TOEFL and TOEIC. The general English classes are arranged according to learners' proficiency levels, ranging from elementary to advanced level, while the test-preparation classes are only for students of intermediate level or higher.

There are six levels of general English classes including pre-beginners, beginners, preintermediate, intermediate, upper-intermediate and advanced. These levels, in turn, are divided into two to four sub-levels, each of which takes the learner three months to finish. The course books in use are the commercial series "New Headway" (Soars \& Sayer, 2003) at one institution and "Cutting Edge" (Cheetham, et al., 2002) at the other institution, which are re-designed to assign a part of each book to each sub-level respectively. However, these course books only served as the framework for the syllabus, and the teachers were free to modify lessons and use teaching materials from other sources to supplement the main course books. At the end of each sub-level, learners have to sit an end-of-course test to decide whether they are qualified for the next sub-level.

Similarly, the IELTS-preparation classes are in three levels: intermediate, upperintermediate and advanced, and are also divided into two sub-levels for students to cover in a three-month period each. The course books in use are "Steps Up to IELTS" for intermediate level and "Focus on IELTS" for upper-intermediate and advanced levels. Like in general English classes, the teachers of these classes were free to use teaching materials from other sources to supplement the main course books. After finishing each sub-level, students take an assessment test to move to the next sub-level. 
As the two most popular English language centres in the region, these two institutions usually have classes across all the sub-levels. The number of enrolled students in English Language Centre 1 was about 300, and there were about 450 students in English Language Centre 2 at the time this study was being conducted. A greater number of students enrol for lower level classes than for higher level ones, which means the size of the lower level classes is often bigger than that of the higher level ones. However, the number of students in each class is limited to 20.

Under the pressure from each other and other competitor institutions, these institutions always strive for the best way to guarantee their teaching and learning quality. Based on the learners' opinions through their evaluation forms, the institutions encourage the professional development of the teachers by increasing their salaries when they obtain new qualifications. They also dismiss any employees who do not meet their learners' expectations.

\subsubsection{Description of class groups}

Classes are usually conducted in the evening every two days, except Sundays. As a result, each class group has three class sessions every week. Each class session lasts 90 minutes with a 10 -minute break in the middle.

At the intermediate level or lower, students have two class sessions a week with a Vietnamese NNS teacher and one with a NS teacher. Meanwhile, at the upperintermediate and advanced levels, students have two class sessions a week with a NS teacher and one with a Vietnamese L1 teacher. For the purposes of the study, the observations were conducted in the class sessions taught by Vietnamese teachers only.

Both types of general English courses and test-preparation courses were expensive and were widely advertised as "English for communication" classes, so the focus on communicativeness was of high priority. In general English classes, though all skills were taught, speaking skills were specially emphasized. As a result, communicative activities like games and social talks were advocated by the administrators. For testpreparation classes, speaking skills were considered difficult for Vietnamese learners because most of them did not use to learn to speak English at school or university before. Consequently, for courses preparing for IELTS test, teachers were expected to 
encourage learners to practise speaking English in order to prepare for the speaking section of this test. IELTS-preparation classes were chosen for this study due to the large amount of interaction expected to take place in these classes. TOEIC- and TOEFL-preparation classes were not chosen because at the time of this study, these classes followed the old formats of these two tests which did not include a speaking section.

The Vietnamese L1 teachers had two classes a week with the beginning class groups, and the two observations of each group were arranged every other day. For the three advanced class groups, the Vietnamese L1 teachers had only one class a week with their class groups, so the two consecutive observations were one week apart.

Table 4.1 describes the class groups participating in this study. There were three class groups of the beginning level; all of them were general English class groups. Two were from English Language Centre 2, taking New Headway - Elementary as the course book. One was from English Language Centre 1, using Cutting Edge - Elementary as the course book. The number of students in these groups ranged from 11 to 18, but the number of those turning up at the observations was only from 8 to 15 . Though all of these class groups were considered at the beginning level, one class group was observed when it was in the first month of the beginning level, while one was in the fourth month and the other was in the sixth month. The class sessions in observation focused on different skills such as reading, listening and vocabulary which led to speaking activities.

Among the three advanced class groups, there were two IELTS-preparation groups and one general English group. The two IELTS-preparation class groups were from English Language Centre 1, and the general English group was from English Language Centre 2. The size of these class groups ranged from 10 to 12 students, but only seven to ten of them showed up at the observations. The two IELTS-preparation class groups were in the fourth and sixth month of a nine-month course, while the general English group was in the sixth month. At the recorded observations, the general English class group had reading and listening tasks which led to speaking tasks. The two IELTS-preparation class groups were observed and recorded when they were preparing for Phase 2 and Phase 3 of the speaking section of the IELTS test by doing one to two-minute presentations on topics and discussing questions related to the topics. 
Table 4.1: Description of class groups

\begin{tabular}{|c|c|c|c|c|c|c|c|}
\hline Centre & $\begin{array}{l}\text { Class } \\
\text { group }\end{array}$ & $\begin{array}{l}\text { Proficiency } \\
\text { level }\end{array}$ & $\begin{array}{l}\text { Number of } \\
\text { students }\end{array}$ & Course & Course book & Observation month & Lessons in observation \\
\hline 1 & B1 & Beginning & $18(12 \text { and } 15)^{*}$ & General English & $\begin{array}{l}\text { Cutting Edge } \\
\text { - Elementary }\end{array}$ & $4^{\text {th }}$ month of a 6 -month course & $\begin{array}{lrr}\text { Reading texts } & \text { and } \\
\text { listening leading } & \text { to } \\
\text { speaking tasks } & \end{array}$ \\
\hline 2 & $\mathrm{~B} 2$ & Beginning & $11(8 \text { and } 8)^{*}$ & General English & $\begin{array}{l}\text { New } \\
\text { Headway - } \\
\text { Elementary }\end{array}$ & $6^{\text {th }}$ month of a 6 -month course & $\begin{array}{l}\text { Listening tasks leading to } \\
\text { speaking tasks }\end{array}$ \\
\hline 2 & B3 & Beginning & $13(10 \text { and } 10)^{*}$ & General English & $\begin{array}{l}\text { New } \\
\text { Headway - } \\
\text { Elementary }\end{array}$ & $1^{\text {st }}$ month of a 6-month course & $\begin{array}{l}\text { Vocabulary and listening } \\
\text { tasks leading to games } \\
\text { and speaking tasks }\end{array}$ \\
\hline 1 & A1 & Advanced & $10(7 \text { and } 7)^{*}$ & $\begin{array}{l}\text { IELTS- } \\
\text { preparation }\end{array}$ & $\begin{array}{l}\text { Focus on } \\
\text { IELTS }\end{array}$ & $6^{\text {th }}$ month of a 9-month course & Speaking test preparation \\
\hline 1 & $\mathrm{~A} 2$ & Advanced & $11(8 \text { and } 9)^{*}$ & $\begin{array}{l}\text { IELTS- } \\
\text { preparation }\end{array}$ & $\begin{array}{l}\text { Focus on } \\
\text { IELTS }\end{array}$ & $4^{\text {th }}$ month of a 9 -month course & Speaking test preparation \\
\hline 2 & A3 & Advanced & $12(7 \text { and } 10)^{*}$ & General English & $\begin{array}{l}\text { New } \\
\text { Headway - } \\
\text { Advanced }\end{array}$ & $6^{\text {th }}$ month of a 9-month course & $\begin{array}{l}\text { Reading and listening } \\
\text { tasks leading to speaking } \\
\text { tasks }\end{array}$ \\
\hline
\end{tabular}

* Numbers of students turning up at the first and second observations were put in brackets respectively 
The administrators remarked that the number of absent students was high during the time of the observations because this was also the mid-term examination time at some schools and universities. The learners (many of whom were also studying at school and university) skipped some English evening classes to concentrate on their preparation for examinations.

\subsubsection{Description of teachers}

As is typical at private English language institutions, the Vietnamese L1 teachers were giving classes at these institutions as part-time jobs, which mostly took place in the evening. However, in order to be employed, they had to pass a strict recruiting process which assessed their qualifications and experiences, and their teaching skills. The administrative staff of the institutions are responsible for regularly monitoring the teachers' class performance and collecting learners' evaluation about the teachers which decide whether the teacher could continue to work at the institution.

Table 4.2 describes the participant teachers in this study. Pseudonyms were used to refer to the teachers. Thuy, Hong and Huong who were in charge of the three beginning class groups were female with age ranging from 26 to 43 and teaching experience ranging from 1.5 years to 21 years. All of them held a bachelor's degree in English Teaching.

One of them just obtained a Masters' degree in English Language while another was taking a course toward the same degree. Two of them were teaching at two different universities and one at a high school.

The three teachers in charge of the three advanced class groups were Thien, Nguyen and Phuong (pseudonyms), whose age ranged from 37 to 45 and experience from 14 to 23.5 years. They all held a Bachelor's degree and a Masters' degree. Thien, the oldest teacher, also held a PhD degree in Linguistic Theories. Two of them were lecturers at a public university, and the other was a freelanced teacher who had resigned from a private university two years previously. 
Table 0.2: Description of teacher participants

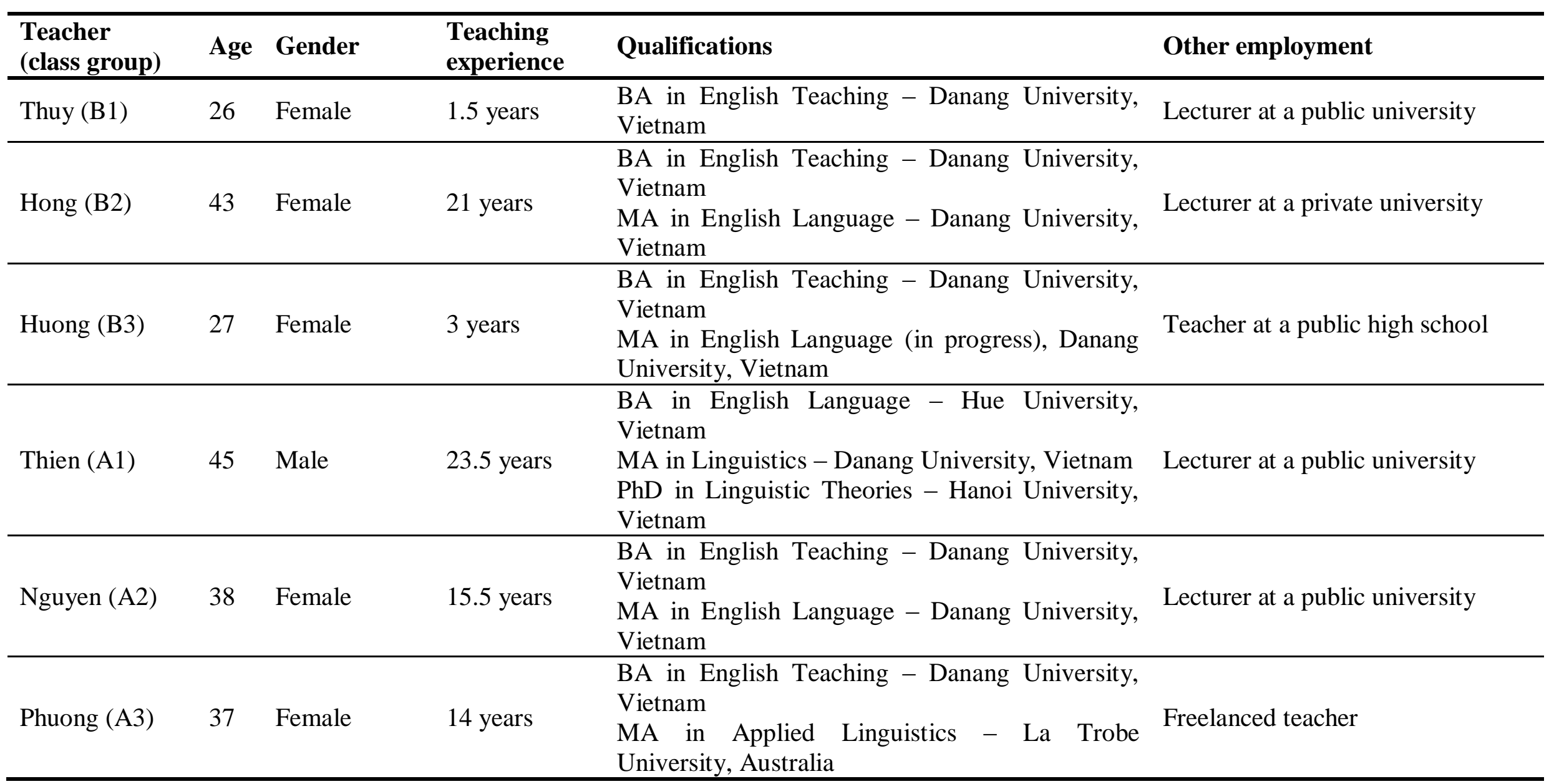


They were five females and one male, which is quite representative of the profession where the number of females is overwhelming. This profile of the teachers also clearly reflects the institutions' policy in recruiting teachers: teachers must be well-qualified and experienced in teaching English, and those who hold a bachelor's degree usually had high grades at university and are expected to pursue further education.

Though there were no explicit regulations about the NNS teachers' particular qualifications and teaching experiences required to teach particular classes, more experienced and better-qualified teachers were assigned to higher level classes. The advanced class groups in this study were taught by the doctor's degree holder and two of the three master's degree holders, all of whom have been teaching English for more than ten years.

Sharing their class groups with NS teachers, these teachers usually worked with their NS partners to agree on who would teach what parts of the course books. In this study, the Vietnamese L1 teachers of the beginning class groups were in charge of general skills including speaking, listening, writing and reading, while their NS partners were responsible for speaking and listening with a special focus on pronunciation. Similarly, in the advanced class groups, the Vietnamese L1 teachers were responsible for most parts of the course with a focus on grammar, whereas their NS partners were supposed to provide the students with more exposure to the NSs" "real speaking" and accents. Both the NS teachers and the Vietnamese L1 teachers had some autonomy in redesigning their lessons to improve the quality of the lesson and the communicativeness of the class, which was interpreted as the learners' active participation in the class activities.

\subsubsection{Description of learners}

There were 56 learner participants in the six class groups observed. Twenty two of them were from the three advanced class groups and 34 of them were from the three beginning class groups. Twenty three were from one institution and 33 from the other. At the beginning of the data collection session, they were asked to answer some questions about their background information in a form that was issued together with the consent form and the information leaflet about the research (see Appendix 3). 
As mentioned in the description of the institutions, students at these two institutions are recruited regardless of their age or job. As a matter of fact, the learners range widely in ages and jobs. However, a great majority of the learner participants were students (69 out of 75 , accounting for $92 \%$ ), and a large percentage (80\%) of the learner participants were teenagers and young adults. There were two learners aged from 31 to 40, and two aged over 40 . Thirty nine learners were females, and 36 males.

Since the tuition fees were charged in US dollars and quite high compared to the living standard of the community, the learners (and/or their parents) expected high-quality teaching from the institutions. As part of their commitment to improving the quality of teaching, at the end of each sublevel three-month course, the institutions sent an evaluation form to collect learners' feedback about their administrative, teaching and learning issues. While the practice of evaluating teachers is unfamiliar in Vietnam, where teachers are highly respected and usually exempted from learners' criticism, the learners were well aware that they could enjoy the rights to be critical to the quality of teaching, and of course, of the teachers.

When being asked about their overall motivation to learn English, only two learners at the beginning level defined it as "weak". The rest of the learners (96.4\%) identified themselves having "moderate", or "strong", or "very strong" motivation. The motivation together with their feeling about their power in the class might have given the learners confidence, and hence driven their active participation in class activities, making their classes very different from the classes described in the feasibility study of this research and the foreign language class described by Ellis (2008).

\subsubsection{Class observations}

The observations were conducted in the class sessions with the Vietnamese NNS teachers, so for each of the three beginning level groups, two consecutive sessions which took place every other day were observed. I chose the two consecutive sessions so that the data could be grounded in a clear context where the class activities were usually more or less continued or inherited from the previous class sessions.

I was introduced to the learners in all of the 12 class sessions as a non-participant observer. To do the observations, I sat at the last row of the classroom to have an overall 
observation of the whole class. A video recorder had been used at first, but since both the learners and the teachers seemed quite uneasy being video recorded, the video recorder was replaced by MP3 players to avoid the "problem of reactivity" when a video camera was installed (Cohen, Manion, \& Morrison, 2004, p. 313). The class sessions were recorded using two MP3 players: a smaller and more compact one attached to the teacher and a bigger and more powerful one put on the teacher's table in front of the class. To keep track of who said what, I made a class map with learners' seats coded as S1, S2, etc., and took notes on learners' turns, keeping the time of their turns. As the size of these class groups was quite small, it was not too difficult to keep track of the learner-teacher interaction, which was the main focus of the study.

\subsubsection{Data analysis methods}

The methods used to analyse the data are based on techniques and methods widely used in the field. To begin with, data were transcribed in accordance with the purposes of the study. Then they were categorized according to the variables under investigation to answer the research questions. To ensure the reliability of the data coding, a second rater coded about 12 per cent of the data.

\subsubsection{Data transcription process}

I transcribed all of the recordings of the 12 observations, using the versions from the recorder put on the teachers' tables. When these versions had any unrecognizable details of the teacher-student interaction, the other versions would be referred to clarify these details. The notes taken during the class observations were also used to ensure the match between the interaction turns and the speakers. The transcriptions of the observation were narrow, as described by Ellis (2008); that is, they included pauses, suprasegmental information, and other discoursal events relevant to the goals of the study.

About five minutes of the class talk at the beginning and at the end of each class session which was usually unrelated to the instruction scheduled to be covered in the session was excluded from the transcribed data. Likewise, 'silent time' including the time allotted to students for preparing the tasks and learner-learner interaction, was also excluded from the data for the purposes of the study. The 'chunks' of the teacher- 
student interaction in each recording were transcribed with a note on the duration, and these lengths of time were added up to become the 'net time' of the teacher-student interaction in each recording.

The transcription of an approximate time period of 40 minutes was taken from the 'net time' of the teacher-student interaction in each observation to use for data coding and analysis. The chosen parts of the transcriptions started at the beginning of the recording and lasted to the fortieth minute of the transcriptions. In case the last minute ended before an FFE did, the data would be extended to cover the last FFE, but the extended time must not be more than one minute. If the extended time was more than one minute, the last FFE was excluded from the data.

Altogether, transcriptions of 480 minutes of teacher-student interaction were coded. The recordings were transcribed in utterances, which were determined by intonation contours (Duff \& Polio, 1990). An utterance, as defined by Crystal (2008, p. 505), is a behavioural unit rather than a grammatical one, characterized as a 'stretch of speech preceded and followed by silence or a change of speaker'. In the transcriptions, utterances were separated from one another by new lines and numbered. All paralinguistic features available in the audio recordings were also transcribed to help clarify the discourse and hence define the types and the purposes of the utterances in the context. The transcription conventions can be found in Appendix 4.

\subsubsection{Data coding}

The results from the feasibility study revealed that in the Vietnamese EFL setting, teacher feedback in an FFE did not take place in L1 or the TL only; the teachers usually combined the two languages when giving feedback on a single linguistic item. Thus, to accurately describe the use of L1 and the TL in FonF by L1 Vietnamese teachers, the data was not only coded in FFEs as in the conventional way in FonF research but also in feedback moves. The procedure of data coding was comprised of two steps: coding FFEs and coding form-focused moves.

\section{Coding the FFEs}

The FFEs were identified with respect to the definition of FFEs used in Basturkmen, et al. (2004) and Ellis, et al. (2001a). In these studies, FFEs are defined as the occasions in 
which attention to linguistic form takes place, triggered by learners' errors or by questions raised by learners or teachers. The prerequisite of an FFE in this study was the existence of an interlanguage gap by a learner. An FFE started when there was a trigger in the form of a learner's error, or a learner's query about a linguistic item, or a teacher's question about a linguistic form. It ended when the attention was shifted back to focus on meaning or to a new linguistic form (Ellis, et al, 2001a). All FFEs were numbered and coded with their number and the class code. Episode 01 B2 gives an example of an FFE from the data.

\section{Episode 01 B2}

Sx: How do you feel before an important exam?

Sxx: I... I feel nervous /'ne-v3s/ before an important exam. <=learner's pronunciation error

T: uhm, you feel nervous /'n3:-v3s/ $<=$ teacher's feedback

Sxx: /n3:-v3s/ $<=$ learner's uptake

T: before an important exam, ok.

Sx: an important exam

T: yep

In this example, the three types of moves in an FFE are marked out. The FFE started with a learner's pronunciation error followed by the teacher's feedback and ended when the learner made an uptake move. In the following moves, the focus returned to the previous topic.

However, there were some occasions in which "fake" FonF took place. In these occasions, the teacher started to correct before the learner finished his/her turn, and when the learner continued with his/her utterance, it turned out that the error did not exist. There were six episodes of this type and they were eliminated from the data since the interlanguage gap did not exist. Episode 32 A3 below is an example.

\section{Episode 32 A3}

T: Ben says that he has too much work at school, too much homework, too much work at school.

What about you? 


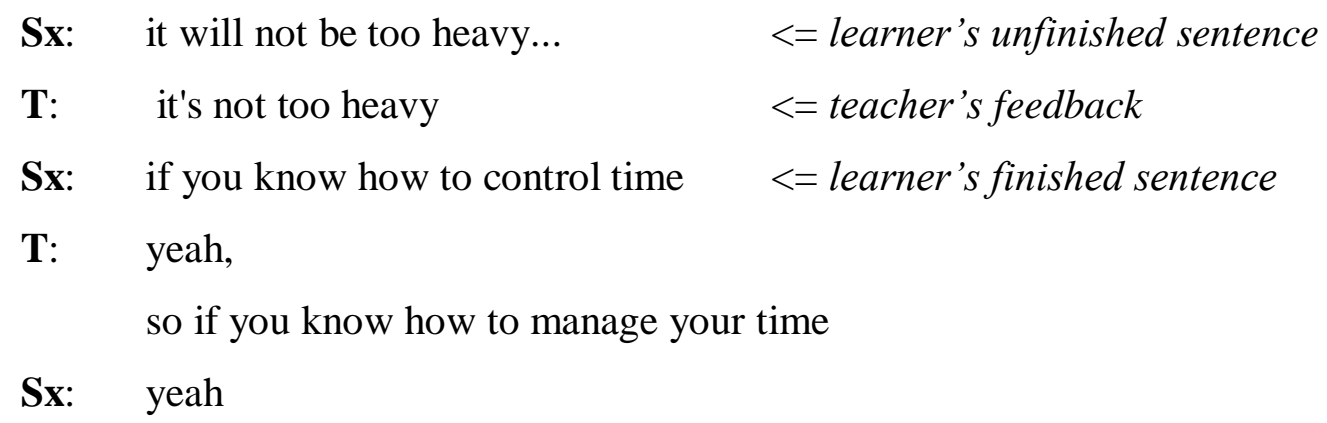

In this episode, the teacher made a feedback move to correct the learner's unfinished turn as she thought that the learner made a mistake when using "will". However, when the learner finished his turn, the teacher did not insist on the learner's error correction, and she turned to recast the learner's vocabulary error which started a different FFE. The context was taken in account to

Also, occasions in which a learner made an error or enquired about a linguistic feature but the teacher did not make an attempt to address it, and occasions in which learners corrected themselves or corrected each other, were not coded. That was because these occasions did not represent the teacher-student interaction in the classroom, which is the target of this study. A couple of the episodes focusing on the content of the lessons rather than on language issues were also eliminated from the data. Similar cases had been observed and eliminated from the data by other researchers (e.g. Ellis, et al, 2001).

After being identified, the FFEs, in turn, were coded as either single-move FFEs (which contain only one teacher feedback move) or multi-move FFEs (which have more than one teacher feedback move). Episode 01 A3 is an example of a single-move episode.

\section{Episode 01 A3}

Sx: My aunt has gone to Canada because her husband live there.

T: Her husband lives there. $\quad<=$ teacher feedback move Uhm. (.)

Fred, you've got any relatives or acquaintances or friends who have gone to live in a foreign country?

In this example, it can be seen that there was only one teacher feedback move addressing the learner's pronunciation error of the word "live". Episode 01 A1 below gives an example of a multi-move FFE. 


\section{Episode 01 A1}

Sx: I think it taking a chance or playing it safe, it depends on every situation.

we can try every decision /di-'sai-sn/

T: we can...? < $\quad<$ teacher feedback move 1

what do you mean 'we can try every decision /di-'si-zn/ ? < = teacher feedback move 2

You mean 'decision' /di-'si-zn/, not decision /de-'sai-sn/ <= teacher feedback move 3

Decision, 'quyết định', hả? [T gives the translation of the word] $<=$ teacher feedback move 4

Sx: decision /di-'si-zn/

In this example, the teacher made four feedback moves to address the learner's pronunciation error of the word "decision".

\section{Coding moves in the FFEs}

From my observation of the classroom practice in Vietnam, I found that the Vietnamese L1 teachers tended to combine the TL and L1 when giving feedback, especially in multi-move FFEs. Similar observations are also reported by many NNS teachers on their online forum. Therefore, when describing the use of L1 and the TL in FonF, I used moves instead of episodes in order to distinguish L1 and TL use more accurately.

Since this research is one of the pioneering studies exploring the use of L1 and TL in L1 teachers' feedback, the use of moves for coding the teacher use of L1 and TL is unprecedented. This construct, therefore, is based on the use of utterances in some previous studies such as Duff \& Polio's (1990) and Crystal's (2008) definition of an utterance. The moves were identified as a 'stretch of speech preceded and followed by silence or a change of speaker' (Crystal, 2008, p. 505) and in accordance with intonation contours (Duff \& Polio, 1990). Moves were identified as utterances separated from one another by new lines and numbered in the transcriptions. 
The form-focused moves in these episodes were coded according to the characteristics in Table 4.3, which is adapted from Loewen (2005). Since this study focused on the teachers' feedback and the learners' responses, the initiating moves (or trigger moves) were not coded. 


\begin{tabular}{|c|c|c|}
\hline Characteristic & Definition & Categories \\
\hline \multirow{3}{*}{ Type } & \multirow{3}{*}{$\begin{array}{l}\text { Type of } \\
\text { feedback } \\
\text { provided by } \\
\text { teachers }\end{array}$} & $\begin{array}{l}\text { Provide: Teacher gives explicit information in the } \\
\text { form of definitions, examples or explanations. }\end{array}$ \\
\hline & & $\begin{array}{l}\text { Elicit: Teacher repeats the error, gives prompts, } \\
\text { clues or elicits solutions so that Ss recognize the } \\
\text { gaps and correct themselves. }\end{array}$ \\
\hline & & $\begin{array}{l}\text { Reformulate: Teacher gives implicit information in } \\
\text { the form of recasts to reformulate part or all of the } \\
\text { erroneous utterance. }\end{array}$ \\
\hline \multirow{2}{*}{ Source } & \multirow{2}{*}{$\begin{array}{l}\text { Reason for } \\
\text { feedback }\end{array}$} & $\begin{array}{l}\text { NoM: negotiation of meaning, triggered by } \\
\text { miscommunication between teacher and student. }\end{array}$ \\
\hline & & $\begin{array}{l}\text { NoF: negotiation of form, attention to form } \\
\text { drawn by teacher or student. }\end{array}$ \\
\hline $\begin{array}{l}\text { Linguistic } \\
\text { focus }\end{array}$ & $\begin{array}{l}\text { Linguistic } \\
\text { target }\end{array}$ & $\begin{array}{l}\text { spelling } \\
\text { pronunciation, } \\
\text { morphosyntax } \\
\text { vocabulary }\end{array}$ \\
\hline \multirow[b]{2}{*}{ Language } & \multirow{2}{*}{$\begin{array}{l}\text { Language } \\
\text { teacher uses to } \\
\text { give feedback } \\
\text { and/or draw } \\
\text { students' } \\
\text { attention to } \\
\text { form. }\end{array}$} & $T L$ : when a move is completely in English \\
\hline & & $\begin{array}{l}\text { L1: when a move is partly or completely in } \\
\text { Vietnamese }\end{array}$ \\
\hline \multirow{5}{*}{ Uptake } & \multirow{5}{*}{$\begin{array}{l}\text { Student's } \\
\text { response to } \\
\text { feedback }\end{array}$} & $\begin{array}{l}\text { Repair: student's incorporation of teacher's } \\
\text { feedback in response }\end{array}$ \\
\hline & & $\begin{array}{l}\text { Needs-repair: student's failure to incorporate } \\
\text { feedback in response }\end{array}$ \\
\hline & & $\begin{array}{l}\text { L1 response: student responds partly or completely } \\
\text { in Vietnamese. }\end{array}$ \\
\hline & & Acknowledge: student responds with 'yes', 'ah'... \\
\hline & & $\begin{array}{l}\text { No opportunity: Teacher goes on; student has no } \\
\text { opportunity to respond to feedback. }\end{array}$ \\
\hline
\end{tabular}

Besides coding the language (i.e., the TL or L1) of moves used by the teachers to draw learners' attention to form, I also coded these moves according to (1) different types of feedback moves made by the teachers, (2) different reasons for the feedback moves, (3) 
different language foci of the feedback moves, (3) and the learners' responses to the teachers' feedback moves.

It was common in the data for teacher feedback moves to address more than one linguistic item (Loewen, 2004b). The coding practice for this aspect in this study, therefore, was done in a hierarchical order as illustrated below.

Figure 0.2: Coding the FFE language foci.

\section{A feedback move}

focus on spelling?

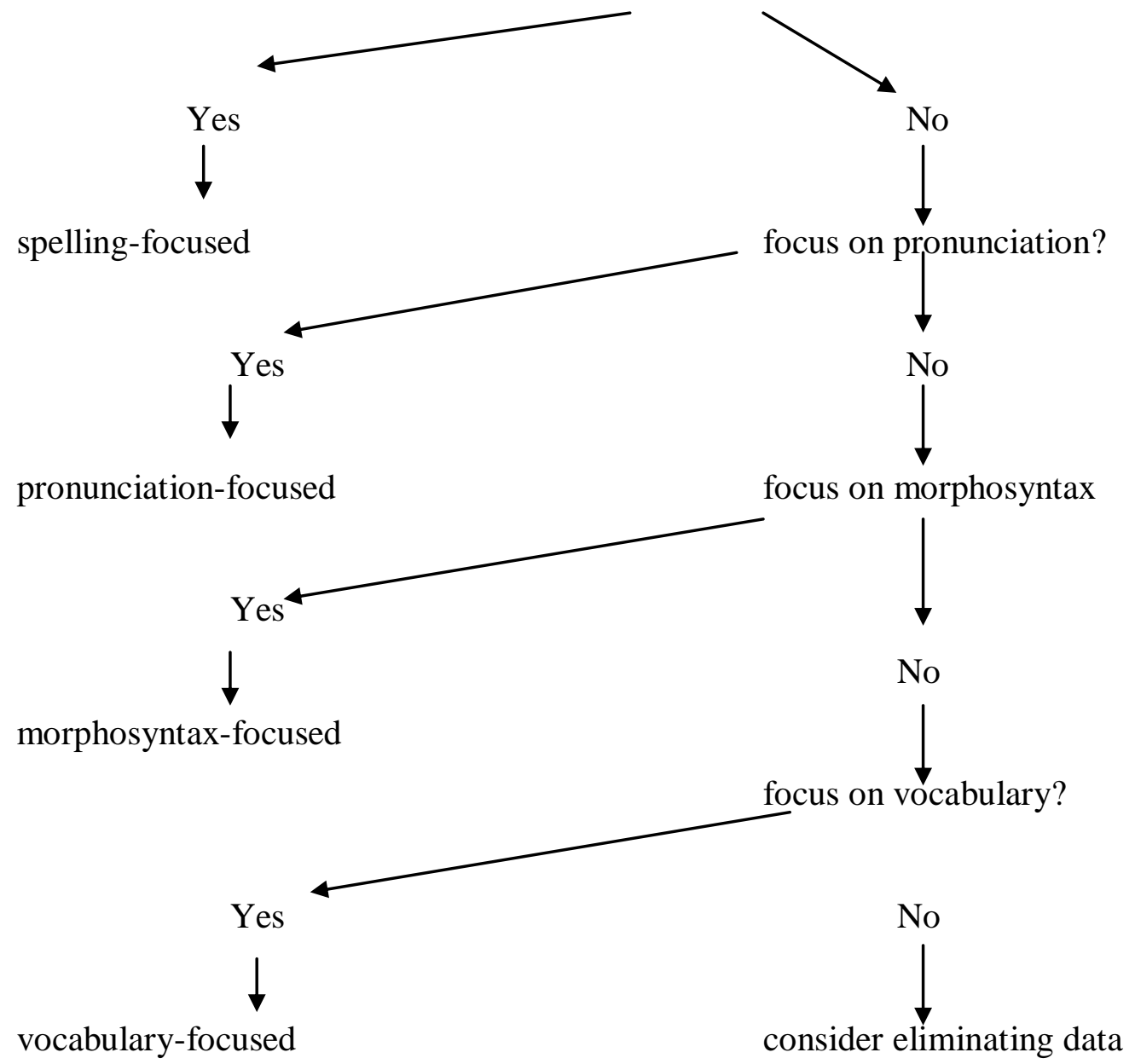

The episodes falling into the last subcategory of 'considering eliminating the data' were mostly the episodes which belonged to one of the irrelevant types mentioned in the preceding section. 
The following examples are taken from the data to illustrate how the moves in FFEs were coded in accordance with the characteristics described in Table 4.3 and the coding procedure in Figure 4.2. Only the feedback moves and the uptake moves were coded. Episode 02 A3 and Episode 18 B2 are examples of how FFEs were analysed.

\section{Episode 02 A3}

Sx: I know one person.

When he cames, he's a British or somewhere in Europe.

She come to Vietnam and live here in about 8 years $<=$ trigger move

T: $\quad$ she has lived here for 8 years

$<=$ feedback move

Sx: $\quad$ yes, for 8 years.

$<=$ uptake move

Analysis of Episode 02 A3

Type: $\quad$ Reformulate Teacher recasts the erroneous utterance.

Source Morphosyntax Teacher corrects the wrong tense and wrong preposition.

Language TL Teacher gives feedback completely in English.

Uptake Repair Student incorporates (partly) the feedback in response.

\section{Episode 18 B2}

Sx: you come /koum/ home

$<=$ trigger move $(\mathrm{TM})$

T: $\quad$ you come $/ \mathrm{k}^{\wedge} \mathrm{m} /$ home',

$<=$ feedback move 1 (FM1)

yeah, 'you come $/ \mathrm{k}^{\wedge} \mathrm{m} /$,

$<=$ feedback move 2 (FM2)

'come $/ \mathrm{k}^{\wedge} \mathrm{m} /$ ', not 'come $/ \mathrm{koum} /{ }^{\prime}$

$<=$ feedback move 3 (FM3)

Sx: $\quad / \mathrm{kam} / \ldots / \mathrm{kam} /$

$<=$ uptake move 1(UM1)

T: $\quad / \mathrm{k}^{\wedge} \mathrm{m} /$ do nghe (it must be $/ \mathrm{k}^{\wedge} \mathrm{m} /$ ), yeah. $\quad<=$ feedback move 4 (FM4)

Sx: $\quad / k^{\wedge} \mathrm{m} /$ home

$<=$ uptake move 2 (UM2)

T: you come home. And then?

Analysis of Episode $18 \mathrm{~B} 2$

Type: $\quad$ Reformulate (FM1)

Teacher fully recasts trigger move.

Reformulate (FM2)

Teacher fully recasts trigger move. 
Provide (FM3)

Provide (FM4)

Source $\quad$ NoF No miscommunication takes place

Linguistic Pronunciation (FM1-4) Teacher corrects the wrong pronunciation focus

Language $\quad T L$ (FM1-3) Teacher's feedback is completely in English.

L1 (FM4) Teacher's feedback is partly in Vietnamese.

Uptake No opportunity Teacher continues with her three feedback moves

(after FM1-2) (FM4-6). Student has no opportunity to give uptake.

Needs-repair (UM1) Student fails to incorporate feedback in his response.

Repair (UM2) Student successfully incorporates feedback in his response

\subsubsection{Statistical tools used for data analysis}

In this descriptive research study, the frequencies and percentages of the coded categories were calculated as raw data and presented in accordance with the research questions on the amounts and types of FonF and uptake taking place in the research context, and the use of the TL and L1 during FonF. The raw data were then analyzed using inferential statistics. The Statistical Package for Social Sciences (SPSS) was used to perform the necessary tests to analyze the patterns of the number and types of FFEs and FonF moves occurring across the classes and the proficiency levels. For independent samples like the number of FFEs and teacher feedback moves across the class groups, the chi-square goodness-of-fit test was used to determine whether the differences between the observed number and the expected number of the records were statistically significant (Moore \& McCabe, 2003; Siegel \& Castellan, 1988). For the difference in the number of FFEs and feedback moves between the two proficiency groups, a one-way ANOVA was performed to investigate the difference between mean 
scores of these two groups. If the difference was found to be statistical, effect sizes were also reported (Larsen-Hall, 2010).

When it was necessary to examine the interaction between two variables in the form of an $r$ x $k$ contingency table such as different types of FFEs, feedback moves and uptake moves across the class groups, the chi-square analysis was carried out to determine whether there was any statistically significant difference in these categories across the class groups (Siegel \& Castellan, 1988). If the difference was found to be significant, the adjusted standardized residuals (ASRs) were computed as a partitioning procedure to discover how much each variable contributed to the differences found in the chisquare tests (Siegel \& Castellan, 1988).

To examine the variation of the data such as different types of FFEs, feedback moves and uptake moves across the two proficiency levels, full-factorial ANOVAs were used. If the interaction between these variables and the learners' proficiency levels was found significant, effect sizes would be reported accordingly.

In the descriptive study, the level of significance was set at $\alpha=0.01$, which is lower than the conventional level of 0.05 . Due to the considerable variation in the features of the participants, this reduction in the alpha level is made so that the most important variation in the data and the most significant interaction between variables could be revealed and reported. The ASR threshold is set at 2.6 in accordance with the alpha level of 0.01 (Moore \& McCabe, 2003).

\subsubsection{Validity and reliability}

As a descriptive study, this study aims to describe phenomena which take place naturally (Seliger \& Shohamy, 1989). To do this, intact class groups were observed and recorded when they were occurring as part of the routine learning and teaching process without any changes in time or place or syllabus.

I observed all of the 12 class sessions as a non-participant observer. This practice was very familiar to the teachers and the learners since the administrators of the institutions carried out regular observations for evaluation purposes. In addition, the participants, both learners and teachers, were not made aware of the specific purposes of the study. 
In the information sheet (see Appendix 2), they were simply told that the study aimed to investigate teacher-student interaction in an EFL classroom. As a result, it was unlikely the participants might have behaved in some way that may harm the validity and reliability of the collected data.

To ensure the reliability of the data analysis procedure, a postgraduate student was employed as a second rater. This student was working on a minor thesis on CF toward her Masters' degree. She was trained in the use of the data coding system and was given a one-hour practice session. After that, she was asked to code about 12 per cent of the data (containing 71 FFEs with 144 teacher feedback moves). The inter-rater agreement rate was 88.9 per cent. In an interactive session to reconcile the differences, the second rater and I found the reasons for the differences and discussed them. Out of the 16 feedback moves in disagreement, eight feedback moves were miscoded by mistake. The other eight remained in disagreement and were excluded from the data. The final interrater agreement was 95.8 per cent.

\subsubsection{Summary}

The feasibility study was designed to confirm the availability of FonF in the EFL setting. After that the descriptive study was designed to answer the three research questions on the occurrence of FonF and its characteristics in an EFL context, the teacher use of L1 and the TL in FonF, and learner uptake in this context. The research design involved class observations carried out in six different class groups at two private English Language Centre in Vietnam. The collected data was then transcribed and coded in accordance with a taxonomy built from those used in previous studies in the field. The data was analysed and interpreted using a number of statistical tools including chi-squre tests, one-way ANOVAs and full-factorial ANOVAs. A second rater coded 12 per cent of the data to guarantee the reliability of the process.

The results of the descriptive study were then utilized to design the interactive tasks for the experimental study, the methodology of which will be discussed in detail in the next chapter. 


\section{Chapter 5: Methodology for the experimental study}

This chapter will describe the questions, the research design, the data collection methods and the data analysis methods. The statistical tools used for data analysis and the validity and reliability of the research are also discussed in this chapter.

\subsection{The research questions}

This experimental study aims to answer the following research questions.

In an EFL setting instructed by Vietnamese EFL teachers in Vietnam:

1. Does the teacher use of L1 in FonF during teacher-student interaction lead to more noticing than the use of the TL?

2. Does the teacher use of L1 in FonF during teacher-student interaction lead to more uptake than the use of the TL?

3. Does the teacher use of L1 in FonF during teacher-student interaction lead to more language development than the use of the TL?

The research procedure designed to answer these questions will be discussed in the following section.

\subsection{The research design}

The aims of the experimental study were to juxtapose the teacher's use of the TL and L1 in FonF during teacher-student interaction to find out whether there were any differences in learner uptake, noticing and language development when the two languages of FonF (i.e., the TL and L1) were used. Forty three volunteer learners were invited to participate in the experimental study. 


\subsubsection{Stages of the research}

The data collection procedure was carried out between the researcher and each learner participant individually over two consecutive days and was staged as follows:

Figure 0.1: Stages of the experimental procedure

Day 1: Individual task-based interactions

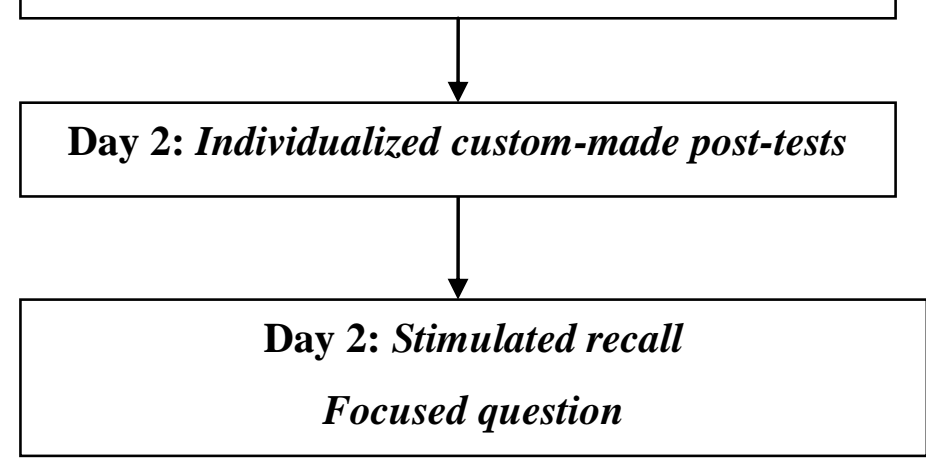

This was designed as a lab-based study to isolate the use of L1 and the TL in FonF. To do this, during the individual task-based interactions on the first day, the researcher as the teacher responded to the learner participants' interlanguage gaps using the TL for the first two different proficiency level groups and using mostly L1 for the other two. These interactive activities were video-recorded, transcribed and coded for the occurrence of FFEs and uptake. FFEs initiated by the learners in these tasks were used for individualized testing (Adams, 2007; Loewen, 2005) which took place on the second day. Data collected from the interactive tasks and individual tests were analyzed to compare learner uptake and language development levels of different groups.

After completing the individualized post-tests, the learners participated in stimulated recall (SR) sessions and completed a focused question (FQ) session. They were asked to watch the FFEs they participated in and comment on what they could recall that had happened and what they had thought when the FFEs took place. From their stimulated recall, the researcher could find out if they accurately perceived their teachers' responses to their interlanguage gaps as they were intended (Gass \& Mackey, 2000). These sessions were conducted individually and recorded to explore learner noticing in the two different settings. Finally, the learners were asked questions about what they noticed in particular during the interactive tasks they participated in such as the linguistic focus of the tasks (Mackey, 2006). The purpose of this step was to gain more information about learner noticing of the goals of the interactive tasks. 
The experimental procedure was carried out individually with every learner participant to guarantee that each participant could get a similar number of opportunities for receiving FonF. The time between the first and second stages gave the researcher some time to identify FFEs from the interactive tasks, write and administer custom-made post-tests, and conduct SR and FQs in the shortest time possible. This procedure was piloted with six participants from the two groups of FonF language (i.e., L1 and the TL), and the two proficiency levels before being brought into use in the study.

\subsubsection{Selection of participants}

To ensure the homogeneity of the participants across the two studies of the research, learner participants were drawn from the two institutions where the descriptive study was conducted. Three weeks before conducting the data collection procedure, the researcher advertised for volunteers from beginning-level and advanced-level class groups at the two institutions. The number of volunteer participants was balanced at around 13 for each proficiency level at each of the two institutions. As there were more volunteers than enough, the participants were selected on a first-come, first-served basis.

\subsubsection{Participants}

Table 5.1 shows the information of the learner participants across the two language centres and two proficiency levels.

\section{Table 0.1: Learner participant information}

\begin{tabular}{llllll}
\hline $\begin{array}{l}\text { English } \\
\text { Language } \\
\text { Centre }\end{array}$ & $\begin{array}{l}\text { Proficiency } \\
\text { level }\end{array}$ & $\begin{array}{l}\text { Number of } \\
\text { participants }\end{array}$ & $\begin{array}{l}\text { Gender } \\
\text { Female/Male }\end{array}$ & $\begin{array}{l}\text { Age } \\
\text { range }\end{array}$ & Note \\
\hline 1 & Beginning & $12(9)^{*}$ & $7 / 5(6 / 3)^{*}$ & $13-21$ & $\begin{array}{l}2 \text { in piloting } \\
1 \text { dropped out }\end{array}$ \\
\hline 2 & Beginning & $14(13)^{*}$ & $7 / 7(6 / 7)^{*}$ & $15-19$ & 1 in piloting \\
\hline 1 & Advanced & $13(11)^{*}$ & $6 / 7(5 / 6)^{*}$ & $16-25$ & $\begin{array}{l}1 \text { in piloting } \\
1 \text { dropped out }\end{array}$ \\
\hline 2 & Advanced & $13(10)^{*}$ & $9 / 4(7 / 3)^{*}$ & $15-28$ & $\begin{array}{l}2 \text { in piloting } \\
1 \text { dropped out }\end{array}$ \\
\hline
\end{tabular}

\footnotetext{
*the numbers in brackets are the final numbers of participants from whom data was collected.
} 
Fifty two learners participated; 25 from English Language Centre 1, and 27 from English Language Centre 2. Twenty-six were advanced level students, and 26 were beginning level students. Six of these were involved in the piloting stage and three did not complete the study. The final number of learner participants taking part in the study was 43.

Nineteen participants were male, and 24 were female. Their ages range from 13 to 28 . Only three of the participants were working; the others were students at the universities and schools in the region. This range of participants' employment status seemed slightly at odds with that in the descriptive study, but this might be because the workers were busier and less interested in the research itself or the pay from the research than the students.

Table 5.2 shows how the students were assigned in four experimental groups.

Table 0.2: Participant groups

\begin{tabular}{|c|c|c|c|}
\hline \multicolumn{2}{|c|}{ TL use (English) } & \multicolumn{2}{c|}{ Maximized L1 use (Vietnamese) } \\
\hline Advanced level & Beginning level & Advanced level & Beginning level \\
\hline 11 learners & 12 learners & 10 learners & 10 learners \\
\hline
\end{tabular}

From Table 5.2, it can be seen that the learners were randomly divided into four groups: one TL-use group and one maximized-L1-use group for each of the two different proficiency levels (beginning and advanced). Different proficiency levels were included to determine whether there was any difference between the influence of different FonF language use on learner noticing, uptake and language development in beginning learners and advanced learners.

The participants were active and interested in the study. Most of them asked questions about the research. They did the interactive tasks and the post-tests and subsequent second language and FQ with interest. I took the role of the interlocutor in the interactive tasks to maintain consistency across treatments. 


\subsection{Data collection methods}

There were three stages of data collection using four data collection methods: individual interactive tasks, custom-made post-tests, SR and FQs.

\subsubsection{Individual interactive tasks}

The results of the descriptive study revealed some features of the Vietnamese L1 teachers' use of L1 and the TL in FonF during teacher-student interaction in the EFL classroom. As for the types of feedback, it was found that the Vietnamese L1 teachers resorted to L1 the most in provide (that is, when they gave explicit information in the form of explanation, definitions or examples), and the second most in elicit (that is, when they repeat the learners' errors, give prompts, clues or elicit solutions so that the learners recognize the gaps and correct themselves). For the linguistic foci of the teachers' feedback moves, they tended to use L1 the most when the linguistic attention in FonF was on vocabulary and morphosyntactic items. Also, the teachers were found to use L1 more during multi-move FFEs than during single-move FFEs. These findings suggest that the Vietnamese L1 teachers may have had the belief that the use of L1 may be helpful when the feedback was morphosyntax- or vocabulary-focused, involved giving explicit information or eliciting solution, and included more than one feedback move. These features served as the guidelines for building and conducting the interactive tasks in the experimental study.

From the findings mentioned above, the interactive tasks were designed with morphosyntax and vocabulary foci. Three similar types of tasks were used for both beginning and advanced levels, but they differed in the difficulty levels to suit the developmental levels of the groups as listed in Table 5.3.

Table 0.3: Types of interactive tasks

\begin{tabular}{llll}
\hline & Task type & Language focus & Duration \\
\hline Task 1 & Jigsaw task & Vocabulary & $3-5$ minutes \\
\hline Task 2 & Describing/Guessing actions & Morphosyntax & $3-5$ minutes \\
\hline Task 3 & Story-telling & Vocabulary and morphosyntax & $3-5$ minutes \\
\hline
\end{tabular}


The jigsaw task for the beginning level was chosen from a commercial course book for elementary students. In this task, there were two sets of two pictures depicting a living room with six missing items in each picture (see Appendix 5). The learner participants and $I$ as the interlocutor took turns to ask questions to find out where the missing items were. The jigsaw task for the advanced level was a set of pictures describing a kitchen with different kitchen items and the interlocutors borrowed from each other what they did not have (see Appendix 6). These jigsaw tasks were designed to trigger vocabulary for items in the house (for the beginning level) and in the kitchen (for the advanced level). This task lasted from three to five minutes.

The second task for the beginning level was from an activity book for elementary students. This task required the learner participants to describe actions which have just happened in the second picture of a pair of two pictures (see Appendix 5). Similarly, the advanced level learners were asked to guess what had happened in a picture (see Appendix 6). These tasks aimed to promote use of Present Perfect Tense (for the beginning level) and Past Modal (e.g. must have, might have for the advanced level). The duration of this task was three to five minutes.

In the third task, the learners were given a series of pictures telling a story. These picture series were chosen from the resource books for learners at the beginning and advanced levels. This task targeted both the morphosyntax and vocabulary gaps. This task also took three to five minutes. All the materials for these tasks can be found in Appendix 5 and Appendix 6.

The interactive tasks were conducted between the learners and me as the interlocutor one on one. Each session with each learner participant lasted from 10 to 15 minutes and was video-recorded with the learners' consent. With the results of the descriptive study as the guidelines, I used the FonF types of provide and elicit, and the FFEs were multimove.

During the interactive tasks, many types of linguistic problems emerged in the learners' talk, but only the vocabulary and morphosyntax problems were targeted with FonF. Other linguistic problems were addressed only if they occurred repetitively and might influence the learners' overall performance of the tasks, and these episodes were not 
considered in data coding and analysis. Although the linguistic foci had been well planned, the specific items discussed in the FFEs were incidental and brief (Ellis, et al., 2001a, 2001b, 2002; Long \& Robinson, 1998).

To use the FonF type of provide, when making a response to the learners' linguistic gaps, the researcher usually gave explicit information by rejecting the erroneous utterances and providing the correct ones, giving metalinguistic explanations, or supplying definitions or examples. Also some of the teacher's response moves were of the elicit type of FonF, in which the teacher repeated the learners' errors in a rising tone, or gave prompts or clues, or elicited solutions so that students recognized the gaps and corrected themselves. The FFEs, though transitory, usually contained more than one move in the teacher's response, and a pause was deliberately made at the end of each response move to allow for opportunities for uptake.

Both learner-triggered gaps and teacher-triggered gaps were addressed. The learnertriggered gaps consisted of learners' errors and questions raised by errors during the task-based interactions. For the teacher-triggered gaps, I always confirmed that the gaps were real before addressing them by asking "do you know...?" questions. These gaps were re-confirmed in the SR and FQ session.

For the two TL-use groups, the interlocutor's responses were entirely in English, and the learners were left to use English or Vietnamese at their convenience. On a few occasions when the teacher had to use Vietnamese to quickly clarify some linguistic points due to time constraint of the tasks, these episodes were excluded from the subsequent data analysis.

For the two maximized-L1-use groups, the teacher's responses were mainly in Vietnamese except for the language items in focus themselves and the metalinguistic terms. The content of the teacher's responses in Vietnamese was maintained to be equivalent to that of the responses in English by using scripts with similar number of moves in each language group for each linguistic item. In addition, the time allotted for the three interactive tasks was kept between 12 and 15 minutes for each learner participant to provide a similar level of the teacher's response to the interlanguage gaps of each learner. 
During the period of developing and conducting the interactive tasks it was seen that several learners took notes of the feedback. While piloting the data collection procedure on six students, I found that when being given feedback or learning some new linguistic items, they tried to take notes by writing on the table with their hands. Learners' notetaking during FFEs has also been observed by other researchers (Ellis, et al., 2001b; Farrokhi \& Gholami, 2007; Loewen, 2005). Ellis, et al. (2001b) argue that note-taking may lead to the low level of uptake in spelling-focused episodes, and Farrokhi \& Gholami (2007) even suggest considering note-taking as a new form of uptake: "camouflaged uptake".

Given learners' preference for note-taking, I decided to give the participants paper and pens for note-taking for their optional use. At the end of the tasks, the notes were collected and used together with the video recordings to explore the possible effect of note-taking on learner uptake, noticing and test performance.

On subsequent days, the interactive tasks were followed the custom-made post-tests and the SR session and a FQ.

\subsubsection{Custom-made post-tests}

The video recordings of the interactive tasks were reviewed to identify morphosyntaxor vocabulary-focused FFEs in which the teacher's feedback was provide or elicit. After the FFEs in the interactive tasks were identified, the individualized custom-made posttests were made accordingly and conducted orally. All these tests were audio-recorded for subsequent data coding and analysis. The number of test items varied from one individualized custom-made post-test to another, depending on the number of the FFEs. The test item number ranged from seven to 13 items, and each test lasted from three to five minutes. The tests were slightly different across the groups' proficiency levels.

In the tests for the beginning-level participants, there were two types of test items: picture-word items and acceptability judgment items (adapted from Adams, 2007). Picture-word items were built from the learners' vocabulary gaps in the FFEs; for these items, the learner participants were shown the pictures of articles in the living room with some explanation and were asked to give their respective names. Episode 10 BE22 
gives an example of a vocabulary-focused episode and its subsequent picture-word test item.

\section{Episode 10 BE22}

A vocabulary-focused episode

R: Where is my cushion?

BE22: my cushion. Can you repeat it?

R: cushion

BE22: cushion (.)

R: cushion is something like a square pillow.

It is a cloth bag filled with soft material and you use it when you sit on a sofa or on the floor.

BE22: ahhh, yeah, it's here [points at the cushion in the picture]

R: yeah, this one is the cushion.

BE22: your cushion is on your sofa... my sofa.

\section{Subsequent picture-word test item}

R: $\quad$ how do you call a thing like a small square pillow you sit on or lean on, on a sofa or on the floor? [points at the cushion]

BE22: $u h m . . .($.) this is...

In this example, the learner's vocabulary gap was identified as the word "cushion", and thus a picture-word test item was built in which the picture of the cushion was shown with some explanation, and the participant was asked to give its name.

For the acceptability judgment items, the linguistic foci were morphosyntactic, and the learner participants were asked to judge whether a sentence was grammatically correct or not correct. If the answer was "not correct", the participants were asked to give explanation or correction. Episode 07 BE01 gives an example of a morphosyntaxfocused episode and its subsequent acceptability judgment test item.

\section{Episode 07 BE01}

\section{A morphosyntax-focused episode}

BE01: the man catch his hat [the participant was telling a story) 
R: not "catch", caught.

You should say "caught"

BE01: caught, yes

R: the man caught?

BE01: his hat.

\section{Subsequent acceptability judgment test item}

R: $\quad$ Please listen and tell me if this sentence is grammatically correct:

'The boy catch the ball in the game yesterday'.

BE01: no, 'the boy caught'.

In this example, the learner participant used the wrong form of the verb "catch". This incorrect form was used to build an acceptability judgment test item in which the participant was asked to judge the morphosyntactic correctness of the sentence.

For advanced-level groups, three types of test items were used: definition-word items, guessing-from-picture items and acceptability judgment items. Since the learners' errors and enquiries about linguistic features were incidental, the foci of the FFEs were quite extensive (Ellis, et al., 2001a, 2001b; Williams, 2005). The numbers of test items types therefore varied from two to three types, depending on the types of errors and enquiries.

For the vocabulary gaps, definition-word test items were designed. The participants were given the definitions of words and were asked to give the respective words. Episode 01 AE12 gives an example of a definition-word test item

\section{Episode 01 AE12}

\section{A vocabulary-focused episode}

AE12: may I borrow your broom?

$\mathbf{R}$ that one is actually not a broom; it is a mop.

AE12: (.)

R: It is a long stick with a piece of cloth attached to one end and you use it to clean the floor a mop.

AE12: uhuh, a mop [tries to write the word down and R helps).

May I borrow your mop? 


\section{Subsequent definition-word test item}

R: $\quad$ How do you call a piece of cloth attached to a long stick that you use to wipe the floor or clean the floor?

AE12: a mop

Guessing-from-picture test items were constructed when, during the interactive tasks, the learners made errors or enquiries about use of past modal to guess what has happened. In the custom-made post-test, learners were given a picture of a car accident and were asked to guess what has happened. Episode 10 AV21 gives an example of a guessing-from-picture test item

\section{Episode 10 AV21}

\section{A morphosyntax-focused episode}

R: (shows the learner a picture of a showroom with a one-armed man and a tiger head on the wall. The man told the visitors, "He was very tame. He used to eat out of my hand".) Please make a few guesses about what has happened to the man and what has happened to the tiger.

AV21: he fed the tiger and the tiger ate out of his hand, and when tiger eat, he ... I think he eat his hand ...

R: $\quad$ minh khong biet chac chuyen gi xay ra voi ong nay dau, nen minh phan doan, co cai cau truc la 'might have done sth', (when you are not sure what has happened to him, you should use 'might have done something') 'the tiger might have eaten the man's hand'

AV21: yeah

R: $\quad$ con neu nhu em rat chac chan thi em noi la (and if you are very sure, you may say) 'the tiger must have eaten his arm'.

AV21: yes

\section{Subsequent guessing-from-picture test item}

R: $\quad$ Please look at this picture and make a few guesses about what the two people have done.

AV21: (.) They might called the police. 
Acceptability judgment test items were also used when other incidental morphosyntax gaps were revealed during the interactive tasks. Episode 10 AV21 gives an example of an acceptability judgment test item.

\section{Episode 10 AV21}

A morphosyntax-focused episode (other than past modal)

AV21: So she phoned for the police.

R: minh goi 'phone the police', (we say 'phone the police') khong can chu 'for' (no need to say 'for').

AV21: yeah, phoned the police. So I think... ah she think that...

\section{Subsequent acceptability judgment test item}

$\boldsymbol{R}$ : $\quad$ Listen to this sentence and tell me if it is grammatically correct:

'She phoned for the police'.

AV21: she phoned for the police. No, the word 'for' is not necessary here.

After the custom-made post-tests, the learner participants were invited to participate in a session of SR and FQs as described next.

\subsubsection{Stimulated recall $(\mathrm{SR})$}

Introspective techniques have been promoted as an effective research tool to collect information on learners' insights into their learning process (Ellis, 2008; Long \& Robinson, 1998; Swain, 2005). Among these techniques, SR has been widely used in the body of research on conversational interaction in the language classroom (e.g. Adams, 2003; Egi, 2004; Mackey, 1999; Polio, Gass, \& Chapin, 2006). As pointed out by Gass \& Mackey (2000, p. 17), SR can "prompt participants to recall thoughts they had while performing a task or participating in an event". Learners' memories are stimulated by listening to or watching video or audio recordings of the task or event. Many researchers have chosen this tool because, in addition to getting data on noticing as a cognitive process, it can also uncover information on knowledge types, knowledge structures and learner strategies (Gass \& Mackey, 2000, pp. 21-23).

In this study, the learners participated in individual SR interviews with the researcher. During the interviews, they were first asked to listen to a few sampled episodes of SR 
done by the pilot participants. Then they were invited to watch the video recording of their own task-based interactions. While watching, they were instructed to temporarily stop the video recordings whenever they recalled what had happened and talk about it. Their SR interviews were audio recorded and transcribed to find data about their noticing of the teacher's responses to their interlanguage gaps. The learners were invited to report their noticing in L1 or in the TL at their convenience, but all of them chose L1 (Vietnamese) to talk at length about their experience.

During these SR interviews, the learner participants usually stopped the recordings to talk about a linguistic form before they watched it, since some details from some parts of the video recordings could remind them of what would happen in the coming parts. This provides evidence that actual recall was taking place, and the researcher immediately made an oral remark of this to be recorded in the audio recording for the data analysis process thereafter. When a recalled episode took place after the participants watched that part of the recordings, they were asked to confirm whether it was what they recalled, or what just came up to their minds when they were watching. This step helped reduce the danger of the method as pointed out by Ellis (2008, p. 209) that the participants' comments might reflect what they just notice during the SR.

They not only talked about their noticing of the feedback they had received or the new linguistic items they had learned from the task-based interactions, the learner participants also talked about other aspects of their learning experience during the tasks: explanation for their reaction toward feedback or their remarks on the learning context. Apart from learner noticing, this session also provided the researcher with insights into learners' cognitive processes (Gass \& Mackey, 2000).

The findings from the SR interviews also helped to determine whether the FFEs addressed errors and enquiries that reflected real gaps in language knowledge. In these interviews, if the learners rejected some gaps, the corresponding FFEs and test items were discarded and were not taken into account in the subsequent data analysis. Episode 11 AE14 gives an example of a rejected FFE.

\section{Episode 11 AE14}

R: what usually happens after someone dies and then what happens to his fortune...? 
you know a will?

AE14: a will?

R: $\quad$ what is a will? (.)

a will is a piece of paper in which a dead person says that he wants to give his money to this person or that person, you know.

AE14: (.)

\section{Subsequent definition-word test item}

R: How do you call a document left by a dead person saying what he wants to do with his fortune?

AE14: will, a will.

\section{Subsequent SR session}

AE14: That word "will" was not new to me; I know its meaning. At that time, I was busy thinking about another word in your explanation, the word "fortune". Does it mean money and things you have? I was not familiar with the pronunciation of that word though I know its spelling. Pronunciation is my bad, ha ha...

In this example, from the episode, it appeared that the learner did not know the meaning of the word "will". The SR session, however, revealed that he knew that word, but he did not attend to that word in the episode because he was attracted by another word in the teacher's explanation.

\subsubsection{Focused questions}

A second tool for collecting information about learner noticing was focused questions (FQs) (Mackey, 2006). After finishing the SR interview, the learners were asked questions about their noticing of anything in particular about each interactive task and the language foci of the tasks. They were asked to give their answers in Vietnamese or English at their convenience so that their English proficiency level would not be a constraint to their self-expression (Mackey, 2006). The purpose of this measure of noticing was to give the learners more opportunities to talk about what they had noticed during the tasks, but did not discuss in the SR. The general question about the language foci of the tasks may help the learners recall on their noticing of some linguistic items 
they had failed to mention before. The length of the SR and FQ session varied from participant to participant, depending on how much the participants could recall.

\subsection{Data analysis methods}

In this section, the process of coding learner uptake, test results and learner noticing will be presented.

\subsubsection{Coding learner uptake}

The data on learner uptake were coded from the FFEs identified in the interactive tasks. The video recordings of the interactive tasks were reviewed, and FFEs were identified and transcribed. These video recordings had been watched and listened to once before to design the custom-made post-tests, so the FFEs transcribed in this part of the coding process were also those used for building the individualized custom-made tasks. The definition of FFEs from Ellis, et al. (2001a, 2001b, 2002) provided the guidelines for this process: an FFE has to contain at least two compulsory moves: a trigger move and a (teacher's) response move, and one optional move: a (learner's) uptake move. Also, an FFE has to address a gap in learner interlanguage exposed during the interactive tasks.

Besides transcribing the teacher-student interactions, the researcher also made notes on the learners' note-taking practice during the FFEs by simultaneously watching them in the video and using the notes collected from them at the end of the interactive tasks.

Not only the uptake moves were coded, other aspects of the FFEs were also coded in order to discover any relationships between these aspects and learner uptake. 
Table 0.4: Coding learner uptake and other characteristics of FFEs (adapted from

Loewen, 2004b)

\begin{tabular}{|c|c|c|}
\hline Characteristic & Definition & Categories \\
\hline Linguistic focus & $\begin{array}{l}\text { Linguistic aspect } \\
\text { addressed in an FFE }\end{array}$ & $\begin{array}{l}\text { Vocabulary-focused } \\
\text { Morphosyntax-focused }\end{array}$ \\
\hline Trigger & How an FFE is triggered & $\begin{array}{l}\text { Reactive: an FFE triggered by learner's } \\
\quad \text { errors } \\
\text { Learner-initiated: an FFE triggered by a } \\
\quad \text { learner's query about form } \\
\text { Teacher-initiated: an FFE with a } \\
\text { linguistic form pre-empted by the } \\
\text { teacher }\end{array}$ \\
\hline Uptake & Learner's response & $\begin{array}{l}\text { Repair: learner incorporates or repeats } \\
\text { the new linguistic item in his response } \\
\text { Needs-repair: learner fails to repeat or } \\
\text { incorporate the new linguistic form in } \\
\text { his response. } \\
\text { Acknowledge: learner acknowledges the } \\
\text { new linguistic item by saying 'yes', } \\
\text { 'ok'... } \\
\text { No uptake: learner makes no response to } \\
\text { the new linguistic item despite the } \\
\text { uptake opportunity given }\end{array}$ \\
\hline Note-taking & $\begin{array}{l}\text { Learner's note-taking } \\
\text { during an FFE }\end{array}$ & $\begin{array}{l}\text { Note-taking: learner takes notes of the } \\
\text { new linguistic form addressed in an FFE } \\
\text { No note-taking: learner does not take } \\
\text { notes of the new linguistic form. }\end{array}$ \\
\hline
\end{tabular}

\section{Example 1}

\section{Episode 2 BE04}

R: $\quad$ Have you seen my pipe anywhere?

BE04: uhm, (.) can you explain what is pipe? $\quad<=$ trigger move

R: $\quad$ pipe is a kind of things used to smoke. $\quad<=$ feedback move

People put tobacco in it and they smoke.

BE04: ok, I understand... understood. $<=$ uptake move

Your pipe is on the table, next to the radio and the lamp.

\section{Analysis of Example 1}

$\begin{array}{lll}\text { Linguistic focus: } \quad \text { Vocabulary-focused } & \begin{array}{l}\text { Teacher explains a new word } \\ \text { (feedback move). }\end{array} \\ \text { Trigger: } & \text { Learner-initiated } \quad \begin{array}{l}\text { Learner asks a question about the new } \\ \end{array} \\ & \text { word (trigger move). } \\ & -80-\end{array}$




$\begin{array}{lll}\text { Uptake: } & \text { Repair } & \begin{array}{l}\text { Learner incorporates the new word in his } \\ \text { response (uptake move). }\end{array} \\ & \text { No note-taking } & \text { Learner does not take notes of the new } \\ \text { Note-taking } & \text { word. }\end{array}$

Example 2

Episode 4 AV23

R: Can I borrow your mug, please?
AV23: (.)
R: You know a mug?
$<=$ trigger move

AV23: No

R: $\quad$ mug giong nhu cai tach, nhung no cao hon, day hon, minh goi la cai coc vai (it is like a cup, but taller and thicker. It's called a mug).

This one (points at a mug). $\quad<=$ feedback moves

AV23: cai nay la cup (This is a cup)

R: mug. La cai mug do, khong phai cup dau. $\quad<=$ feedback move

(That one is not a cup. It is a mug.)

AV23: [tries to write the word down and $\mathrm{R}$ helps] $\quad<=$ note-taking practice

\section{Analysis of Example 2}

Linguistic focus: Vocabulary

Teacher explains a new word (feedback moves).

Trigger: Teacher-initiated Teacher pre-empts a learner's linguistic problem (trigger move).

Uptake: No uptake Learner fails to incorporate the new word in her response.

Note-taking Note-taking Learner takes notes of the new word (note-taking practice).

\subsubsection{Coding the test results}

The audio-recordings of the individualized custom-made post-tests were transcribed, and the learner participants' answers to the test items were coded. Generally, there were three types of test results coded as described in the table below. 
Table 0.5: Coding learners' test results

\begin{tabular}{lll}
\hline Aspect & Categories & Explanation \\
\hline Target-like & $\begin{array}{l}\text { The answer is given in the correct form of the } \\
\text { language. }\end{array}$ \\
Test results & Non-targetlike & $\begin{array}{l}\text { The answer is given in the incorrect form of the } \\
\text { language, from the point of view of the participant's } \\
\text { ultimate goal of speaking the language accurately. }\end{array}$ \\
No answer & $\begin{array}{l}\text { The answer is not given or is given in an off-target } \\
\text { way. }\end{array}$ \\
\hline
\end{tabular}

Despite the explanation of the three categories mentioned in the table, the detailed procedure of coding the test results varied slightly, depending on the types of test items as explained in the following section.

\section{Coding the results of vocabulary-focused test items}

Vocabulary-focused test items were composed of picture-word test items for the beginning level participants and definition-word test items for the advanced level groups. For these types of test items, a targetlike test result was coded when the learner participants gave a correct word for the picture or definition given. A non-targetlike test result was a mispronounced form of the correct word described in the test item. The learner's test result was coded as "no answer" when he kept silent, or gave a wrong word for the definition or the picture. The following is an example of a target-like test result

\section{Test item from Episode 11 AE14}

R: How do you call a document left by a dead person saying what he wants to do with his fortune?

AE14: will, a will.

In this example, the learner participant gave the correct answer to the test item.

\section{An example of a non-targetlike test result}

\section{Test item from Episode 02 AV12}

R: How do you call a drinking vessel which is very much like a cup, but taller and thicker? 
AV20: $a / m^{\wedge} \mathrm{t} /$

In this example, the learner participant tried to answer the test question accurately, but mispronounced the word "mug".

The following is an example of a "no answer" test result.

\section{Test item from Episode 5 BE21}

R: how do you call a cloth bag filled with soft material used when you sit on a sofa or on the floor? [points at the cushion]

BE21: (.)

In this example the participant kept silent, and as she said in the SR session that followed, she knew that she had learnt this word, but she could not remember it for the test.

\section{Coding the results of morphosyntax-focused test items}

As mentioned in the previous section, morphosyntax-focused test items consisted of guessing-from-picture and acceptability judgment test items.

\section{Coding guessing-from-picture test items}

For guessing-from-picture test items, a targetlike test result was an answer in which the participant accurately used the Past Modal to guess the action in the picture. A nontargetlike result showed the participant's effort in using the Past Modal, but the answer contained errors. A "no answer" result was coded when the participant simply gave no answer, or the answer did not show any attempt to make use of the expected structure, and thus, was usually grammatically unacceptable. The answers which did not use the expected structure and were grammatically acceptable were eliminated from the data, and their related FFEs and SR sessions were not considered in the subsequent analysis. An example of a targetlike result is given below.

\section{Test item from Episode 08 AE14}

R: [shows a picture] Please make a guess on what these two people have done.

AE14: I saw there was an accident. The woman might have called an ambulance. 
In this test item, the learner participant accurately used Past Modal to guess the action that might have happened in the picture. An example of a non-targetlike result is given below.

\section{Test item from Episode 08 AE10}

R: [shows a picture] Please make a guess about what has happened to the man in the picture.

AE10: I think ... my first guess is that the man may get drowned... he may fell into the river (.)

I think that this kettle fell... must have fall into the river and he jumped into the river to get the kettle.

The participant's answer to this test question showed that he made a few attempts to use the Past Modal, but a grammatically accurate answer was not produced. The following is an example of a "no answer" result.

\section{Test item from Episode 12 AE15}

R: $\quad$ Please look at this picture and make a guess on what has happened to these two people.

AE15: they played with the child and both did not know he has got a tooth.

While they were playing with the child, he ...bit their fingers [laughs] and both had their fingers bit... bitten. They sent the child to someone else...

In this example, the participant produced a few narrative sentences to describe her guesses about what had happened in the picture. Despite the well expressed ideas in the answer, the participant failed to use the Past Modal to express the correct modality of the context.

\section{Coding acceptability judgment test items}

The acceptability judgment test items were designed to ask the participant to judge whether a sentence was grammatically correct. The scheme used for coding these test items can be described in as follows: 
Figure 0.2: Coding scheme for acceptability judgment test items

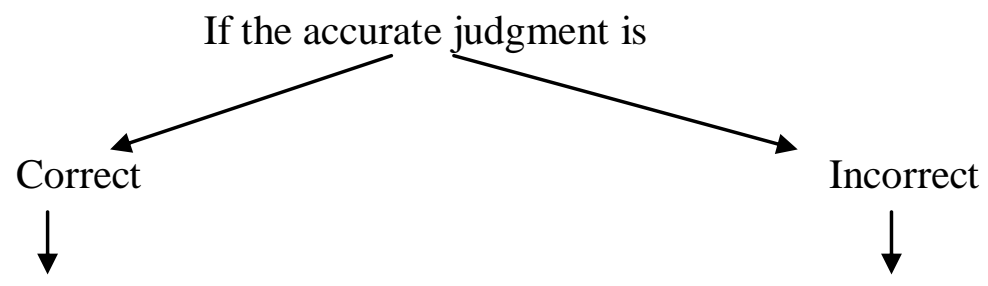

The participant's answer is

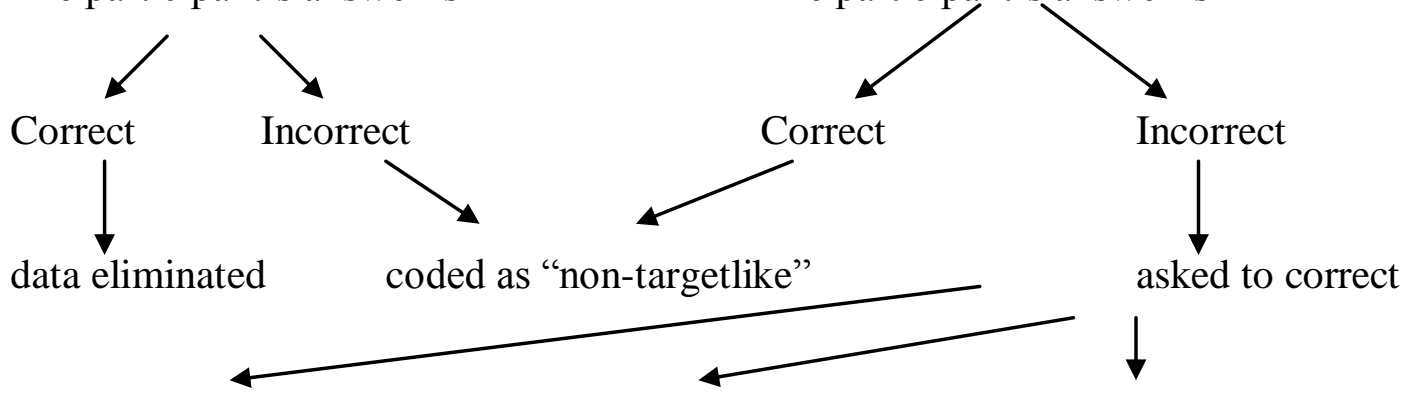

accurate correction partly accurate correction

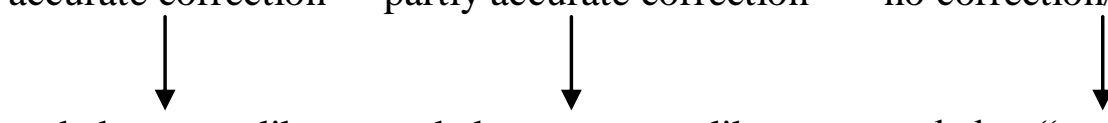

coded as targetlike coded as non-targetlike coded as "no answer"

To guarantee the construct validity of the acceptability judgment test items, the number of accurate judgments had to be equally divided between the two choices of "correct" and "incorrect". Figure 5.2 shows that when the accurate judgment was "correct" and the participant's answer was also "correct", the related data would be eliminated from the data coding and analysis procedure. The reason for this elimination is that in this case there was not enough information to judge whether the learner acquired the specific linguistic feature in the previous FFE. As a result, the construct validity of the tests was ensured at the expense of the data quantity. However, this type of test item accounted for only about $8 \%$ of the entire test items, and only a couple of test items and their related data were eliminated, causing inconsiderable loss of data.

The participants' answers were immediately coded as "no answer" when their judgments were inaccurate. If a judgment was accurate, but the correction that followed was off-target or no correction was given, the test result was also coded as "no answer".

After making an accurate judgment of an "incorrect" sentence, the participant was asked to correct it. If the correction was successful, the answer was then coded as targetlike result. If the correction showed the learner's attempt to use the targeted item, but still 
minor mistakes were made, the answer was coded as non-targetlike result. An example of a data-eliminating occasion is given below.

\section{Test item from Episode 7 BE21}

R: $\quad$ Please listen to this sentence and tell me if it is grammatically correct?

"Where are my socks?"

BE21: right

In this example, the learner's answer could not reveal whether he acquired the plural form of the verb on which feedback had been given in the previous FFE. This test item was discarded due to lack of information. The following is an example of a targetlike answer.

\section{Test item from Episode 6 BE22}

R: $\quad$ Please listen to this sentence and tell me if it is grammatically correct?

"Where is my socks?"

BE22: not correct, 'where are'

In this example, the learner made the accurate judgment for the test item and also gave a correct answer to replace the wrong one. This result was hence coded as targetlike. The following is an example of a non-targetlike answer.

\section{Test item from Episode 10 BV11}

R: $\quad$ Please listen to this sentence and tell me if it is grammatically correct?

"Yesterday, I find a bag under a tree."

BV11: wrong. /fou/, not "find".

This example shows that the learner made the correct judgment, but she made another mistake in trying to provide the correct answer. The result was coded as non-targetlike. An example of a "no answer" (off-target correction) is given below.

\section{Test item from Episode 10 BV10}

$\mathbf{R}$ : Please listen to this sentence and tell me if it is grammatically correct?

"He took the dog go home."

BV10: wrong. He has taken the dog go home. 
The learner in this example did not seem to acquire the phrase "take the dog home" in the teacher feedback. His answer revealed that the mistake stayed intact while he tried to correct an off-target feature of the sentence in the test item.

\subsubsection{Coding learner noticing}

The SR and FQ sessions, which lasted from eight to 15 minutes with each participant, were transcribed and translated into English for coding and analyzing data on learner noticing. The SR transcriptions were then compared with the respective transcriptions of the participants' interactive tasks to find out if noticing of the linguistic items targeted in the FFEs took place. Such noticing was regarded as having occurred when the participants reported they had a problem with production or comprehension, or they had learnt new linguistic items in the FFEs (Mackey, 2006). In the following scheme, learner noticing was coded as "yes" for its existence, and "no" for non-existence.

Figure 0.3: Coding learner noticing

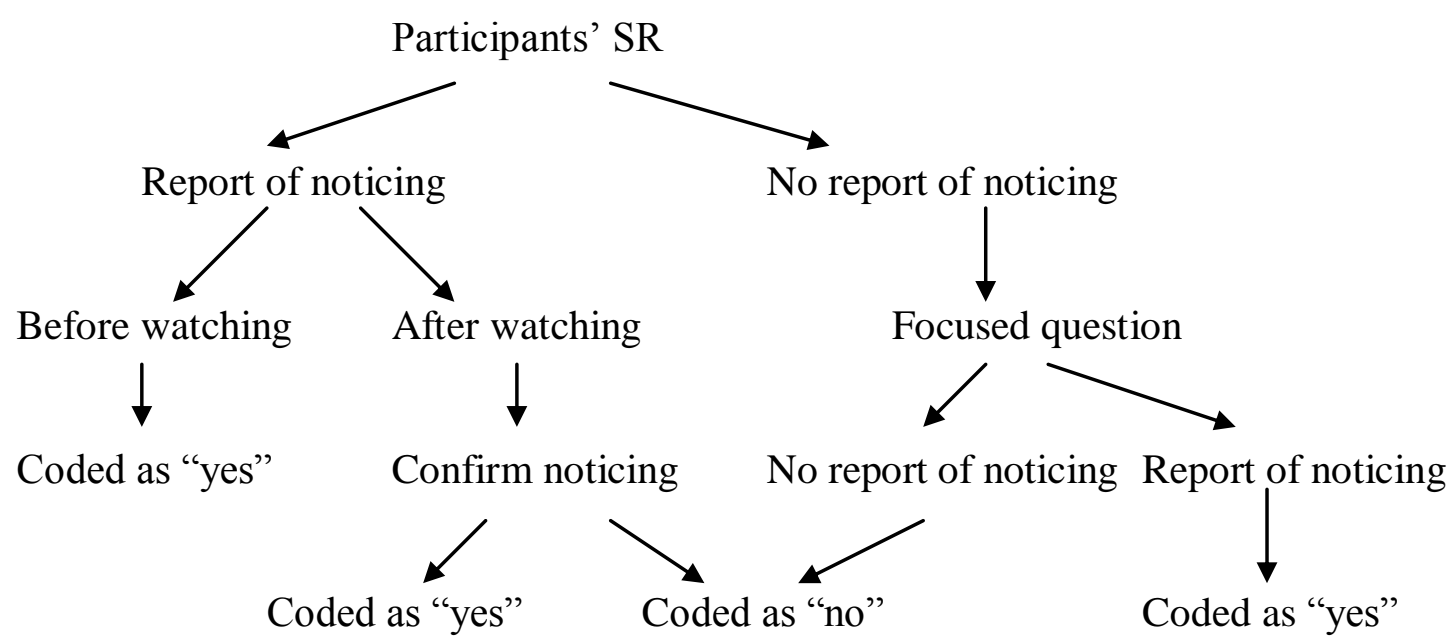

According to Figure 5.3, if the participants paid their attention to the targeted linguistic items right before the respective FFEs were watched (which was usually the case), noticing was considered to have occurred, and "yes" was coded for this case. When the participants reported noticing the linguistic items after watching the respective FFEs, they would be asked to confirm whether the report was of their recall or of what just emerged when they were watching the FFEs. If the noticing incidence was confirmed, it 
was coded as "yes"; if rejected, "no". For a linguistic item addressed in the interactive tasks but ignored in the SR report, the respective FQ transcription would be consulted. If there was report of noticing of this linguistic item in the FQ sub-session, the noticing of the item was coded as "yes"; if not, "no".

The following is an example of coding "yes" for noticing (before watching the respective part of the video recording).

\section{Episode 03 B V05}

\section{The FFE}

R: $\quad$ where are my socks?

BV05: your socks are on the chair. $\quad<=$ trigger move

$\mathbf{R}$ ok, actually this one is not a chair. [points at the chair in the picture] This is a chair. and this one is...? (.) an armchair.

BV05: armchair

R: $\quad$ cai nay no goi la armchair vi no co cho de cai arm ne (it is called armchair because you have space to rest your arms here)

BV05: arm

R: $\quad$ arm la cai canh tay do, em biet chu "arm" chu? (Do you know 'arm'?)

BV05: $D a$, yes

R: $\quad$ canh tay do, em phai goi no la armchair (so call it an armchair)

BV05: armchair, yes.

\section{The test item}

R: how do you call this? [shows the picture of an armchair]

BV05: this is a... armchair

\section{The SR report of noticing}

BV05: [the participant stops the video recording after the trigger move of the FFE and says] I learnt the word 'armchair' here. I didn't know the meaning of that word. I called all kinds of seats as "chair" then.

This is an example of coding "yes" for noticing (with participant's confirmation).

\section{Episode 01 AE03}




\section{The FFE}

AE03: do you have any spoon?

R: $\quad$ it is not a spoon; it is big and has a long handle.

You use it to convey food from a pot or pan into a bowl or plate.

We call it a ladle.

AE03: a ladle.

\section{The test item}

R: How do you call a long-handled big spoon in the kitchen that you use to convey food from a pot or pan into a plate or bowl?

AE03: uhm, sorry, I forgot it.

\section{The SR report of noticing}

AE03: I learnt the word 'ladle'.

$\mathbf{R}$ did you learn this word just now when you were watching the video?

AE03: No, I remember learning that word then, though I couldn't remember it.

An example of coding "yes" for noticing after consulting FQ sub-session is given below.

\section{Episode 06 AE15}

\section{The FFE}

AE15: I want this but I can't.

$\mathbf{R}$ : this is a food blender.

You use it to mix food, to make food smooth, well-mixed, you know.

AE15: food blender. Can I have a food-blender?

R: $\quad$ sure. Here you go

AE15: mix food.

\section{The test item}

R: how do you call a machine in the kitchen that you use to mix food and make food become smooth?

AE15: a food mixer

\section{The SR and FQ report of noticing}

SR: [the participant does not report anything about this vocabulary item) 


\section{FQ sub-session:}

R: what do you think is the language focus of the kitchen task?

AE15: in this activity, I learnt a lot of new words. This part also reminded me of some words I had known but I forgot like 'food blender', then you reminded me and then I forgot again.

The following is an example of coding "no" for noticing (with participant's confirmation).

\section{Episode 01 BE17}

\section{The FFE}

$\mathbf{R}$ : where is my pipe?

BE17: (.)

R: you know a pipe?

BE17: (.)

R: pipe is something used for smoking.

It has a small bowl at one end and they put tobacco in and they smoke.

BE17: yes, yes. It's on table.

\section{The test item}

R: How do you call this thing that is used for smoking? [points at the pipe).

BE17: I don't know.

\section{The SR report of noticing}

BE17: [stops the recording after watching this episode]. The word "pipe" was new.

R: You learnt it then, or just now when you are watching?

BE17: I didn't focus much on this word then, I think.

That's why I didn't remember anything about it.

An example of coding "no" for noticing is given below.

\section{Episode 03 BE14}

\section{The FFE}

R: ok, good.

BE14: where is /glouv/, my /glouv/?

R: $\quad$ gloves 
BE14: gloves

R: gloves are plural, so you cannot say 'where is'. Where? where...?

BE14: where are my gloves?

\section{The test item}

R: Listen to this sentence and tell me whether it is grammatically correct:

"Where is my gloves?"

BE14: correct

\section{The SR and FQ report of noticing}

SR: I mispronounced that word.

FQ: [the participant does not mention this item either]

\subsubsection{Statistic tools used for data analysis}

The Statistical Package for Social Sciences (SPSS) was used to perform the necessary tests to analyze the patterns of learner uptake, noticing and language development across the teacher use of L1 and the TL with consideration of the possible influence of the learners' proficiency levels. To examine the differences in learner uptake, notetaking practice, noticing and custom-made post-test results across the teacher use of L1 and the TL in FonF as presented in an $r \times k$ contingency table, chi-square tests were used (Siegel \& Castellan, 1988). If the difference was found to be statistically significant, it was partitioned by using adjusted standardized residuals (ASRs). This procedure helps discover how much each variable contributed to the differences found in the chi-square tests (Siegel \& Castellan, 1988). Odd ratios were also calculated accordingly to find out the power of the effect (Larsen-Hall, 2010). As this calculation can only be performed on binary variables, variables with more than two levels such as uptake (four levels) will be collapsed into binary variables in which the effect size will be reported of one level against the others (for example, the odds ratio of repair against other types of uptake across the teacher use of L1 and the TL in giving feedback).

The strict control of variables such as the teacher, the input and the teaching and testing setting in the lab study conditions meant that the variation of data was very likely to be lower than that of the descriptive study. The level of significance, therefore, is increased to the conventional level of $\alpha=0.05$ so as to ensure approriate statistical sensitivity. The 
ASR threshold is adjusted to 2.0 to comply with the new alpha level of 0.05 (Moore \& McCabe, 2003).

\subsection{Validity and reliability}

Before the data collection procedure was conducted, all the participants had an individual ten-minute briefing with the researcher to ask questions about the study. They were made aware that all of the sessions they were to join were only for the research, and they would not be assessed at all. They were encouraged to do the interactive tasks, the custom-made post-tests, and the SR and FQ session in a relaxed way and were free to withdraw from the research whenever they wanted to. These conditions and the stress-free atmosphere with the researcher teacher who had experience in working with EFL students in Vietnam helped bring about the desirable setting for the data collection procedure.

The three stages of the data collection procedure were designed to examine different aspects of the teacher use of L1 and the TL in giving feedback, and at the same time the data collected in the next stage could be used to verify the data in the previous stage. For example, a learner interlanguage gap found in an FFE was confirmed in the custommade post-tests and was re-confirmed in the SR and FQ session to become eligible for the subsequent data analysis. In this way, the research design has contributed to the validity of the data.

During the data coding process, another researcher who was an expert in this research field acted as the second rater. The second rater coded 18.6 per cent of the data. The inter-rater agreement was 91.2 percent of the number of decisions made throughout the double-coded data, and this rate went up to 97.7 per cent as a result of a session reconciling the differences.

\subsection{Summary}

From the results of the descriptive study, the experimental study was designed to examine the effects of L1 and TL use in FFEs, if any, on learner uptake, noticing, and language development. The experimental study was conducted in three stages: individual task-based interactions, individualized custom-made post-tests, and SR and 
FQ sessions. The interactive tasks used in the first stage of the experimental study were built to reflect the findings of the descriptive study about the Vietnamese NNS teachers' routine use of L1 and the TL in the classrooms: they resorted to L1 when they gave explicit information in FonF, when vocabulary or morphosyntax was the linguistic focus, and when an FFE contained more than one move. The task-based interactions were video-recorded, transcribed and coded for the data on FFEs and learner uptake. The custom-made post-tests were built from the linguistic items identified in the FFEs, and were conducted to collect data on learners' language development. Finally, the SR and FQ sessions were coded for learner noticing and were also used to verify the validity of the collected FFEs. A second rater was involved to guarantee the reliability of the data coding process.

The following chapters will present and discuss the findings of the two studies. 


\section{Chapter 6: FonF in an EFL context and its characteristics}

\subsection{Introduction}

In this chapter, I present and discuss the findings of the first part of the descriptive study which addressed the research question how much and what kinds of FonF take place during teacher-student interaction in EFL classrooms in Vietnam. In the following sections, the amount and characteristics of FonF will be discussed in turn. The amount of FonF in the EFL classrooms will be presented in Sections 6.2, followed by the characteristics of FonF discussed in Section 6.3. The whole chapter will be summarised in Section 6.4.

\subsection{The amount of FonF in EFL classrooms}

In this section, I discuss the question of how much FonF took place in the EFL classrooms. The analysis first focuses the frequency of FFEs and then the frequency of teacher feedback moves. The complexity of FFEs is also examined.

\subsubsection{Frequency of FFEs and teacher feedback moves}

The time during which FonF took place was measured in two ways in this study ${ }^{2}$. First, the time was measured in net minutes (that is, teacher-learner interaction time only). A total of 480 net minutes of interaction were taken from the twelve 90-minute observations (40 net minutes each). Second, the 480 net minutes was measured again in conventional minutes to compare the findings of this study with the results of the other studies. The total amount of interaction time measured in the conventional way was 16.75 hours (1,005 minutes).

Table 6.1 shows the frequency of FFEs and teacher feedback moves recorded in 480 net minutes of teacher-learner interaction (1,005 conventional minutes).

\footnotetext{
${ }^{2}$ Since this study explores the teacher use of language (L1 or the TL) when giving feedback in teacherlearner interaction, only the teacher-learner interaction time was measured as net minutes. Meanwhile, in most FonF studies, the conventional way to measure FonF include all lesson time excluding the class management time at the beginning and the end of a class. For the purpose of this study both ways were used. For more information, please refer to Section 4.2.5.
} 
Table 0.1: Frequency of FFEs and teacher feedback moves

\begin{tabular}{llll}
\hline Focus on form & Count & $\begin{array}{l}\text { Frequency (per net } \\
\text { minute) }\end{array}$ & $\begin{array}{l}\text { Frequency (per conventional } \\
\text { minute) }\end{array}$ \\
\hline FFEs & 584 & 1.22 & 0.58 \\
\hline $\begin{array}{l}\text { Teacher feedback } \\
\text { moves }\end{array}$ & 1,198 & 2.50 & 1.19 \\
\hline
\end{tabular}

A total number of 584 FFEs were identified. These FFEs contained 1,198 teacher feedback moves. The average frequency of FFEs is 1.22 FFEs per net minute $(0.58$ FFEs per conventional minute). The average frequency of teacher feedback moves is 2.5 moves per net minute (1.19 moves per conventional minute).

Table 6.2 shows the number and frequency of FFEs recorded in 480 net minutes of teacher-learner interaction across the six class groups of the two proficiency levels.

Table 0.2: Frequency of FFEs across class groups and proficiency levels

\begin{tabular}{lcc}
\hline $\begin{array}{l}\text { Teacher (Class group) } \\
\text { LEVEL }\end{array}$ & FFEs & Frequency (per net minute) \\
\hline Thuy (B1) & 88 & 1.10 \\
\hline Hong (B2) & 101 & 1.26 \\
\hline Huong (B3) & 66 & 0.83 \\
\hline BEGINNING LEVEL & $\mathbf{2 5 5}$ & $\mathbf{1 . 0 6}$ \\
\hline Thien (A1) & 152 & 1.90 \\
\hline Nguyen (A2) & 104 & 1.30 \\
\hline Phuong (A3) & 73 & 0.91 \\
\hline ADVANCED LEVEL & $\mathbf{3 2 9}$ & $\mathbf{1 . 3 7}$ \\
\hline Total & $\mathbf{5 8 4}$ & $\mathbf{1 . 2 2}$ \\
\hline
\end{tabular}


From Table 6.2, it can be seen that the class group with the largest number of FFEs was advanced class group A1 with 152 FFEs (1.9 FFEs per minute). The smallest number (66) was found in beginning class group B3 (0.83 FFE per minute). The chi-square goodness-of-fit test $\left(\chi^{2}(d f=5, n=584)=48.363, p<0.001\right)$ indicated that there was a significant difference in the number of FFEs produced in the class groups.

In examining the difference in the number of FFEs across the two proficiencies, a oneway ANOVA was performed. The descriptive statistics for the groups were: beginning level, $\bar{X}=85.0, \mathrm{sd}=17.7, \mathrm{n}=3$; and advanced level, $\overline{\mathrm{X}}=109.7$, sd=39.8, $\mathrm{n}=3$. The result $(\mathrm{F}(1,4)=0.962, p=0.382)$ was not statistically significant, suggesting that the difference in the number of FonF between the two proficiency levels was not significant.

Beside the number of FFEs, the number of teacher feedback moves produced across the class groups and the two proficiency levels was analysed and is presented in the following table.

Table 0.3: Frequency of feedback moves across class groups and proficiency levels

\begin{tabular}{lcc}
\hline $\begin{array}{l}\text { Teacher (Class group) } \\
\text { LEVEL }\end{array}$ & Feedback moves & Frequency (per net minute) \\
\hline Thuy (B1) & 277 & 2.84 \\
\hline Hong (B2) & 178 & 2.23 \\
\hline Huong (B3) & 165 & 2.06 \\
\hline BEGINNING LEVEL & $\mathbf{6 2 0}$ & $\mathbf{2 . 3 4}$ \\
\hline Thien (A1) & 325 & 4.06 \\
\hline Nguyen (A2) & 163 & 2.04 \\
\hline Phuong (A3) & 90 & 1.13 \\
\hline ADVANCED LEVEL & $\mathbf{5 7 8}$ & $\mathbf{1 . 7 6}$ \\
\hline Total & $\mathbf{1 1 9 8}$ & $\mathbf{2 . 5 0}$ \\
\hline
\end{tabular}


From Table 6.3, it can be seen that the number of teacher feedback moves varied from 90 made by Phuong, teacher of Class A3, to 325 by Thien of A1. The average frequency of teacher feedback among the beginning classes was 2.34 moves per net minute while this rate was 1.76 at the advanced level. The chi-square goodness-of-fit test $\left(\chi^{2}(d f=5\right.$, $n=1198)=184.0, p<0.001)$ demonstrated a statistically significant difference in the frequencies of feedback moves across the six teachers.

To examine the difference in the number of feedback moves across the two proficiencies, a one-way ANOVA was performed. The descriptive statistics for the groups were: beginning level, $\bar{X}=192.7$, sd=120.3, $n=3$; and advanced level, $\bar{X}=206.7$, $\mathrm{sd}=61.3, \mathrm{n}=3$. The result $(\mathrm{F}(1,4)=0.032, p=0.866)$ was not statistically significant, suggesting that the difference in the number of teacher feedback moves between the two proficiencies was not significant.

In order to further understand the complexity of the FFEs in the data, a more detailed analysis was carried out in which single-move FFEs are distinguished from multi-move FFEs. The results, including the ASR analysis, are presented in Table 6.4.

Table 0.4: Complexity of FFEs across class groups and proficiency levels

\begin{tabular}{lcccccc}
\hline $\begin{array}{l}\text { Teacher } \\
\text { (Class group) } \\
\text { LEVEL }\end{array}$ & \multicolumn{2}{c}{$\begin{array}{c}\text { Single-move } \\
\text { FFEs }\end{array}$} & $\begin{array}{c}\text { ASR } \\
\text { (single-move) }\end{array}$ & \multicolumn{2}{c}{ Fulti-move } & \multicolumn{2}{c}{ Average } \\
Thuy (B1) & 30 & $34.1^{*}$ & $-4.8^{*}$ & 58 & 65.9 & 3.15 \\
\hline Hong (B2) & 64 & 66.4 & 1.3 & 37 & 33.6 & 1.76 \\
\hline Huong (B3) & 33 & 50.7 & -1.3 & 33 & 49.3 & 2.50 \\
\hline $\begin{array}{l}\text { BEGINNING } \\
\text { LEVEL }\end{array}$ & $\mathbf{1 3 7}$ & $\mathbf{5 1 . 7}$ & $\mathbf{n} / \mathbf{a}$ & $\mathbf{1 2 8}$ & $\mathbf{4 8 . 3}$ & $\mathbf{2 . 3 4}$ \\
\hline $\begin{array}{l}\text { Thien (A1) } \\
\text { Nexity }\end{array}$ & 80 & 52.6 & -1.4 & 72 & 47.4 & 2.14 \\
\hline $\begin{array}{l}\text { Nguyen (A2) } \\
\text { Phuong (A3) }\end{array}$ & 65 & 63.1 & 1.2 & 39 & 36.9 & 1.57 \\
\hline $\begin{array}{l}\text { ADVANCED } \\
\text { LEVEL }\end{array}$ & $\mathbf{2 0 8}$ & $\mathbf{6 3 . 4}$ & $\mathbf{n} / \mathbf{a}$ & $\mathbf{1 2 0}$ & $\mathbf{3 6 . 6}$ & $\mathbf{1 . 7 6}$ \\
\hline
\end{tabular}




\begin{tabular}{lllllll}
\hline Total & 335 & 58.2 & $n / a$ & 249 & 41.8 & 2.05 \\
\hline
\end{tabular}

* Adjusted standardized residual of 2.6 or greater

From Table 6.4, it can be seen that overall, multi-move FFEs made up over 58 percent of the total FFEs, while nearly 42 percent of the total FFEs were made of more than one move. On average, each FFE contained 2.05 teacher feedback moves. The rate of single-move FFEs varied from $86.3 \%$ in Phuong's A3 class to $34.1 \%$ in Thuy's B1 class. To explore the variation of the complexity of FFEs across the class groups, a chi-square analysis was performed and the result showed a significant difference among the six class groups $\left(\chi^{2}(d f=5, n=584)=49.946, p<0.001\right)$. To partition the difference, the adjusted standardized residuals (ASRs) were calculated. ASRs greater than 2.6 (marked by asterisks) demonstrated that Phuong, the teacher in Class A3, used significantly more single-move FFEs, and Thuy, the teacher in Class B1, used significantly fewer singlemove FEEs.

The descriptive statistics for the groups were: single-move FFEs, $\bar{X}=55.8$, sd=19.9, n=6; multi-move FFEs, $\bar{X}=41.5$, sd=21.4, $n=6$. Controlling for teacher effect, the difference between the number of simple FFEs and the number of complex FFEs across the proficiencies was not significant $(\mathrm{F}(1,4)=2.034, p=.227)$, suggesting that learners' proficiency levels had no effect on the number of single-move and multi-move FFEs .

\subsubsection{Occurence of FonF in EFL classrooms}

There are three noteworthy points from the results which will be discussed in this section: the frequent occurrence of FonF, the complexity of the FFEs and the variations of FonF occurrence and FFE complexity across the class groups and proficiencies.

\subsubsection{The frequent occurrence of FonF}

The data showed that FonF did occur in EFL classes taught by Vietnamese L1 teachers: 584 FFEs took place during 480 net minutes of teacher-student interaction. The ratio of 1.22 FFEs per net minute suggests that FonF accounted for a considerable proportion of teacher-learner interaction. In this setting where the focus was on language rather than 
on content, it is not surprising that attention to linguistic code was an essential part of the teacher-learner interaction. Despite the average occurrence of 1.22 FFEs per minute of teacher-learner interaction, the teachers' efforts to draw the learners' attention to form did not seem to interfere with the communication flow of the class groups. From observation, the researcher's general impression was that the teachers and students' main foci were on the communicative tasks, and at the end of the class sessions, the communicative tasks were completed as the top priority. The learners' involvement was considered an important goal of the class sessions, and in line with Ellis, et al.'s (2002) definition of FonF, attention to form was incidental, mainly short and unobtrusive.

Measured in conventional minutes, the rate was 0.58 FFE per minute. This rate is lower than the ratio of 0.62 FFEs per minute in Ellis, et al. (2001a) or 0.72 FFEs per minute in Loewen (2004b) partly because the present study was confined to teacher-student interaction only. However, the rate found in this study is higher than that of 0.53 LRE (language-related episodes, as they called them) per minute in Farrokhi \& Gholami (2007). This study was carried out in Iranian meaning-focused IELTS preparatory classes where the teachers and the students shared the L1, which is very similar to the present research. The difference in the number of FFEs between the present study and the other studies mentioned is, however, not outstanding.

As for the frequency of teacher feedback moves, a total of 1,198 moves took place throughout 480 minutes of teacher-learner interaction. The rate of 2.5 feedback moves per net minute reflects the teachers' regular engagement in giving feedback to the learners. This regular feedback is typical of teacher-fronted classes such as these in which 'I-R-F' (Sinclair \& Coulthard, 1975) sequences dominate. I (initiate), and F (feedback) moves are typically teachers' turns in the classroom discourse, while $\mathrm{R}$ (response) is a learners' turn. In his study on supportive teacher talk, Cullen (2002) argues that teachers may adopt the 'I-R-F' mode of instruction as a powerful pedagogic device in which the F-move playing discoursal and evaluative roles provides learners with supportive teacher talk. Moreover, though the classes in this study were supposed to teach "English for communication", the classrooms were organized in the traditional teacher-fronted mode, which may explain why teacher-led interaction predominated (Cullen, 1998). 
When measured in the conventional way, the rate of teacher feedback moves was 1.19 moves per minute. This rate is much higher than that of 0.62 feedback turn per minute in an earlier study in a Canadian immersion setting by Lyster \& Ranta (1997); however, this earlier study did not consider pre-emptive FonF, and as pointed out by Ellis, et al. (2001a, 2001b), the focus of immersion classes in Lyster and Ranta's (1997) study was on content rather than on language. Another possible reason for this difference comes from the context of the EFL classes in the study where grammar has been an important subject in learning and teaching English at school and university. In this setting, despite the teachers being expected to teach English for communication, they still tended to give some priority to linguistic forms due to the influence of their experience in learning the language.

The observation that FonF happened in an EFL setting in Vietnam almost as often as in ESL settings seemed different from what was reported happening in the EFL setting in Vietnam in several research studies (e.g. Bao, 2007; Le, 1999). In these studies, there was a common claim that the Vietnamese L1 teachers used the traditional GrammarTranslation method, and little communicative interaction took place in this setting. The learners in these studies were students at schools or universities where English was a compulsory subject, and they learned English to pass the paper-based exams focusing on grammar and vocabulary. On the contrary, the learners in the present study paid high fees to go to private language learning centres to improve their communication skills in English for their personal needs such as sitting IELTS tests or communicating with their foreign colleagues at work. While the traditional Grammar-Translation method at the Vietnamese schools and universities could hardly induce FonF due to the lack of communicative interaction, the teaching method adopted by the teachers at the private language learning centres was communication-oriented. The difference in the teaching and learning contexts between the above-mentioned studies and this study may explain the considerable amount of FonF taking place in a setting which was usually claimed to nurture FonFS. The findings from this study suggests that in an EFL setting where learners are well-motivated, teachers are qualified and language classes are communication-oriented, FonF can occur as often as it does in similar EFL settings in the studies by Farrokhi \& Gholami (2007) and Farrokhi, Ansarin, \& Mohammadnia (2008), or in other ESL settings of the studies in the field (e.g. Ellis, et al., 2001a; Loewen, 2005). 


\subsubsection{The complexity of the FFEs}

The average complexity of the FFEs (2.05 moves per FFE, as per Table 6.4) in this study showed that on average, each FFE contained over two feedback moves from the teachers. This rate suggests that the teachers in this setting tended to make more than two follow-up moves in each of their feedback turns to address the learners' interlanguage gaps. This feature of the practice of giving feedback can find a possible explanation in Cullen's (2002) study on teachers' F-turns in the I-R-F model. According to him, teachers' feedback turns contain complicated discoursal and/or evaluative moves which employ various strategies: reformulation, elaboration, comment, and repetition, and are featured by responsiveness (Cullen, 2002). In the present study, the teachers seemed to be trying to boost up the communicative atmosphere by using many strategies in one feedback turn to get the learners involved. Their multiple follow-up moves after the learners' interlanguage gaps exposed in the interaction flow may reflect the teachers' efforts in being responsive and supportive to the learners in order to a develop meaningful dialogue with them (Cullen, 2002). The teachers' practice of producing multiple follow-up moves in the F-turns may originate from the teaching and learning setting at the two institutions in this study where the teachers were expected to create a communicative environment and to involve the learners in practicing English.

\subsubsection{The variation of the FonF amount and FFE complexity across classes and proficiencies}

The data analysis showed a significant variation in the frequency of FonF and the complexity of the FFEs across the six class groups, but not across proficiencies. In this study, the numbers of FFEs varied significantly across the class groups, ranging from 66 in the class group B3 to 152 in the class group A1 (see Table 6.2). The difference in the number of FFEs among the class groups has been observed in several other studies (e.g. Ellis, et al., 2001a, 2001b; Lyster \& Ranta, 1997; Tsang, 2004b). As for the frequency of the teachers' feedback moves, the data show that it ranged significantly from 90 moves made by Phuong to 325 made by Thien. While Thien used up to over four moves per minute, Phuong only produced only 1.13 moves per minute (see Table 6.3). Similar results were also reported by Tsang (2004a) where the number of teachers' feedback turns on learners errors varied from 0 turn to 39 turns across 18 lessons. 
Like the frequency of FonF across the class groups, the average complexity of the FFEs across the class groups varied widely, ranging from 1.23 moves per FFE by Phuong the teacher in charge of Class A3, to 3.15 moves per FFE by Thuy, the teacher in charge of Class B1 (see Table 6.3). The data analysis also revealed that Phuong produced significantly more simple FFEs while Thuy had significantly more complex FFEs than the other teachers.

The variation in teachers' behaviour towards FonF which led to the variation in the frequency of FonF and the complexity of the FFEs is not surprising. To justify this variation, many possible factors can be noted including teacher-related factors and context-related factors courses. Teacher-related factors including teachers' individual differences will play a role since the type of FonF examined in this study takes place during teacher-learner interaction where the teachers usually decided which linguistic forms to draw learners' attention to. In addition, given that the learners and learning settings were similar for all the classes in this study, the differences are also likely to be attributed to the different context-related factors such as the courses taught in the classes.

The different beliefs in practising FonF in class may come from their individual differences including their age, teaching experience and training. As pointed out by Loewen (2005), most teachers were not given training in the practice of FonF. Their practices have been shaped through their own teaching experiences and self-training, and they may be adapted to suit specific teaching situations. Since the teachers' teaching and training backgrounds and the teaching situations varied, their FonF behaviour varied accordingly. The pattern of the frequency of FonF across the classes (see Table 6.2) shows that another possible influence of the teachers' FonF behaviour is their teaching experience. An investigation of the teachers' teaching experience shows that more experienced teachers like Thien, Nguyen or Hong produced more FFEs (1.90, 1.29 and 1.26 per minute, respectively) than less experienced teachers like Thuy or Huong (1.10 and 0.83, respectively) (see Table 6.2). This finds support in a study by Mackey and her colleagues (2004) which also reported that the teachers' experience influenced their use of incidental FonF techniques. In their study, the experienced teachers tended to implement more incidental FonF techniques (0.57 FFEs per minute) while inexperienced ones seemed to ignore the learners' errors (only 0.21 FFEs per minutes). Given that incidental FonF requires teachers' improvisational ability, it is 
understandable that inexperienced teachers may stay on the safe side rather than risk spontaneously addressing some linguistic items which are not in the pre-planned lesson.

Another possible reason for the wide range of the FonF amount across the class groups is the different courses being taken in the classrooms. Among the six classes observed in this study, two were IELTS-preparation classes and the other four were general English classes which were also dubbed English for communication classes. The two IELTS-preparation classes had the highest frequencies of FFEs among the six class groups (152 FFEs in Class A1 and 104 FFEs in Class A2, as per Table 6.2). This fact may result from the different purposes of the two types of courses. While the general English classes gave priority to the learners' oral communication skills, the IELTS classes prepared their learners to take all round tests focusing on all four skills of speaking, listening, speaking and writing. This difference may explain the fact that the teachers of the two IELTS classes drew the learners' attention to linguistic features more often than those in the other classes.

As for the complexity of FonF, it is important to note that there is also a wide variation in the complexity of the FFEs produced across the class groups, and this variation is likely to interrelate with the teacher variables in complex ways to produce the patterns that we see in this data. From Table 4.2 describing the teachers' individual differences, it can be seen that Phuong, who made the fewest FonF moves and the simplest average FFEs, with only 1.23 moves per FFE (see Table 6.4), has a different training background from the other teachers. She is the only one who received a Masters' degree from an Australian university. During the time she obtained the training, CLT was introduced to Vietnam and widely promoted as the best option for language teachers This method discourages teachers from interfering with the communication flow in the classroom by focusing on error correction and grammatical explanation. This fact may explain her practice of refraining from inhibiting learners' interactive flow by making few FFEs and mostly single-move FFEs throughout her classes. On the contrary, Thuy, the youngest and least experienced teacher, tended to linger with her feedback, using significantly more multi-move FFEs than the other teachers. She seemed to eagerly draw the linguistic forms in focus to the attention of every student in the class, and only felt comfortable when the learners paid their attention to the targeted forms. The two following examples illustrate the typical ways of giving feedback by these two teachers. Episode 03 A3 illustrates a typical FFE with Phuong as the teacher. 


\section{Episode 03 A3}

Sx: I know one person. When he cames, he's a British or somewhere in Europe.

She come to Vietnam and live here in about 8 years

T: $\quad$ she has lived here for 8 years

Sx: yes, for 8 years.

T: uhm [the learner goes on with his story]

In this example, the learner made a series of errors. However, Phuong chose to correct only one utterance with two morphosyntactic errors: the present perfect tense for the verb "live" and the preposition "for" instead of "in", and she did so using a recast, the least interfering feedback type (Ellis, et al., 2006; Loewen \& Philp, 2006; Lyster, 1998). In his uptake move, the learner acknowledged the feedback and produced repair for the preposition only. The teacher, nevertheless, let the learner move on with his story.

Episode 15 B1 below is a typical FFE with Thuy as the teacher.

\section{Episode 15 B1}

Sx: I'm going to /wrai/ a letter tonight.

T: /wrai/?

am gi о cuoi nua? (What is the final sound?)

Sx: $\quad /$ rai/

T: $\quad$ ok, nho hi, gap cai am ni la am cam nghe, khong doc nghe!

(Please remember, this sound is silent, please don't read!)

[Teacher writes the word 'write' on the board and underlines the letter ' $w$ ']

Am ni la am cam hi, khong doc la /wrail, khong doc la /vrai/ chi het!

(This sound is silent, don't read this word as /wrai/ or /vrai/!)

/rait/, nho /t/ dang sau (remember the final sound /t/).

/rait/, ok? [Some learners nod and T goes on asking another learner]

What are you going to do tonight?

In this example, Thuy seemed to be the controller of the interaction. When the learner made a pronunciation error of the word "write", she made one elicit move by repeating the mispronounced word in a rising tone, followed by another elicit move in L1 to draw the learner's attention to one aspect of the pronunciation error (the missing final sound 
/t/). The learner, however, produced a needs-repair move by addressing another aspect of the mispronounced word (the excessive sound /w/) while ignoring the missing final sound elicited in the teacher feedback. The teacher took the opportunity to emphasize the excessive sound and moved on to remind the learner of the missing final sound $/ \mathrm{t} /$. The whole FFE was dominated by teacher talk with six feedback moves while the learner produced only one uptake move.

Besides the two cases of Thuy and Phuong, the pattern of the FFE complexity across the other teachers also seems to be related to their qualifications, training and teaching experiences. Nguyen and Hong, the teachers who obtained a Masters' degree in English Education a few years ago and had 15-20 years of teaching experience, were more inclined to produce fewer feedback moves in one FFE (with average FFE complexity of 1.57 and 1.76 moves, respectively) than the less experienced and qualified teachers, like Huong and Thuy (2.50 and 3.15 moves, respectively). While complex FFEs are more likely to induce learner uptake and noticing than simple ones, they are also more likely to interfere with the communicative flow (Alcon-Soler, 2009; Loewen, 2004b). The data suggests that the teachers may learn from their teaching experience and training how to regulate the complexity of FonF so that their feedback could be supportive without being too intrusive.

Meanwhile, Thien, the teacher of Class A1, produced 325 feedback moves during 152 FFEs, the largest number of feedback moves of all (see Table 6.3). Beside the above mentioned fact that his class was an IELTS-preparation one, which may have contributed to the large amount of FonF taking place in his class, a possible explanation for Thien's exceptionally large amount of feedback moves may come from the training and teaching experience he has acquired over the time. He received his doctorate degree on theoretical linguistics seven years previously. In Vietnam, where teacher development is more or less a one-off package for the teachers to get a qualification for their jobs rather than a continuous process (Truong, 2004), the top degree seemed to have secured Thien a good job at the institution. Since his training background did not involve much of teaching English, his practice of FonF may have been influenced by his own language learning and teaching experience. At his university, he has been teaching some theoretical linguistic subjects which are not related to communication skills. As the oldest teacher, his learning experience took place when correcting learners' mistakes was an important part of the teacher's role in the classroom in Vietnam (Le, 1999). The 
learning experience may have influenced his practice of being very responsive to learners' interlanguage gaps and ready to provide feedback while he was still trying to help his learners conduct the communicative tasks.

As for the impact of the learners' proficiencies on the teachers' practice of FonF, the data shows that though there is some difference in the aggregated amounts of FonF across the two proficiencies, the difference in the means of the two proficiencies was not significant. The aggregated number of FFEs at the advanced level was 329, making an average of 1.37 FFEs per minute, which is larger than that of the beginning level (1.06 FFE per minute) (see Table 6.2). A similar difference in the amounts of FonF across the proficiencies is also mentioned in the result of a recent study by Farrokhi, Ansarin, \& Mohammadnia (2008), which reported a ratio of 0.38 FFE per minute in the EFL beginning classes, while it was 0.47 in the advanced classes. A possible explanation for this difference may come from the nature of the two levels of the classes in which the pace of instruction in the beginning classes were slower than that in the advanced classes. The number of linguistic features addressed was, therefore, smaller, accordingly. However, the variation in the amount of FonF ranged similarly within each proficiency level (from 0.83 to 1.26 FFEs per minute at the beginning level, and from 0.91 to 1.90 FFEs per minute at the advanced level, as per Table 6.2), making the difference of the means of the FonF amount across the two proficiencies insignificant. The fact that the teachers teaching classes of the same proficiency level practised FonF differently may reflect the differing views of the teachers on the practice of FonF as revealed in their conversations with the researcher. Some argue that there is a higher expectation of accuracy at the advanced level, while teachers should be more tolerant of errors at the beginning level, which explains a larger amount of FonF taking place at the advanced level. Meanwhile, others argue that low-level learners may need more supportive teacher talk in the form of feedback.

The number of teacher feedback moves was also not significantly different across the proficiencies. A closer look at the range of the teacher feedback moves in each proficiency level revealed that while the number of feedback moves ranged from 165 to 277 at the beginning level, this variation was much wider at the advanced level where Thien, the teacher of Class A1, produced over three times as many feedback moves as Phuong, the teacher of Class A3 (325 compared to 90 moves) (see Table 6.3). Such a large difference in the number of feedback moves produced among the teachers at the 
same level may have resulted in no significant differences across proficiencies. Though learners' proficiency levels have been found to be a compounding factor which may influence the amount of FonF (Alegría de la Colina \& del Pilar García Mayo, 2009; Farrokhi, et al., 2008; Iwashita, 2001; Leeser, 2004; Williams, 1999), the teachers' differences in this study may have contributed a significant part to the variation in the amount of FonF. The analysis of this data set, therefore, does not provide enough information to confirm the influence of the learners' proficiency levels on the amount of FonF.

\subsection{The characteristics of FonF in EFL classrooms}

To answer the second part of the first research question of this thesis addressing the characteristics of FonF in the EFL classrooms in Vietnam, some characteristics of FonF including the types, source and linguistic foci are presented and discussed in this section.

\subsubsection{Types, sources and linguistic foci of FonF in EFL classrooms}

The results about the characteristics of FonF are presented in three categories: types of teacher feedback, source of FonF and linguistic foci.

\subsubsection{Types of teacher feedback}

The types of teacher feedback refer to the ways the teachers responded to the learners' interlanguage gaps, including provide, elicit and reformulate coded across the six class groups and the two proficiency levels. Provide refers explicit information given by the teacher in the form of definitions, examples or explanations. In an elicit move, the teacher repeats the error, or gives prompts or clues, or elicits solutions so that learners recognize the gaps and correct themselves. Reformulate refers to implicit information given by the teacher in the form of recasts to reformulate part or all of an erroneous utterance. The amount of each type was coded in accordance with the teachers' feedback moves produced during teacher-learner interaction in order to fully cover all the follow-up moves in complex FFEs in which the teachers may use various types of feedback moves in one episode. The detailed coding procedure is described in Section 4.2.5.2. 
The following table shows the frequencies of the teachers' three different ways of giving feedback to the learners: provide, elicit and reformulate in the six class groups of two proficiencies in observation.

Table 0.5: Types of teacher feedback across class groups

\begin{tabular}{|c|c|c|c|c|c|c|}
\hline \multirow{2}{*}{$\begin{array}{l}\text { Class group (Teacher) } \\
\text { LEVEL }\end{array}$} & \multicolumn{2}{|c|}{ Provide } & \multicolumn{2}{|c|}{ Elicit } & \multicolumn{2}{|c|}{ Reformulate } \\
\hline & $\mathbf{n}$ & $\%$ & $\mathbf{n}$ & $\%$ & $\mathbf{n}$ & $\%$ \\
\hline Thuy (B1) & 67 & 24.2 & 113 & 40.8 & 97 & 35.0 \\
\hline Hong (B2) & 40 & 22.5 & 33 & 18.5 & 105 & 59.0 \\
\hline Huong (B3) & 65 & 39.4 & 47 & 28.5 & 53 & 32.1 \\
\hline BEGINNING LEVEL & 172 & 27.8 & 193 & 31.1 & 255 & 41.1 \\
\hline Thien (A1) & 113 & 34.8 & 112 & 34.5 & 100 & 30.8 \\
\hline Nguyen (A2) & 73 & 44.8 & 11 & 6.7 & 79 & 48.5 \\
\hline Phuong (A3) & 14 & 15.6 & 20 & 22.2 & 56 & 62.2 \\
\hline ADVANCED LEVEL & 200 & 34.6 & 143 & 24.7 & 235 & 40.7 \\
\hline Total & 372 & 31.1 & 336 & 28.0 & 490 & 40.9 \\
\hline
\end{tabular}

From Table 6.5, it can be seen that, on average, reformulate was the most common type of FonF, which accounted for $40.9 \%$ of the total number of feedback moves made by the teachers. The other two types of feedback moves, provide and elicit, on average, made up similar amounts of the feedback: $31.1 \%$ and $28 \%$, respectively. Table 6.5 also indicates that while there was a similar and dominating use of reformulate (around 41\%) across the two proficiency levels, the use of provide and elicit varied between the two levels. The teachers of the advanced classes tended to use more provide than those of the beginning classes (34.6\% and $27.8 \%$, respectively), and the teachers of the beginning classes, in turn, used more elicit than those of the advanced classes $(31.1 \%$ and $24.7 \%$, respectively). 
The chi-square analysis of the types of feedback indicates a statistically significant difference among the six teachers $\left(\chi^{2}(d f=10, n=1198)=124.6, p<0.001\right)$. The ASRs were also computed to analyze the data further in order to understand where the differences were. The following table shows the ASRs for the types of teacher feedback across the class groups.

Table 0.6: ASRs for teacher feedback types

\begin{tabular}{cccc}
\hline Teacher & Provide & Elicit & Reformulate \\
\hline Thuy (B1) & $-2.8 *$ & $5.4 *$ & -2.3 \\
\hline Hong (B2) & $-2.7 *$ & $-3.1 *$ & $5.3 *$ \\
\hline Huong (B3) & 2.5 & .1 & -2.5 \\
\hline Thien (A1) & 1.7 & $3.0 *$ & $-4.4 *$ \\
\hline Nguyen (A2) & $4.1 *$ & $-6.5 *$ & 2.1 \\
\hline Phuong (A3) & $-3.3 *$ & -1.3 & $4.3 *$ \\
\hline
\end{tabular}

* Adjusted standardized residual of 2.6 or greater

In Table 6.6, ASRs greater than $2.6^{3}$ (marked by asterisks) demonstrate that the teacher in Class A2 made significantly more provide moves than other teachers did, and the teachers in Class A3, Class B1 and Class B2 made significantly fewer provide moves. Similarly, the teachers in Class A1 and Class B1 used significantly higher numbers of elicit moves than the other teachers did, while the teachers in Class A2 and Class B2 produced significantly lower numbers of elicit moves. For the type of reformulate, the teachers of Class A1 made fewer reformulate moves than did the other teachers, while the teachers of Class A3 and Class B2 used significantly more moves of this type.

A 2 (proficiency level) x 3 (teacher feedback type) full-factorial ANOVA (see Table 6.5) was conducted to explore the interaction between the learners' proficiency level and the

\footnotetext{
${ }^{3}$ For more information, see Section 4.2.5.3.
} 
types of teacher feedback. The descriptive statistics for the groups were: provide,

$\overline{\mathrm{X}}=62.0, \mathrm{sd}=33.3, \mathrm{n}=6$; elicit, $\overline{\mathrm{X}}=56.0, \mathrm{sd}=45.4, \mathrm{n}=6$; and reformulate, $\overline{\mathrm{X}}=21.7, \mathrm{sd}=22.8$, $\mathrm{n}=6$. The ANOVA found that the interaction was not statistically significant $(\mathrm{F}(2,12)$ $=.173, p=.843)$.

\subsubsection{FonF source}

The source of FonF refers to the trigger of feedback. It could be categorized as either negotiation of meaning (NoM) when there was a communication breakdown during a conversation in the classroom, or negotiation of form $(\mathrm{NoF})$ when there was no miscommunication but attention to form still occurred for didactic purposes (Ellis, et al., 2001a).

Table 6.7 shows the number of FFEs triggered by NoM and NoF across the six class groups and the two proficiency levels. ASRs for NoM are also presented.

Table 0.7: Source of FFEs across class groups and proficiencies

\begin{tabular}{ccccc}
\hline $\begin{array}{c}\text { Teacher (Class) } \\
\text { LEVEL }\end{array}$ & $\mathbf{n}$ & NoM & $\mathbf{n}$ & NoF \\
\hline Thuy (B1) & 6 & 6.8 & 82 & 93.2 \\
\hline Hong (B2) & 10 & 9.9 & 91 & 90.1 \\
\hline Huong (B3) & 7 & 10.6 & 59 & 89.4 \\
\hline BEGINNING LEVEL & $\mathbf{2 3}$ & $\mathbf{9 . 0}$ & $\mathbf{2 3 2}$ & $\mathbf{9 1 . 0}$ \\
\hline Thien (A1) & 16 & 10.5 & 136 & 89.5 \\
\hline Nguyen (A2) & 4 & 3.8 & 100 & 96.2 \\
\hline Phuong (A3) & 1 & 1.4 & 72 & 98.6 \\
\hline ADVANCED LEVEL & $\mathbf{2 1}$ & $\mathbf{6 . 4}$ & $\mathbf{3 0 8}$ & $\mathbf{9 3 . 6}$ \\
\hline Total & $\mathbf{4 4}$ & $\mathbf{7 . 5}$ & $\mathbf{5 4 0}$ & $\mathbf{9 2 . 5}$ \\
\hline
\end{tabular}


Table 6.7 reveals that the rates of FFEs triggered by NoM ranged from 1.4 to $10.6 \%$ across the six teachers. On average, NoF was the source of an overwhelming $92.5 \%$ of the FFEs. The chi-square test was performed, and the result $\left(\chi^{2}(d f=5, n=584)=9.736\right.$, $p=0.083$ ) indicated no significant difference in the source of the FFEs across the six observed class.

A 2 (proficiency level) x 2 (FonF source) full-factorial ANOVA (see Table 6.7) was conducted to explore the interaction between the learners' proficiency level and the FFE source. The descriptive statistics for the groups were: NoM, $\bar{X}=7.3, \mathrm{sd}=5.2, \mathrm{n}=6$; and NoF, $\bar{X}=90.0, s d=26.7, n=6$. The ANOVA found that the interaction was not statistically significant $(\mathrm{F}(1,8)=1.481, p=.258)$.

The source of teacher feedback moves produced in these FFEs was also recorded across the class groups and proficiencies. The results are presented in Table 6.8 below together with the ASRs computed for the NoM category.

Table 0.8: Source of teacher feedback moves across class groups and proficiencies, and ASRs for NoM

\begin{tabular}{cccccc}
\hline $\begin{array}{c}\text { Teacher (Class) } \\
\text { LEVEL }\end{array}$ & $\mathbf{n}$ & $\mathbf{\%}$ & $\begin{array}{c}\text { ASRs } \\
\text { (NoM) }\end{array}$ & $\mathbf{n}$ & NoF \\
\hline Thuy (B1) & 10 & 3.6 & $-3.5^{*}$ & 267 & 96.4 \\
\hline Hong (B2) & 32 & 18.0 & $4.7^{*}$ & 146 & 82.0 \\
\hline Huong (B3) & 12 & 7.3 & -.7 & 153 & 92.7 \\
\hline BEGINNING LEVEL & $\mathbf{5 4}$ & $\mathbf{8 . 7}$ & $\mathbf{n} / \mathbf{a}$ & $\mathbf{5 6 6}$ & $\mathbf{9 1 . 3}$ \\
\hline Thien (A1) & 44 & 13.5 & $3.6^{*}$ & 281 & 86.5 \\
\hline Nguyen (A2) & 6 & 3.7 & -2.5 & 157 & 96.3 \\
\hline Phuong (A3) & 1 & 1.1 & $-2.7^{*}$ & 89 & 98.9 \\
\hline ADVANCED LEVEL & $\mathbf{5 1}$ & $\mathbf{8 . 8}$ & $\mathbf{n} / \mathbf{a}$ & $\mathbf{5 2 7}$ & $\mathbf{9 1 . 2}$ \\
\hline
\end{tabular}




\begin{tabular}{llllll}
\hline Total & 105 & 8.8 & $n / a$ & 1093 & 91.2 \\
\hline
\end{tabular}

* Adjusted standardized residual of 2.6 or greater

From Table 6.8 , it can be seen that $8.8 \%$ of the teacher feedback moves was triggered by miscommunication between the teachers and the learners. The rate of the source of teacher feedback moves ranged from $82 \%$ of Hong's in Class B2 to $98.9 \%$ of Phuong's in Class A3. The chi-square test was performed, and the result $\left(\chi^{2}(d f=5, n=1,198)\right.$ $=49.680, p<0.001$ ) indicated a significant difference in the source of teacher feedback moves across the six observed class. To partition the difference, ASRs were also calculated. The result shows that while Thuy and Phuong produced significantly fewer message-related feedback moves, Hong and Thien produced significantly more message-related feedback moves than the other teachers.

A 2 (proficiency level) x 2 (FonF source) full-factorial ANOVA (see Table 6.8) was carried out to explore the interaction between the learners' proficiency level and the source of the teacher feedback moves. The descriptive statistics for the groups were: NoM, $\bar{X}=17.5, \mathrm{sd}=16.8, \mathrm{n}=6$; and NoF, $\bar{X}=182.2, \mathrm{sd}=75.4, \mathrm{n}=6$. The ANOVA found that the interaction was not statistically significant $(\mathrm{F}(1,8)=.029, p=.869)$.

\subsubsection{Linguistic foci}

The linguistic foci of the FFEs and teacher feedback moves were categorized as spelling, pronunciation, morphosyntax and vocabulary. Table 6.9 shows the number of FFEs of four different linguistic foci across the six class groups and two proficiencies.

Table 0.9: Linguistic foci of FFEs across class groups and proficiencies

\begin{tabular}{ccccccccc}
\hline $\begin{array}{c}\text { Teacher (Class) } \\
\text { LEVEL }\end{array}$ & \multicolumn{2}{c}{ Spelling } & \multicolumn{2}{c}{ Pronunciation } & \multicolumn{2}{c}{ Morphosyntax } & \multicolumn{2}{c}{ Vocabulary } \\
n & \% & n & \% & n & \% & n \\
\hline Thuy (B1) & 1 & 1.1 & 53 & 60.2 & 20 & 22.7 & 14 & 15.9 \\
\hline Hong (B2) & 0 & 0.0 & 35 & 34.7 & 43 & 42.6 & 23 & 22.8 \\
\hline Huong (B3) & 0 & 0.0 & 38 & 57.6 & 18 & 27.3 & 10 & 15.2 \\
\hline
\end{tabular}




\begin{tabular}{ccccccccc}
\hline BEGINNING LEVEL & $\mathbf{1}$ & $\mathbf{0 . 4}$ & $\mathbf{1 2 6}$ & $\mathbf{4 9 . 4}$ & $\mathbf{8 1}$ & $\mathbf{3 1 . 8}$ & $\mathbf{4 7}$ & $\mathbf{1 8 . 4}$ \\
\hline Thien (A1) & 2 & 1.3 & 67 & 44.1 & 54 & 35.5 & 29 & 19.1 \\
\hline Nguyen (A2) & 1 & 1.0 & 11 & 10.6 & 69 & 66.3 & 23 & 22.1 \\
\hline Phuong (A3) & 0 & 0.0 & 10 & 13.7 & 41 & 56.2 & 22 & 30.1 \\
\hline ADVANCED LEVEL & $\mathbf{3}$ & $\mathbf{0 . 9}$ & $\mathbf{8 8}$ & $\mathbf{2 6 . 7}$ & $\mathbf{1 6 4}$ & $\mathbf{4 9 . 8}$ & $\mathbf{7 4}$ & $\mathbf{2 2 . 5}$ \\
\hline Total & $\mathbf{4}$ & $\mathbf{0 . 7}$ & $\mathbf{2 1 4}$ & $\mathbf{3 6 . 6}$ & $\mathbf{2 4 5}$ & $\mathbf{4 2 . 0}$ & $\mathbf{1 2 1}$ & $\mathbf{2 0 . 7}$ \\
\hline
\end{tabular}

The teachers focused on morphosyntactical forms the most, at $42 \%$ of the overall number of FFEs, followed by pronunciation (36.6\%), vocabulary (20.7\%) and spelling (only $0.7 \%$ ). The table also shows that the number of spelling-focused episodes was too marginal to guarantee the requirement of chi-square tests that no more than $20 \%$ of the expected cell counts be lower than 5 (Moore \& McCabe, 2003; Siegel \& Castellan, 1988). As a result, to perform the chi-square test, the category of spelling-focused episodes was excluded. The chi-square test result $\left(\chi^{2}(d f=10, n=580)=89.932, p<0.001\right)$ indicated a significant difference in the frequencies of the three linguistic foci across the six observed class.

A 2 (proficiency level) x 4 (linguistic foci) full-factorial ANOVA was conducted to explore the interaction between the learners' proficiency level and the linguistic foci of the FFEs . The descriptive statistics for the groups were: spelling, $\bar{X}=0.7$, sd=0.8, $n=6$; pronunciation, $\bar{X}=35.7$, sd=22.6, $\mathrm{n}=6$; morphosyntax, $\bar{X}=40.8, \mathrm{sd}=19.6, \mathrm{n}=6$; and vocabulary, $\bar{X}=20.2, \mathrm{sd}=6.9, \mathrm{n}=6$. The ANOVA found that the interaction was not statistically significant $(\mathrm{F}(3,16)=2.129, p=.137)$.

As the difference across the six class groups was significant, further analysis was performed to partition the difference in the frequencies of the linguistic foci of the FFEs taking place across the six class groups. Table 6.10 shows the ASRs of the linguistic foci of the FFEs. 
Table 0.10: ASRs of linguistic foci of FFEs across class groups

\begin{tabular}{cccc}
\hline Teacher (Class) & Pronunciation & Morphosyntax & Vocabulary \\
\hline Thuy (B1) & $5.0^{*}$ & $-3.9^{*}$ & -1.2 \\
\hline Hong (B2) & -.5 & .1 & .5 \\
\hline Huong (B3) & $3.7^{*}$ & $-2.6^{*}$ & -1.2 \\
\hline Thien (A1) & 2.3 & -1.8 & -0.5 \\
\hline Nguyen (A2) & $-6.1^{*}$ & $5.6^{*}$ & .4 \\
\hline Phuong (A3) & $-4.4^{*}$ & $2.6^{*}$ & 2.1 \\
\hline
\end{tabular}

* Adjusted standardized residual of 2.6 or greater

The ASRs reveal significant differences in the amounts of pronunciation- and morphosyntax-focused FonF, but not in vocabulary. Nguyen of Class A2 and Phuong of Class A3 focused less on pronunciation and more on morphosyntax than the teachers in the other class groups. In contrast, in Class B1 of Thuy and Class B3 of Huong, the pronunciation-targeted FFEs occurred significantly more often and morphosyntaxtargeted FFEs took place less often than in the other class groups.

As stated in the methodology section, the data is also coded in moves to get a detailed description of the complexity of the FFEs in the EFL classrooms in Vietnam. Table 6.11 shows the number of teacher feedback moves used in four different linguistic foci across the class groups and the proficiencies. 
Table 0.11: Linguistic foci of feedback moves across class groups and proficiencies

\begin{tabular}{|c|c|c|c|c|c|c|c|c|}
\hline \multirow{2}{*}{$\begin{array}{c}\text { Teacher (Class) } \\
\text { LEVEL }\end{array}$} & \multicolumn{2}{|c|}{ Spelling } & \multicolumn{2}{|c|}{ Pronunciation } & \multicolumn{2}{|c|}{ Morphosyntax } & \multicolumn{2}{|c|}{ Vocabulary } \\
\hline & n & $\%$ & $\mathbf{n}$ & $\%$ & $\mathbf{n}$ & $\%$ & $\mathbf{n}$ & $\%$ \\
\hline Thuy (B1) & 1 & 0.4 & 173 & 62.5 & 65 & 23.5 & 38 & 13.7 \\
\hline Hong (B2) & 0 & 0 & 47 & 26.4 & 63 & 35.4 & 68 & 38.2 \\
\hline Huong (B3) & 0 & 0 & 76 & 46.1 & 36 & 21.8 & 53 & 32.1 \\
\hline $\begin{array}{l}\text { BEGINNING } \\
\text { LEVEL }\end{array}$ & 1 & 0.2 & 296 & 47.7 & 164 & 26.5 & 159 & 25.6 \\
\hline Thien (A1) & 9 & 2.8 & 119 & 29.8 & 119 & 35.4 & 78 & 18.5 \\
\hline Nguyen (A2) & 1 & 0.6 & 15 & 9.2 & 105 & 61.3 & 42 & 25.2 \\
\hline Phuong (A3) & 0 & 0 & 10 & 11.1 & 46 & 50.0 & 34 & 37.8 \\
\hline $\begin{array}{l}\text { ADVANCED } \\
\text { LEVEL }\end{array}$ & 10 & 1.7 & 144 & 24.9 & 270 & 46.7 & 154 & 26.6 \\
\hline Total & 11 & 0.9 & 440 & 36.7 & 434 & 36.2 & 313 & 26.1 \\
\hline
\end{tabular}

As seen in Table 6.11, on average, the most common linguistic foci of the teacher feedback moves were pronunciation (36.7\%) and morphosyntax (36.2) followed by vocabulary $(26.1 \%)$ of the total. Spelling made up a marginal $0.9 \%$. Across the class groups, there were some variations in the rates of the feedback moves produced to address the four different linguistic foci. A chi-square analysis was performed to decide whether the variations were significant. To do this, spelling-focused moves were again excluded from the data to conform the low-cell-count rule (Moore \& McCabe, 2003). The results revealed a statistically significant difference across the six class groups $\left(\chi^{2}\right.$ $(d f=10, n=1,187)=204.366, p<0.001)$.

A 2 (proficiency level) x 4 (linguistic foci) full-factorial ANOVA (see Table 6.11) was carried out to explored the interaction between the learners' proficiency level and the linguistic foci of the feedback moves. The descriptive statistics for the groups were: spelling, $\overline{\mathrm{X}}=1.8, \mathrm{sd}=3.5, \mathrm{n}=6$; pronunciation, $\overline{\mathrm{X}}=73.3$, sd=63.5, $\mathrm{n}=6$; morphosyntax, $\overline{\mathrm{X}}=72.3, \mathrm{sd}=32.9, \mathrm{n}=6$; and vocabulary, $\overline{\mathrm{X}}=52.2, \mathrm{sd}=17.6, \mathrm{n}=6$. The ANOVA found that the interaction was not statistically significant $(\mathrm{F}(3,16)=1.412, p=.276)$. 
As the difference in the feedback moves used in each linguistic focus across the class groups was found significant, the ASRs were also computed to partition the differences among these categories. Table 6.12 shows the ASRs of the linguistic foci of the teacher feedback moves across the six class groups.

Table 0.12: ASRs of linguistic foci of feedback moves across class groups

\begin{tabular}{cccc}
\hline Teacher (Class) & Pronunciation & Morphosyntax & Vocabulary \\
\hline Thuy (B1) & $10.1^{*}$ & $-5.1^{*}$ & $-5.4^{*}$ \\
\hline Hong (B2) & $-3.2^{*}$ & -.4 & $3.9^{*}$ \\
\hline Huong (B3) & $2.6^{*}$ & $-4.2^{*}$ & 1.8 \\
\hline Thien (A1) & .3 & .5 & -.8 \\
\hline Nguyen (A2) & $-7.9^{*}$ & $8.0^{*}$ & -.1 \\
\hline Phuong (A3) & $-5.3^{*}$ & $3.0^{*}$ & $2.6^{*}$ \\
\hline
\end{tabular}

* Adjusted standardized residual of 2.6 or greater

The analysis of ASRs demonstrates that Thuy of Class B1 produced significantly more pronunciation-focused feedback moves and fewer morphosyntax- and vocabularyfocused feedback moves than the other teachers. Meanwhile, Phuong of Class A3 addressed linguistic foci in an opposite way: she used significantly more feedback moves for morphosyntax- and vocabulary-related FonF and fewer moves for pronunciation. Another pair of teachers with opposite trends was Huong (B3) and Nguyen (A2); the former produced significantly more feedback moves in pronunciationfocused FonF and fewer in morphosyntactic problems, while the opposite was true for the latter. Hong of Class B2 produced significantly more feedback moves addressing vocabulary-focused features and significantly fewer moves for pronunciation-focused FFEs. 


\subsubsection{Pattern and variation of FonF characteristics in EFL classrooms}

From the data analysis, there are two substantial points that will be discussed accordingly in the following section. Firstly, the data shows that the frequencies of the types of teacher feedback, FonF source and linguistic foci of FonF in this study were different from those in the other studies. Secondly, the variation in the FonF characteristics was significant across the teachers, but it was not statistical across the proficiencies.

\subsubsection{A different pattern of the characteristics of FonF}

The patterns of the characteristics of FonF in this study were not consistent with those of other studies on FonF. First of all, the ways the teachers in this study addressed learners' errors and linguistic queries were considerably different. In this study, the rate of reformulate was $40.9 \%$; provide occupied $31.1 \%$, and elicit 28\% (see Table 6.6). This pattern of the rates of teacher feedback types is different from that of other studies. For example, in Sheen (2004), the average percentages of these three types across the four different setting described in this study were $64 \%, 13.7 \%$, and $22.3 \%$, respectively

${ }^{4}$. The difference in the rates of each feedback type between the studies mentioned in Sheen (2004) and the present study is substantial.

Reformulate (or recast as it is referred to in other studies), is often reported to be the most common type of response teachers made to address learners' errors (e.g. Ellis, et al., 2001a; Loewen, 2004b; Lyster \& Ranta, 1997; Panova \& Lyster, 2002; Tsang, 2004a). In this study, the amount of reformulate was also the largest, but it was much lower than in the other studies. It occupied only $40 \%$ of the total amount of FonF, while this rate was $64 \%$ on average in Sheen (2004). The difference may be traced back to the difference in the TL proficiency of the teachers in this study and in the other studies. In the instructional settings in Sheen (2004), the teachers were all NSs of English. The ease with which they used recast reflect their position as NS teachers who are much

\footnotetext{
${ }^{4}$ In Sheen (2004), there are seven types of teachers feedback: explicit correction, recasts, clarification requests, metalinguistic feedback, elicitation, repetition and translation. To conveniently compare with the results of the present study, translation was excluded from the data and the other six types were combined to make three types accordingly. Explicit correction and metalinguistic feedback were mingled into provide; recasts were reformulate, and clarification requests, elicitation and repetition were grouped into elicit.
} 
more proficient and confident speakers of the TL than NNS teachers (Medgyes, 1994). Their use of recasts, therefore, is as natural and spontaneous as that of parents or adults to correct children in L1 acquisition. In contrast, NNS teachers have a weaker command of the TL, and as a result, may judge their feedback cautiously before giving it, and would rather turn to other types of feedback that give them more time to consider like provide or elicit than a spontaneous feedback type like reformulate. In a study by Tsang (2004a) in a similar EFL setting with the present study where all the teachers and learners were NNSs, the percentages of reformulate was $48 \%$, which was not markedly different from the present study.

The teachers' second most common type of feedback was provide, which made up $31.1 \%$ of the total amount of FonF. The rate of elicit (28\%) was nearly as high as that of provide. In Sheen's (2004) study, elicit (referred to as clarification requests, elicitation and repetition) accounted for about $21 \%$, while provide (as explicit correction and metalinguistic feedback) was less common (nearly 13\%). This difference may be attributed to the teachers' different training and education background. The Vietnamese L1 teachers in EFL countries like Vietnam were more likely to be exposed to a learning setting where FonFS with explicit teaching of linguistic items was the norm (Ellis, 2008; Le, 1999). Becoming a teacher with such a background in such a setting is likely to influence teacher practice in the classroom. In addition, giving feedback in a straightforward and judging way as provide has been common in a teaching context where the teachers' roles are influenced by Confucian values (e.g. Bao, 2007) which put teachers one rank higher than parents in the society. With such a power in the classroom, it is not surprising that saying "you're wrong", "you shouldn't say it that way", or "you must say like this" has been considered part of the teacher's work in the class and is generally accepted rather than being considered discouraging or face-threatening. Besides, the learners can notice their gaps easily thanks to the salience of this type of feedback and correct their errors. This may explain the fact that both the teachers and the students in the observed classes seemed to be comfortable with this type of feedback.

As for the linguistic foci of FonF, the data in this study also shows some similarities and differences from the other studies in FonF. Table 6.13 shows the percentages of the linguistic foci of the FFEs of the present study in comparison with two other studies in the field. 
Table 0.13: Linguistic foci of FFEs across FonF studies

\begin{tabular}{lccc}
\hline \multicolumn{1}{c}{ Study } & Morphosyntax & Pronunciation & Vocabulary \\
\hline The present study & $42.0 \%$ & $36.6 \%$ & $20.7 \%$ \\
\hline Basturkmen, et al. (2004) & $35.5 \%$ & $23.7 \%$ & $40.8 \%$ \\
\hline Farrokhi, et al. (2008) & $22.2 \%$ & $13.2 \%$ & $64.6 \%$ \\
\hline
\end{tabular}

As can be seen from Table 6.13, the results of the present study indicate that morphosyntax, pronunciation and vocabulary were the three linguistic foci that the teachers chose to tackle the most often $(42.0 \%, 36.6 \%$ and $20.7 \%$, respectively). These three linguistic foci were also the main FonF sources in focus in the other studies in the field (e.g. Basturkmen, et al., 2004; Farrokhi, et al., 2008). In Farrokhi, et al. (2008), on average, the percentages for these three linguistic forms were $64.6 \%$ for vocabulary, $22.2 \%$ for grammar and $13.2 \%$ for pronunciation. In Basturkmen, et al. (2004), 40.8\% of the total number of FFEs focused on vocabulary, 35.5\% grammar, and $23.7 \%$ pronunciation. In these studies, other types of FonF source like spelling were also excluded either from the coding system or from analysis due to the marginal amount.

Despite the similarity in the major linguistic foci in this study and the two studies mentioned above, there were some differences as presented in Table 6.13. Morphosyntax-focused episodes (referred to as grammar-focused elsewhere) were the most frequent in this study but second most frequent in the other two studies. Pronunciation was the second most commonly-focused in this study while it was the least common in the other two studies. Vocabulary was the least commonly-focused in the FFEs in this study, while the opposite results were found in the other two studies.

Since the data was confined to teacher-student interaction, all the specific forms coded in this study were chosen to address by the teachers, including correcting learners' errors in reactive FFEs, raising queries on linguistic forms in teacher-initiated preemptive FFEs, and answering learners' queries in learner-initiated pre-emptive FFEs. The difference across the studies, to some extent, is likely to be attributed to the teachers. The fact that morphosyntax was the most frequent focus in the FFEs found in this study can be explained by the traditional method of teaching English in Vietnam 
that the teachers experienced in their education. In the English language program at schools and universities in Vietnam, grammar has contributed an essential part in teaching and assessment systems. Grammar has been such an obsession for the teachers as well as the students in Vietnam (e.g. H. Chau, 2009; Le \& Barnard, 2008) that it is not surprising that the teachers usually gave considerable priority to morphosyntactic errors or queries emerging during the class. This is also observed and reported in other Asian countries such as China (e.g. Larsen-Freeman, 2007), Korea (e.g. Kim \& Mathes, 2001), or Japan (e.g. Long, Inagaki, \& Ortega, 1998).

Pronunciation was the second most common focus in these classes. Communicativeness is explicitly stated and commercially advertised as the core of the English courses at the two private language institutions where the present study was conducted, and so the teachers in this study tended to attend more to the learners' speaking skill than other skills. Meanwhile, before taking these classes, most of the learners have been taught English for coping with written tests at school or at work. As a result, the learners at the English courses for communication often made plenty of pronunciation errors, or had many queries on pronunciation. In addition, since the pronunciation systems of the TL and L1 are quite different from each other, the teachers also successfully pre-empted a lot of gaps in the learners' pronunciation which, in turn, contributed to the considerable number of pronunciation-focused FFEs.

\subsubsection{The variation of FonF characteristics across the classes and proficiencies}

In this study, two characteristics of FonF which are teacher feedback types and linguistic foci of FonF varied significantly across the teachers, while the learners' proficiency levels did not seem to influence these two characteristics.

As for the teacher feedback types, the teachers behaved in totally different ways. For example, Table 6.6 shows that while Nguyen used plenty of provide and little elicit (44.8\% and 6.7\%, respectively), Thuy implemented a large amount of elicit and little provide $(40.8 \%$ and $24.2 \%$, respectively). Or Thien used an ample amount of elicit $(34.5 \%)$ and not much reformulate compared with his colleagues in this study $(30.8 \%)$, whereas Hong gave little provide and elicit (22.5\% and $18.5 \%$, respectively), but plenty of reformulate (59\%). The teachers' diverse habits of giving feedback were also 
reported in other studies (e.g. Basturkmen, et al., 2004; Farrokhi \& Gholami, 2007; Loewen, 2003, 2004b). Also, from Table 6.10, there was a wide variation across the teachers in addressing the learners' morphosyntactic and pronounciation gaps. Nguyen and Phuong, attended to morphosyntactic gaps significantly more often than the other teachers $(66.3 \%$ and $56.2 \%$, respectively), whereas Thuy and Huong chose to tackle this type significantly less than the other teachers $(22.7 \%$ and $27.3 \%$, respectively). On the contrary, Nguyen and Phuong addressed the learners' gaps in pronunciation much less often than the other teachers (only $10.6 \%$ and $13.7 \%$, respectively). Thuy and Huong, in turn, were much keener addressing learners' pronunciation problems than the other teachers $(60.2 \%$ and $57.6 \%$, respectively).

One of the reasons for the teachers' wide variation in the teachers' feedback types and, as pointed out in Loewen (2003) and Basturkmen, et al. (2004) may stem from the fact that the teachers' teaching and training background varied widely (see Table 4.2). For example, Phuong, the teacher who obtained a Masters' degree on Applied Linguistics from an Australian university during the CLT movement, tended to use significantly less provide and more reformulate than the other teachers (see Table 6.6). The explanation for this fact may come from her belief in avoiding interrupting the learners' communication flow by trying to use reformulate rather than provide because the former is much implicit and unobtrusive than the latter. The teachers' differences in age may also have played a role. This fact can find support from the recent trend toward communicative English language teaching in Vietnam. As young teachers, Thuy and Huong were more likely to be influenced by this.

Another possible reason for the difference in the teachers' feedback types may originate from the types of courses they taught. Table 6.6 reveals that Thien and Nguyen used much more provide (34.8\% and $44.8 \%$, respectively) than Phuong (15.6\%). This is possibly due to the coming tests for the learners of the two advanced IELTS preparation courses taught by Thien and Nguyen. In the conversations with the researcher, the teachers admitted that they were under pressure to get their students to successfully handle some specific linguistic items assumingly necessary for the tests. As a result, they might have chosen an explicit type of feedback like provide to efficiently draw learners' attention to some language forms which, otherwise, may be ignored if they had used more implicit types like elicit or reformulate. Meanwhile, Phuong, the teacher in charge of Class A3, which was an advanced general English class, did not make as 
much use of provide as Thien and Nguyen and used plenty of reformulate instead (62.2\%). This washback effect of testing has been reported to influence learning and teaching in many research studies (e.g. Alderson \& Hamp-Lyons, 1996; Cheng, 2005; Cheng, Watanabe, \& Curtis, 2004; Muñoz \& Álvarez, 2010).

In other research in this field, the percentages were calculated out of the total number of FFEs rather than FonF moves, which cannot reflect how much effort the teachers spent on each linguistic focus since the complexity of the FFEs was not taken into consideration. In this study, both FFEs and feedback moves were calculated. The percentage of each type of FonF source measured in moves is not significantly different from that in FFEs. The FonF amount in moves also shows that the teachers spent the most of their turns giving feedback on morphosyntax, pronunciation and vocabulary $(35.1 \%, 34 \%$, and $21.3 \%$ of the total FonF moves, respectively). However, this coding system has pointed out some aspects that the conventional system of coding in FFEs has failed to address. For example, while on average, morphosyntax-focused episodes were the most frequent ( $42 \%$ of the total FFEs), they occupied only $36.2 \%$ of the total FonF moves and were the least complex episodes with only 1.78 moves per FFE. Vocabularyfocused episodes were the least frequent of the three major types of FonF source (only $20.7 \%$ of the total FFEs), but they made up $26.1 \%$ of the total number of moves, making the most complex average FFE of 2.48 moves per episode. These results suggest that the linguistic foci may have influenced the complexity of FonF. Vocabulary items usually took the teachers more efforts to deal with than pronunciation or morphosyntax items. This may stem from the fact that vocabulary is closely related with meaning and the learners' gaps in vocabulary may lead to miscommunication. When addressing this type of problems, the teachers and the learners needed to negotiate for the meaning to find out the reason for communication breakdown before errors in vocabulary items could be corrected. In these cases, the teachers usually had to produce several follow-up moves, which led to more complex FFEs.

The research results also show that the characteristics of FonF were not related to the class levels. It is possible that when the teachers addressed different characteristics of FonF, they did not take the class levels into account. Another possibility is that due to their different views on how the characteristics of FonF should be addressed, they behaved differently in their practices, which resulted in no significant difference across the class levels. 


\subsection{Summary}

To determine how much FonF took place in EFL classrooms in Vietnam, the data shows that on average, 1.22 FFEs occurred per each minute of teacher-student interaction, or 0.58 FFEs per each minute of class time. The rate suggests that in an EFL setting with qualified teachers and motivated learners, the amount of FonF is almost similar to that in other EFL or ESL settings. On examining the complexity of the FFEs, this study, it is found that there was a frequency of 2.5 teacher feedback moves per minutes and the average complexity of each FFE was 2.05 moves, suggesting that the teachers in this study tended to produce multiple follow-up moves in each feedback turn to support their students' learning process. However, further analysis revealed that the occurrence of FonF varied significantly across the class groups, but not across proficiencies. The significant variation of FonF occurrence across the class groups may reflect the differences in the teachers' teaching and learning background as well as the courses taught in each class. As the teachers' FonF behaviour varied across the class groups, the data suggests that the teachers' approach to FonF was not influenced significantly by the proficiency level of the learners, but was more a case of teachers exercising their personal choice.

The research results show that FonF did occur in the EFL classroom in Vietnam at a similar rate with those of other studies in the area. This finding differs from research findings which assert that learning can hardly take place in EFL settings where learners are passive and unmotivated (e.g. Lewis \& McCook, 2002). Though the scope of this study is confined to privately-owned institutions, it reveals positive development in English teaching in Vietnam, which is confirmed in a recent study by Utsumi \& Doan (2009) that there is a shift in teaching and learning English in Vietnam from a traditional teacher-centred classes with little or no communicative activities to a more communicative-oriented learner-centred classes. The variation in the amount of FonF also suggests the need for further research into teacher-related factors, which in turn provides input for pedagogical developments and teacher training.

As for the characteristics of FonF, from this study, it can be seen that a great majority of teacher feedback moves were reformulate, though at a lower percentage than that of other research which investigated ESL or EFL settings with NS teachers. There was a wide range of teacher use of feedback types across the class groups, implying the teachers' different beliefs on the efficacy of each type of feedback and little training or 
guidance on FonF they received in the teacher training process. Across the proficiency levels, the teachers seemed to produce feedback in a similar way. However, the two teachers teaching the IELTS-preparation classes at the advanced level tended to use more provide than those at the other classes, implying the washback of the test on teaching.

Like many other studies in the field, it was found that when incidental FonF took place in the EFL setting, the teachers mainly drew the learners' attention to pronunciation, morphosyntax and vocabulary while little attention was paid to spelling. However, unlike the other studies, the most commonly focused linguistic forms in this study were morphosyntax and pronunciation. The special focus on morphosyntax can be explained by the fact that the teachers and the learners were used to a learning and assessment system at school or university where grammar played an essential part. The high frequency of pronunciation-focused episodes may partly be due to the recent trend toward learning English for communication in Vietnam, especially at private language institutions while the learners' background of learning English at school has not given them much speaking practice. This mismatch may result in pronunciation to become a high priority, especially at the beginning level.

The number of teacher feedback moves as well as the number of FFEs focusing on each type varied widely across the class groups according to the goals of the class and the class needs as perceived by the teachers. This may also reveal the teachers' uncertainties about what types and how much of each type of FonF they should deal with, which is one of the difficulties the teachers met at the level of practice when they tried to maintain a communicative class (Pham, 2007). In addition, the data shows that younger teachers tended to focus more on pronunciation and less on grammar than the older ones, reflecting the influence of the very recent method of CLT in Vietnam on the teachers and their teaching practice. This point finds support from a report by Utsumi and Doan (2009) on the shift from traditional teacher-centred method to a more communicative learner-centred one in the EFL classrooms in Vietnam.

There was no significant difference in the characteristics of FonF between the two proficiency levels. This result may reflect differences in the teachers' beliefs about how to address different types of FonF, source of FonF and linguistic foci of FonF across the proficiency levels. This result also suggests further research which explores teachers' 
reflections about and insights into their practices from that a more concrete answer could be drawn. 


\section{Chapter 7: Teacher use of $\mathrm{L1}$ and $\mathrm{TL}$ in FonF and learner uptake}

This chapter presents the findings about the teacher use of L1 and the TL in FonF and learner uptake. The first section reports the results on teacher use of the TL and L1 in FonF according to the frequency of teacher feedback moves. The second section describes the occurrence of learner uptake and its relation to the teacher use of L1 and the TL in FonF.

\subsection{Teacher use of $L 1$ and the TL in FonF}

The main results are reported in Section 7.1.1, followed by three sections presenting the amount of teacher use of L1 and the TL across the types of feedback, the source of FonF and the linguistic foci. Factors such as the class groups, proficiency levels, teacher feedback types and FonF source which may have influenced this practice are also examined and discussed.

\subsubsection{The amount of feedback in $L 1$ and the $T L$}

Table 7.1 shows the number of feedback moves made by the teachers in L1 and the TL across the six classes and the two proficiencies. Twelve 90-minute observations is recorded and 40 net minutes (that is, teacher-learner interaction time only) were extracted from each observation for analysis. 
Table 0.1: Teacher feedback moves in $\mathrm{L1}$ and the TL across class groups and proficiencies

\begin{tabular}{cccccc}
\hline $\begin{array}{c}\text { Teacher (Class) } \\
\text { LEVEL }\end{array}$ & \multicolumn{2}{c}{ FonF moves in L1 } & \multicolumn{2}{c}{ FonF moves in TL } & Total \\
Thuy (B1) & 115 & 41.5 & 162 & 58.5 & 277 \\
\hline Hong (B2) & 19 & 10.7 & 159 & 89.3 & 178 \\
\hline Huong (B3) & 4 & 2.4 & 161 & 97.6 & 165 \\
\hline BEGINNING LEVEL & $\mathbf{1 3 8}$ & $\mathbf{2 2 . 3}$ & $\mathbf{4 8 2}$ & $\mathbf{7 7 . 7}$ & $\mathbf{6 2 0}$ \\
\hline Thien (A1) & 32 & 9.8 & 293 & 90.2 & 325 \\
\hline Nguyen (A2) & 44 & 27.0 & 119 & 73.0 & 163 \\
\hline Phuong (A3) & 4 & 4.4 & 86 & 95.6 & 90 \\
\hline ADVANCED LEVEL & $\mathbf{8 0}$ & $\mathbf{1 3 . 8}$ & $\mathbf{4 9 8}$ & $\mathbf{8 6 . 2}$ & $\mathbf{5 7 8}$ \\
\hline Total & $\mathbf{2 1 8}$ & $\mathbf{1 8 . 2}$ & $\mathbf{9 8 0}$ & $\mathbf{8 1 . 8}$ & $\mathbf{1 , 1 9 8}$ \\
\hline
\end{tabular}

Graph 0.1: FonF moves in $\mathrm{L} 1$ and the $\mathrm{TL}$ across classes

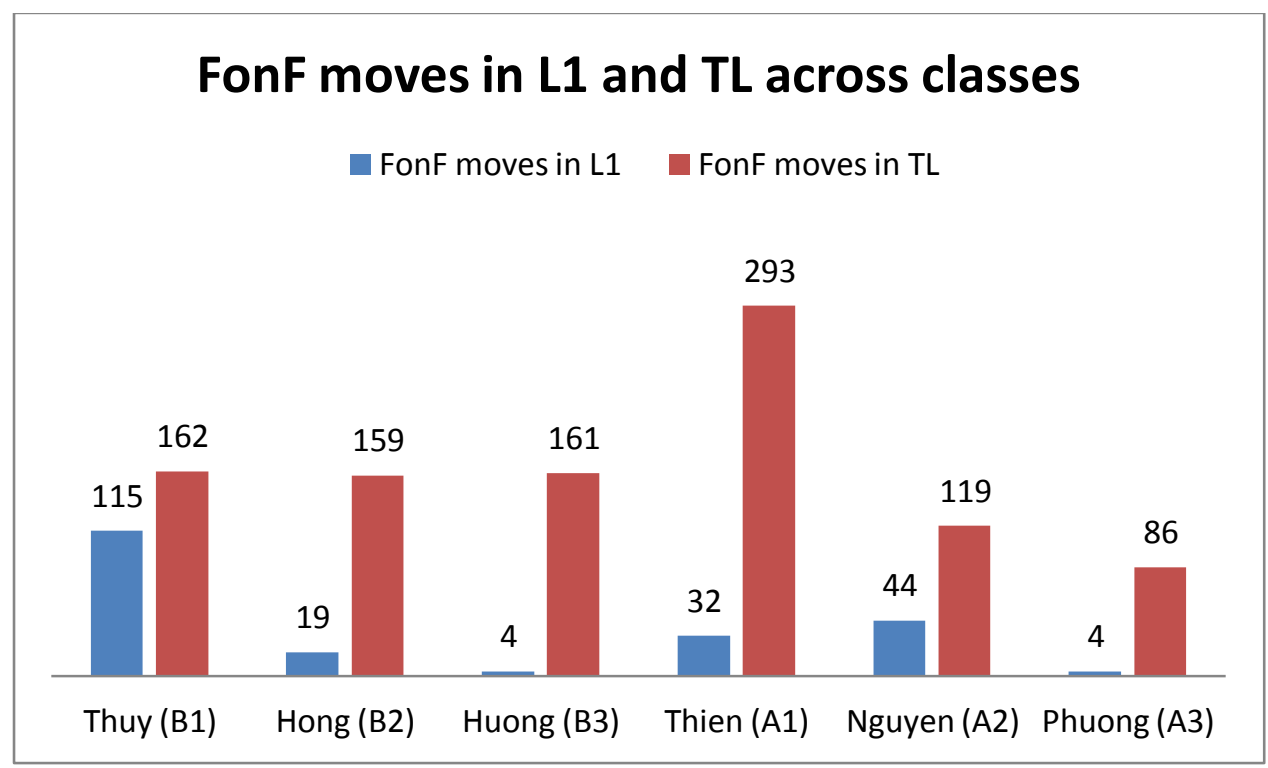

The table shows that on average, 138 teacher feedback moves (18.2\%) were given in L1. It can also be seen from the table that the teacher use of L1 in giving feedback took place in all the class groups at widely varying degrees from 4 moves $(2.4 \%)$ in Class B3 
to 115 moves (41.5\%) in Class B1. Similarly, the rate of teacher use of the TL in giving feedback ranged from $58.5 \%$ to $97.6 \%$, making an average of $81.8 \%$. The chi-square analysis of the frequencies of teacher feedback moves in L1 and the TL $\left(\chi^{2}(d f=5\right.$, $n=1,198)=170.7, p<0.001)$ indicates a statistically significant difference across the class groups.

A 2 (proficiency level) x 2 (FonF language) full-factorial ANOVA (see Table 7.1) was performed to explore the interaction between the learners' proficiency levels and the teacher use of L1 and the TL in their feedback moves. The descriptive statistics for the groups were: $\mathrm{L} 1, \overline{\mathrm{X}}=36.3$, sd=41.6, $\mathrm{n}=6$; and $\mathrm{TL}, \overline{\mathrm{X}}=163.3$, $\mathrm{sd}=70.4, \mathrm{n}=6$. The result shows that the interaction was not statistically significant $(\mathrm{F}(1,8)=.111, p=.747)$.

As the difference between the groups was found significant, ASRs were calculated to partition the difference. Table 7.2 presents the result of the calculation.

Table 0.2: ASRs of teacher use of $\mathrm{L} 1$ and the TL in feedback moves across class groups

\begin{tabular}{ccc}
\hline Teacher (Class) & Feedback moves in L1 & Feedback moves in TL \\
\hline Thuy (B1) & $11.5^{*}$ & $-11.5^{*}$ \\
\hline Hong (B2) & $-2.8^{*}$ & $2.8^{*}$ \\
\hline Huong (B3) & $-5.7^{*}$ & $5.7^{*}$ \\
\hline Thien (A1) & $-4.6^{*}$ & $4.6^{*}$ \\
\hline Nguyen (A2) & $3.1^{*}$ & $-3.1^{*}$ \\
\hline Phuong (A3) & $-3.5^{*}$ & $3.5^{*}$ \\
\hline
\end{tabular}

\section{* Adjusted standardized residual of 2.6 or greater}

The ASR analysis reveals that statistically significant differences exist in every of the six class groups. While Nguyen and Thuy tended to use significantly more L1 to give feedback, the other teachers used significantly more TL in their feedback moves. 


\subsubsection{The use of $L 1$ and the TL across the types of teacher feedback}

The following table shows how L1 and the TL were used across the types of teacher feedback moves in the six class groups and two proficiency levels. 
Table 0.3: Teacher use of $L 1$ and the TL across types of teacher feedback

\begin{tabular}{|c|c|c|c|c|c|c|c|c|c|c|c|c|}
\hline \multirow{3}{*}{$\begin{array}{l}\text { Class group (Teacher) } \\
\text { LEVEL }\end{array}$} & \multicolumn{4}{|c|}{ Provide } & \multicolumn{4}{|c|}{ Elicit } & \multicolumn{4}{|c|}{ Reformulate } \\
\hline & \multicolumn{2}{|l|}{$\mathrm{L} 1$} & \multicolumn{2}{|l|}{$\mathrm{TL}$} & & \multicolumn{2}{|l|}{$\mathrm{TL}$} & & \multicolumn{2}{|l|}{$\mathrm{TL}$} \\
\hline & $\mathrm{n}$ & $\%$ & $\mathrm{n}$ & $\%$ & $\mathrm{n}$ & $\%$ & $\mathrm{n}$ & $\%$ & $\mathrm{n}$ & $\%$ & $\mathrm{n}$ & $\%$ \\
\hline Thuy (B1) & 58 & 86.6 & 9 & 13.4 & 55 & 48.7 & 58 & 51.3 & 2 & 2.1 & 95 & 97.9 \\
\hline Hong (B2) & 15 & 37.5 & 25 & 62.5 & 3 & 9.1 & 30 & 90.1 & 1 & 1.0 & 104 & 99.0 \\
\hline Huong (B3) & 4 & 6.2 & 61 & 93.8 & 0 & 0.0 & 47 & 100.0 & 0 & 0.0 & 53 & 100.0 \\
\hline BEGINNING LEVEL & 77 & 44.8 & 95 & 55.2 & 58 & 30.1 & 135 & 69.9 & 3 & 1.2 & 252 & 98.8 \\
\hline Thien (A1) & 24 & 21.2 & 89 & 78.8 & 7 & 6.3 & 105 & 93.8 & 1 & 1.0 & 99 & 99.0 \\
\hline Nguyen (A2) & 39 & 53.4 & 34 & 46.6 & 3 & 27.3 & 8 & 72.7 & 2 & 2.5 & 77 & 97.5 \\
\hline Phuong (A3) & 2 & 14.3 & 12 & 85.7 & 2 & 10.0 & 18 & 90.0 & 0 & 0.0 & 56 & 100.0 \\
\hline ADVANCED LEVEL & 65 & 32.5 & 135 & 67.5 & 12 & 8.4 & 131 & 91.6 & 3 & 1.3 & 232 & 98.7 \\
\hline Total & 142 & 38.2 & 230 & 61.8 & 70 & 20.8 & 266 & 79.2 & 6 & 1.2 & 484 & 98.8 \\
\hline
\end{tabular}

*For totals in each category, see Table 6.5 . 
Graphs 7.2, 7.3 and 7.4 illustrate how the teachers use L1 and the TL when giving feedback in three different ways: provide, elicit and reformulate.

Graph 0.2: Teachers' use of $L 1$ and the TL in Provide

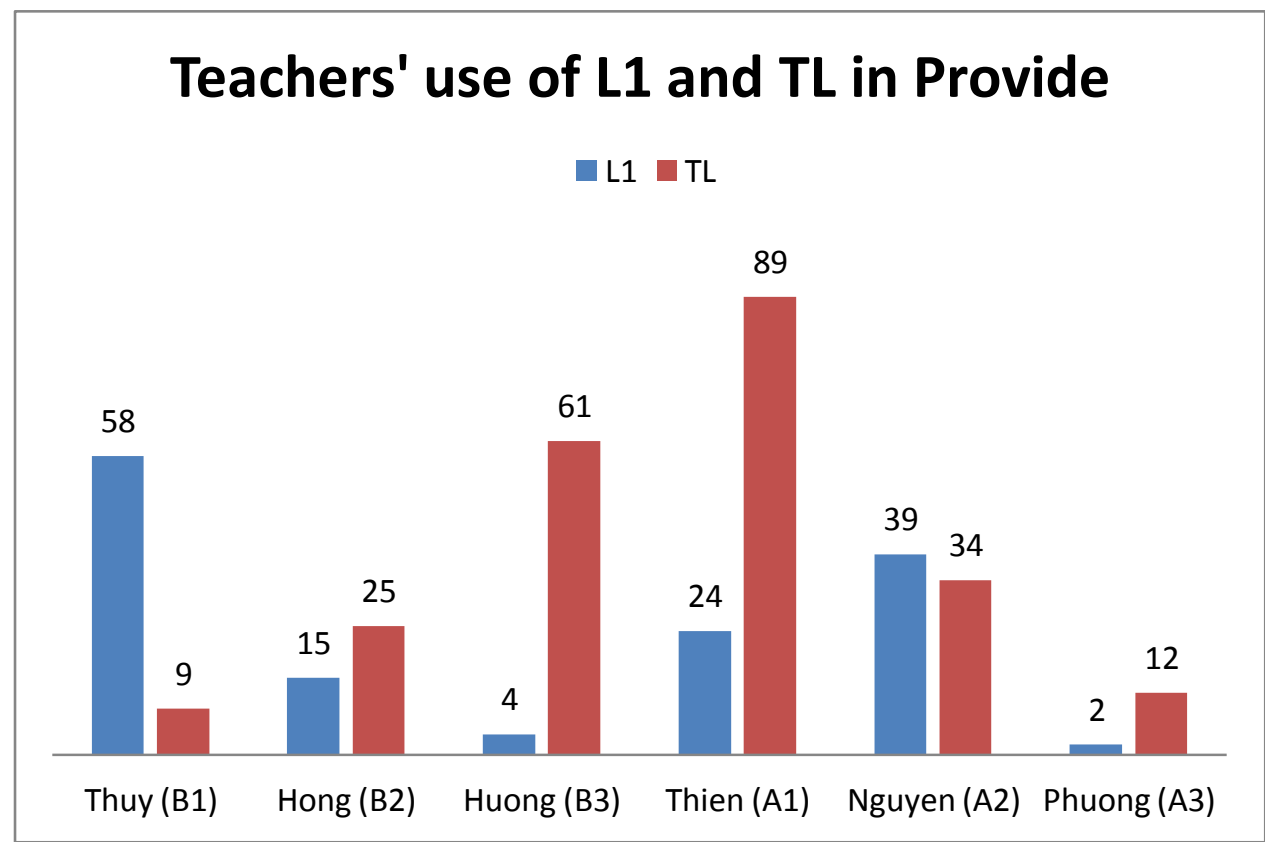

Graph 0.3: Teachers' use of $L 1$ and the TL in Elicit

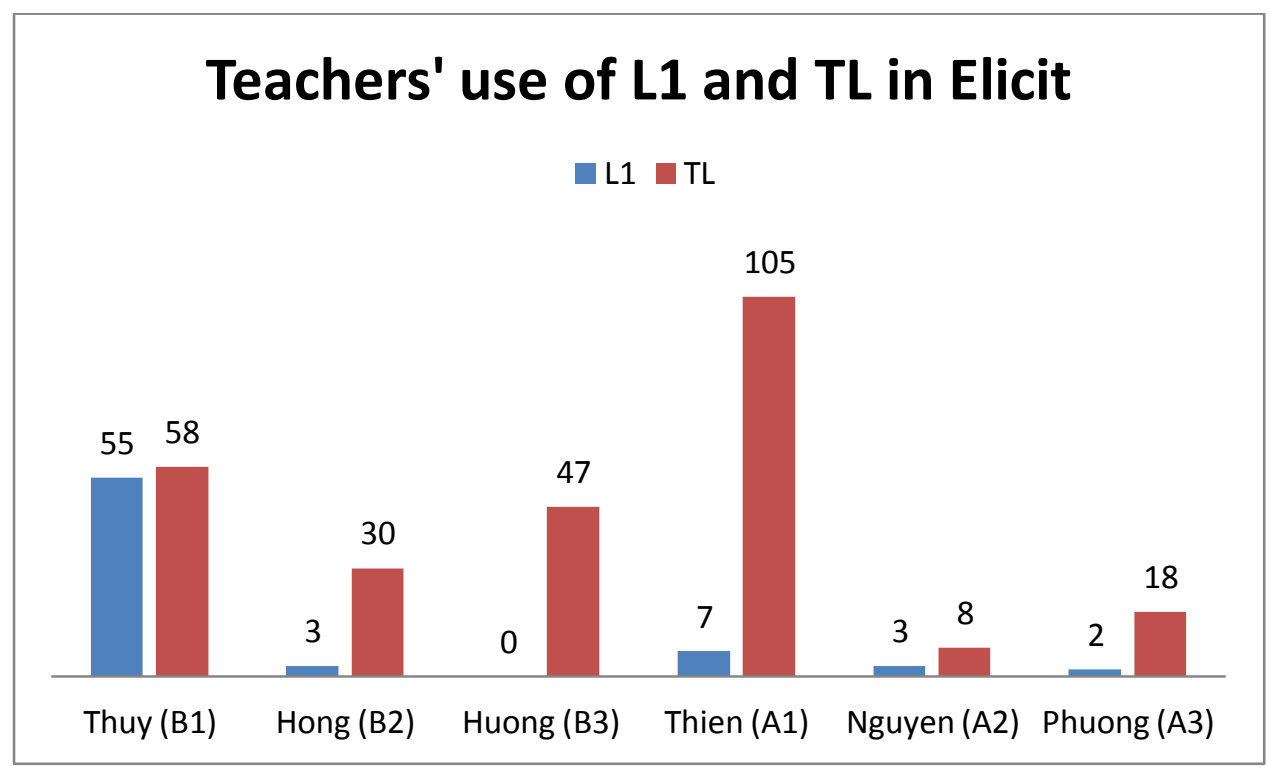


Graph 0.4: Teachers' use of $L 1$ and the TL in Reformulate

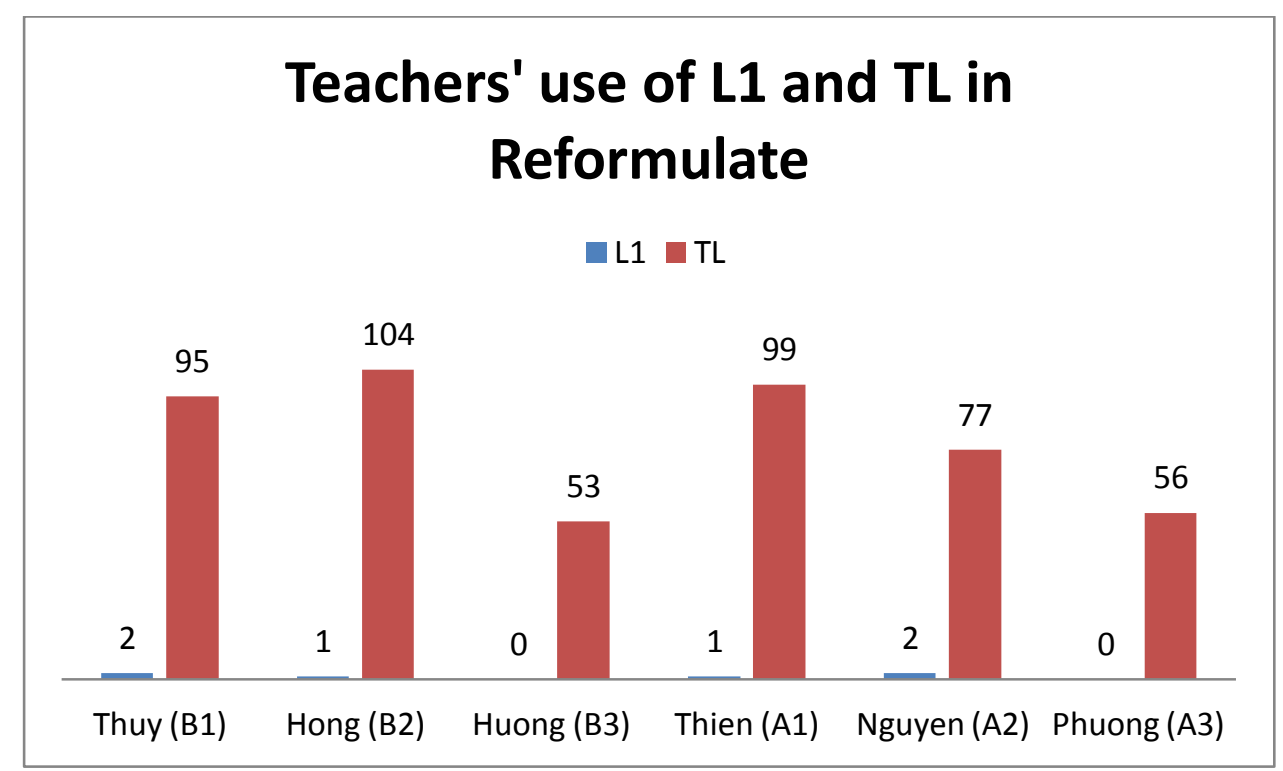

From Table 7.3 and Graphs 7.2, 7.3 and 7.4, it can be seen that while 38.2\% of provide moves were given in L1, only a marginal rate of $1.2 \%$ of reformulate moves were given in L1. The teachers used the TL for up to nearly $80 \%$ of the elicit moves. The chi-square analysis $\left(\chi^{2}(d f=2, n=1,198)=196.1, p<0.001\right)$ indicates that the difference in the use of L1 and the TL across the three types of teacher feedback is significant. ASRs are also computed to locate the main difference in Table 7.4.

Table 0.4: ASRs of the use of L1 and the TL across the teacher feedback types

\begin{tabular}{lccc}
\hline Feedback language & Provide & Elicit & Reformulate \\
\hline L1 (Vietnamese) & $12.0^{*}$ & 1.5 & $-12.7^{*}$ \\
\hline TL (English) & $-12.0^{*}$ & -1.5 & $12.7^{*}$ \\
\hline
\end{tabular}

* Adjusted standardized residual of 2.6 or greater

From Table 7.4, the ASRs reveal that when giving provide, the teachers tended to use significantly more L1 and less TL than when giving the other types of feedback. 
Meanwhile, when providing reformulate, the teachers used much more TL and less L1 than when providing the other types of feedback.

From Table 7.3 and Graph 7.2, it can be seen that the rate of L1 use in the provide category ranged from $6.2 \%$ by Huong of Class B3 to $86.6 \%$ by Thuy of Class B1. Similarly, within the elicit type, the percentage of L1 use varied from $0 \%$ in Class B3 to $48.7 \%$ in Class B1. The rate of L1 use was smallest in the reformulate category, ranging from $0 \%$ in Class B3 and Class A3 to a maximum of $2.5 \%$ in Class A2. To examine the variation in the teacher use of L1 and the TL across different types of teacher feedback, chi-square tests were performed. However, the reformulate category was excluded to avoid violating the low-cell-count principle (Moore \& McCabe, 2003) due to a small number of feedback moves of this type given in L1. The result for provide $\left(\chi^{2}(d f=5\right.$, $n=372)=119.039, p<0.001$ ) shows a significant difference in the use of L1 and the TL across the six teachers. A similar result $\left(\chi^{2}(d f=5, n=336)=84.369, p<0.001\right)$ was also found in the category of elicit.

To partition the difference in the teacher use of L1 and the TL across the class groups within these two types of feedback, ASRs were computed. The results are presented in Table 7.5 below.

Table 0.5: ASRs of teacher use of L1 and the TL in different types of teacher feedback across class groups

\begin{tabular}{ccccc}
\hline $\begin{array}{c}\text { Class group } \\
\text { (Teacher) } \\
\text { LEVEL }\end{array}$ & L1 & TL & L1 & TL \\
\hline Thuy (B1) & $9.0^{*}$ & $-9.0^{*}$ & $8.9^{*}$ & $-8.9^{*}$ \\
\hline Hong (B2) & -.1 & .1 & -1.7 & 1.7 \\
\hline Huong (B3) & $-5.8^{*}$ & $5.8^{*}$ & $-3.8^{*}$ & $3.8^{*}$ \\
\hline Thien (A1) & $-4.4^{*}$ & $4.4^{*}$ & $-4.7^{*}$ & $4.7^{*}$ \\
\hline Nguyen (A2) & $3.0^{*}$ & $-3.0^{*}$ & .5 & -.5 \\
\hline Phuong (A3) & -1.9 & 1.9 & -1.2 & 1.2 \\
\hline
\end{tabular}

* Adjusted standardized residual of 2.6 or greater 
Table 7.5 reveals that for the provide category, while Thuy and Nguyen used significantly more L1, Huong and Thien used significantly more TL to give feedback than the other teachers. In the category of elicit, while Thuy used significantly more L1 providing feedback than the other teachers, the opposite was true for Huong and Thien.

A 2 (proficiency level) x 2 (FonF language) full-factorial ANOVA exploring the interaction between the learners' proficiency level and the teacher use of L1 and the TL in the category of provide. The descriptive statistics for the groups were: $\mathrm{L} 1, \overline{\mathrm{X}}=23.7$, $\mathrm{sd}=21.7, \mathrm{n}=6$; and $\mathrm{TL}, \overline{\mathrm{X}}=38.3, \mathrm{sd}=31.1, \mathrm{n}=6$. The results showed that the interaction was not statistically significant $(\mathrm{F}(1,8)=.262, p=.623)$. A similar ANOVA performed to examine this interaction in the elicit category also found no significant result $(\mathrm{F}(1,8)$ $=.147, p=.712$ ). The descriptive statistics for the groups were: $\mathrm{L} 1, \overline{\mathrm{X}}=11.7, \mathrm{sd}=21.4$, $\mathrm{n}=6$; and $\mathrm{TL}, \overline{\mathrm{X}}=44.3, \mathrm{sd}=34.9, \mathrm{n}=6$.

\subsubsection{The use of $L 1$ and the TL across the source of FonF}

In the following table and graphs, the teacher feedback moves are categorized in accordance with the FonF source (NoM or NoF) and the feedback language (L1 or the TL). 
Table 0.6: Teacher use of L1 and the TL across types of teacher feedback

\begin{tabular}{|c|c|c|c|c|c|c|c|c|}
\hline \multirow{3}{*}{$\begin{array}{l}\text { Class group } \\
\text { (Teacher) } \\
\text { LEVEL }\end{array}$} & \multicolumn{4}{|c|}{ NoM } & \multicolumn{4}{|c|}{ NoF } \\
\hline & \multicolumn{2}{|c|}{$\mathbf{L 1}$} & \multicolumn{2}{|r|}{$\overline{T L}$} & \multicolumn{2}{|c|}{$\overline{\text { L1 }}$} & \multicolumn{2}{|c|}{ TL } \\
\hline & $\mathbf{n}$ & $\%$ & $\mathbf{n}$ & $\%$ & $\mathbf{n}$ & $\%$ & $\mathbf{n}$ & $\%$ \\
\hline Thuy (B1) & 8 & 80.0 & 2 & 20.0 & 107 & 40.1 & 160 & 59.9 \\
\hline Hong (B2) & 8 & 25.0 & 24 & 75.0 & 11 & 7.5 & 135 & 92.5 \\
\hline Huong (B3) & 0 & 0.0 & 12 & 100.0 & 4 & 2.6 & 149 & 97.4 \\
\hline $\begin{array}{l}\text { BEGINNING } \\
\text { LEVEL }\end{array}$ & 16 & 29.6 & 38 & 70.4 & 122 & 21.6 & 444 & 78.4 \\
\hline Thien (A1) & 9 & 20.5 & 35 & 79.5 & 23 & 8.2 & 258 & 91.8 \\
\hline Nguyen (A2) & 3 & 50.0 & 3 & 50.0 & 41 & 26.1 & 116 & 73.9 \\
\hline Phuong (A3) & 0 & 0.0 & 1 & 100.0 & 4 & 4.5 & 85 & 95.5 \\
\hline $\begin{array}{l}\text { ADVANCED } \\
\text { LEVEL }\end{array}$ & 12 & 23.5 & 39 & 76.5 & 68 & 12.9 & 459 & 87.1 \\
\hline Total & 28 & 26.7 & 77 & 73.3 & 190 & 17.4 & 903 & 82.6 \\
\hline
\end{tabular}

* For totals in each category, see Table 6.8.

Graph 0.5: Teacher use of L1 and the TL in NoM

\section{Teachers' use of L1 and TL in NoM}

L1 $\square \mathrm{TL}$

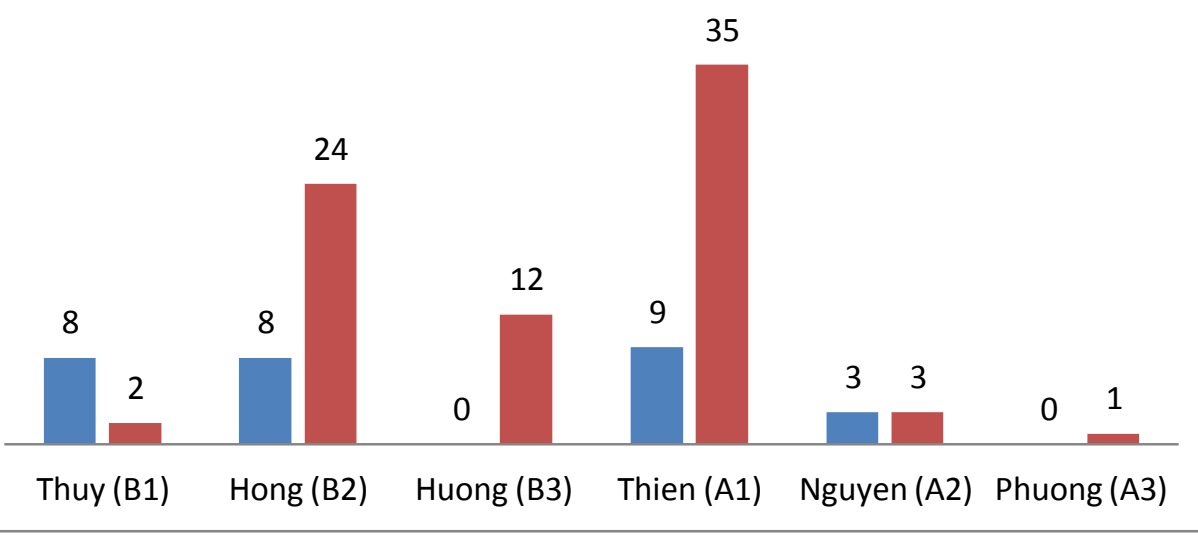




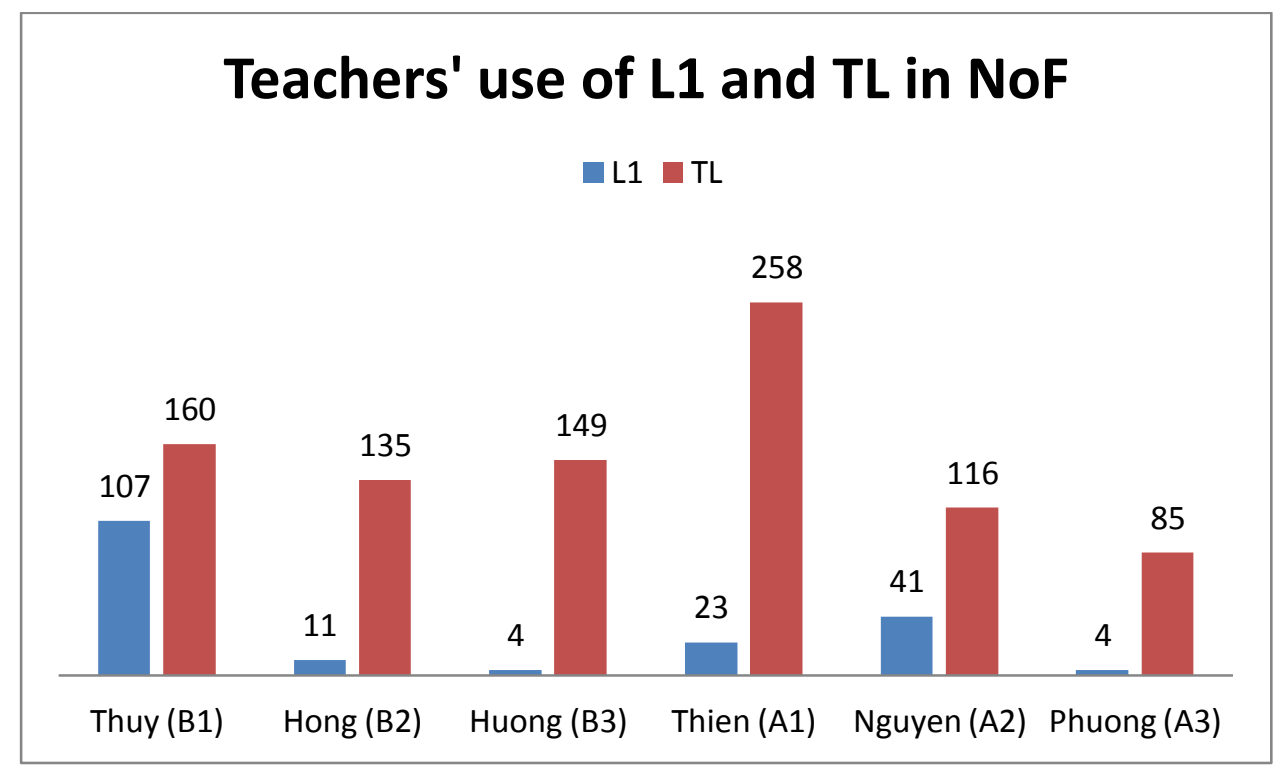

As can be seen from Table 7.6 and Graphs 7.5 and 7.6, 26.7\% of the feedback moves triggered by NoM were given in L1 while this rate was $17.4 \%$ in the TL. A chi-square test $\left(\chi^{2}(d f=1, n=1,198)=5.546, p=0.019\right)$ reveals no significant difference in the use of L1 and the TL across the source of the feedback moves. Chi-square analysis was carried out within each type of FonF source to find out whether the use of L1 and the TL was different across the teachers. However, due to the fact that over $20 \%$ of the expected cell counts was lower than 5, a chi-square test could not be used for the NoM category (Moore \& McCabe, 2003; Siegel \& Castellan, 1988). Within the category of NoF, the chi-square test result $\left(\chi^{2}(d f=5, n=1,093)=164.011, p<0.000\right)$ shows that the teacher use of L1 and the TL varied significantly across the class groups when they gave feedback on the learners' linguistic problems triggered by NoF. ASR analysis was calculated accordingly to partition the difference. Table 7.7 presents the ASRs of the teacher use of L1 and the TL in NoF-triggered feedback across the six class groups. 
Table 0.7: ASRs of the teacher use of $\mathrm{L1}$ and the TL in NoF-triggered feedback across classes

\begin{tabular}{ccc}
\hline Class (Teacher) & L1 (Vietnamese) & TL (English) \\
\hline Thuy (B1) & $11.3^{*}$ & $-11.3^{*}$ \\
\hline Hong (B2) & $-3.4^{*}$ & $3.4^{*}$ \\
\hline Huong (B3) & $-5.2^{*}$ & $5.2^{*}$ \\
\hline Thien (A1) & $-4.7^{*}$ & $4.7^{*}$ \\
\hline Nguyen (A2) & $3.1^{*}$ & $-3.1^{*}$ \\
\hline Phuong (A3) & $-3.3^{*}$ & $3.3^{*}$ \\
\hline
\end{tabular}

* Adjusted standardized residual of 2.6 or greater

The ASR analysis as shown in Table 7.7 reveals that the variation was significant across all the teachers. While Thuy and Nguyen used significantly more L1 to address the learners problems triggered by NoF than the other teachers, who did the opposite.

To examine the difference in the teacher use of L1 and the TL when dealing with different FonF source across the learners proficiencies, a 2 (proficiency level) x 2 (FonF language) full-factorial ANOVA was conducted in each of the two types of FonF source. In the category of NoM, the descriptive statistics for the groups were: $\mathrm{L} 1, \overline{\mathrm{X}}=4.7$, $\mathrm{sd}=4.2, \mathrm{n}=6$; and $\mathrm{TL}, \overline{\mathrm{X}}=12.8, \mathrm{sd}=13.9, \mathrm{n}=6$. The result $(\mathrm{F}(1,8)=.016, p=.903)$ shows no interaction between the learner proficiency and the teacher use of L1 and the TL. A similar result $(\mathrm{F}(1,8)=.129, p=.729)$ is also reported in the NoF category, which means that the learners' proficiencies did not influence the teacher use of L1 and the TL in giving feedback triggered by NoF. The descriptive statistics for the groups were: L1, $\bar{X}=31.7, \mathrm{sd}=39.5, \mathrm{n}=6$; and $\mathrm{TL}, \overline{\mathrm{X}}=150.5, \mathrm{sd}=58.9, \mathrm{n}=6$. 


\subsubsection{The use of $L 1$ and the $T L$ across the linguistic foci}

The teachers' choice of L1 and the TL when addressing the learners' linguistic problems with different linguistic foci is presented and discussed in this section.

Table 7.8 and Graphs 7.7, 7.8, 7.9 and 7.10 present the pattern of the teacher use of L1 and the TL in their feedback moves with different linguistic foci in the six class groups and two proficiency levels.

Graph 0.7: Teacher use of L1 and the TL in spelling-focused moves

\section{Teachers' use of L1 and TL in spelling- focused moves}

$\square \mathrm{L} 1 \mathrm{TL}$

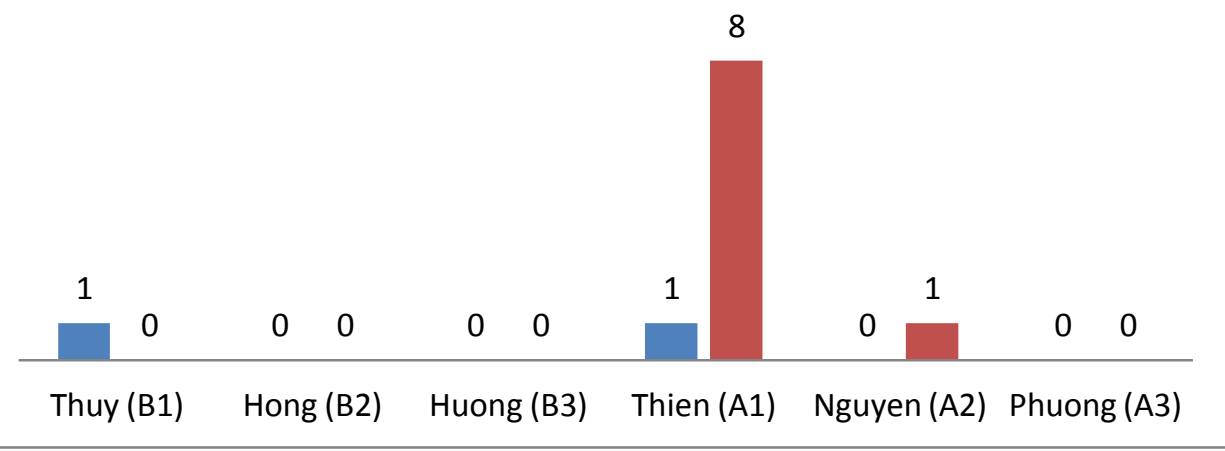

Graph 0.8: Teacher use of $L 1$ and the TL in pronunciation-focused moves

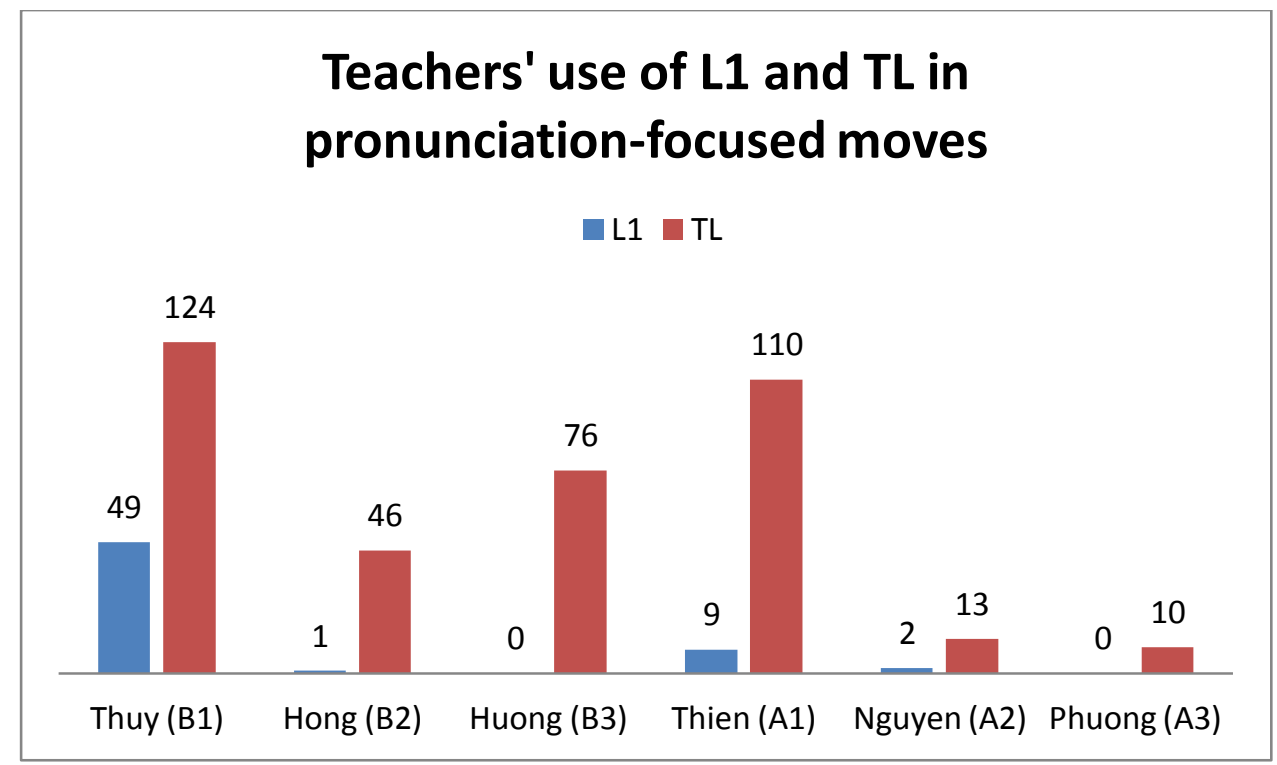


Table 0.8: Teacher use of $\mathrm{L} 1$ and the TL across linguistic foci of feedback moves across class groups and proficiencies

\begin{tabular}{|c|c|c|c|c|c|c|c|c|c|c|c|c|c|c|c|c|}
\hline \multirow{4}{*}{$\begin{array}{l}\text { Class group } \\
\text { (Teacher) } \\
\text { LEVEL }\end{array}$} & \multicolumn{4}{|c|}{ Spelling } & \multicolumn{4}{|c|}{ Pronunciation } & \multicolumn{4}{|c|}{ Morphosyntax } & \multicolumn{4}{|c|}{ Vocabulary } \\
\hline & \multicolumn{2}{|c|}{ L1 } & \multicolumn{2}{|c|}{$\mathrm{TL}$} & \multicolumn{2}{|c|}{ L1 } & \multicolumn{2}{|c|}{$\mathrm{TL}$} & \multicolumn{2}{|c|}{ L1 } & \multicolumn{2}{|c|}{$\mathrm{TL}$} & \multicolumn{2}{|c|}{ L1 } & \multicolumn{2}{|c|}{$\mathrm{TL}$} \\
\hline & $\mathrm{n}$ & $\%$ & $\mathrm{n}$ & $\%$ & $\mathrm{n}$ & $\%$ & $\mathrm{n}$ & $\%$ & $\mathrm{n}$ & $\%$ & $\mathrm{n}$ & $\%$ & & & & \\
\hline & & & & & & & & & & & & & $\mathrm{n}$ & $\%$ & $\mathrm{n}$ & $\%$ \\
\hline Thuy (B1) & 1 & 100.0 & 0 & 0.0 & 49 & 28.3 & 124 & 71.7 & 37 & 56.9 & 28 & 43.1 & 28 & 73.7 & 10 & 26.3 \\
\hline Hong (B2) & 0 & $\mathrm{n} / \mathrm{a}$ & 0 & $\mathrm{n} / \mathrm{a}$ & 1 & 2.1 & 46 & 97.9 & 2 & 3.2 & 61 & 96.8 & 16 & 23.5 & 52 & 76.5 \\
\hline Huong (B3) & 0 & $\mathrm{n} / \mathrm{a}$ & 0 & $\mathrm{n} / \mathrm{a}$ & 0 & 0.0 & 76 & 100.0 & 0 & 0.0 & 36 & 100.0 & 4 & 7.5 & 49 & 92.5 \\
\hline $\begin{array}{l}\text { BEGINNING } \\
\text { LEVEL }\end{array}$ & 1 & 100.0 & $\mathbf{0}$ & 0.0 & 50 & 16.9 & 246 & 83.1 & 39 & 23.8 & 125 & 76.2 & 48 & 30.2 & 111 & 69.8 \\
\hline Thien (A1) & 1 & 11.1 & 8 & 88.9 & 9 & 7.6 & 110 & 92.4 & 4 & 3.4 & 115 & 96.6 & 18 & 23.1 & 60 & 76.9 \\
\hline Nguyen (A2) & 0 & 0.0 & 1 & 100.0 & 2 & 13.3 & 13 & 86.7 & 25 & 23.8 & 80 & 76.2 & 17 & 40.5 & 25 & 59.5 \\
\hline Phuong (A3) & 0 & $\mathrm{n} / \mathrm{a}$ & 0 & $\mathrm{n} / \mathrm{a}$ & 0 & 0.0 & 10 & 100.0 & 0 & 0.0 & 46 & 100.0 & 4 & 11.8 & 30 & 88.2 \\
\hline $\begin{array}{l}\text { ADVANCED } \\
\text { LEVEL }\end{array}$ & 1 & 10.0 & 9 & 90.0 & 11 & 7.6 & 133 & 92.4 & 29 & 10.7 & 241 & 89.3 & 39 & 25.3 & 115 & 74.7 \\
\hline Total & 2 & 18.2 & 9 & 81.8 & 61 & 13.9 & 379 & 86.1 & 68 & 15.7 & 366 & 84.3 & 87 & 27.8 & 226 & 72.2 \\
\hline
\end{tabular}

*For totals in each category, see Table 6.11 . 


\section{Teachers' use of L1 and TL in morphosyntax-focused moves}

$\square \mathrm{L} 1 \mathrm{TL}$

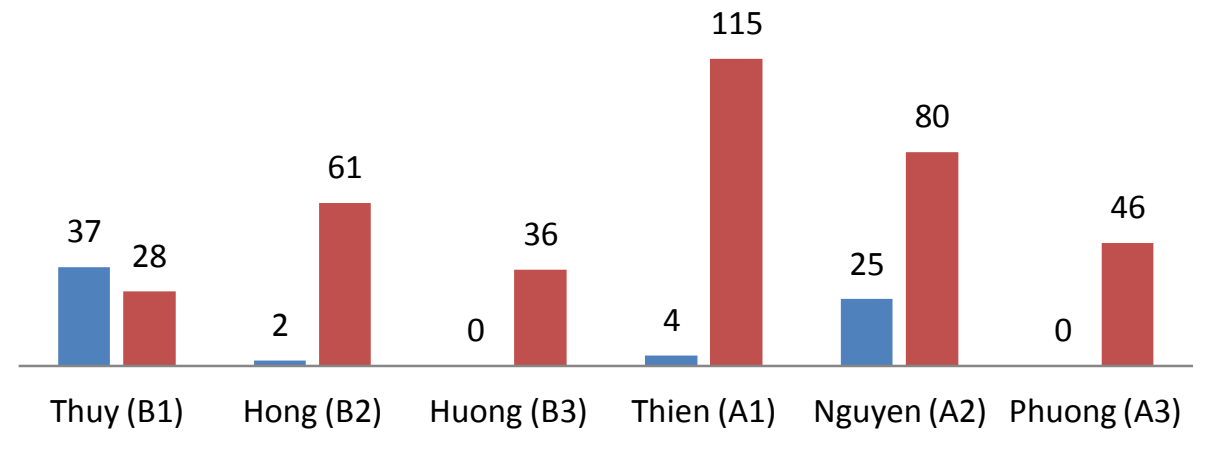

Graph 0.10: Teacher use of $\mathrm{L} 1$ and the TL in vocabulary-focused moves

\section{Teachers' use of L1 and TL in vocabulary- focused moves}

$\square \mathrm{L} 1 \mathrm{TL}$

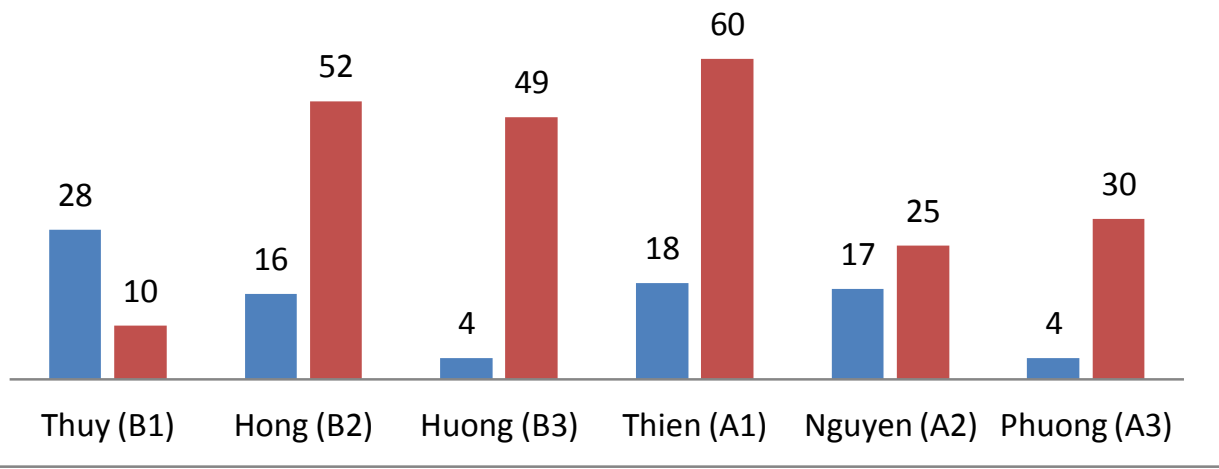

From Table 7.8 and Graphs 7.7, 7.8, 7.9 and 7.10, it can be seen that spelling-focused moves accounted for too small a percentage $(0.9 \%$ of the total moves) to be taken in consideration. As for the other categories, on average, the teachers used L1 the most in vocabulary-focused feedback moves (27.8\%). Morphosyntactic moves were the second most often given in L1 (15.7\%), followed by pronunciation-focused moves at nearly $14 \%$. To examine whether there was any significant variation in the teacher use of L1 and the TL across the linguistic foci of the feedback moves, a chi-square test was 
performed. The category of spelling was excluded to comply with the low-cell-count rule (Moore \& McCabe, 2003). The result $\left(\chi^{2}(d f=2, n=1,187)=27.787, p<0.001\right)$ reveals a significant difference in the teacher use of L1 and the TL across the linguistic foci of their feedback moves.

As a further step taken according to the procedure of statistic analysis of this study to partition the existing difference, ASRs were computed. Table 7.9 presents the results of the ASR analysis of the use of L1 and the TL across the linguistic foci of the feedback moves.

Table 0.9: ASRs of the use of L1 and the TL across the FonF source

\begin{tabular}{cccc}
\hline FonF source & Pronunciation & Morphosyntax & Vocabulary \\
\hline L1 (Vietnamese) & $-3.0^{*}$ & -1.7 & $5.1^{*}$ \\
\hline TL (English) & $3.0^{*}$ & 1.7 & $-5.1^{*}$ \\
\hline
\end{tabular}

* Adjusted standardized residual of 2.6 or greater

The ASRs indicate that the teachers tended to use significantly more L1 when the feedback moves focused on vocabulary and the opposite occurred with regard to pronunciation.

From Table 7.8 and Graphs 7.7, 7.8, 7.9 and 7.10, it can also be seen that the teacher use of L1 to give pronunciation-focused feedback ranged from $0 \%$ in Class B3 and Class A3 to $28.3 \%$ in Class B1. Similarly, for morphosyntax-focused feedback, the rate varied from $0 \%$ in Class B3 and A3 to $56.9 \%$ in Class B1. There was also a wide range of $7.5 \%-73.7 \%$ in the percentage of L1 use by the teachers to address the learners' vocabulary gaps. The chi-square test for the pronunciation category $\left(\chi^{2}(d f=5, n=440)\right.$ $=53.514, p<0.000$ ) shows a significant difference in the teacher use of L1 and the TL across the class groups. Similar results were also found in the morphosyntax category $\left(\chi^{2}(d f=5, n=434)=125.309, p<0.000\right)$ and the vocabulary category $\left(\chi^{2}(d f=5, n=313)\right.$ $=59.899, p<0.000$ ), revealing that the teacher use of L1 and the TL to give feedback in these linguistic foci was significantly different across the six class groups. Therefore, 
ASRs were computed to partition the difference. Table 7.10 presents the results of the ASR analysis.

Table 0.10: ASRs of language foci across the teacher use of L1 and the TL

\begin{tabular}{ccccccc}
\hline & \multicolumn{2}{c}{ Pronunciation } & \multicolumn{2}{c}{ Morphosyntax } & \multicolumn{2}{c}{ Vocabulary } \\
\cline { 2 - 7 } Teacher (Class) & L1 & TL & L1 & TL & L1 & TL \\
\hline Thuy (B1) & $7.1^{*}$ & $-7.1^{*}$ & $9.9^{*}$ & $-9.9^{*}$ & $6.7^{*}$ & $-6.7^{*}$ \\
\hline Hong (B2) & -2.5 & 2.5 & $-3.0^{*}$ & $3.0^{*}$ & -.9 & .9 \\
\hline Huong (B3) & $-3.8^{*}$ & $3.8^{*}$ & $-2.7^{*}$ & $2.7^{*}$ & $-3.6^{*}$ & $3.6^{*}$ \\
\hline Thien (A1) & -2.3 & 2.3 & $-4.3^{*}$ & $4.3^{*}$ & -1.1 & 1.1 \\
\hline Nguyen (A2) & -.1 & .1 & $2.6^{*}$ & $-2.6^{*}$ & 2.0 & -2.0 \\
\hline Phuong (A3) & -1.3 & 1.3 & $-3.1^{*}$ & $3.1^{*}$ & -2.2 & 2.2 \\
\hline
\end{tabular}

* Adjusted standardized residual of 2.6 or greater

From Table 7.10, it can be seen that when drawing the learners' attention to pronunciation and vocabulary features, Thuy of Class B1 used significantly more L1, while Huong of Class B3 used significantly more TL than the other teachers. As for the learners' morphosyntactic gaps, Thuy and Nguyen tended to use significantly more L1 while the other teachers relied significantly more on the TL.

To explore the influence of the learners' proficiencies on the teacher use of L1 and the TL in accordance with each linguistic focus, a 2 (proficiency level) x 2 (FonF language) full-factorial ANOVA was conducted in each of the three linguistic foci. In the category of pronunciation, the descriptive statistics for the groups were: $\mathrm{L} 1, \overline{\mathrm{X}}=10.2$, sd=19.3, $\mathrm{n}=6$; and $\mathrm{TL}, \overline{\mathrm{X}}=63.2, \mathrm{sd}=48.4, \mathrm{n}=6$. The result $(\mathrm{F}(1,8)=.326, p=.583)$ shows no interaction between the learner proficiency and the teacher use of L1 and the TL. Similar statistical tests were also conducted for the categories of morphosyntax and vocabulary. The descriptive statistics for the groups in the morphosyntax category were: $\mathrm{L} 1, \overline{\mathrm{X}}=11.3, \mathrm{sd}=15.8, \mathrm{n}=6$; and $\mathrm{TL}, \overline{\mathrm{X}}=60.1, \mathrm{sd}=32.3, \mathrm{n}=6$, and these statistics for the 
vocabulary groups were: $\mathrm{L} 1, \overline{\mathrm{X}}=14.5, \mathrm{sd}=9.2, \mathrm{n}=6$; and $\mathrm{TL}, \overline{\mathrm{X}}=37.7, \mathrm{sd}=19.1, \mathrm{n}=6$. The ANOVA results found in the morphosyntax category $(\mathrm{F}(1,8)=2.520, p=.151)$ and the vocabulary category $(\mathrm{F}(1,8)=.051, p=.828)$ revealed that the class levels were not related to the teacher use of L1 and the TL in giving feedback on the learners' problems in these linguistic foci.

\subsubsection{Discussion: Factors influencing the use of $\mathrm{L} 1$ and the $\mathrm{TL}$ in FonF}

The following sections discuss the results in relation to a number of factors that appear to influence the teacher use of L1 and the TL in FonF. These include characteristics of FonF, teacher-related factors, and learner-related factors, the class factor.

\subsubsection{The FonF characteristics}

The features of the types of feedback can give possible explanations to the teachers' choice of language when addressing the learners' interlanguage gaps in different ways. Other studies on the use of L1 in ESL and EFL classrooms have pointed out that teachers typically used L1 to explain errors and new concepts (Gill, 2005; Piasecka, 1988; Turnbull \& Arnett, 2002). In this study, provide is the type of feedback which gives the learners explicit information in the forms of definitions, examples or explanations. As a result, provide moves tended to be lengthier and hence more timeconsuming. The teachers, therefore, had quite a few reasons to use L1 when giving provide. First, the use of L1 can be seen to help reduce the learners' efforts in processing the input, especially at the low proficiency level. Second, in the private language institutions, time constraint was of great concern for the teachers. The use of L1 could help them save time because explanations in the TL inevitably take longer (Cook, 2001). Another reason is that when the teachers give complicated explanations, the use of L1 has a 'humanistic value' (Atkinson, 1987) that allows them to say what they really want to say while the TL as a foreign language cannot satisfy them in fully expressing their ideas due to their limited proficiency in the TL.

In contrast, reformulate involves a recast of part or all of the learner's erroneous utterance, and so must be usually given in the TL. This explains a very high percentage of reformulate in the TL (98.8\%). The marginal $1.2 \%$ of reformulate in L1 consists of 
the translations of the preceding recasts in the TL, which the teachers usually did in order to ensure the learners' attention to their feedback.

When dealing with elicit moves, teachers tend to use some suprasegmental features like raising the intonation or stressing on the problematic words or structures, or cliché expressions like "what do you mean by saying...". These ways of eliciting learners' attention to their interlanguage gaps may be familiar for most advanced learners, but they may give some extra load to beginning learners' input process. The limited ability to perceive the teacher feedback of beginning learners has been observed in many studies (e.g. Mackey \& Philp, 1998; Philp, 2003), so the teacher use of L1 in this case can be understood as a way to ensure the attention to form of the beginning learners.

A second characteristic of FonF that appears to influence the use of L1 and the TL in FonF was the linguistic foci. As can be seen from the data in Table 7.8, while $27.8 \%$ of vocabulary-focused feedback was in L1, this rate was only $15.7 \%$ in morphosyntaxfocused and $13.9 \%$ in pronunciation-focused feedback. The frequent use of L1 to deal with lexical items has been reported in many studies on the use of L1 in EFL classroom (e.g. Forman, 2007; Gill, 2005; Polio \& Duff, 1994b). In the previous section, it has been observed that lexical FFEs were more complex than other FFEs. When the explanations of lexical items may become too complicated or time-consuming, a translation of the focused lexical item or an L1 explanation can be a preferable choice for many L1 teachers. The use of L1 in this case saves the learners' efforts to process the TL explanation, especially for beginning learners. It also saves the teachers' time and it helps them avoid TL explanations which may turn out to be more complicated than the targeted lexical item itself.

The frequent use of L1 by the teachers in pronunciation-focused moves is explainable from the nature of the linguistic focus. The feedback moves in this case usually aimed to provide the learners with models of pronouncing the focused sounds. Thus, not much explanation in L1 was required.

The result also shows the teachers' tendency to use L1 for NoM-focused moves. A possible explanation is that when there is miscommunication in a communicationoriented setting, the use of L1 can naturally serve as tool to get the meaning through so that the communication flow can continue. This pattern of L1 use in NoM has also been 
reported in some observational studies on the use of L1 in the ESL or EFL classrooms where L1 is often used to "convey meaning" (e.g. Cook, 2001; Nation, 1997).

\subsubsection{Teacher-related factors}

The results reveal a significant variation in the teacher use of L1 across the class groups. This wide variation is also reported in other studies. In a descriptive study to find out how much foreign language the teachers spoke in university foreign language classrooms by Polio \& Duff (1994a), they also found a wide variation of teacher use of the TL ranging from 100\% to 10\%. Also, Turnbull (2000) (cited in Crawford, 2004) reported a range of $24 \%$ to $72 \%$ of the TL use in his school-based study. Another school-based study by Liu, Ahn, Baek, \& Han (2004) in Korea gave an average rate of $32 \%$ of TL use. As interactional feedback is part of class talk, the result of this study partly reflects the general use of the TL in the EFL classroom with a wide range of $58.5 \%$ to $97.6 \%$ (see Table 7.1). This result suggests that the teachers in the present study used the TL for a major part of their feedback, and a few of them like Huong and Phuong hardly used L1 in giving feedback (2.4\% and 4.4\%, respectively) (see Table 7.1).

The possible reasons for the major use of the TL in FonF across the class groups can be traced back to the teaching and learning context of the two private language institutions where the present study took place. Setting up as "English for communication" institutions, they established their roles as attending to the learners' needs to communicate in English. The teachers were expected to facilitate the learners' use of English in the classroom and hence to use mainly English in their teaching. Their class sessions were regularly observed and evaluated by the academic administrators, and the teachers' use of L1 was usually discouraged. Moreover, the learners going to these institutions also expected to "practise their English"; that is, to speak English to their teachers and classmates. At the end of the course, they were asked to fill the evaluation forms on the course and their teachers, in which their opportunity to speak English was among the evaluating criteria.

Though the teachers' use of the TL occupied a major percentage of their language use, which may meet the expectations of the learners and the institutions, the variation in this practice was significant across the teachers. However, the fact that the teacher use of L1 and the TL in this study varied significantly across the six class groups is not 
surprising. There has been little research on the use of L1 and the TL in the EFL class taught by the L1 teachers, and therefore little in the way of evidence-based guidance on this. As Atkinson $(1987,1993)$ and E. M. Ellis (2007) note, teacher training materials, even those written for L1 teachers of EFL, rarely mention the role of L1 in ESL/EFL classrooms, or given guidance to teachers on this. This fact gives a possible explanation for the variation of the teachers' use of L1 and the TL.

Second, the variation in the L1 use appears to reflect differences in the teachers' age, training, qualifications and teaching experience in this study. The teachers' age ranged from 26 to 45, qualifications from bachelor's degree to doctoral degree and length of experience from under two years to over 20 years. The past 20 years have seen dramatic changes in teaching methods. During this time, the L1 Vietnamese teachers of English rarely received professional development opportunities to bring them up to date with recent teaching methods. In-service training and teacher development program in Vietnam are confined to learning toward a qualification at various institutions of varied curriculum and teaching quality (Larsen-Freeman, 1999; Le, 1999; Truong, 2004; Utsumi \& Doan, 2009). The teachers joining this study also went to different universities for their further education. Those who obtained the degrees from international universities like Phuong and Thien were more likely to prefer TL use in the classroom for all activities. Meanwhile, those who used more L1 like Thuy or Nguyen tended to imitate the language use they observed from the training obtained domestically. Also, as K. Schmidt (1995) argues, teachers using a lot of L1 in the class may lack confidence about their English ability or their learners' listening ability. This may be the case for Thuy who had the least experience in teaching English. As mentioned in the previous section, she was also the teacher whose FFEs were most complex, largely because she was using them to check the learners' comprehension of her English. Huong was also a special case: she used much more TL than the other teachers despite the low proficiency level of her class. This may be partly due her need to confide herself by using plenty of the TL (Medgyes, 1992). This fact may lead to significantly more Vietnamese responses to her feedback from the students, which will be discussed in the coming section on uptake. 


\subsubsection{Proficiency level}

One of the learner factors claimed to influence the teacher use of L1 and the TL is learners' proficiency levels (Crawford, 2004; Forman, 2007; Wang \& Wen, 2002). In this study, however, this is not the case. The data analysis shows that the learners' proficiency levels had little influence on the teacher use of L1 and the TL in FonF. One possible reason for this is the teacher-related factors. Since the teachers' individual background within each proficiency level differed widely in age, experience, and education (see Table 4.2), their FonF behaviour including their use of L1 and the TL varied accordingly. This variation among the teachers was sufficiently large to blur any influence from the learner factor.

\subsubsection{Teachers' use of $L 1$ and the TL: Summary}

This part of the study investigated the teacher use of L1 and the TL in FonF. It reported on the frequencies of L1 versus TL use across the class groups and the proficiency levels, the use of L1 and the TL across the teacher feedback types, and the use of L1 and the TL across the types of FonF source.

There was a wide range across the class groups in the frequencies of L1 use versus TL use in giving feedback, but overall, the teachers showed a preference for the TL in FonF. The teachers' major use of the TL may result from the institutions' and the learners' expectations for the teachers to create an English-speaking environment in the classroom. However, the use of feedback language varied significantly across the class groups, which may reflect the lack of guidance in teacher training on the role of L1 in second language/foreign language classrooms and the teachers' different background and experience in EFL teaching.

A closer analysis of the use of L1 and the TL across feedback types show that the teachers tended to use significantly more L1 to give provide moves and more TL to give reformulate moves. This is not surprising since provide includes giving definitions and explanations which are typically more difficult to convey in the TL compared to L1. Similarly, as the nature of reformulate is to give the learners a model to repeat, it requires TL use. 
Across the types of FonF source and linguistic foci, the patterns of teacher use of feedback language were similar across the two proficiencies. The teachers tended to use L1 more in NoM FFEs than NoF FFEs. As for the linguistic foci, L1 was used most for vocabulary, then morphosyntax and finally least for pronunciation. The teachers used significantly more L1 for vocabulary- and NoM- focused moves since these types require a large amount of explanation and clarification. They also used significantly less L1 in pronunciation-focused moves as this type simply requires providing the learners with models of English pronunciation to repeat.

While other studies on the teacher use of L1 and the TL have so far made general descriptions of the use of L1 and the TL in class talk, this part of the study is the first one to give a detailed report on this practice with a focus on the characteristics of FonF. Since this study took place in intact classes, the result may reflect the status-quo of this practice, which in turn reveals the underpinning beliefs and attitudes of the teachers to this practice. The results suggest that the teachers in the EFL classes in Vietnam tended to resort to L1 when they addressed the learners' interlanguage gaps in vocabulary and morphosyntax, when the FFEs contained more than one move, and when the information in the FFEs were explicitly given. These results to some extent come in terms with findings from other studies in the area which assert that L1 use helps when teachers have to make long and complex explanations about new vocabulary and grammatical rules. Whether L1 helps with learning in these types of FFEs requires further exploration. In the following section of this chapter, the relationship between teacher use of L1 and the TL in FonF and learner uptake types is examined to address this question.

\subsection{Learner uptake in EFL classrooms}

Learner uptake in the data set of this study is categorized into repair, needs-repair, acknowledge, Vietnamese response, no opportunity and no uptake in accordance with each feedback move made by the teachers. The amount of uptake was recorded across the class groups and across the proficiency levels.

The following table and graph shows the amount of different types of uptake taking place in the classes in this study.

Table 0.11: Amount of uptake types 


\begin{tabular}{ccccccc}
\hline Repair & $\begin{array}{c}\text { Needs- } \\
\text { repair }\end{array}$ & Acknowledge & $\begin{array}{c}\text { Vietnamese } \\
\text { response }\end{array}$ & $\begin{array}{c}\text { No } \\
\text { uptake }\end{array}$ & $\begin{array}{c}\text { No } \\
\text { opportunity }\end{array}$ \\
\hline $\mathbf{n}$ & 259 & 140 & 59 & 60 & 305 & 375 \\
\hline$\%$ & 21.6 & 11.7 & 4.9 & 5.0 & 25.5 & 31.3 \\
\hline
\end{tabular}

\section{Graph 0.11: Amount of uptake types}

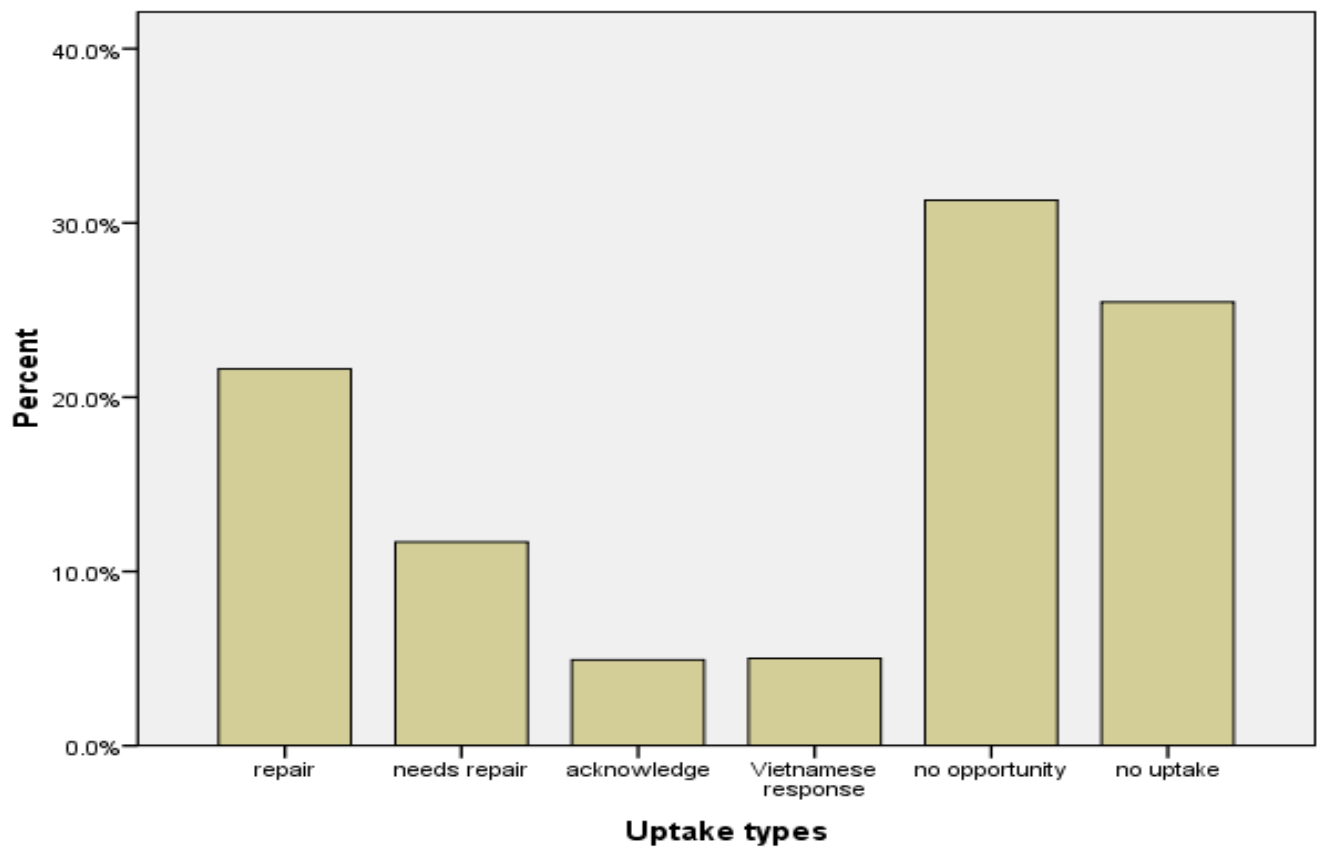

From Table 7.11 and Graph 7.11, it can be seen that $31.3 \%$ of the teacher feedback moves did not give the learners opportunities for uptake. The learners produced no uptake after $25.5 \%$ of the teacher feedback moves, even though uptake opportunities existed. Over $21 \%$ of the feedback moves led to the learners' repair. Needs-repair occupied nearly $12 \%$. Acknowledge and Vietnamese response made up almost the same rate of around $5 \%$.

\subsubsection{Learner uptake types across class groups}

Table 7.12 shows the amount of different responses of the learners to the teacher feedback across the six class groups. 
Table 0.12: Learner uptake across class groups

\begin{tabular}{|c|c|c|c|c|c|c|c|c|c|c|c|c|}
\hline \multirow{2}{*}{$\begin{array}{c}\text { Teacher (Class) } \\
\text { LEVEL }\end{array}$} & \multicolumn{2}{|c|}{ Repair } & \multicolumn{2}{|c|}{ Needs- repair } & \multicolumn{2}{|c|}{ Acknowledge } & \multicolumn{2}{|c|}{ Vietnamese response } & \multicolumn{2}{|c|}{ No opportunity } & \multicolumn{2}{|c|}{ No uptake } \\
\hline & $\mathbf{n}$ & $\%$ & $\mathbf{n}$ & $\%$ & $\mathbf{n}$ & $\%$ & $\mathbf{n}$ & $\%$ & $\mathbf{n}$ & $\%$ & $\mathbf{n}$ & $\%$ \\
\hline Thuy (B1) & 57 & 20.6 & 70 & 25.3 & 0 & 0.0 & 13 & 4.7 & 42 & 15.2 & 95 & 34.3 \\
\hline Hong (B2) & 31 & 17.4 & 12 & 6.7 & 24 & 13.5 & 4 & 2.2 & 51 & 28.7 & 56 & 31.5 \\
\hline Huong (B3) & 30 & 18.2 & 18 & 10.9 & 0 & 0.0 & 25 & 15.2 & 41 & 24.8 & 51 & 30.9 \\
\hline BEGINNING LEVEL & 118 & 19.0 & 100 & 16.1 & 24 & 3.9 & 42 & 6.8 & 134 & 21.6 & 202 & 32.6 \\
\hline Thien (A1) & 112 & 34.5 & 35 & 10.8 & 15 & 4.6 & 11 & 3.4 & 93 & 28.6 & 59 & 18.2 \\
\hline Nguyen (A2) & 9 & 5.5 & 1 & 0.6 & 6 & 3.7 & 4 & 2.5 & 127 & 77.9 & 16 & 9.8 \\
\hline Phuong (A3) & 20 & 22.2 & 4 & 4.4 & 14 & 15.6 & 3 & 3.3 & 21 & 23.3 & 28 & 31.1 \\
\hline ADVANCED LEVEL & 141 & 24.4 & 40 & 6.9 & 35 & 6.1 & 18 & 3.1 & 241 & 41.7 & 103 & 17.8 \\
\hline Total & 259 & 21.6 & 140 & 11.7 & 59 & 4.9 & 60 & 5.0 & 375 & 31.3 & 305 & 25.5 \\
\hline
\end{tabular}


It can be seen from the table that the rates of no opportunity vary between $77.9 \%$ in Class A2 to $15.2 \%$ in Class B1. The percentages of no uptake also range widely from $34.3 \%$ (Class B1) to $9.8 \%$ (Class A2) while the rates of repair range from $34.5 \%$ in Class A1 to a low rate of $5.5 \%$ in Class A2. The range of needs-repair proportions is from $25.3 \%$ (Class B1) to $0.6 \%$ (Class A2). The rate of Vietnamese response to teacher feedback is $15.2 \%$ in Class B3, while it is under $5 \%$ in the other classes.

The chi-square analysis $\left(\chi^{2}(d f=25, n=1,198)=404.1, p<0.001\right)$ indicates a significant difference in learner uptake types across the class groups.

The ASR analysis is performed to partition the difference across the class groups. The following table shows the ASRs of the uptake types across the class groups.

Table 0.13: ASRs of the uptake types across class groups

\begin{tabular}{ccccccc}
\hline Class & Repair & $\begin{array}{c}\text { Needs- } \\
\text { repair }\end{array}$ & Acknowledge & $\begin{array}{c}\text { Vietnamese } \\
\text { response }\end{array}$ & $\begin{array}{c}\text { No } \\
\text { opportunity }\end{array}$ & $\begin{array}{c}\text { No } \\
\text { uptake }\end{array}$ \\
\hline Thuy (B1) & -.5 & $8.0^{*}$ & $-4.3^{*}$ & -.3 & $-6.6^{*}$ & $3.9^{*}$ \\
\hline Hong (B2) & -1.5 & -2.2 & $5.7^{*}$ & -1.8 & -.8 & 2.0 \\
\hline Huong (B3) & -1.2 & -.3 & $-3.1^{*}$ & $6.4^{*}$ & -1.9 & 1.7 \\
\hline Thien (A1) & $6.6^{*}$ & -.6 & -.3 & -1.6 & -1.2 & $-3.5^{*}$ \\
\hline Nguyen (A2) & $-5.4^{*}$ & $-4.7^{*}$ & -.8 & -1.6 & $13.8^{*}$ & $-4.9^{*}$ \\
\hline Phuong (A3) & .1 & -2.2 & $4.8^{*}$ & -.8 & -1.7 & 1.3 \\
\hline$*$ Adjusted standardized residual of 2.6 & or $8 r e a t e r$ & & &
\end{tabular}

* Adjusted standardized residual of 2.6 or greater

The results show that the amount of repair in Class A1 was significantly higher than in the other class groups while the amount of no uptake in this class was considerably lower accordingly. In Class A2, the learners had significantly fewer opportunities for giving uptake, and they made considerably fewer repair and needs-repair moves than in the other classes. Acknowledge took place significantly more often in Class A3 and Class B2 and less often in Class B1 and B3 than in the other class groups. The learners in Class B3 used a lot more Vietnamese responses to the teacher's feedback than in the other classes. The teacher in Class B1 gave her students much more opportunities to 
give uptake, and she received plenty more needs-repair and acknowledge moves than the other teachers. Meanwhile, the learners in her class also made no response to her feedback more often than the learners in the other class groups.

A further step was taken to examine the influence of the teacher use of L1 and the TL on the uptake types. The following table and graph show the learners' production of uptake following teacher feedback in either L1 or the TL.

Table 0.14: Learner uptake types across the use of $\mathrm{L1}$ and the TL

\begin{tabular}{cccccccc}
\hline FonF language & & Repair & $\begin{array}{c}\text { Needs } \\
\text { repair }\end{array}$ & $\begin{array}{c}\text { Acknow- } \\
\text { ledge }\end{array}$ & $\begin{array}{c}\text { VNese } \\
\text { response }\end{array}$ & $\begin{array}{c}\text { No } \\
\text { opportunity }\end{array}$ & No uptake \\
\hline $\begin{array}{c}\text { L1 } \\
\text { Vietnamese })\end{array}$ & $\mathrm{n}$ & 26 & 16 & 8 & 16 & 64 & 88 \\
\cline { 2 - 8 } & $\%$ & 11.9 & 7.3 & 3.7 & 7.3 & 29.4 & 40.4 \\
\hline $\begin{array}{c}\text { TL } \\
(\text { English) }\end{array}$ & $\mathrm{n}$ & 233 & 124 & 51 & 44 & 311 & 217 \\
\cline { 2 - 8 } & $\%$ & 23.8 & 12.7 & 5.2 & 4.5 & 31.7 & 22.1 \\
\hline Total & $\mathbf{n}$ & $\mathbf{2 5 9}$ & $\mathbf{1 4 0}$ & $\mathbf{5 9}$ & $\mathbf{6 0}$ & $\mathbf{3 7 5}$ & $\mathbf{3 0 5}$ \\
\cline { 2 - 8 } & $\mathbf{\%}$ & $\mathbf{2 1 . 6}$ & $\mathbf{1 1 . 7}$ & $\mathbf{4 . 9}$ & $\mathbf{5}$ & $\mathbf{3 1 . 3}$ & $\mathbf{2 5 . 5}$ \\
\hline
\end{tabular}

Graph 0.12: Learner uptake types across the use of $L 1$ and the TL

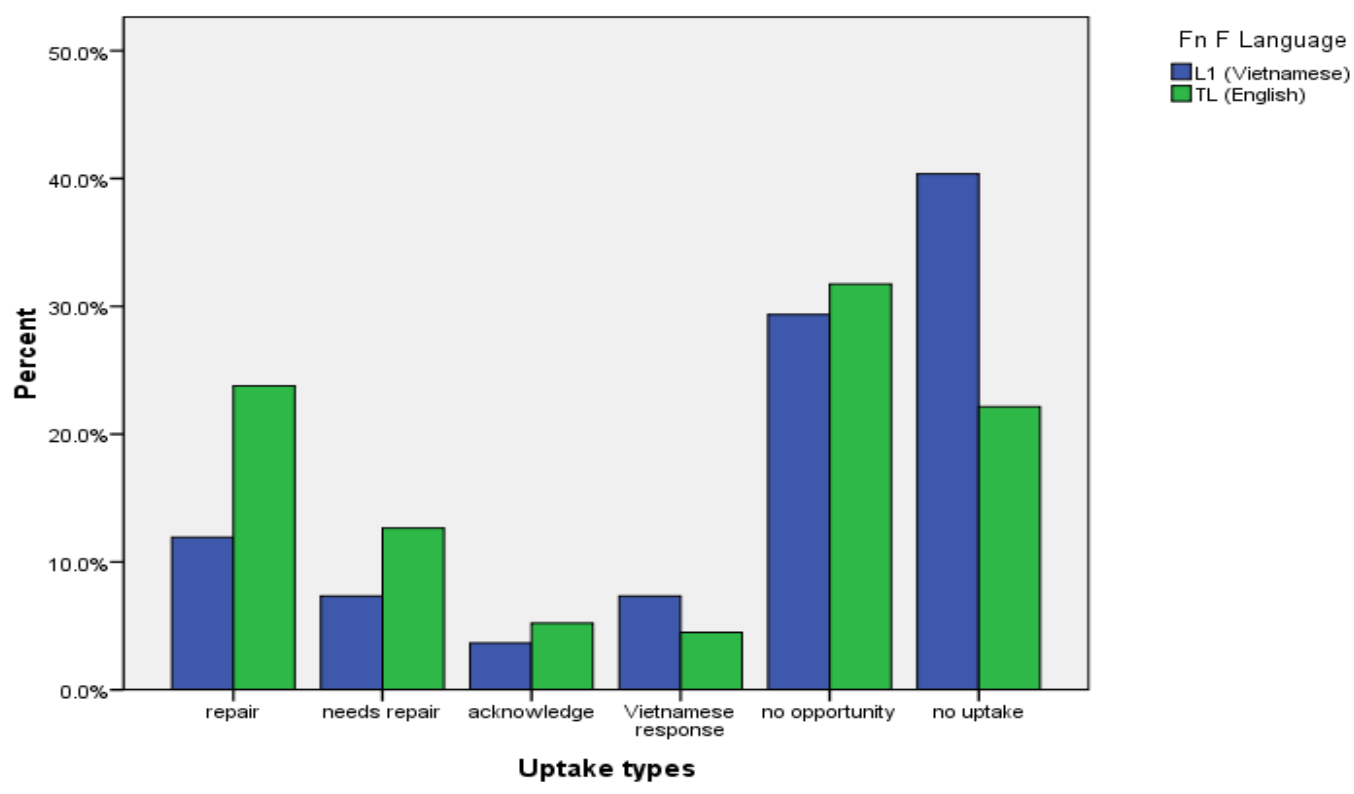


Form Table 7.14 and Graph 7.12, it can be seen that while $23.8 \%$ of feedback in the TL led to repair, this rate was only $11.9 \%$ for L1. On the contrary, $40.4 \%$ of feedback in L1 resulted in no uptake while rate was only $22.1 \%$ for the TL. A chi-square test was performed and the result $(\times 2(d f=5, n=1,198)=43.219, p<0.001)$ shows that the difference among the uptake types across the use of L1 and the TL was statistical. To partition this difference, ASRs were calculated as presented in Table 7.15.

Table 0.15: ASRs of learner uptake types across the use of $L 1$ and the TL

\begin{tabular}{ccccccc}
\hline $\begin{array}{c}\text { FonF } \\
\text { language }\end{array}$ & Repair & $\begin{array}{c}\text { Needs- } \\
\text { repair }\end{array}$ & Acknowledge & $\begin{array}{c}\text { Vietnamese } \\
\text { response }\end{array}$ & $\begin{array}{c}\text { No } \\
\text { uptake }\end{array}$ & $\begin{array}{c}\text { No } \\
\text { opportunity }\end{array}$ \\
\hline $\begin{array}{c}\text { L1 } \\
\text { (Vietnamese) }\end{array}$ & $-3.8^{*}$ & -2.2 & -0.9 & 1.7 & $5.6^{*}$ & -0.7 \\
\hline TL (English) & $3.8^{*}$ & 2.2 & 0.9 & -1.7 & $-5.6^{*}$ & 0.7 \\
\hline
\end{tabular}

From this table, it can be seen that when the teachers used the TL to give feedback, the learners produced significantly more repair, while the use of L1 led the learners to producing no uptake significantly more than the use of the TL.

To examine whether overall class proficiency levels (beginning or advanced) produced uptake differently when receiving feedback in L1 and the TL, the amount of uptake is layered by proficiency levels as in Table 7.16, Graph 7.13 and Graph 7.14. 
Table 0.16: Uptake types across the use of $L 1$ and the TL layered by proficiency levels

\begin{tabular}{|c|c|c|c|c|c|c|c|c|c|}
\hline Proficiency level & FonF language & & Repair & Needs-repair & Acknowledge & Vietnamese response & No uptake & No opportunity & Total \\
\hline \multirow{5}{*}{ Beginning level } & \multirow{2}{*}{ L1 (Vietnamese) - } & $\mathrm{n}$ & 19 & 15 & 1 & 12 & 67 & 24 & 138 \\
\hline & & $\%$ & 13.8 & 10.9 & 0.7 & 8.7 & 48.6 & 17.4 & 100.0 \\
\hline & \multirow{2}{*}{ TL (English) } & $\mathrm{n}$ & 99 & 85 & 23 & 30 & 135 & 110 & 482 \\
\hline & & $\%$ & 20.5 & 17.6 & 4.8 & 6.2 & 28.0 & 22.8 & 100.0 \\
\hline & Subtotal & $\mathbf{n}$ & 118 & 100 & 24 & 42 & 202 & 134 & 620 \\
\hline \multirow{5}{*}{ Advanced level } & \multirow{2}{*}{ L1 (Vietnamese) - } & $\mathrm{n}$ & 7 & 1 & 7 & 4 & 21 & 40 & 80 \\
\hline & & $\%$ & 8.8 & 1.3 & 8.8 & 5.0 & 26.3 & 50.0 & 100.0 \\
\hline & \multirow{2}{*}{ TL (English) } & $\mathrm{n}$ & 134 & 39 & 28 & 14 & 82 & 201 & 498 \\
\hline & & $\%$ & 26.9 & 7.8 & 5.6 & 2.8 & 16.5 & 40.4 & 100.0 \\
\hline & Subtotal & $\mathbf{n}$ & 141 & 40 & 35 & 18 & 103 & 241 & 578 \\
\hline
\end{tabular}


Graph 0.13: Beginning learners' uptake types across the use of $L 1$ and the TL

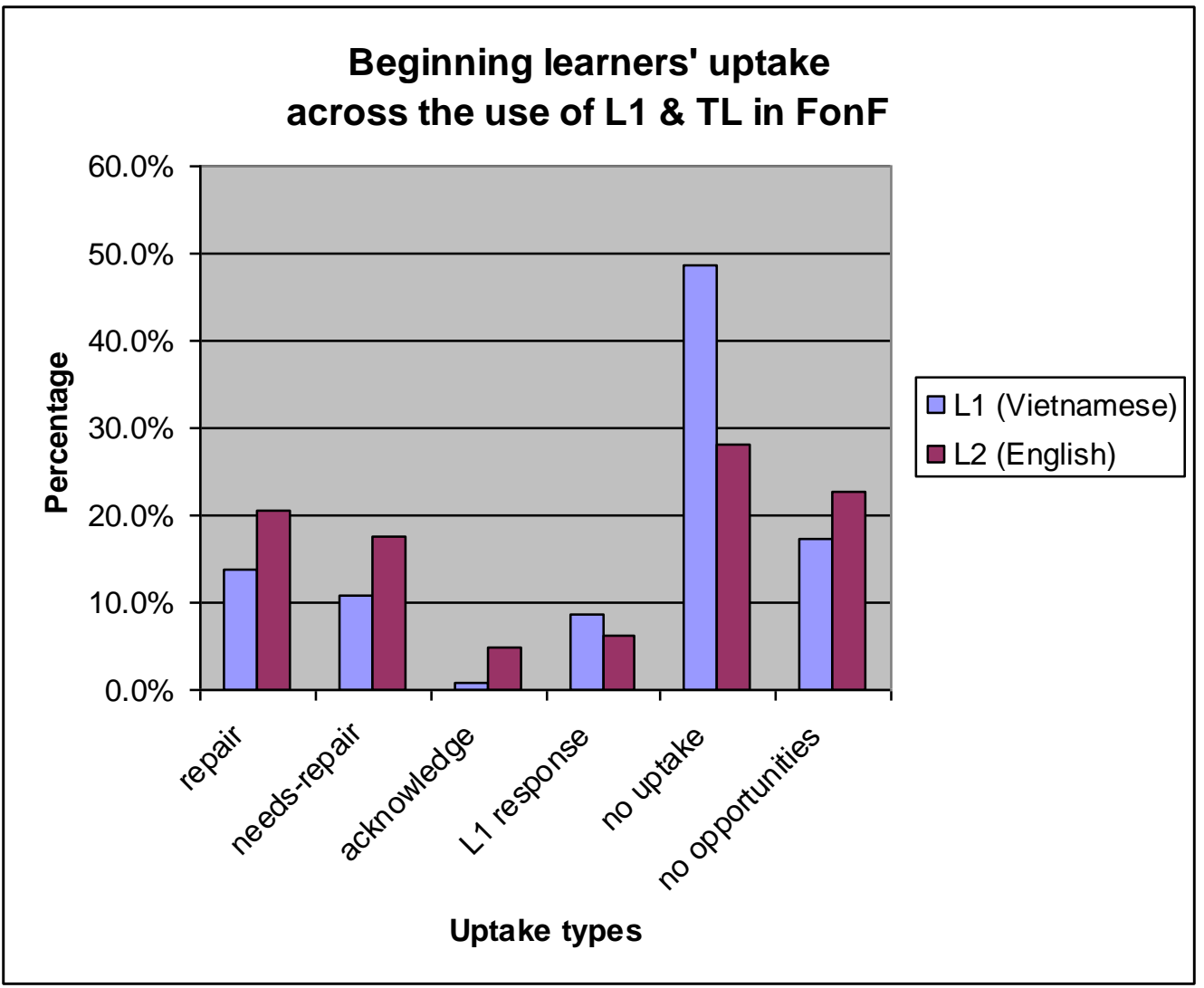

Graph 0.14: Advanced learners' uptake types across the use of L1 and the TL

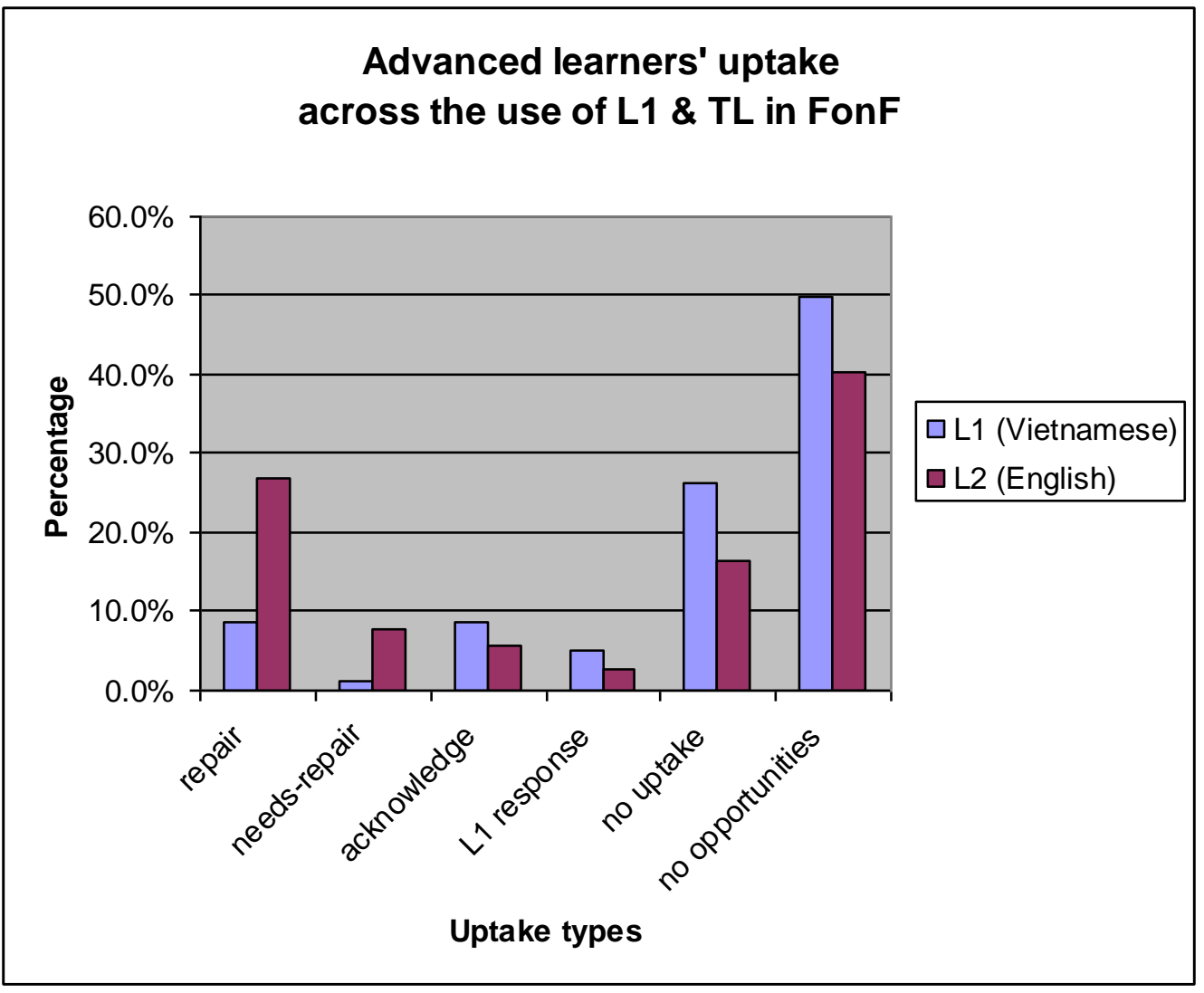


From Table 7.16, Graph 7.13 and Graph 7.14, it can be seen that the learners at two proficiency levels produced uptake similarly when receiving feedback in L1 and the TL. At the beginning level, $13.8 \%$ of feedback in L1 led to repair while this rate was $20.5 \%$ in the TL. At the advanced level, $26.9 \%$ of feedback in the TL resulted in repair while this rate was $8.8 \%$ in L1. An opposite trend can be found in the no uptake category, where $48.6 \%$ of L1 feedback received no uptake compared with $28 \%$ in the TL at the beginning level, and these rates were $26.3 \%$ and $16.5 \%$, respectively at the advanced level. A chi-square test was performed for the uptake types across the use of L1 and the TL in the beginning classes and the result $(\times 2(d f=5, n=620)=25.695, p<0.001)$ shows that the difference among the uptake types across the use of L1 and the TL was statistically significant. A similar chi-square test was performed for the uptake types across the use of L1 and the TL in the advanced classes and the result ( $x 2(d f=5, n=578)$ $=20.954, p<0.001$ ) shows that there was a statistically significant difference among the uptake types across the use of L1 and the TL at the advanced level.

To explore the interaction between the learners' proficiencies and uptake types, a 2 (proficiency level) x 6 (uptake types) full-factorial ANOVA (see Table 7.16) was conducted. The result $(\mathrm{F}(5,48)=1.281, p=0.287)$ shows no interaction between the learners' proficiency levels and learner uptake types.

\subsubsection{Pattern of uptake types and teacher use of $\mathrm{L} 1$ and the TL}

The results reveal two issues which will be discussed in the following section: the pattern of uptake types in the Vietnamese EFL classes and the relationship between the teacher use of L1 and the TL and learner uptake.

\subsubsection{The pattern of uptake types}

The data shows that there is one more type of uptake recorded in this study: learners' Vietnamese response. Learners' use of L1 to respond to teacher feedback is part of learner L1 use in the EFL class taught by teachers who share the mother tongue with learners, but it has not been mentioned in similar studies such as Farrokhi \& Gholami (2007). In the immersion setting, learners' L1 response may be treated as CF triggers and is recasted by the teacher with a translation (e.g. Lyster \& Ranta, 1997). This study 
reveals the existence of this uptake type, which suggests further research on its nature and its association with learning.

The average percentage of repair in this study is $21.6 \%$. This rate is higher than the rate of $16 \%$ reported in the study by Panova \& Lyster (2002) using the same coding system. It is also higher than the rate of $15.2 \%$ stated in a study by Farrokhi \& Gholami (2007) in a very similar EFL setting although this study used a slightly different coding system. However, in comparison with other studies in the ESL settings, the repair rate in this study is much lower than the rate of $72 \%$ reported in Ellis, et al. (2001a) and $48.3 \%$ in Loewen (2004b), but closer to the rate of $27 \%$ in Lyster \& Ranta (1997), and $21 \%$ in child learners and $30 \%$ in adults reported by Oliver (2000).

The wide variation in uptake types across the studies including this study in the FonF research has various possible explanations. First, as pointed out by Ellis, et al. (2001a), in a private language school setting, repair is more likely to occur than an immersion or content-based class setting since the learners as fee payers were more motivated and committed to the learning process. Second, and most importantly to this study, there is a marked difference in the teachers' mind-set in the EFL setting in this study and the ESL settings in Ellis, et al. (2001a), Lyster \& Ranta (1997), Oliver (2000), and other ESL setting studies. The teachers in this setting were Vietnamese L1 teachers who were used to a traditional teacher-centred classroom (Utsumi \& Doan, 2009). Despite the institutions' and the teachers' encouragement for the students' involvement in the class activities, both the teachers and the learners in this setting seemed to be pleased with the teachers playing the active role of giving feedback and the learners playing the passive role of receiving feedback and taking notes of the feedback rather than using it on the spot. The learners in these observed classes took notes as an essential part of their class study. Learners' note-taking habit has also been noticed by Loewen (2004b) and Farrokhi \& Gholami (2007) as part of learner noticing practice which uptake fails to reflect. Ellis, et al. (2001a) also contend that FonF involves the learner's observable and interactional behaviour rather than intramental activities. Therefore, as a superficial index of learning, uptake is facilitative of acquisition but not essential for acquisition. Further research is needed to investigate this silent part of learners' reaction to teacher feedback, which Farrokhi \& Gholami (2007) termed as 'camouflaged uptake'. 
The teacher's and learner's expected behaviour in the Vietnamese EFL setting is also a possible reason for the rates of no opportunity and no uptake in this study $(31.3 \%$ and $25.5 \%$, respectively), much higher than those in Loewen (2004b) (9.5\% and 17.5\%, respectively). The teachers in the Vietnamese classrooms are accustomed to taking it as their job to give long explanations and the students' job to listen and taking notes.

A further reason for the variation in uptake types between this study and other FonF studies is that, unlike the coding system used in other studies like Loewen's (2004b) or Ellis, et al. (2001a) which codes only the last uptake move as final, this coding system covers all the feedback moves and the uptake moves taking place throughout the observations. This coding system helps bring about a more exact description of the learners' reaction to the teacher feedback though the records of uptake to some extent are not comparable to those in the other studies.

The wide range of uptake patterns across the class groups is also observed in this study. The older teachers like Nguyen in Class A2 tended to make continuous feedback moves without giving the learners a chance for feedback (77.9\% no-opportunity moves) while younger teachers Thuy in Class B1 or Huong in Class B3 seemed to have treated the learners in a more equal way by giving them more opportunities to give uptake $(15.2 \%$ and $24.8 \%$ of no-opportunity moves, respectively). Phuong, the teacher of Class B3, who was communication-oriented, also made fewer no-opportunity moves $(23.3 \%)$. However, younger teachers were more likely to receive no uptake than older teachers. Being more experienced, the older teachers seemed to be more aware of the importance of learner noticing of their feedback and manipulate some pushed output in the forms of repair, needs-repair or acknowledge from the learners rather than let them make no response to their feedback. However, since uptake is defined as the learners' responses to the teacher feedback, not only the teachers' beliefs and individual factors including age, experience and training, but also the learners' individual differences need to be further investigated.

\subsubsection{Teacher use of $\mathrm{L} 1$ and the $\mathrm{TL}$ and learner uptake}

This data shows that there is an association between the teacher use of L1 and the TL in giving feedback and learner uptake. The teacher use of L1 in giving feedback tended to make the learners produce less repair and more no uptake. The learners' less production 
of repair could possibly because the teachers' use of L1 in the language classroom may result in the learners being demotivated from using the TL, and hence, less modified output was produced (e.g. Bailey, 1985; Brosh, 1996). When the teachers used the TL to give feedback, the learners may have felt the need to incorporate feedback into their output to catch up with the communication flow. This could explain how repair was produced more in response to teacher feedback in the TL. More no uptake in response to feedback in L1 may be explained by the purpose of L1 use in the language classroom. One of the main purposes of the teachers when using L1 to give feedback was to help the learners with comprehension, to which the learners usually responded with acknowledging tokens like nodding or saying yes.

The case of Huong, the teacher in charge of the beginning class B3 is also worth mentioning. Despite the fact that her class is at the beginning level, she was the teacher who used the TL the most among the six teachers (97.5\% as per Table 7.1). It should be noted that Huong was the second youngest and second least experienced teacher, who was more likely to learn English when the shift to a more communicative teaching method was on the way. In the conversation with the researcher, she insisted that teacher should use the TL throughout class activities to create an English-speaking environment for the students who usually did not have anywhere to use English other than in the classroom. However, the learners in her class produced significantly more Vietnamese responses to her feedback than the others $(15.2 \%$ as per Table 7.12$)$. Episode 19 A3 is a typical example of her feedback and the learners' Vietnamese responses.

\section{Episode 19 A3}

T: [points at the family tree drawn on the board] This is your cousin. You know cousin?

Ss: $(\ldots)$

T: cousin is like... your aunt's son

Sx: $a$, di, di a ha co? (you mean 'aunt'?)

T: no, your aunt's son

Sxx: khong phai, con trai ma (No, she means 'son')

$\mathbf{T}$ : cousin is the son of your aunt, the son of your uncle like here... and here, you are here [points at the family on the board]

Sx: $o$, rua la anh trai minh (so that's my brother)

T: cousin, not brother, son of your aunt or son of your uncle, not son of your mother. 
Ss: $a$, anh ho, anh ho do (oh, so that's cousin, cousin)

$\mathbf{T}$ : yes, that's cousin.

From Episode 19 A3, we can see that the learners seemed to have problems with comprehending her TL-only explanation. Their Vietnamese responses contained their guesses about her TL explanations, and the teacher kept repeating and modifying her

feedback to make it comprehensible. This example suggests that when input is not comprehensible, it may induce more negotiation for meaning (Ellis, 2008), but in this case, when the learners were not sufficiently proficient, their recourse to L1 was inevitable. Moreover, the feedback turned lengthy, time-consuming and mostly repetitive. This observation raises issues about the need for comprehensible input when TL-only was the choice for feedback.

\subsubsection{Learner uptake: Summary}

In this study, the amount of uptake was different from that reported in other studies in the research field. There was more no opportunity and no uptake and less repair than in other studies which also took place in language-focused classes. A possible reason is the different instructional settings across the studies. In this study, the particular expectations about the roles of the teachers and the learners in a teacher-centred EFL classroom in Vietnam may have played a role.

The results also reveal that the teachers' use of L1 and the TL in giving feedback is associated with the learners' uptake. Feedback in L1 led to less repair and more no uptake than feedback in the TL. This result suggests that teacher use of the TL in giving feedback is more likely to push learners to produce output while teacher use of the TL is more likely to make learners receive feedback in silence. This finding has an important pedagogical significance since L1 is usually claimed to be useful in teaching the TL, but there has been no evidence for or against that claim. This finding, therefore, sheds some light on the long-claimed roles of L1 in the language classroom by providing evidence that teacher use of L1 in giving feedback is not helpful in inducing learners' output production. As a result, the teacher use of $\mathrm{L} 1$ in FonF does not facilitate learning.

However, this descriptive study only investigated uptake, one of the indexes for language learning, and the superficiality of this index has been pointed out in several 
studies (Ellis, et al., 2001a; Loewen, 2004b; Sheen, 2004). As a result, in the experimental study of this thesis, the relationship between the teacher use of L1 and the TL and language learning was addressed, using simultaneously several indexes: learner uptake, noticing and language development.

\subsection{Summary}

This part of the research investigated the use of the L1 and the TL by the teachers in FonF, and the uptake types produced by the learners in this context. As for the language of FonF, this study also found that the teachers tended to use L1 in complex vocabularyor morphosyntax- focused FFEs in which the teachers gave feedback explicitly using provide or elicit. This result reflects the teachers' beliefs which have been widely observed in other studies (e.g. Atkinson, 1987; E. Chau, 2007; Weschler, 1997) that L1 is useful in giving long and complex explanations about vocabulary and grammar.

The study also found a relationship between the teacher use of L1 and the TL in FonF and learner uptake. The data analysis reveals that feedback in the TL is more likely to push learners to produce uptake, especially successful uptake than feedback in L1. This finding gives evidence that the teacher use of L1 in giving feedback is not more helpful than the TL as teachers and researchers may think.

However, there are a few reasons why further research is needed to give a thorough answer to the question whether the use of L1 and the TL has an impact on learning. Firstly, as an observational study, this study involved so many variables such as teacherrelated factors, learner-related factors and context-related factors that the findings could hardly be justified thoroughly. The need for an experimental study to control the variables is evident. Secondly, uptake only is not enough to assert the association between the teacher use of L1 and the TL and learning. Thirdly, the teachers' beliefs about the need to use L1 for particular types of FonF found in this study also need to be verified. The experimental study of this thesis was designed to address these three points: it used multiple indexes such as uptake, noticing and language development measure to explore the relationship between the teacher use of L1 and the TL and language learning. The design of this study focused on the FonF types which have been believed to require L1 use and took place in a lab-study to exclude unwanted variables. The following chapter describes the experimental study of this thesis. 


\section{Chapter 8: FonF in L1 and the TL: Impact on uptake}

\subsection{Introduction}

The design of this experimental study was informed by the results of the descriptive study described in the previous chapter. From this study, it was observed that when the Vietnamese L1 teachers give complex and explicit feedback on learners' morphosyntactic and lexical problems, they are more likely to resort to L1. In addition, many descriptive studies also observe that when giving long explanations about grammar and vocabulary, teachers usually switch to L1 (e.g. Atkinson, 1987; E. Chau, 2007; Weschler, 1997). These research findings suggest that there is an assumption among teachers that the use of L1 is more beneficial for teaching morphosyntactical points and new words, and giving metalinguistic explanations than the use of the TL. In this experimental study, interactive tasks were designed to be morphosyntax- and vocabulary-focused to test this widely observed belief. This study also aims to answer the question "how" rather than "how often" L1 is being used in the ESL and EFL classroom (E. Chau, 2007). Another reason for the need to conduct a lab study also comes from the findings of the descriptive study: there were too many variables which could possibly influence the relationship between the teacher use of L1 and the TL in FonF and language learning including the teachers, the learners and the contexts. The use of lab study aims to control unwanted variables so that the findings could be judiciously interpreted. In addition, not only learner uptake but also noticing measures and custom-made post-tests were included so that the experimental study could seek to understand the relationship, if any, between the use of L1 and the TL in FonF and language learning.

In order to answer the research question about whether the use of L1 and the TL has any impact on learner uptake, three interactive dyadic tasks were performed by individuals from two groups of learner participants with the researcher as interlocutor. As informed by the results of the descriptive study, the types of feedback used in this study are provide (i.e., giving explicit information about the targeted linguistic forms) and elicit (i.e., giving prompts, clues or solutions for the linguistic problems), and each FFE contained more than one feedback move. Learners from one group received feedback in L1 $(n=20)$; learners from the other group in the TL $(n=23)$. Each group was, in turn, 
divided into two subgroups of two proficiency levels: beginning learners $(n=22)$ and advanced learners $(n=21)$.

The results of this study will be presented in accordance with the amounts of learner uptake across the use of L1 and the TL, and across the proficiency levels. In the last section of this chapter, further investigation into a number of neglected aspects of the construct of uptake in FonF is also presented.

\subsection{Amount of learner uptake}

A total of 457 FFEs were recorded during the interactive tasks with 43 participants, 20 of whom received feedback in L1 and 23 in the TL. The amount and types of uptake are presented in Table 8.1 and Graph 8.1.

Table 0.1: Frequency of learner uptake types

\begin{tabular}{ccccccc}
\hline & Repair & Needs-repair & Acknowledge & No uptake & Total \\
\hline \multirow{2}{*}{ Frequency } & $\mathrm{n}$ & 273 & 8 & 109 & 67 & 457 \\
\cline { 2 - 7 } & $\%$ & 59.7 & 1.8 & 23.9 & 14.7 & 100.0 \\
\hline
\end{tabular}

Graph 0.1: Frequency of types of learner uptake

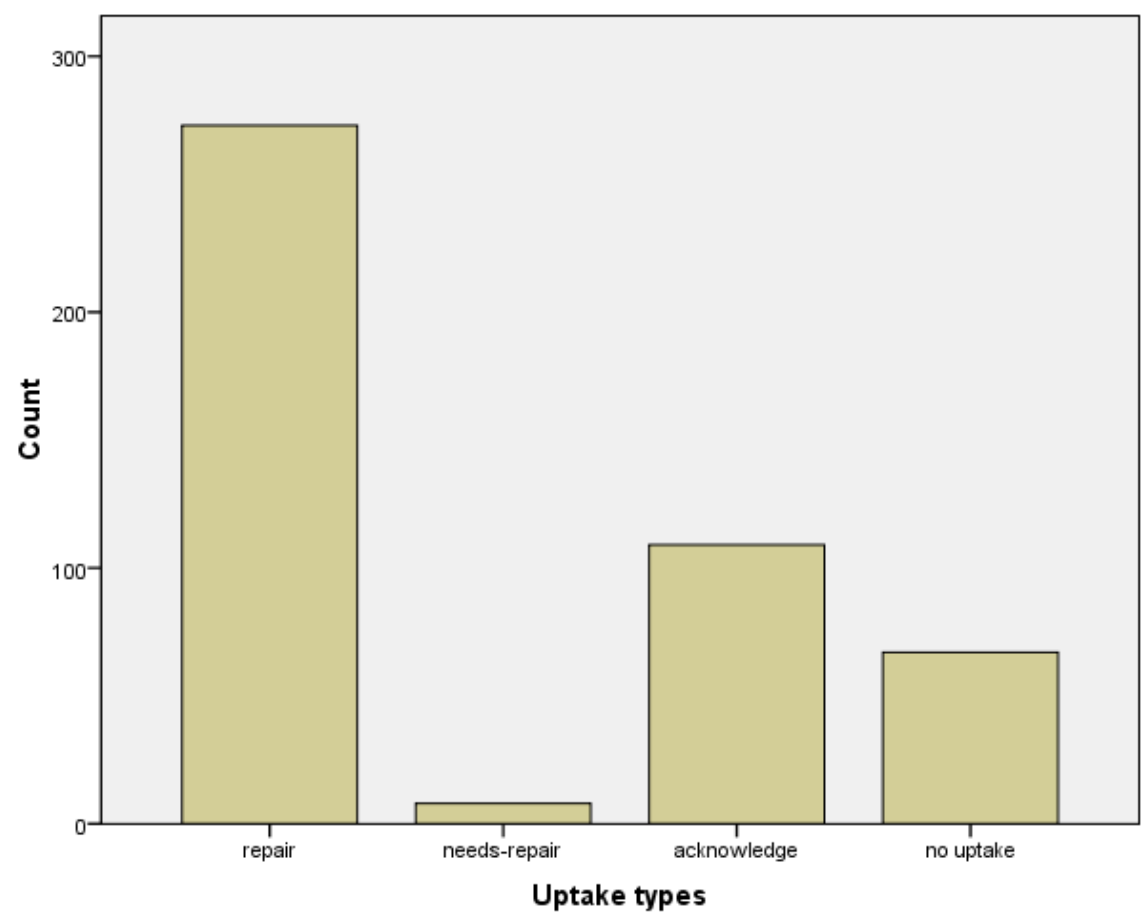


It can be seen from Table 8.1 and Graph 8.1 that, overall, repair is the most common type of feedback accounting for nearly $60 \%$ of the total uptake amount. The second most common is acknowledge (23.9\%), and only $1.8 \%$ of the total uptake amount is needs-repair. Nearly $15 \%$ of the teacher feedback receives no response from the learner participants.

\subsubsection{Amount of uptake types across the use of $L 1$ and the TL}

Table 8.2 and Graph 8.2 present the types of uptake across the use of L1 and the TL.

Table 0.2: Types of uptake across the use of $L 1$ and the TL

\begin{tabular}{ccccccccc}
\hline \multirow{2}{*}{ FonF language } & \multicolumn{2}{c}{ Repair } & \multicolumn{2}{c}{ Needs-repair } & \multicolumn{2}{c}{ Acknowledge } & \multicolumn{2}{c}{ No uptake } \\
& $\mathbf{n}$ & $\mathbf{\%}$ & $\mathbf{n}$ & $\boldsymbol{\%}$ & $\mathbf{n}$ & $\boldsymbol{\%}$ & $\mathbf{n}$ & $\boldsymbol{\%}$ \\
\hline L1 (Vietnamese) & 120 & 56.3 & 3 & 1.4 & 42 & 19.7 & 48 & 22.5 \\
\hline TL (English) & 153 & 62.7 & 5 & 2.0 & 67 & 27.5 & 19 & 7.8 \\
\hline Total & 273 & 59.7 & 8 & 1.8 & 109 & 23.9 & 67 & 14.7 \\
\hline
\end{tabular}

Graph 0.2: Types of uptake across the use of $L 1$ and the TL

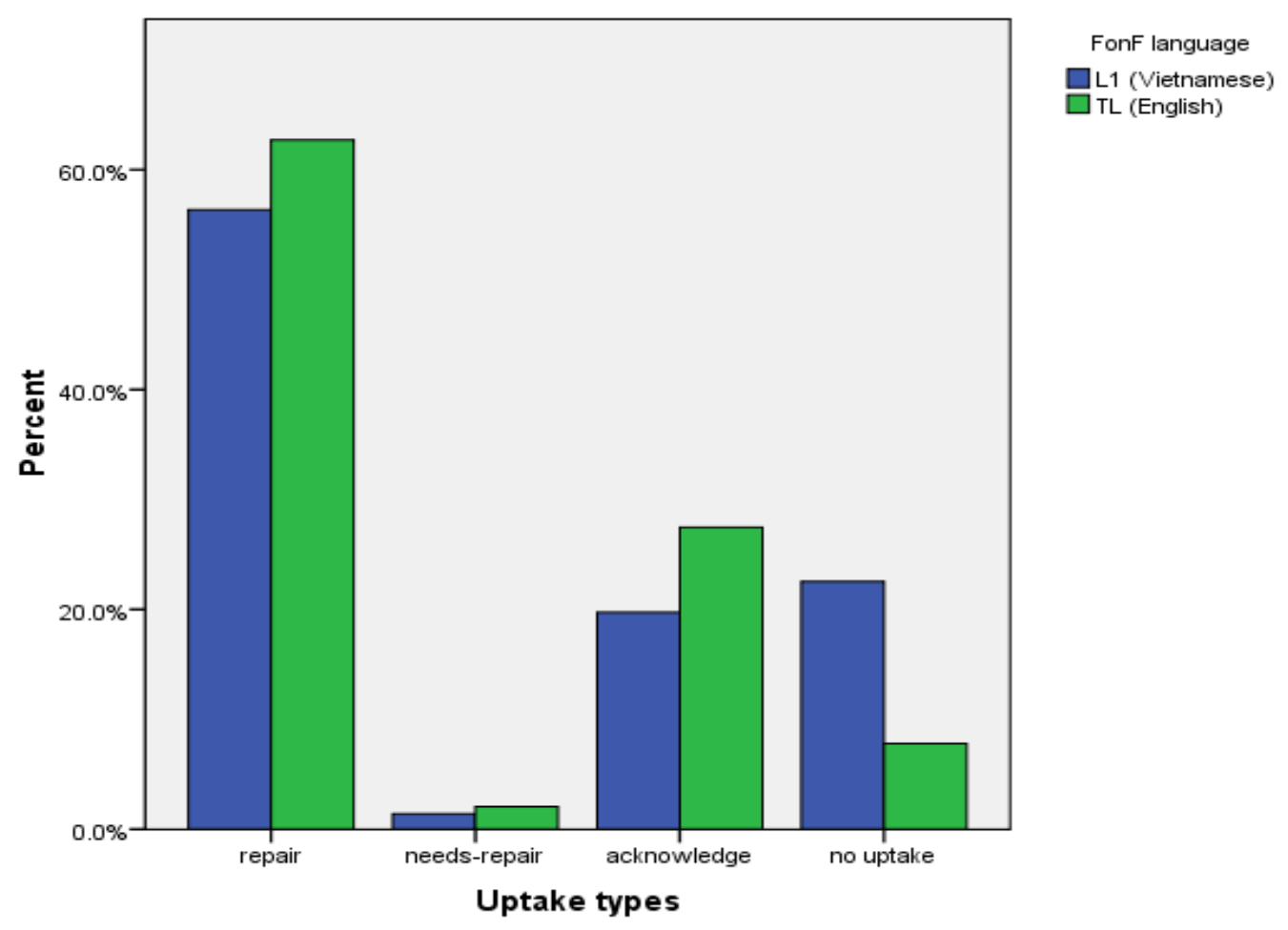


The table and graph show that the percentage of repair is higher in the TL groups than in the L1 groups (62.7\% and 56.3\%, respectively). Similarly, the rate of acknowledge is higher in the TL groups $(27.5 \%)$ than in the L1 groups $(19.7 \%)$. While both the TL groups and the L1 groups produce similar low rates of needs-repair (2\% and $1.4 \%$, respectively), $22.5 \%$ of the teacher's feedback receives no response from the learners in the L1 groups, nearly three times as high as that rate in the TL group (7.8\%).

In order to perform the chi-square test to see whether there is any statistically significant difference in learner uptake across the use of L1 and the TL in FonF, I slightly adjusted the coding of the uptake data so that the low rates of the needs-repair category would not invalidate the statistical result (Moore \& McCabe, 2003; Siegel \& Castellan, 1988). The needs-repair category was conflated into the acknowledge category to become unsuccessful uptake category, versus repair as the successful uptake. The chi-square analysis $\left(\chi^{2}(d f=2, n=457)=20.765, p<0.001\right)$ shows that there is a significant difference in the uptake types across the use of FonF language.

To partition the difference in the types of uptake across the use of L1 and the TL, the ASRs were computed. The following table presents the ASRs of the three uptake types which point out the contribution of each uptake type to the difference.

Table 0.3: ASRs for uptake types across the use of L1 and the TL

\begin{tabular}{cccc}
\hline FonF language & Successful uptake & Unsuccessful uptake & No uptake \\
\hline L1 (Vietnamese) & -1.4 & $-2.0^{*}$ & $4.4^{*}$ \\
\hline TL (English) & 1.4 & $2.0^{*}$ & $-4.4^{*}$ \\
\hline
\end{tabular}

*Adjusted standardized residual of 2.0 or greater

The ASR analysis in Table 8.3 shows that the difference is statistically significant in the no-uptake category, which suggests that the learners in the L1 groups tended to make no response to the teacher feedback significantly more often than those in the TL groups. On the contrary, the learners in the L1 groups tended to produce much less unsuccessful uptake. 
As the differences in the types of uptake were statistical, the effect size was computed using odds ratios (Larsen-Hall, 2010). The odds ratios of the occurrences of each uptake type against the other types with the use L1of versus the TL were also calculated and are presented in Table 8.4.

Table 0.4: Odds ratios of the occurrences of uptake types with the use of L1 versus the TL

\begin{tabular}{ccccc}
\hline Variable & Odds ratio & \multicolumn{2}{c}{$95 \%$ confidence intervals } & Significance \\
\hline $\begin{array}{c}\text { Unsuccessful } \\
\text { uptake }\end{array}$ & 1.563 & 1.018 & 2.400 & .041 \\
\hline No uptake & .290 & .164 & .512 & .000 \\
\hline
\end{tabular}

Table 8.4 shows that the use of L1 or the TL has a significant association with the learners' production of unsuccessful uptake and no uptake. The odds ratio for unsuccessful uptake was 1.563 , determining that in this study, unsuccessful uptake is about 1.6 times more likely to occur than other types of uptake when the teacher feedback is in the TL. The odds ratio of .290 for no uptake indicated that in this data set, the learners were less than one-third as likely to produce no uptake as other uptake types when they received the teacher feedback in the TL. Overall, the odds ratio in this table shows that learners receiving feedback in the TL were more likely to produce uptake, successful or unsuccessful than make no response to the teacher feedback.

To discover if learner proficiency contributes to the difference in learner uptake between FonF in L1 and FonF in the TL, the uptake data is analysed across the language use layered by the proficiency levels. The following table and graph present the results of the analysis. 
Table 0.5: Frequency of uptake types across proficiency levels layered by the use of L1 and the TL

\begin{tabular}{|c|c|c|c|c|c|c|}
\hline FonF language & Proficiency & vel & Repair & $\begin{array}{l}\text { Needs- } \\
\text { repair }\end{array}$ & Acknowledge & $\begin{array}{c}\text { No } \\
\text { uptake }\end{array}$ \\
\hline \multirow{5}{*}{ L1 (Vietnamese) } & \multirow{2}{*}{$\begin{array}{l}\text { Beginning } \\
\text { level }\end{array}$} & $\mathrm{n}$ & 64 & 1 & 18 & 25 \\
\hline & & $\%$ & 59.3 & 0.9 & 16.7 & 23.1 \\
\hline & \multirow{2}{*}{$\begin{array}{l}\text { Advanced } \\
\text { level }\end{array}$} & $\mathrm{n}$ & 56 & 2 & 24 & 23 \\
\hline & & $\%$ & 53.3 & 1.9 & 22.9 & 21.9 \\
\hline & Total & $\mathrm{n}$ & 120 & 3 & 42 & 48 \\
\hline \multirow{5}{*}{ TL (English) } & \multirow{2}{*}{$\begin{array}{l}\text { Beginning } \\
\text { level }\end{array}$} & $\mathrm{n}$ & 85 & 2 & 34 & 8 \\
\hline & & $\%$ & 65.9 & 1.6 & 26.4 & 6.2 \\
\hline & \multirow{2}{*}{$\begin{array}{l}\text { Advanced } \\
\text { level }\end{array}$} & $\mathrm{n}$ & 68 & 3 & 33 & 11 \\
\hline & & $\%$ & 59.1 & 2.6 & 28.7 & 9.6 \\
\hline & Total & $\mathrm{n}$ & 153 & 5 & 67 & 19 \\
\hline
\end{tabular}

Graph 0.3: Frequency of uptake types across proficiency levels layered by the use of $\mathrm{L} 1$ and the TL

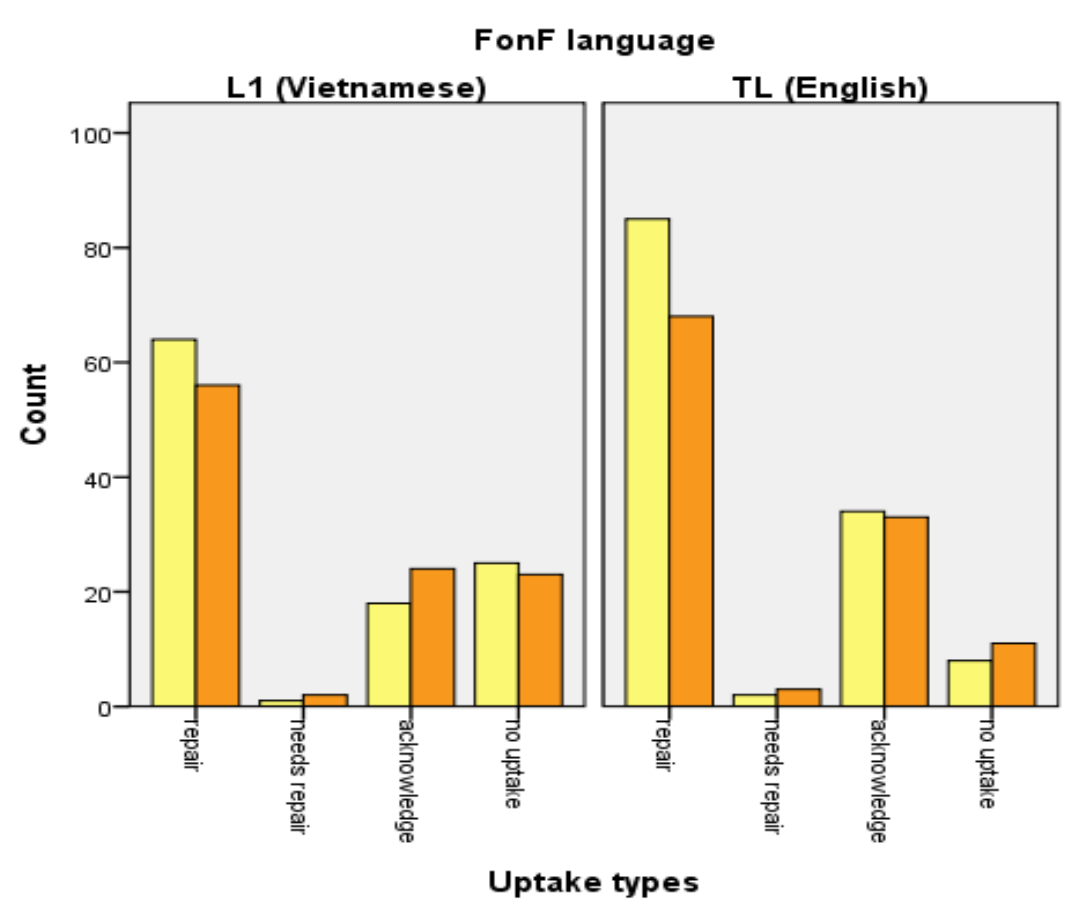

Proficiency Level

$\square$ Beginning

$\square$ Advanced 
In the L1 category, as can be seen from the table and graph, while the rate of repair is $59.3 \%$ at the beginning level, it is $53.3 \%$ at the advanced level. Needs-repair is the least common type at both levels $(0.9 \%$ at the beginning level and $1.9 \%$ at the advanced level). Nearly $17 \%$ of the teacher feedback moves receive acknowledging tokens from the beginning learners, while this uptake type is more common among the advanced learners (nearly 23\%). The no-uptake rate is $23.1 \%$ at the beginning level and $21.9 \%$ at the advanced level.

For the TL groups, the percentage of repair is also the highest at both proficiency levels (65.9\% for the beginning level and $59.1 \%$ for the advanced level). The second most common uptake type is acknowledge, which is $26.4 \%$ among the beginning learners and $28.7 \%$ among the advanced learners. Over $6 \%$ of teacher feedback moves given to the beginning learners are not responded to while this rate is $9.6 \%$ at the advanced level. Needs-repair is the least frequent uptake type which occupies $1.6 \%$ of the beginning learners' uptake moves and $2.6 \%$ of the advanced learners' uptake moves.

To identify whether the difference in learner uptake across proficiency levels is statistically significant within each FonF language group, two chi-square tests were conducted separately. However, to avoid low-cell counts (Moore \& McCabe, 2003), the needs-repair and the acknowledge categories were combined into the category of unsuccessful uptake. The chi-square result for the L1 group $(\chi 2(d f=2, n=213)=1.664$, $p=0.435$ ) show that there is no statistically significant difference between the beginning level and the advanced level in the L1 category. Similarly, the chi-square analysis for the TL group $(\chi 2(d f=2, n=244)=1.564, p=0.457)$ also reveals no significant difference between the two proficiency levels. The results suggest that the patterns of learner uptake are similar across the learners' proficiency levels in each FonF language setting.

Another step was taken to analyse the data across the proficiency levels layered by the FonF language use to detect any difference in the patterns of the uptake types between the two proficiency levels. The results are presented in the following table and graph. 
Table 0.6: Frequency of uptake types across the use of L1 and the TL layered by the proficiency levels

\begin{tabular}{|c|c|c|c|c|c|c|}
\hline Proficiency level & FonF languag & & Repair & Needs-repair & Acknowledge & $\begin{array}{c}\text { No } \\
\text { uptake }\end{array}$ \\
\hline \multirow{5}{*}{ Beginning } & \multirow{2}{*}{ L1 (Vietnamese) } & $\mathrm{n}$ & 64 & 1 & 18 & 25 \\
\hline & & $\%$ & 59.3 & 0.9 & 16.7 & 23.1 \\
\hline & \multirow{2}{*}{ TL (English) } & $\mathrm{n}$ & 85 & 2 & 34 & 8 \\
\hline & & $\%$ & 65.9 & 1.6 & 26.4 & 6.2 \\
\hline & Total & $\mathrm{n}$ & 149 & 3 & 52 & 33 \\
\hline \multirow{5}{*}{ Advanced } & \multirow{2}{*}{ L1 (Vietnamese) } & $\mathrm{n}$ & 56 & 2 & 24 & 23 \\
\hline & & $\%$ & 53.3 & 1.9 & 22.9 & 21.9 \\
\hline & \multirow{2}{*}{ TL (English) } & $\mathrm{n}$ & 68 & 3 & 33 & 11 \\
\hline & & $\%$ & 59.1 & 2.6 & 28.7 & 9.6 \\
\hline & Total & $\mathrm{n}$ & 124 & 5 & 57 & 34 \\
\hline
\end{tabular}

Graph 0.4: Uptake types across the use of $L 1$ and the TL layered by the proficiency levels

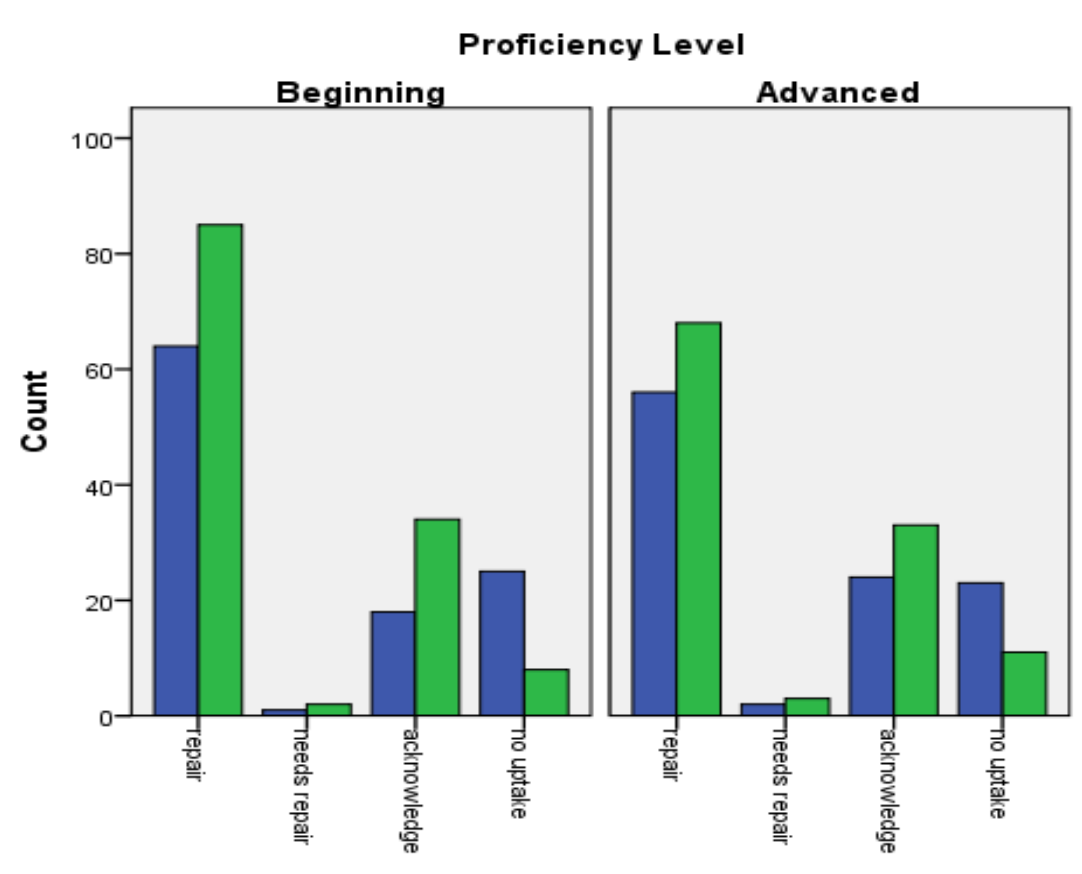


It can be seen from Table 8.6 and Graph 8.4 that the patterns of uptake types are similar between the two proficiency levels. The percentages of repair, acknowledge and needsrepair are higher in the TL groups while the rates of no uptake are higher in the L1 groups across both proficiency levels. At the beginning level, the learners receiving teacher feedback in L1 produced $59.3 \%$ repair while this rate is $65.9 \%$ for the learners receiving feedback in the TL. The rate of acknowledge is also higher in the TL group than in the L1 group ( $26.4 \%$ and $16.7 \%$, respectively). Over $23 \%$ of the teacher feedback moves are not responded to by the beginning learners in the L1 group, while this rate is only $6.2 \%$ in the TL group. At the advanced level, while $59.1 \%$ of teacher feedback moves given in the TL results in repair, this rate is $53.3 \%$ in the L1 group. Teacher feedback in L1 also receives no response from learners more often than that in the TL $(21.9 \%$ and $9.6 \%$, respectively). Nearly $29 \%$ of teacher feedback in the TL receives acknowledge, while this rate is nearly $23 \%$ when feedback is given in L1.

Two chi-square tests were also run separately for each proficiency level to find out if the differences between the FonF language groups are statistically significant. In order for these tests to be valid, the needs-repair category and the acknowledge category were again grouped to make the unsuccessful uptake type to avoid low-cell counts (Moore \& McCabe, 2003). The result for the beginning level $(\chi 2(d f=2, n=237)=15.231, p<0.001)$ demonstrates that the difference is significant across the FonF language groups. Likewise, the chi-square analysis for the advanced level groups ( $\chi 2(d f=2, n=220)$ $=6.569, p=0.037$ ) also shows that there is a significant difference between the L1 and the TL group. The results suggest that the patterns of uptake are significantly different across the use of L1 and the TL in each proficiency level. To partition the contribution of each category to the difference, ASRs are calculated and presented in the following table. 
Table 0.7: ASRs of the uptake types across the use of the TL and L1 layered by the proficiency levels

\begin{tabular}{ccccc}
\hline $\begin{array}{c}\text { Proficiency } \\
\text { level }\end{array}$ & $\begin{array}{c}\text { FonF } \\
\text { language }\end{array}$ & $\begin{array}{c}\text { Successful } \\
\text { uptake }\end{array}$ & $\begin{array}{c}\text { Unsuccessful } \\
\text { uptake }\end{array}$ & No uptake \\
\hline \multirow{2}{*}{ Beginning level } & Vietnamese & -1.1 & -1.9 & $3.8^{*}$ \\
\cline { 2 - 5 } & English & 1.1 & 1.9 & $-3.8^{*}$ \\
\hline \multirow{2}{*}{ Advanced level } & Vietnamese & -.9 & -1.1 & $2.5^{*}$ \\
\cline { 2 - 5 } & English & .9 & 1.1 & $-2.5^{*}$ \\
\hline
\end{tabular}

\section{*Adjusted standardized residual of 2.0 or greater}

The ASR analysis reveals that the difference is most significant in the no-uptake category, in which at both proficiency levels, the learners receiving teacher feedback in L1 produce no uptake significantly more often than those receiving feedback in the TL. Though insignificant, the ASR for unsuccessful uptake among the beginning learners is very near to the threshold of 2.0, which suggests that the learners receiving teacher feedback in the TL tended to produce more unsuccessful uptake than those receiving feedback in L1.

\subsubsection{Amount of "camouflaged uptake" across the use of $L 1$ and the TL}

The data also recorded the learners' habit of taking notes when receiving teacher feedback. This practice is also reported in Ellis, et al.'s (2001a) study in which they find that some learners in the ESL classes took notes about the teacher feedback instead of giving any uptake. In another study taking place in an EFL setting in Iran, Farrokhi \& Gholami (2007) also observe learners' habit of taking notes about the teachers' feedback and argue that this habit may contribute to the low uptake rate in their study. They also suggest some possible relation between this practice and learning, terming this practice "camouflaged uptake" and call for further research on it.

The following table and graph show the amount of note-taking practice across the use of L1 and the TL. 
Table 0.8: Note-taking or "Camouflaged uptake" across the use of $L 1$ and the TL

\begin{tabular}{ccccc}
\hline \multirow{2}{*}{ FonF language } & \multicolumn{2}{c}{ Note-taking } & \multicolumn{2}{c}{ No note-taking } \\
& $\boldsymbol{n}$ & \% & n & \% \\
\hline L1 (Vietnamese) & 71 & 33.3 & 142 & 66.7 \\
\hline TL (English) & 22 & 9.0 & 222 & 91.0 \\
\hline Total & 93 & 20.4 & 364 & 79.6 \\
\hline
\end{tabular}

Graph 0.5: Note-taking or "Camouflaged uptake" across the use of L1 and the TL

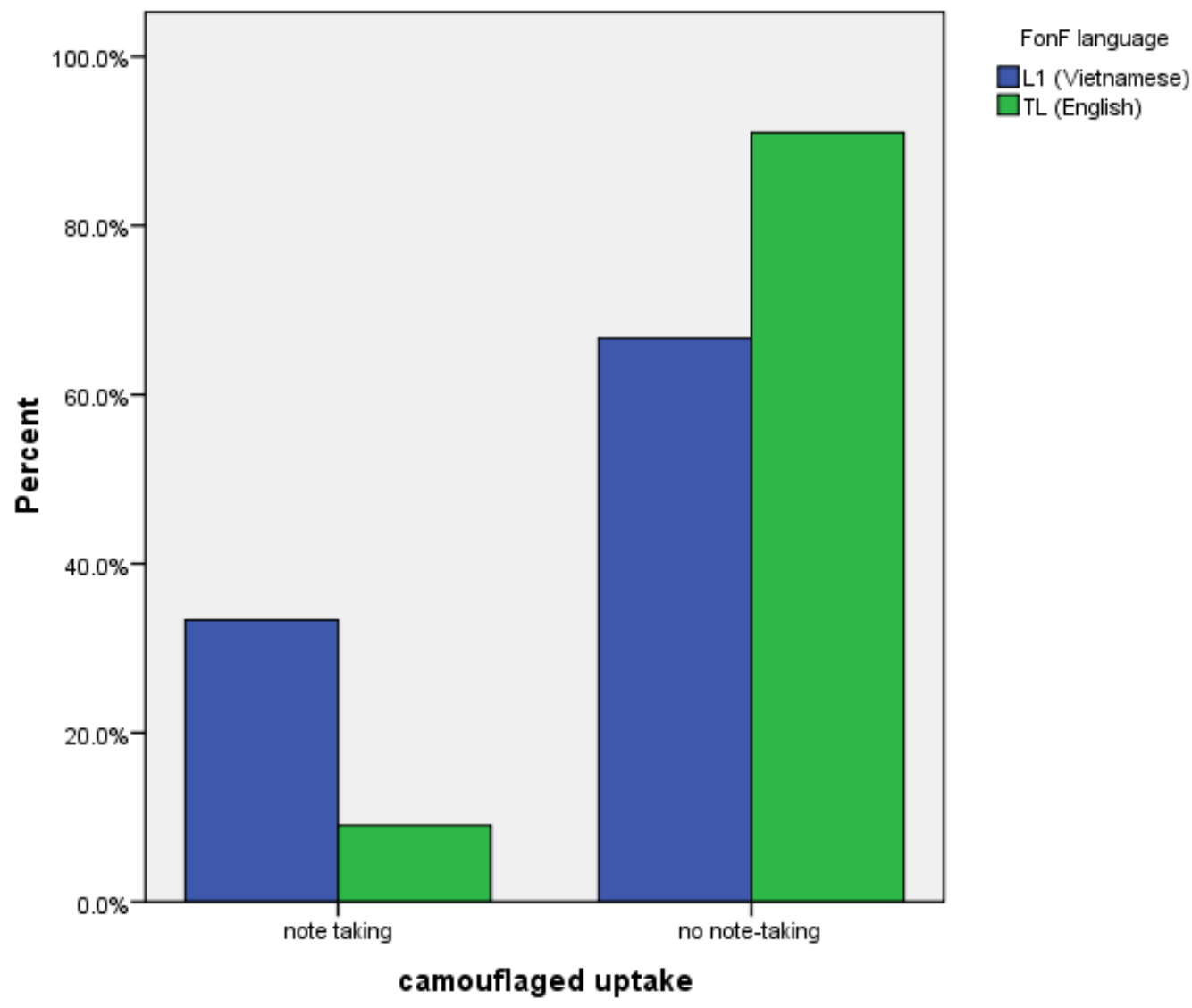

Table 8.8 and Graph 8.5 show that on average, the participants wrote down $20.4 \%$ of the linguistic items addressed in the FFEs. While only $9 \%$ of the feedback given in the TL was written down, the learner participants receiving feedback in L1 took notes of a third of the linguistic items given to them. 
The chi-square analysis is performed and the result $(\chi 2(d f=1, n=457)=41.488, p<0.001)$ reveals a significant difference between the two groups of FonF language. In other words, the learners receiving teacher feedback in L1 are significantly more likely to take notes about the feedback than those receiving feedback in the TL.

The following table and graph present the amount of note-taking across the uptake types.

Table 0.9: Note-taking or "camouflaged uptake" practice across uptake types

\begin{tabular}{ccccccccc}
\hline \multirow{2}{*}{ Note-taking practice } & \multicolumn{2}{c}{ Repair } & \multicolumn{2}{c}{ Needs repair } & \multicolumn{2}{c}{ Acknowledge } & \multicolumn{2}{c}{ No uptake } \\
& $\mathbf{n}$ & $\mathbf{\%}$ & $\mathbf{n}$ & $\mathbf{\%}$ & $\mathbf{n}$ & $\mathbf{\%}$ & $\mathbf{n}$ & $\boldsymbol{\%}$ \\
\hline Note taking & 58 & 62.4 & 2 & 2.2 & 16 & 17.2 & 17 & 18.3 \\
\hline No note-taking & 215 & 59.1 & 6 & 1.6 & 93 & 25.5 & 50 & 13.7 \\
\hline Total & 273 & 59.7 & 8 & 1.8 & 109 & 23.9 & 67 & 14.7 \\
\hline
\end{tabular}

Graph 0.6: Note-taking practice across uptake types

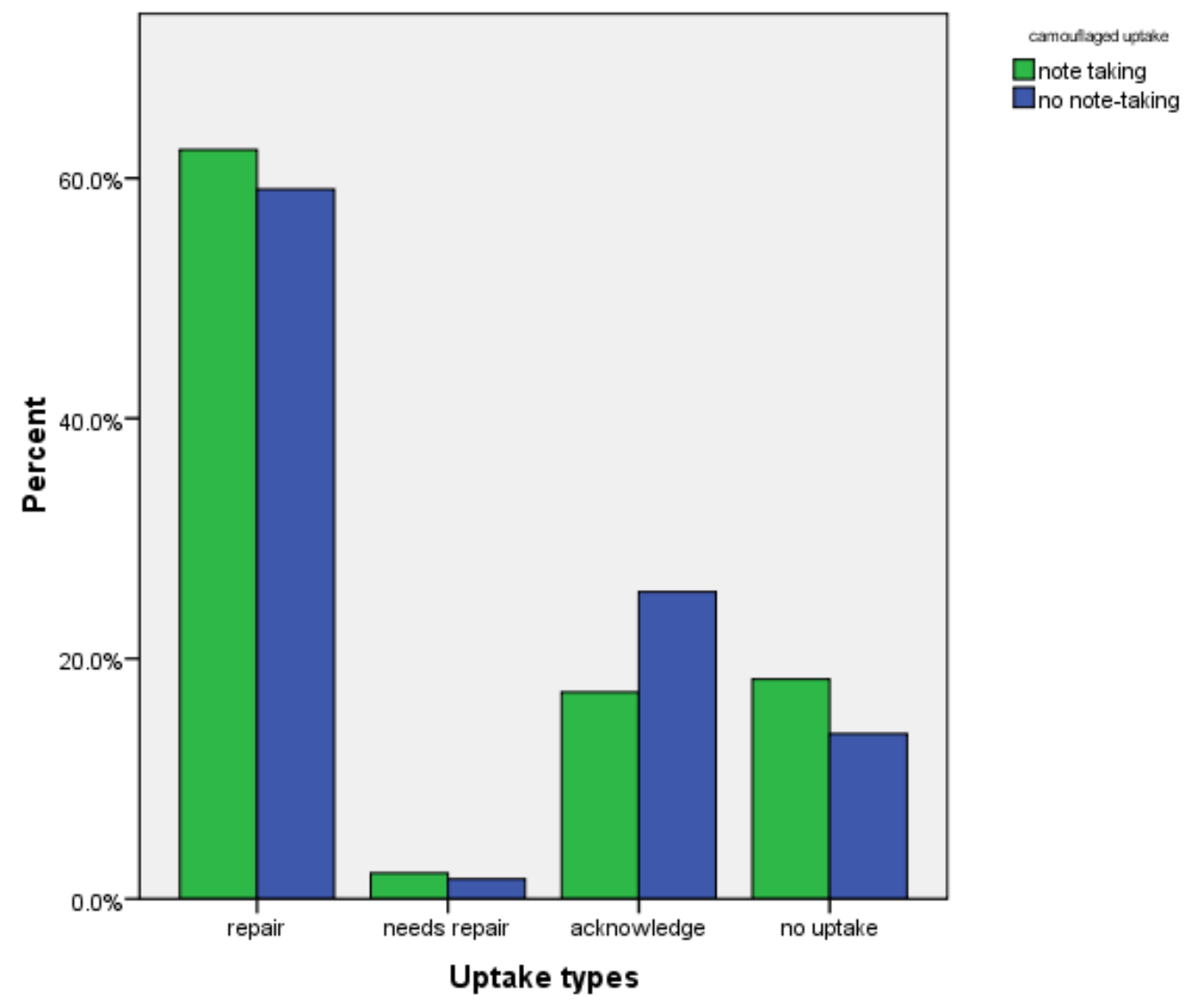


It can be seen from Table 8.9 and Graph 8.6 that the percentages of each of the uptake types are not dramatically different between the note-taking and no note-taking categories. While $62.4 \%$ of the FFEs with note-taking has repair as learner uptake, this rate is $59.1 \%$ for FFEs without note-taking. The rate of acknowledge is lower among FFEs with note-taking $(17.2 \%)$ than those without note-taking $(25.5 \%)$. On the contrary, the percentage of no uptake is higher when learners take notes of the teacher feedback than when they do not (18.3\% and $13.7 \%$, respectively).

Further chi-square analysis was performed to find out if the learners' note-taking had any impact on learner uptake. To do this, the needs-repair category is collapsed into the acknowledge category to make the unsuccessful uptake category to avoid low-cell counts (Moore $\&$ McCabe, 2003). The result $(\chi 2(d f=2, n=457)=2.958, p=0.228)$ shows that there is no significant association between the learners' note-taking practice and their production of uptake.

\subsection{Teacher use of $L 1$ and the $T L$ and its impact on learner uptake and note-taking}

In the 457 FFEs recorded during the interactive tasks in this study, $60 \%$ of the FFEs contained repair, followed by acknowledge (23.9\%). Only $1.8 \%$ of the FFEs had needsrepair as the uptake type. Nearly $15 \%$ of the teacher feedback receives no uptake from the learner participants.

The discussion section will start by addressing the frequency and types of uptake occurring in the experimental study before answering the question: whether the use of L1 leads to more learner uptake than the use of the TL. Learner proficiency and notetaking as possible factors influencing learner uptake across the use of L1 and the TL will also be examined.

\subsubsection{The frequency and types of uptake in an experimental study}

The following table shows the rates of repair and no uptake in this study and other studies in FonF. 
Table 0.10: Rate of repair and no uptake across the studies

\begin{tabular}{lcc}
\hline \multicolumn{1}{c}{ Study } & Repair & No uptake \\
\hline This study & $59.7 \%$ & $14.7 \%$ \\
\hline The descriptive study of this thesis & $21.6 \%$ & $25.5 \%$ \\
\hline Lyster \& Ranta (1997a) & $26.8 \%$ & $45 \%$ \\
\hline Ellis, et al. (2001a) & $54.8 \%$ & $26.1 \%$ \\
\hline Panova \& Lyster (2002) & $15.8 \%$ & $53.4 \%$ \\
\hline Loewen (2004b) & $50.2 \%$ & $18.2 \%$ \\
\hline Sheen (2004) & $56.5 \%$ & $17.7 \%$ \\
\hline Farrokhi \& Gholami (2007) & $15.2 \%$ & $\mathrm{n} / \mathrm{a}$ \\
\hline
\end{tabular}

From Table 8.10, it can be seen that in this study, the rate of successful uptake (or repair) on average is $59.7 \%$ of all the FFEs, needs-repair $1.8 \%$, acknowledge $23.9 \%$, and no uptake $14.7 \%$ (see Table 8.1 for details). In their study on CF conducted in four immersion classrooms at the primary level in Canada, Lyster \& Ranta (1997) report the rate of student turns with repair is $26.8 \%$ of the teachers' feedback turns (184 out of 686 turns) and the rate of no uptake is 309 out of 686 turns (45\%). In an adult ESL classroom in Canada, Panova \& Lyster (2002) find that the proportion of repair is $15.8 \%$ (65 out of 412 CF moves), while no uptake occupies $53.4 \%$ of the total CF moves. In their study taking place in an ESL setting in New Zealand, Ellis, et al. (2001a) report $54.8 \%$ of the FFEs results in learners' repair, and $26.1 \%$ of the FFEs has no uptake from the learners. In as similar setting, Loewen (2004b) reports 662 repair moves out of 1,318 FFEs, at the rate of $50.2 \%$, while no uptake occurs in 240 out of 1,318 FFEs, at the rate of $18.2 \%$. Another study on CF in two Korean EFL classrooms by Sheen (2004) reveals the rates of $56.5 \%$ of repair moves (105 out of 186 feedback moves) and $17.7 \%$ of no uptake. Farrokhi \& Gholami (2007) identify 115 successful uptake moves out of 641 LREs, at the rate of $15.2 \%$, in EFL classrooms in Iran. In the descriptive study of this thesis reported in the previous chapter, the rate of repair is $21.6 \%$ of the total feedback moves, and no uptake 25.5\%. The studies by Lyster \& Ranta (1997), Panova \& Lyster (2002), and Sheen (2004), however, do not include preemptive FonF. 
The above juxtaposition of research results shows that the rate of successful uptake in this experimental study is higher than in all the other studies mentioned. There are many reasons for this difference. First and foremost, the present study took place in an experimental setting in which the learners performed interactive tasks with the researcher as interlocutor. In this type of interaction, the learner participants had the interlocutor researcher's full attention to address their linguistic problems if any, and the learner participants, in turn, were less likely to be distracted from the feedback they were given. Moreover, the three interactive tasks lasted only between 10 and 15 minutes, which would not have tired out the learner participants as long classes may have. The intense attention to the short tasks inevitably resulted in more response to the interlocutor's feedback, and hence more successful uptake.

Secondly, the types of feedback given during these interactive tasks could also be counted as another reason for a higher rate of successful uptake. The researcher interlocutor used the FonF types of provide and elicit. Provide refers to explicit information given in the form of definitions, examples or metalinguistic explanations, and elicit refers to repeating errors, or giving prompts or clues, or eliciting solutions so that students recognize the gaps and correct themselves. These two types of feedback have been reported to result in the most successful uptake. For example, in their study, Lyster \& Ranta (1997) find that metalinguistic feedback can result in $45 \%$ of repair, and elicitation can lead to $46 \%$ of repair. Similarly, in Panova \& Lyster's (2002) study, there is $40 \%$ of metalinguistic feedback and $73.3 \%$ of elicitation leading to repair. Similar results can also be found in the studies by Sheen (2004) and Ellis, et al. (2001a).

Also, in the present study, the FFEs contain more than one teacher feedback move. The complexity of FFEs has been reported to be related to the success level of uptake. For example, in their study, Ellis, et al. (2001a) find that $89.7 \%$ of multi-move FFEs leads to successful uptake, while this rate is only $69.9 \%$ for single-move ones. In his study, Loewen (2005) discovers that multi-move FFEs are about 4.5 times more likely to than single-move FFEs to produce learner uptake.

Another factor which also plays a part in the high level of uptake in this study comes from the experimental setting where the learner participants were paid a small sum to perform the interactive tasks. The pay seemed to bind them to some responsibility to do 
their best at the tasks. In addition, the learner participants were volunteers who were excited to know about the research. They participated in the tasks with exceptional effort. Compared with the descriptive study of this thesis, the learner participants made very few Vietnamese responses to the teacher feedback. It could be assumed from this fact that they found using Vietnamese inappropriate in the situation. Their commitment in participating in the interactive tasks may have resulted in such a high level of successful uptake and a low level of no uptake

\subsubsection{The use of $L 1$ and the TL and its impact on learner uptake}

From the results of the statistical analysis, the answer to the question whether the use of L1 and the TL has any impact on learner uptake could be put as follows: while the teacher use of L1 and the TL does not have any significant impact on learners' production of successful uptake, it significantly influences learners' producing unsuccessful uptake or no uptake. The data analysis shows that the learner participants receiving teacher feedback in $\mathrm{L} 1$ are significantly more likely to give no response and less likely to produce unsuccessful uptake than those receiving teacher feedback in the TL. In other words, the learner participants in both experimental groups produce similar amount of successful uptake, but those in the TL groups produced more uptake overall than those in the L1 groups. The learners receiving feedback in the TL seemed more ready to use the TL even though they might make more mistakes, or misunderstand the feedback, or may practise very minimal responses like acknowledging tokens "uh", "yeah" rather than keep silent. On the contrary, when they could not produce successful uptake, the learners receiving feedback in L1 tended to keep silent instead of responding to teacher feedback.

This behaviour by learners has been widely observed in other studies describing learners' practice in classroom (e.g. Bailey, 1985; Brosh, 1996; Prodromou, 1991). The teacher who is active and invites interaction will receive more verbal response from his learners. The teacher's exclusive use of the TL will push the learners to use the TL (especially in this experimental study where each learner participant has all the attention of the interlocutor researcher). On the contrary, the teacher's use of L1 implicitly gives the learners the permission to use L1; however, they chose to keep silent rather than giving any Vietnamese response since they were supposed to "perform some communicative tasks in English in 10-15 minutes" as the advertisement put to recruit 
volunteers for the research. Being in an unfamiliar setting where they received one on one English interaction and volunteering to join the study may have pushed the learners to perform the tasks at their best without involving L1 use. While carrying out the interactive tasks for the learner participants in the L1 group, the researcher also observed that some advanced learner participants showed their surprise (and slight discontent) when I kept giving them feedback in L1. This behaviour is understandable because as reflected in the descriptive study of this thesis, at the advanced level, only $13.8 \%$ of teacher feedback moves were given in L1.

The results suggest that the teacher use of the TL when giving feedback induce more learner production than the teacher use of L1. As pointed out by Swain (2005), learner production of output helps them move from the "semantic level" of the comprehension stage to the "syntactic level" of the production stage. Even though uptake may not be successful, the learners at least practised the new linguistic items and tested their interlanguage hypotheses (Ellis, et al., 2001a; Lyster \& Ranta, 1997; Swain, 2005), and they were open to receiving more feedback for their errors and hence being offered more learning opportunities. As a result, the teacher use of the TL in giving feedback may have led to more learning opportunities for learners than that of L1.

From the data analysis of this study, the argument that the teacher use of L1 is more helpful for learners at low proficiency levels than the TL does not seem to apply to learners' production of uptake in FonF. In this study, the data analysis shows that the patterns of learner uptake at the advanced level and the beginning level are similar within each FonF language group while they are significantly different between the two language groups within each proficiency level. In other words, despite the learners' proficiency level, they produced significantly more uptake (both successful and unsuccessful) when receiving feedback in the TL than in L1. The results suggest that no matter which proficiency level they were at, the teacher use of the TL is significantly more likely to induce learners to produce output than the use of L1.

The finding that there is no significant difference in the uptake types related to L1 and TL use across the proficiency levels can be explained in many ways. First of all, it finds support in the Input Hypothesis which emphasizes the role of comprehensible input in language learning (Krashen, 1980, 1985). A common explanation for the use of L1 in providing feedback, especially to beginning learners is that this use improves the 
comprehensibility of input for learners (e.g. E. Chau, 2007; Forman, 2007). In this study, the interactive tasks were picture-based and focused on vocabulary items and grammatical points illustrated by the pictures, which means comprehensible input was partly enabled by the visuals. Moreover, the researcher used a script for the tasks which had been piloted on a group of participants to guarantee the input in the TL was as comprehensible as it is in L1 at both proficiency levels. Secondly, the participants were volunteers who were usually quite confident about their ability and capable enough to join the interactive tasks. Last but not least, the tasks were confined to vocabulary items (such as items in the living room for the beginning level and kitchen items for the advanced level) and grammatical points (past tense for the beginning level and modal verb form), which were well illustrated by the pictures in use. Abstract notions which usually give a good reason to teacher use of L1 (e.g. Butzkamm, 1978; Franklin, 1990) are absent from these tasks. These facts may contribute to the comprehensibility of the input in the TL to become intake (Krashen, 1985).

However, this experimental study also sheds some light on the some neglected aspects of the construct of uptake in the operationalisation of uptake in FonF research. The following section will discuss the mismatch between the definition and rationales of uptake and the operationalisation of uptake in FonF. The learner's note-taking practice, another under-researched aspect of the learner's reaction to teacher feedback, will also be discussed.

\subsubsection{The use of $L 1$ and the TL and its impact on "camouflaged uptake"}

Firstly, the statistical analysis shows that the learners who received feedback in the TL are less likely to take notes about the feedback than those receiving feedback in L1. There are some possible explanations for this fact. First of all, in this experimental study which is based on vocabulary- and morphosyntax-focused interactive tasks, the number of vocabulary-focused FFEs occupies $76.4 \%$ of the total. Learners have been observed to use note-taking as a cognitive strategy when they receive translations of vocabulary items (C. J. White, 1996). This may explain the significantly higher rate of the learners taking notes when they received teacher feedback in L1 than in the TL.

Secondly, this fact can find an explanation from van Patten's (1996) hypothesis on input processing stating that in real-time language processing by second language learners, 
meaning and form compete for a limited attentional resources. When receiving feedback in L1, the attentional resources of the learners in this study were not taxed as much as those of the learners receiving feedback in the TL. As a result, they could more easily attend to meaning and form simultaneously including processing the input to give uptake and taking notes about the feedback.

The statistical data analysis reveals no association between the taking-note practice and uptake. This result contradicts Farrokhi \& Gholami's (2007) explanation that the low rate of uptake in their study may have some association with the learners' note-taking practice. However, it is likely that learners in dyadic tasks with a researcher interlocutor in an experimental study will have different learning conditions from those in intact EFL classes. The learners in the experimental study may have opportunities to take notes and provide uptake with the interlocutor's full attention, while those in realistic EFL classes are more likely to do either of the two activities as the teacher may have to pay attention to other learners at the same time.

The results from this set of data in this study suggest several things. First, since notetaking practice does not seem to influence uptake types, further research needs to be conducted on this practice in relation to learner noticing and language development (which will be discussed in the next two sections on noticing and learners' language development in this study). Since teacher use of L1 in giving feedback seems to induce more note-taking among learners, the relationship between note-taking and learners' noticing and language learning needs to be explored before any implications could be induced from this practice. Another point which also calls for further exploration is the linguistic types in relation to learners' note-taking practice. In this study where the linguistic items are lexical and morphosyntactic, the learners are found to take notes significantly more about lexical items than morphosyntactic items. This fact suggests that learners' note-taking practice may vary across the types of linguistic items and hence, the teacher use of L1 in giving feedback may have different impact on FFEs with different linguistic foci. 


\subsection{The neglected aspects of the construct of uptake in FonF}

The analysis of the data sets in this study and the descriptive study raises two issues about the operationalization of uptake in FonF research which are discussed in this section.

\section{Issue 1: Mismatch between definition and operationalisation of uptake}

The first issue concerns the invisibility of uptake in pre-emptive FonF triggered by learners' comprehension problems. Although it is included in the definition of uptake provided by Long and Robinson (1998), it was not included in the operationalisation of uptake in FonF research to date. This is a problem that has its roots in the history of the terminology used in this area of research. The concept of uptake as used presently in FonF research dates back to research on corrective feedback (CF). $\mathrm{CF}$ as defined by Chaudron (1977, p. 31) is the teacher's reaction "which clearly transforms, disapprovingly refers to, or demands improvement of the learner utterance". The definition implies that $\mathrm{CF}$ revolves around learners' errors during their process of producing an utterance. When FonF is first defined by Long \& Robinson (1998, p. 23), it refers to "an occasional shift of attention to linguistic code features - by the teacher and/or one or more students - triggered by perceived problems with comprehension or production". For some time, FonF was considered a new term for CF or negative evidence (Lyster \& Ranta, 1997) until later, when Ellis and his colleagues (2001; 2002) separate FonF from CF by defining the learner's interlanguage gap as the trigger for FonF rather than the learner's error in CF. By taking interlanguage gaps as FonF trigger, Ellis and his colleagues refer to the original definition by Long and Robinson (1998), emphasising that FonF covers not only learners' gaps in production (e.g. errors made while learners are attempting to interact), but also learners' gaps in comprehension (e.g. learners' queries about features of the linguistic code they encounter in communicative tasks).

Just as the construct of FonF has a larger scope than CF (Ellis, et al., 2001b, 2002), so also the definition of uptake has been expanded by Ellis and his colleagues (2001a). Originally used by Allwright (1984 in Ellis, et al., 2001a) to refer to what learners report learning during or at the end of the lesson, uptake was later used by Lyster \& Ranta (1997) in their study on CF to refer to learners' immediate response to teacher feedback for communication purposes. In FonF research, uptake has been redefined with a broader prospective according to which uptake is an optional move made by a 
learner in response to some preceding move made by another participant (usually the teacher) when the learner's interlanguage gap is revealed (Ellis, et al., 2001a). Ellis and his colleagues (2001a, p. 286) consider an uptake move successful "when it demonstrates that a student can use a feature correctly or has understood a feature". However, while the new definition of uptake covers the comprehension aspect, the new operationalisation of uptake does not include the comprehension aspect of the uptake definition. The following range of examples is taken from the data set of this study to illustrate this issue.

The following example illustrates an error a learner made when doing the interactive tasks. The learner receives feedback and gives uptake in the form of repair in a reactive FFE (Ellis, et al., 2001a; Lyster \& Ranta, 1997).

\section{Episode 05 AE18}

[According to the task, it is the learner's turn to borrow a kitchen item from the researcher]

AE18: (.) Could you lend me a ...big spoon? [laughs]

R: this is not a spoon. As you see, it is big, long-handled, with a deep scoop. You use it to convey food from a pot to a plate, for example. It is called a ladle.

AE18: ladle

R: $\quad$ uhuh. Ladle

AE18: ladle. Thank you. Could you lend me a ladle?

The following example from this data set illustrates a learner interlanguage gap in production. The learner inquires about a new vocabulary item, receives feedback and give uptake in the form of apply in a preemptive FFE (Ellis, et al., 2001a).

\section{Episode 04 AE14}

[According to the task, it is the learner's turn to borrow a kitchen item from the researcher]

AE14: how about this? [points at the picture of a whisk]

R: this one is a whisk.

AE14: whisk. How to spell? 
R: whisk, w-h-i-s-k. This is a bundle of wires attached to a handle and you use it to stir liquid like oil or you mix oil or flour or eggs together to make a cake for example. A whisk.

AE14: a whisk. Can I borrow you a whisk?

The following FFE exemplifies a learner interlanguage gap in production. The learner gets stuck describing a new item, receives feedback and acknowledges the feedback by saying "yes". The learner's uptake move is of an acknowledge type in a preemptive FFE (Ellis, et al., 2001a).

\section{Episode 09 BE01}

[According to the task, the learner describes what happened in a picture including a lady slipping on a banana skin.]

BE01: the lady slipped on the... (.)

R: how do you call this? [points at the banana skin] (.) banana...?

BE01: banana...

R: skin

BE01: yes

R: banana skin

BE01: yes

The three examples above illustrate FFEs triggered by the leaers searching for unfamiliar wordsbthat they need to use in subsequent turns in order to complete the task. In the first and the third examples, the teacher initiates the FFE, while in the second example, the learner is the initiator. All three FFEs address a feature of the linguistic code which the learners need to retrieve for their productive turns. In the first two examples, the uptake moves are considered successful since the learners make use of the targeted linguistic features correctly after feedback (Ellis, et al., 2001a; Lyster \& Ranta, 1997). In the third example, however, the uptake move is coded as unsuccessful since the learner fails to make use of the new vocabulary item given in the teacher feedback (Ellis, et al., 2001a).

The following example, however, illustrates a learner interlanguage gap in comprehension. The learner asks about the meaning of a new vocabulary item, receives feedback, and acknowledges the feedback by saying "yes". 


\section{Episode 02 AE16}

[According to the task, it is the researcher's turn to borrow a kitchen item from the learner]

R: can I borrow your whisk?

AE16: your whisk? [looks for the whisk for a moment]

R: you know what a whisk is?

AE16: no

R: a whisk is a bundle of wire attached to a short handle and you use it to stir things like eggs or oil to mix them together...

AE16: yes [picks out the whisk and gives it to the researcher]

In this example, the communication flow is halted due to the learner's interlanguage gap in understanding a new vocabulary item. The learner needs to retrieve the meaning of the new vocabulary item for a receptive turn in which he needs to pick out the correct kitchen item and give it to the interlocutor. In this example, the uptake move is coded as acknowledge and considered unsuccessful since the learner fails to produce the new vocabulary item (Ellis, et al., 2001a).

In the first three examples, the learners move from meaning to form, a process equivalent to productive retrieval in which the learner searches for or retrieves a form to express a given meaning (e.g. sees a picture of a banana skin and has to name it) (Nation, 2001). In contrast, in the last example, the learner searches for or retrieves a meaning for a given form (hears 'whisk' and tries to locate the picture which matches it), a process equivalent to receptive retrieval (Nation, 2001; van Patten, 1996). In the first two examples, the learners' uptake moves are considered successful because they can use the two new linguistic features correctly. In the third and fourth examples (09 BE01 $\&$ 02AE16) the moves are considered unsuccessful because the learners do not use the target forms. However, there is an important difference between these two "unsuccessful" uptake moves. In the third example, there is no way of knowing whether the learner did in fact comprehend and/or understand the word "skin". By contrast, in the last example, the learner clearly shows he comprehends the targeted word "whisk" by successfully selecting a picture of a whisk in response to the interlocutor's request. But he does so without having to use the targeted word. The operationalization of the construct of uptake as used in recent research studies on FonF (e.g. Ellis, et al., 2001a; 
Loewen, 2004b) fails to deal with this type of uptake and indiscriminately groups this successful receptive retrieval into the category of unsuccessful uptake with the third example.

\section{Issue 2: Mismatch between rationales for uptake and operationalisation of uptake}

The second issue concerns a mismatch between a rationale for linking uptake to acquisition in FonF research and the operationalization of uptake. The rationale in question is that uptake facilitates acquisition in two ways: it provides the learners with opportunities for pushed output and for automatizing retrieval of the new linguistic items through practice (Ellis, et al., 2001a; Lyster \& Ranta, 1997). The following example illustrates the learner making use of the new linguistic item explained in the teacher feedback.

\section{Episode 02 BE04}

[According to the task, the learner tells the interlocutor where the pipe is in her picture]

R: Have you seen my pipe anywhere?

BE04: uhm, (.) can you explain what is pipe?

R: $\quad$ pipe is a kind of equipment for smoking.

People put tobacco in its small bowl and they smoke

[points at the pipe in the picture].

BE04: ok, I understand... understood.

Your pipe is on the table, next to the radio and the lamp.

In this example, the learner initially does not understand the meaning of the word "pipe". However, after it is explained, he successfully finishes the task using the new word accordingly. The uptake move in this example is categorised as apply (Ellis, et al., 2001a), successful uptake in a preemptive FFE. The word is used twice by the learner, one before the feedback and one after.

In the following example, however, the learner does not make use of the new vocabulary item after it is explained.

\section{Episode 02 BE21}

[According to the task, the learner tells the interlocutor where the pipe is in her picture] R: $\quad$ where is my pipe? 
BE21: my pipe?

R: pipe

BE21: what's pipe?

R: $\quad$ pipe is an implement for people to smoke.

It has a small bowl at one end and people put tobacco in there to smoke [points at the pipe in the picture].

BE21: oh, I see. It is in the table, behind the radio.

The situation is similar to the one in the previous example, but in this example, the learner successfully finished the task without using the new word "pipe". Instead of using the word, the learner replaced the new noun with the pronoun "it". The uptake move in this example is categorised as no uptake since the word is not put into use after the feedback is given (Ellis, et al., 2001a). However, it is used twice, before the feedback.

The two examples show that the learners in both situations use the unfamiliar word twice (and before the word is understood!). If uptake facilitates learning because by providing uptake, learners practise new linguistic items, then the learners in these examples have similar amount of "practising" the new linguistic item: they both use the word "pipe" twice in the FFEs. The follow-up SR sessions and custom-made post-tests indicate that they both report noticing of the item, and they both fail to produce this word in the test question about this item. This juxtaposition of the two examples suggests that the operationalisation of uptake in some cases may be misleading when judging the success of learner uptake without taking into consideration the comprehension side of an FFE. This situation is most likely to happen when FFEs are preemptive and a learner's inquiry of a linguistic item is for a comprehension turn rather than a production one.

In conclusion, the operationalisation of uptake in this data set reveals a neglected aspect of the construct of uptake: comprehension aspect of the learners' response to teacher feedback. This aspect is not addressed in CF where the trigger of the teacher feedback is learners' errors in producing output. While the scope of FonF and uptake in FonF has been widened to cover both reactive feedback and preemptive feedback (Ellis, et al., 2002), the operationalisation of uptake in FonF research seems to fail to take into account the nature of uptake in preemptive FFEs in which learners inquire about a 
linguistic form for the purpose of receptive retrieval rather than productive retrieval (Nation, 2001). Though this data set is confined to vocabulary- and morphosyntaxfocused episodes, these make of the majority of FFEs in preemptive FonF (Ellis, et al., 2001a; Farrokhi \& Gholami, 2007; Loewen, 2004b). Failure to discriminate the learner reaction in their receptive turns from that in their productive turns when judging the success of learner uptake, therefore, compromises the validity of the construct of uptake as an index of language acquisition.

In this study, the FFEs in which these aspects of uptake were observed accounted for a small fraction of the data set (under $2 \%$ in the descriptive study and under $4 \%$ in the experimental study) which did not influence the final findings. As a result, the data coding system was not adjusted. This also ensured that comparison with the findings of other studies involving comparing like wtith like. However, as pointed out in the previous section, it is necessary to consider these aspects of uptake, especially when the data set focuses on vocabulary and when learners are performing interactive tasks involving comprehension as well as production. These findings also suggest that other tools measuring learning should be used simultaneously besides uptake to obtain a comprehensive analysis of the data.

\subsection{Summary}

The analysis of this data set has given an answer to the research question about whether the teacher use of L1 in FonF leads to more learner uptake than the TL. To begin with, the data analysis indicates that learner uptake in this experimental study occurs more frequently than in the descriptive study of this research and other descriptive studies in the field. This fact suggests that in dyadic interactions with the researcher as interlocutor, the learners receive the interlocutor's full attention and they are less likely to be distracted from the tasks than the learners in intact classes. In addition, the types of feedback in the study are provide and elicit with multi-moves, which have been documented to lead to more uptake than other types of feedback. However, although the learners are well-motivated and well-resourced in dyadic interactions with the researcher in the experimental study, they do not give uptake in every FFE. Since a large amount of input is condensed in the three interactive tasks performed in a short period of time, the learners may not be able to process all the provided input. When 
cognitive overload occurs, it is unlikely that all comprehensible input will become intake.

The data analysis also reveals that feedback in L1 did not lead to more successful uptake than feedback in the TL. On the contrary, teacher feedback in the TL induced significantly more unsuccessful uptake and less silence than feedback in L1. In other words, when the interlocutor used the TL to give feedback, the learners were more responsive and more productive by responding by unsuccessful uptake such as needsrepair or acknowledge rather than keeping silent. The learners receiving teacher feedback in the TL may have felt more pushed to produce output in response, while teacher feedback in L1 may have discouraged the learners from practising the language when the teacher does not use it herself. The results of the data analysis hence suggest that the teacher use of the TL in giving feedback makes learners more open to production and further feedback, which, in turn, brings them more learning opportunities. This finding confirms the result of the descriptive study that teacher feedback in L1 led to more no uptake and less learner output production in the forms of successful uptake and unsuccessful uptake.

The patterns of feedback types in relation to the use of L1 and the TL are similar across the proficiency levels. The data analysis suggests that the learners at a low proficiency level do not always need teacher feedback in L1 as long as the input is made comprehensible enough and the learners are well-motivated. In other words, despite learners' proficiency levels, when learners are supplied with comprehensible input in the TL, they are more likely to produce output than receiving input in L1. This finding confirms the result of the descriptive study that learners' proficiency levels are not associated with their uptake production when they receive feedback in L1 or the TL.

The findings of the present study shows that though the learners' note-taking practice does not influence the types of uptake they produced, there is an association between the teacher use of L1 and the TL when giving feedback and the learners' note-taking practice. The analysis reveals that the learners were significantly more likely to take notes about the teacher feedback when they received the feedback in L1 than in the TL. This result suggests that the low level of cognitive challenge in processing the input in L1 may have led to the learners' more frequent note-taking practice. 


\section{Chapter 9: FonF in L1 and the TL: Impact on learner noticing and language development}

This chapter presents the findings about the relationship between the language of FonF (that is, L1 or the TL) and learner noticing and language development. The first section of this chapter reports and discussed the levels of learner noticing across the use of L1 and the TL in FonF. In the second section of the chapter, the relationship between the use of L1 and the TL in FonF and language development will be presented.

\subsection{FonF in L1 and the TL: Impact on learner noticing}

After the learners finished the interactive tasks, they participated in stimulated recall (SR) and focused question (FQ) sessions on the following days. SR sessions were conducted individually between the learner participants and the researcher. During these sessions, the learners talked about the feedback they received, and the data on learner noticing was coded as noticing and no noticing.

\subsubsection{The levels of learner noticing across the use of $L 1$ and the $T L$ in FonF}

The table and graph below show the amount of learner noticing across the use of L1 and the TL in the experimental study (for more information about coding learner noticing, please refer to Section 5.4.3).

Table 0.1: Amount of learner noticing across the use of $L 1$ and the TL

\begin{tabular}{ccccc}
\hline FonF language & \multicolumn{2}{c}{ Noticing } & \multicolumn{2}{c}{ No noticing } \\
\hline L1 (Vietnamese) & 189 & 88.7 & 24 & n \\
\hline TL (English) & 218 & 89.3 & 26 & 11.3 \\
\hline Total & 407 & 89.1 & 50 & 10.7 \\
\hline
\end{tabular}




\section{Graph 0.1: Amount of learner noticing across the use of L1 and the TL}

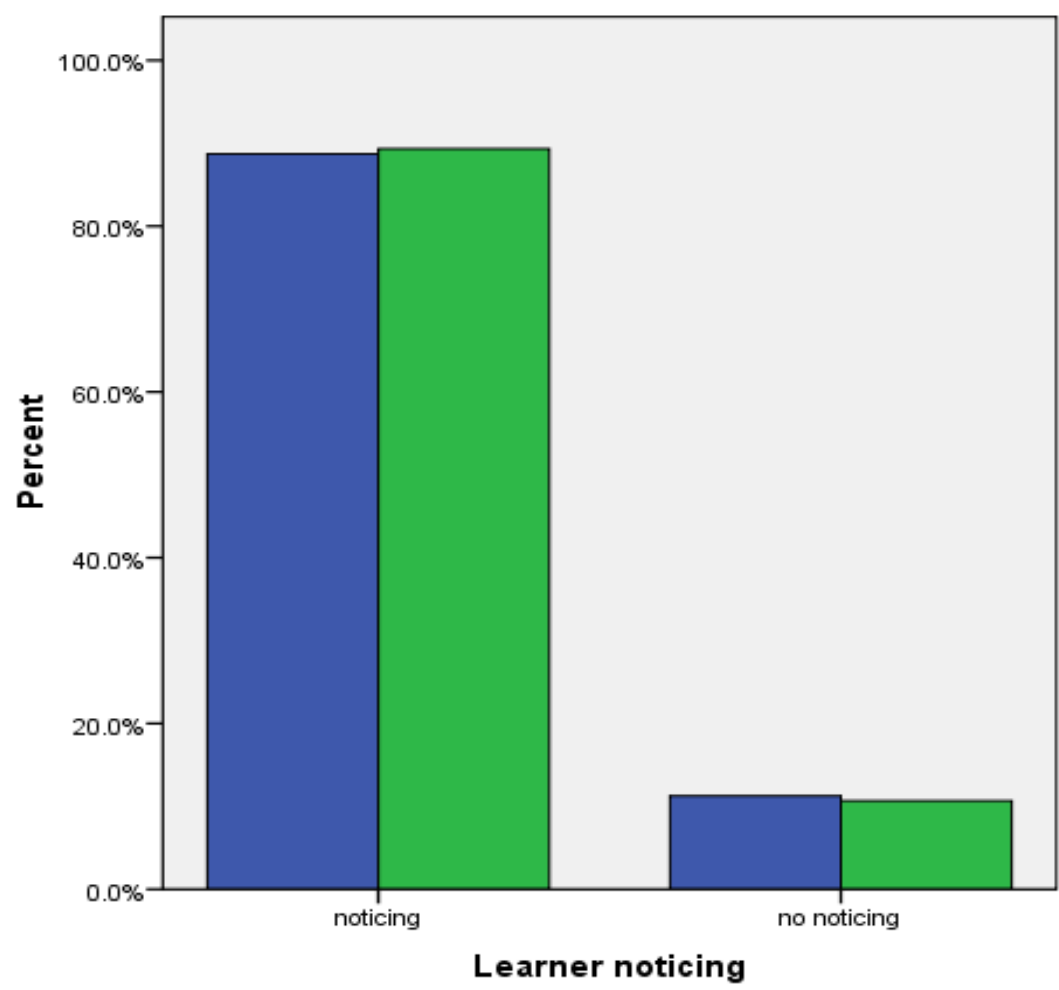

FonF language

L1 (Vietnamese)

$\square T L$ (English)

As can be seen from Table 9.1 and Graph 9.1, the learners in the L1 groups report noticing of $88.7 \%$ of the linguistic items addressed in the teacher feedback while this rate is $89.3 \%$ in the TL groups. To investigate the significance of the difference between the two FonF language groups, the chi-square analysis is performed. The result $\left(\chi^{2}\right.$ $(d f=1, n=457)=.044, p=0.834)$ indicates no statistically significant difference between the L1 groups and the TL groups.

To identify whether the teacher use of different FonF languages makes any differences within each proficiency level, the data of the two proficiency groups is analysed separately. 
Table 0.2: Learner noticing across the teacher use of L1 and the TL layered by the proficiency levels.

\begin{tabular}{cccccc}
\hline \multirow{2}{*}{ Proficiency level } & \multirow{2}{*}{ FonF language } & \multicolumn{2}{c}{ Noticing } & \multicolumn{2}{c}{ No noticing } \\
\multirow{2}{*}{ Beginning } & L1 (Vietnamese) & 93 & 86.1 & 15 & 13.9 \\
\cline { 2 - 6 } & TL (English) & 113 & 87.6 & 16 & 12.4 \\
\cline { 2 - 6 } & Total & 206 & 86.9 & 31 & 13.1 \\
\hline \multirow{2}{*}{ Advanced } & L1 (Vietnamese) & 96 & 91.4 & 9 & 8.6 \\
\cline { 2 - 6 } & TL (English) & 105 & 91.3 & 10 & 8.7 \\
\cline { 2 - 6 } & Total & 201 & 91.4 & 19 & 8.6 \\
\hline
\end{tabular}

Graph 0.2: Learner noticing across the teacher use of L1 and the TL layered by the proficiency levels.

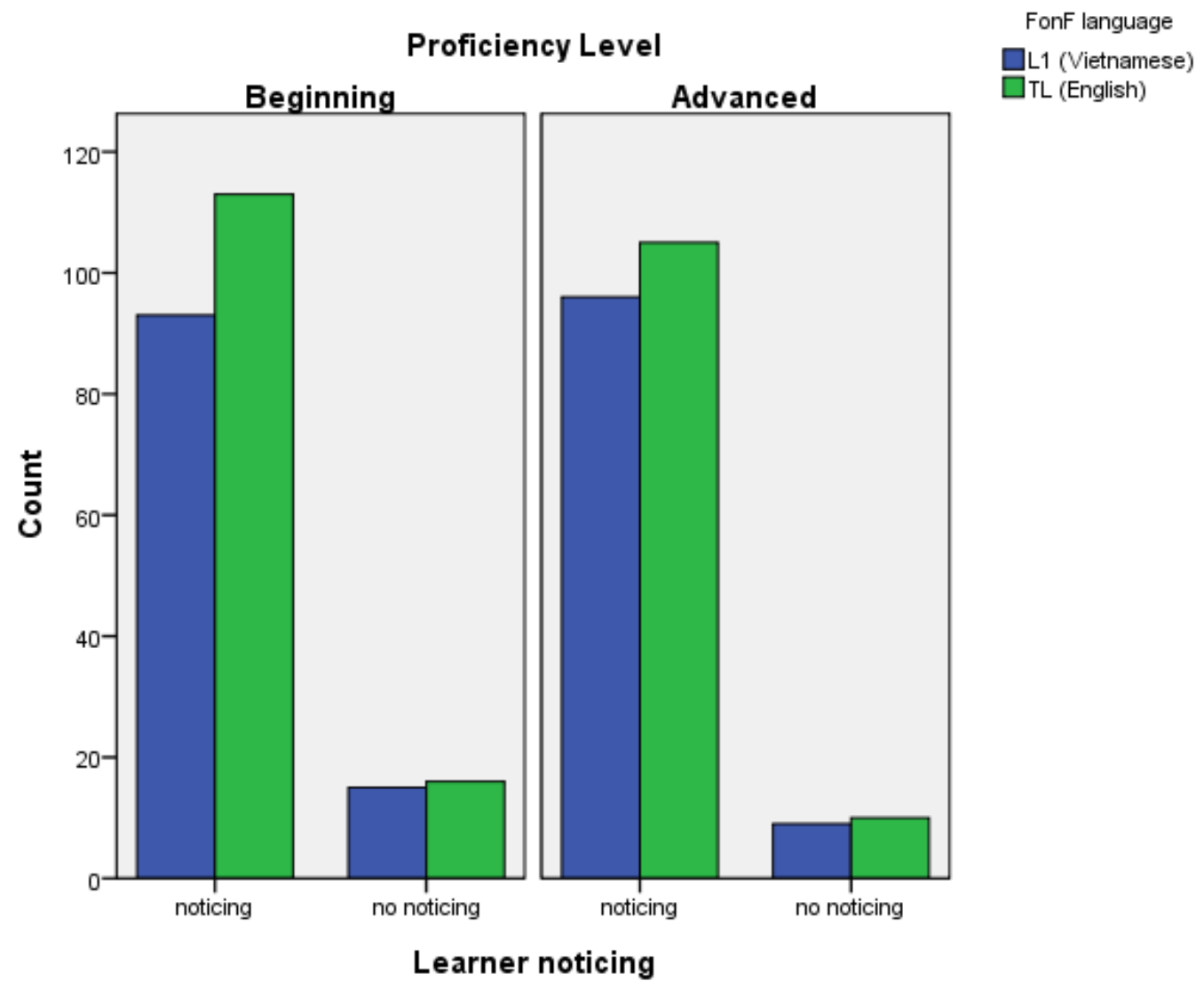


Table 9.2 and Graph 9.2 show that at the beginning level, the learners receiving feedback in L1 report noticing of $86.1 \%$ of the feedback while for those receiving feedback in the TL, this rate is $87.6 \%$. Noticing is reported with higher proportions at the advanced level than at the beginning level with $91.4 \%$ for the L1 group and $91.3 \%$ for the TL group.

Two chi-square analysis tests are performed separately for the two proficiency levels and the result reveals that at the beginning level, there is no significant difference in learner noticing between the group receiving feedback in L1 and that in the TL $\left(\chi^{2}\right.$ $(d f=1, n=237)=0.114, p=0.735)$. Similarly, the result also shows no significant difference in the amounts of noticing reported by the two groups receiving teacher feedback in the two different languages at the advanced level $(\chi 2(d f=1, n=220)=0.001$, $p=0.974)$.

To find out whether learner noticing is different between the two proficiency groups within each FonF language group, the data is analysed across the proficiency layered by the teacher use of L1 and the TL.

Table 0.3: Learner noticing across the proficiency levels layered by the teacher use of L1 and the TL.

\begin{tabular}{cccccc}
\hline \multirow{2}{*}{ FonF language } & Proficiency level & \multicolumn{2}{c}{ Noticing } & \multicolumn{2}{c}{ No noticing } \\
& Beginning & 93 & 86.1 & 15 & 13.9 \\
\hline \multirow{2}{*}{ L1 (Vietnamese) } & Advanced & 96 & 91.4 & 9 & 8.6 \\
\cline { 2 - 6 } & Total & 189 & 88.7 & 24 & 11.3 \\
\cline { 2 - 6 } TL (English) & Beginning & 113 & 87.6 & 16 & 12.4 \\
\cline { 2 - 6 } & Advanced & 105 & 91.3 & 10 & 8.7 \\
\cline { 2 - 6 } & Total & 218 & 89.3 & 26 & 10.7 \\
\hline
\end{tabular}


Graph 0.3: Learner noticing across the proficiency levels layered by the teacher use of $L 1$ and the TL.

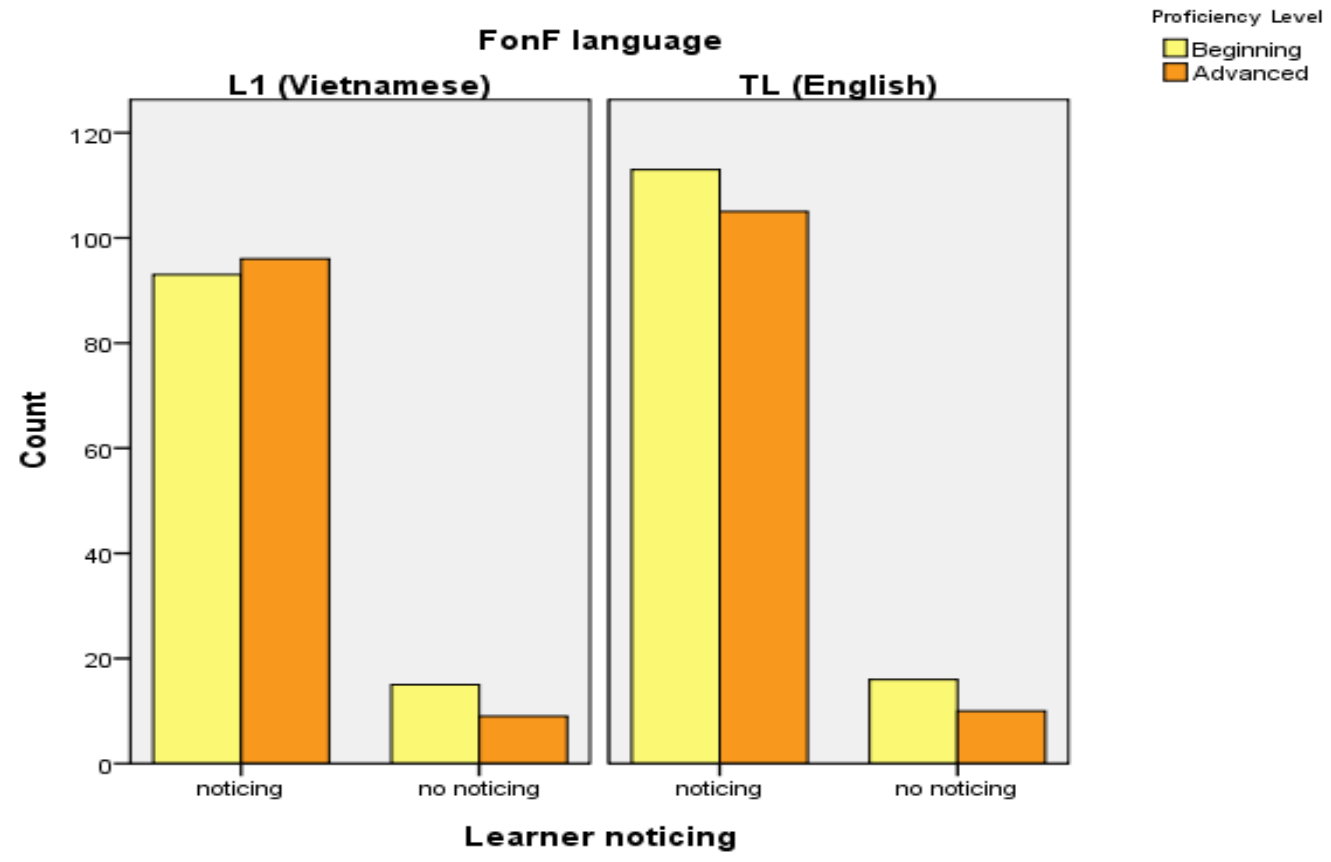

Table 9.3 and Graph 9.3 show that among the learners receiving feedback in L1, the learners at the advanced level reported more noticing than those at the beginning level (91.4\% and $86.1 \%$, respectively). Similarly, in the TL groups, the advanced learners reported more noticing $(91.3 \%)$ than the beginning learners $(87.6 \%)$.

Two separate chi-square tests are performed to identify any significant difference between the two proficiency levels within each language group. The result for the L1 groups $(\chi 2(d f=1, n=213)=1.506, p=0.220)$ reveals that there is no significant difference in learner noticing between the two proficiency groups. Likewise, the chi-square analysis result for the TL groups $\left(\chi^{2}(d f=1, n=244)=0.878, p=0.349\right)$ also shows that the difference in learner noticing between the advanced learners and the beginning learners is not statistically significant.

The following table and graph present how learner noticing takes place in relation to the learners' note-taking practice. 
Table 0.4: Learners' note-taking practice and learner noticing

\begin{tabular}{ccccc}
\hline $\begin{array}{c}\text { Note-taking } \\
\text { practice }\end{array}$ & n & Noticing & \multicolumn{2}{c}{ No noticing } \\
\hline Note taking & 91 & 97.8 & 2 & n \\
\hline No note-taking & 316 & 86.8 & 48 & 13.2 \\
\hline Total & 407 & 89.1 & 50 & 10.9 \\
\hline
\end{tabular}

\section{Graph 0.4: Learners' note-taking practice and learner noticing}

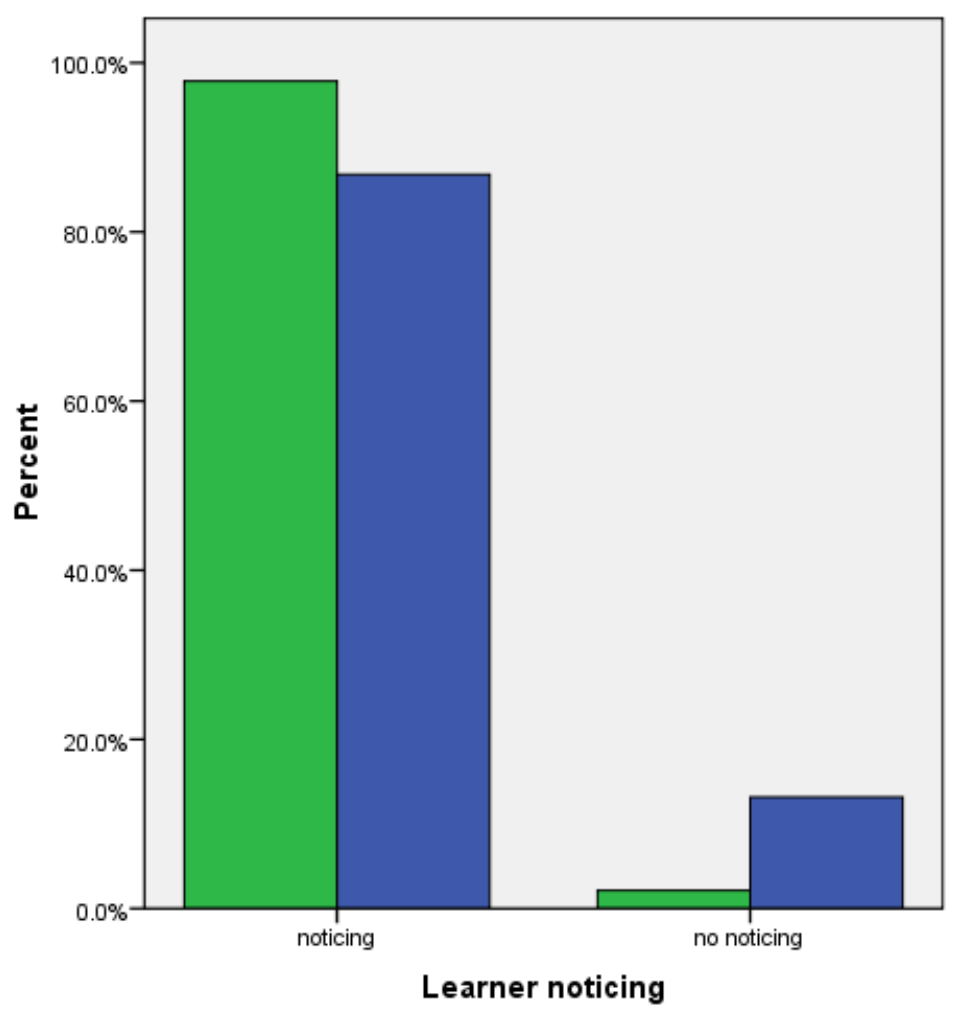

camoulagod uptake

note taking

$\square$ no note-taking

Learner noticing

It can be seen from the table and graph that the learners report noticing of $97.8 \%$ of the FFEs they take notes about while this rate is only $86.8 \%$ of the FFEs they do not take notes about. A chi-square test was performed to decide whether the difference between learner noticing with and without note-taking is significant. The result ( $\chi 2(d f=1, n=457)$ $=9.259, p=0.002$ ) indicates that the difference is statistically significant. In other words, when the learners take notes about the teacher feedback, they are significantly more likely to notice the feedback. 


\subsubsection{Teacher use of $L 1$ and the TL and its impact on learner noticing}

Across the entire data set, over $89 \%$ of the linguistic items are reported as noticed. This rate in this study is higher than in Mackey's (2006) which reports learner noticing of $60 \%$ (27 out of 45) of the linguistic items in the experimental study conducted in an ESL setting in the States. The difference in the levels of learner noticing between the current study and Mackey's (2006) study can be explained by the different types of targeted items and feedback used in the two studies. In Mackey (2006), the three targeted linguistic forms received different levels of learner noticing. She argues that among the three forms, the grammatical form of questions was most often reported noticed since it was more often negotiated (that is, of the feedback types of provide and elicit) than the other two types which were more often recast (that is, of the feedback type of reformulate) (Mackey, 2006). On the contrary, in the present study, all the linguistic forms are of the types of provide and elicit with more than one feedback move from the teacher, which are more likely to induce the learners' modified output and negotiation.

The result of the statistical analysis of the data in this study suggests that the use of L1 and the TL does not have any significant impact on learner noticing. In other words, to answer the research question addressed in this section, it can be said that the use of L1 does not lead to more learner noticing than the use of the TL. There are some possible explanations for this finding.

At first, since the types of the FFEs taking place in this experimental study are provide and elicit, which are very explicit, they are more likely to induce learner noticing. In their study on FonF types and learner uptake in ESL classrooms in New Zealand, Ellis and his colleagues (2001a) find that the more salient the FFEs are, the more likely learners are to notice their interlanguage gaps. Similar results can also be found in other studies on FonF such as Panova \& Lyster's (2002) or Sheen's (2006). Moreover, the teacher feedback given in the present study is of the multi-move and complex type which is more likely to give the learners opportunities for producing modified output and, therefore, involves negotiation. In her study on the relationship between noticing and interactional feedback, Mackey(2006) also contends that when interactional feedback involves negotiation, it is more likely to induce learner noticing. Similarly, Loewen (2004b) and Izumi (2002) both report that complex FFEs tend to lead to more noticing of the focused linguistic items. In this experimental study, though the teacher used the TL and L1 for the two groups of learners, the noticing levels of the two FonF 
language groups were not significantly different since the teacher feedback was salient to the learners in both groups.

Similar to the findings on uptake, the types of tasks may have led to high levels of noticing despite the language of feedback or learner proficiency. Besides the fact that the teacher feedback was salient across the language groups due to the explicitness of the feedback types, the feedback given to the learners was also supported by the use of pictures. All of the three tasks used for each of the two language groups are picturebased. While the interactive tasks used in this study focused on new vocabulary items and verb forms describing actions which were illustrated in the pictures, the learners seemed to have no difficulties understanding the feedback. As pointed out by Izumi (2002), the use of visual aids can enhance input, which, in turn, leads to more learner noticing. The enhanced input may have reduced the cognitive burden for the low-level learners who usually focus more on meaning than form due to their limited input processing ability (van Patten, 1996). This may explain how the visual aids used in this study may have contributed to very high rates of learner noticing across the learner groups despite the proficiency levels.

The analysis of this data set, however, shows some association between the learners' note-taking practice and their report of noticing. This finding supports the attention hypothesis arguing that note-taking makes learners pay more attention to presented information in class (C. J. White, 1996). However, as also pointed out by White (1996), while note-taking induces learners to pay attention to targeted forms, the motor act of writing involved in note-taking also distracts learners from listening more fully in the interactive process. The practice of learners' note-taking as a response to teacher feedback in FonF, therefore, needs further research before any implications and applications could be made about how this practice should be done. In the following section of this research, further analysis of the relationship between note-taking and the learners' short-term learning will be presented and discussed as part of the further exploration into this practice. 


\subsubsection{The use of $\mathrm{L} 1$ and the $\mathrm{TL}$ and its impact on learner noticing: Summary}

The analysis of this data set of the use of L1 and the TL and its impact on learner noticing reveals that the teacher use of L1 in giving feedback does not lead to more learner noticing than the use of the TL. This is also true within each proficiency group, which means that the levels of noticing between the learners at the two proficiency levels were similar. This finding could be attributed to the facts that the types of feedback used in this study were very explicit, and that the linguistic foci of the interactive tasks were well illustrated with pictures. These two facts may have made the linguistic items be well noticed despite the teacher use of different languages for FonF and learners' different proficiencies.

The data analysis reveals that the teacher use of L1 in giving feedback led to significantly more note-taking among the learners than the use of the TL. A possible explanation could be that the feedback in L1 did not require as much effort to process input from the learners as feedback in the TL. As a result, the learners in the L1 groups were more able to perform "multi-tasks" in response to the teacher feedback. However, whether note-taking benefits learning requires further investigation.

\subsection{FonF in $L 1$ and the TL: Impact on language development}

After doing the one-to-one interactive tasks with the researcher as teacher, each participant participated in an individual custom-made oral test on the following day. The results of the tests were analysed to find out if the use of L1 and the TL in FonF has any impact on the learners' language development (Mackey, 1999, 2006) (see Section 5.3.1 for more information about the interactive tasks).

\subsubsection{Learners' test results across the teacher use of $L 1$ and the TL in FonF}

The results of the custom-made post-tests across the teacher use of L1 and the TL in giving feedback will be presented and discussed with a focus on the impact of the learners' proficiency levels.

Table 9.5 and Graph 9.5 show the results of the custom-made post-tests which were coded in three types of results: targetlike answer, non-targetlike answer and no answer. 
Table 0.5: Results for custom-made post-tests across the use of L1 and the TL

\begin{tabular}{ccccccc}
\hline & \multicolumn{2}{c}{ Targetlike } & \multicolumn{2}{c}{ Non-targetlike } & \multicolumn{2}{c}{ No answer } \\
FonF language & \multicolumn{2}{c}{ answer } & answer & n & $\%$ \\
\hline L1 (Vietnamese) & 64 & 30.0 & 43 & 20.2 & 106 & 49.8 \\
\hline TL (English) & 107 & 43.9 & 35 & 14.3 & 102 & 41.8 \\
\hline Total & 171 & 37.4 & 78 & 17.1 & 208 & 45.5 \\
\hline
\end{tabular}

Graph 0.5: Results for custom-made post-tests across the use of L1 and the TL

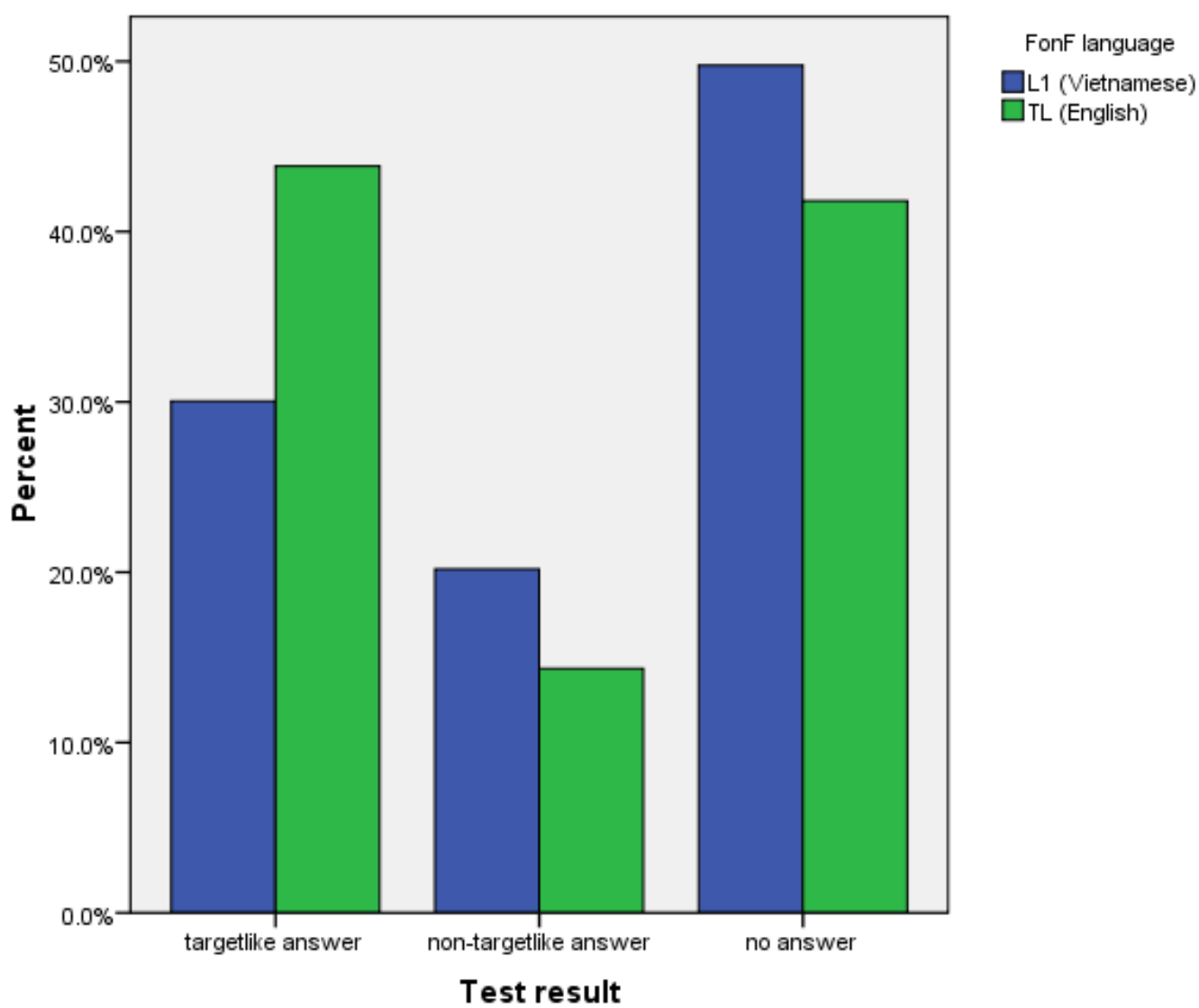

Table 9.5 and Graph 9.5 show that the learners receiving teacher feedback in L1 are less likely to produce targetlike test results than those receiving the teacher feedback in the TL (30\% and $43.9 \%$, respectively). On the contrary, the rate of non-targetlike answers from the learners receiving feedback in L1 (20.2\%) is higher than that from those 
receiving feedback in the TL. Also, the learners in the L1 groups are more likely to give no answer to the test questions than those in the TL groups $(49.8 \%$ and $41.8 \%$, respectively).

A chi-square analysis was performed to identify whether the difference between the two FonF language groups are significant. The result $(\chi 2(d f=2, n=457)=9.652, p=0.008)$ shows a statistical significant difference in the test results between the learners receiving feedback in L1 and the TL. A further step was taken to partition the difference by calculating the ASRs of all the variables. The following table presents the ASRs of the learners' test results across the teacher use of L1 and the TL in FonF.

Table 0.6: ASRs of learners' test results across the use of L1 and the TL

\begin{tabular}{cccc}
\hline FonF language & $\begin{array}{c}\text { Targetlike } \\
\text { answer }\end{array}$ & $\begin{array}{c}\text { Non-targetlike } \\
\text { answer }\end{array}$ & No answer \\
\hline L1 (Vietnamese) & $-3.0^{*}$ & 1.7 & 1.7 \\
\hline TL (English) & $3.0^{*}$ & -1.7 & -1.7 \\
\hline
\end{tabular}

*Adjusted standardized residual of 2.0 or greater

The ASRs reveal that the learners in the TL groups are significantly more likely to give a targetlike answer to a test question than those in the L1 groups. The differences in the other two types of test results are not significant between the learners of the two FonF language groups, though the data show that the learners in the L1 groups tended to produce more non-targetlike answers and no answer than those in the TL groups.

As the difference in the test results was statistically significant across the use of L1 and the TL in the category of targetlike answers, the power of effect was computed using odds ratios (Larsen-Hall, 2010). The odds ratios of the occurrences of targetlike answer against the other types with the use of the TL versus L1 are calculated and presented in the following table. 
Table 0.7: Odds ratios of the occurrences of targetlike answer with the use L1 of versus the TL

\begin{tabular}{ccccc}
\hline Variable & Odds ratio & \multicolumn{2}{c}{ 95\% confidence intervals } & Significance \\
\hline $\begin{array}{c}\text { Targetlike } \\
\text { answer }\end{array}$ & 1.818 & 1235 & 1677 & .002 \\
\hline
\end{tabular}

This table shows that the use of L1 or the TL has a significant association with the learners' production of targetlike answer. The odds ratio was 1.818 , determining that in this study, targetlike answers are about 1.8 times more likely to occur than other types of test results when the teacher feedback is in the TL.

In order to identify whether the learners within each proficiency group produced different types of test result, the data is analysed in accordance with the proficiency groups. The following table and graph shows the test results of the learners in the two proficiency groups layered by the teacher use of L1 and the TL.

Table 0.8: Results for custom-made post-tests across the use of $\mathrm{L1}$ and the TL layered by proficiency levels

\begin{tabular}{ccccccccc}
\hline \multirow{2}{*}{ Proficiency level } & FonF language & \multicolumn{2}{c}{ Targetlike } & \multicolumn{2}{c}{ Non-targetlike } & \multicolumn{2}{c}{ No answer } \\
& & answer & \multicolumn{2}{c}{$\begin{array}{c}\text { answer } \\
\text { n }\end{array}$} & n & \% & n & \% \\
\hline \multirow{2}{*}{ Beginning } & L1 (Vietnamese) & 30 & 27.8 & 19 & 17.6 & 59 & 54.6 \\
\cline { 2 - 8 } & TL (English) & 47 & 36.4 & 15 & 11.6 & 67 & 51.9 \\
\cline { 2 - 8 } & Total & 77 & 32.5 & 34 & 14.3 & 126 & 53.2 \\
\hline \multirow{3}{*}{ Advanced } & L1 (Vietnamese) & 34 & 32.4 & 24 & 22.9 & 47 & 44.8 \\
\cline { 2 - 8 } & TL (English) & 60 & 52.2 & 20 & 17.4 & 35 & 30.4 \\
\cline { 2 - 8 } & Total & 94 & 42.7 & 44 & 20.0 & 82 & 37.3 \\
\hline
\end{tabular}


Graph 0.6: Results for custom-made post-tests across the use of $L 1$ and the TL layered by proficiency levels

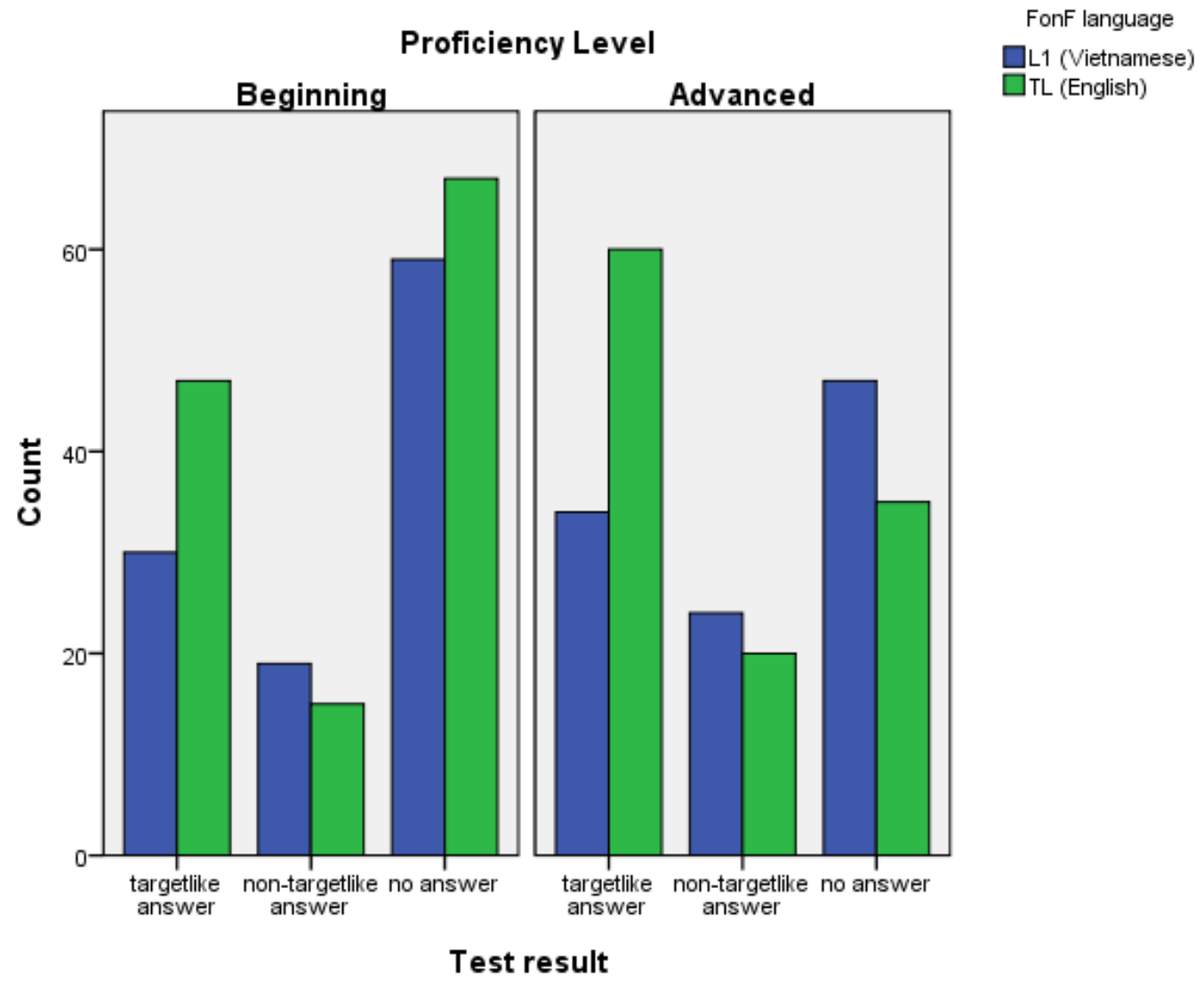

From the table and graph, it can be seen that at the beginning level, the learners receiving teacher feedback in the TL were more likely to produce targetlike answers than in L1 (36.4\% and $27.8 \%$ of the test questions, respectively). Similarly, at the advanced level, the learners receiving feedback in the TL also produced more targetlike answers $(52.2 \%)$ than in L1 $(32.4 \%)$. The patterns are similar at both proficiency levels for the non-targetlike answer and no-answer types of test result. In other words, the learners receiving feedback in the TL at both levels are less likely to produce nontargetlike answer (11.6\% compared to $17.6 \%$ for the beginning level, and $17.4 \%$ compared to $22.9 \%$ for the advanced level) and no answer (51.9\% compared to $54.6 \%$ for the beginning level, and $44.8 \%$ compared to $53.2 \%$ for the advanced level) than those receiving feedback in $\mathrm{L} 1$.

To identify the level of significance of the differences in the learners' test result, two chi-square tests are conducted separately. The result at the beginning level $(\chi 2(d f=2$, $n=237)=2.894, p=0.235$ ) shows no significant difference in the learners' test result 
between the use of L1 and the TL in FonF. In contrast, chi-square analysis reveals a significant difference in the learners' test result between the two groups receiving feedback in different languages at the advanced level $(\chi 2(d f=2, n=220)=8.875$, $p=0.012$ ).

Since the difference was significant in the advanced level only, the ASRs are also calculated to partition the difference to each variable at this level. From the table below, it can be seen that among the advanced learners, those receiving feedback in the TL are significantly more likely to produce a targetlike answer and significantly less likely to give no answer than those receiving feedback in L1.

Table 0.9: ASRs of test result across the use of $L 1$ and the TL, layered by proficiency levels

\begin{tabular}{ccccc}
\hline Proficiency level & FonF language & $\begin{array}{c}\text { Targetlike } \\
\text { answer }\end{array}$ & $\begin{array}{c}\text { Non-targetlike } \\
\text { answer }\end{array}$ & No answer \\
\hline \multirow{2}{*}{ Advanced } & L1 (Vietnamese) & $-3.0^{*}$ & 1.0 & $2.2^{*}$ \\
\cline { 2 - 5 } & TL (English) & $3.0^{*}$ & -1.0 & $-2.2^{*}$ \\
\hline
\end{tabular}

*Adjusted standardized residual of 2.0 or greater

Another statistical analysis is also performed to decide whether the learners' proficiency has any association to the test result across the use of L1 and the TL in FonF. The data is analysed within each FonF language group and presented in the following table and graph. 
Table 0.10: Test result across proficiency levels layered by the use of $\mathrm{L1}$ and the TL

\begin{tabular}{cccccccc}
\hline \multirow{2}{*}{ FonF language } & \multirow{2}{*}{ Proficiency level } & \multicolumn{2}{c}{ Targetlike } & \multicolumn{2}{c}{ Non-targetlike } & \multicolumn{2}{c}{ No answer } \\
& & $\mathbf{n}$ & $\boldsymbol{\%}$ & $\mathbf{n}$ & $\mathbf{0}$ & $\mathbf{n}$ & $\boldsymbol{\%}$ \\
\hline \multirow{2}{*}{ L1 (Vietnamese) } & Beginning & 30 & 27.8 & 19 & 17.6 & 59 & 54.6 \\
\cline { 2 - 8 } & Advanced & 34 & 32.4 & 24 & 22.9 & 47 & 44.8 \\
\cline { 2 - 8 } & Total & 64 & 30.0 & 43 & 20.2 & 106 & 49.8 \\
\hline \multirow{2}{*}{ TL (English) } & Beginning & 47 & 36.4 & 15 & 11.6 & 67 & 51.9 \\
\cline { 2 - 8 } & Advanced & 60 & 52.2 & 20 & 17.4 & 35 & 30.4 \\
\cline { 2 - 8 } & Total & 107 & 43.9 & 35 & 14.3 & 102 & 41.8 \\
\hline
\end{tabular}

Graph 0.7: Test result across proficiency levels layered by the use of L1 and the TL

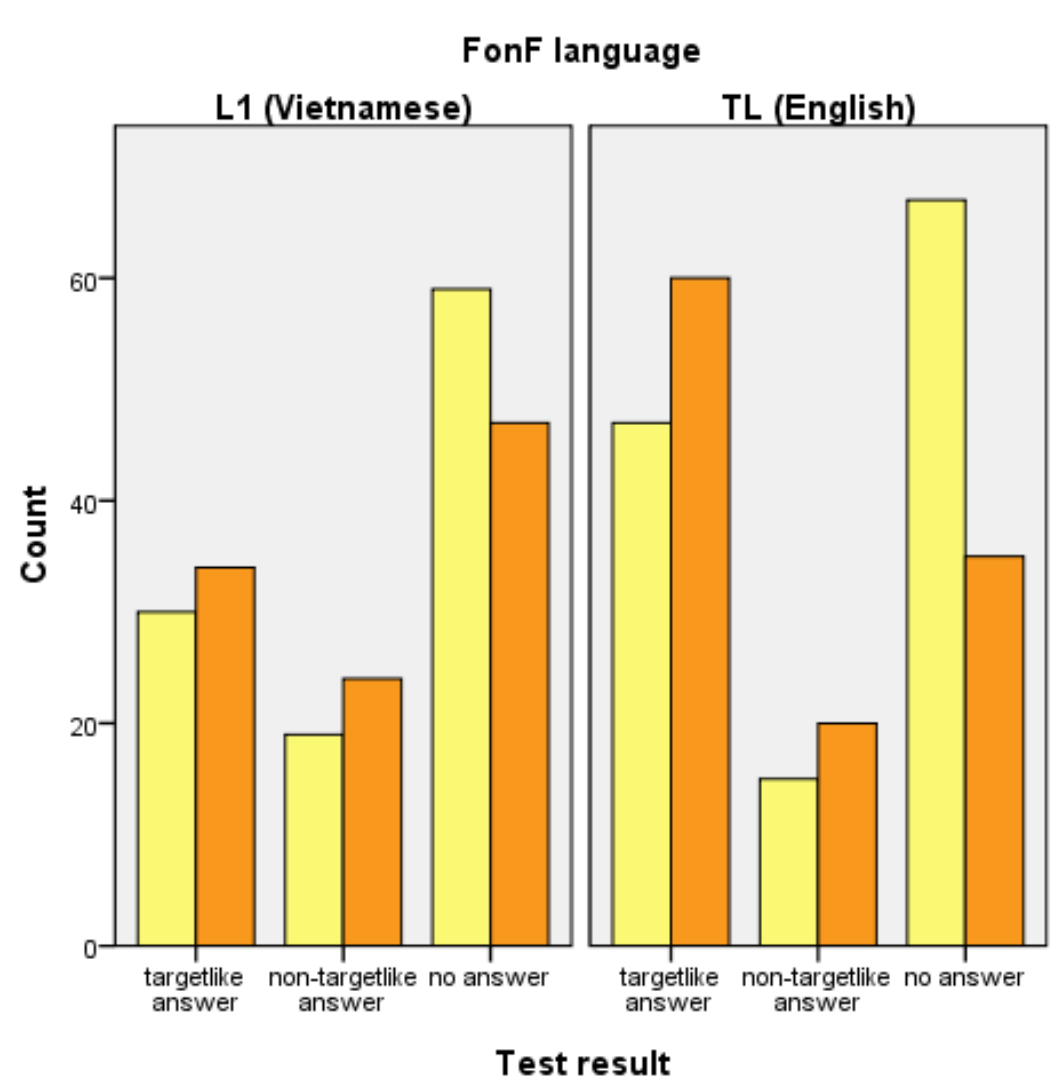

Proficiency Level

$\square$ Beginning

$\square$ Advanced 
Table 9.10 and Graph 9.7 show that among the learners receiving teacher feedback in L1, the advanced learners performed better on the custom-made post-tests than the beginning learners $(32.4 \%$ and $27.8 \%$, respectively). This fact happened in the TL groups where the advanced learners produced targetlike answers for $52.2 \%$ of the test items, while this rate was only $36.4 \%$ for the beginning learners. As for non-targetlike answers, the rates were higher for the advanced learners in both the L1 and TL groups (22.9\% and $17.4 \%$, respectively) compared with the beginning learners in the L1 and TL groups (17.6\% and $11.6 \%$, respectively). Among the learners receiving teacher feedback in L1, those at the beginning level were more likely to give no answer (54.6\%) than at the advanced level (44.8\%). Similarly, in the TL groups, the advanced learners produced no answer to only $30.4 \%$ of the test items, while this rate was much higher $(51.9 \%)$ for the beginning learners.

Two chi-square tests were performed for the two FonF language group to find out whether the learners at the two proficiency levels produced significantly different test result. The result for the L1 groups $(\chi 2(d f=2, n=213)=2.148, p=0.342)$ shows that the difference between the two proficiency groups are not statistically significant. Meanwhile, the analysis result for the TL groups $\left(\chi^{2}(d f=2, n=244)=11.568, p=0.003\right)$ show that the difference in the learners' test result is statistically significant between the two proficiency groups.

As the difference was statistical within the TL group only, ASRs are computed to partition the difference across the variables in this group. The table below presents the ASRs of the test result across the proficiency levels within each FonF language group.

Table 0.11: ASRs of test result across proficiency levels layered by the use of L1 and the TL

\begin{tabular}{ccccc}
\hline FonF language & $\begin{array}{c}\text { Proficiency } \\
\text { level }\end{array}$ & $\begin{array}{c}\text { Targetlike } \\
\text { answer }\end{array}$ & $\begin{array}{c}\text { Non-targetlike } \\
\text { answer }\end{array}$ & No answer \\
\hline \multirow{2}{*}{ TL (English) } & Beginning & $-2.5^{*}$ & -1.3 & $3.4^{*}$ \\
\cline { 2 - 5 } & Advanced & $2.5^{*}$ & 1.3 & $-3.4^{*}$ \\
\hline
\end{tabular}

\footnotetext{
*Adjusted standardized residual of 2.0 or greater
} 
The ASRs show that among the learners receiving feedback in the TL, the advanced learners are significantly more likely to produce targetlike answer than the beginning learners. Meanwhile, the beginning learners gave no answer to the test items significantly more often than the advanced level.

\subsubsection{Teacher use of $\mathrm{L} 1$ and the $T L$ and its impact on language development}

Out of the 457 linguistic items targeted in the FFEs and tested in the custom-made posttests, $37.4 \%$ of them was remembered and produced in targetlike forms by the learners. This rate is slightly higher than the rate of $33.3 \%$ in the experimental group reported in Mackey (2006), but it is considerably lower than the rate of $47.6 \%$ reported in Loewen (2005). The differences can be explained by the variation in the research designs of the two studies and the current study. In Mackey (2006), the types of feedback were less explicit than those used in the current study, which in turn led to less noticing and less learning. The higher percentage of the learners' correct answers in Loewen (2005) may be due to the extended learning time which lasted one week in real and intact classes compared with 10-15 minutes in the three interactive tasks of the current study. Moreover, while the learners in the experimental study did the tasks as a one-off learning experience, the learners in the intact classes were more likely to have opportunities for reusing the targeted linguistic items or revising them during the classes or at home.

The third research question in this experimental study asked whether the teacher use of L1 in FonF leads to more language development than the TL. The results showed that the teacher use of L1 in FonF during teacher-learner interaction does not lead to more language development than the use of the TL. On the contrary, the analysis of this data set reveals a significant difference in the test results between the learners receiving the teacher feedback in L1 and those in the TL. When receiving the teacher feedback in the TL, the learners were much more likely to remember and produced correctly the linguistic items than when they received the teacher feedback in L1 $(43.9 \%$ and $30 \%$, respectively).

As pointed out by Crawford (2004), teacher use of the TL in the foreign language classroom is usually the only source of live, scaffolded input. In the experimental study, 
when the interlocutor used L1 to provide feedback, the learners seemed to be demotivated from using the TL because the teacher was not the language user herself for the learners to follow suit (Crawford, 2004). As a result, the learners could not find the point in using the TL purposefully and actively to communicate since the artificial need for the TL use which was supposed to be created by the teacher did not exist. The previous section of this chapter discussing the teacher use of L1 and the TL in giving feedback and learner uptake also reveals that receiving feedback in the TL made the learners produce more uptake (both successful and unsuccessful) than receiving feedback in L1. As uptake is found to facilitate learning (e.g. Ellis, et al., 2001a; Loewen, 2005), producing more uptake may be one of the reasons for the learners in the TL groups to outdo those in the L1 groups. The lack of opportunities to use targeted language items may also lead to the higher number of mistakes in the custom-made post-tests by the L1 groups.

A closer analysis of the data in each of the two proficiencies reveals that while the patterns of impact of the feedback in L1 and the TL on the test results were similar between the two proficiency levels, the teacher use of L1 had significantly more negative impact on recall of the targeted forms by the advanced learners than the beginning learners. While the differences in the beginning learners' test results between the L1 group and TL group were not significant, the advanced learners receiving the teacher feedback in the TL significantly outperformed those getting L1 feedback. The advanced learners in the TL group accurately produced $55.2 \%$ of the linguistic items in the targetlike forms, while this rate was only $32.4 \%$ in the L1 group (see Table 9.10). The TL group also failed to answer only $30.4 \%$ of the test items compared to $44.8 \%$ in the L1 group (see Table 9.10). The data analysis reflects a considerable impact of the teacher use of L1 and the TL on the advanced learners' performance of the custommade post-tests. In addition to the reasons given previously, the difference in the impact of the teacher language use on their test results between the two proficiency levels can be explained in some ways. First, while the beginning learners were used to the teacher use of L1 in giving explanations, this practice was of great surprise to the advanced learners who expected to participate in "some communicative tasks in English in 10-15 minutes" as the advertisement put to recruit volunteers for the research. From the researcher's observation, the advanced learners looked perplexed when the researcher kept giving feedback in L1. While the tasks were carried out in English, the teacher use of L1 during the FFEs was distracting since it may make the learners wonder about 
whether to response to the feedback in L1 or in the TL rather than concentrate on the new linguistic items addressed in the FFEs. The lack of concentration may have caused some detrimental effect on retaining and reproducing the new linguistic aspects even though the level of noticing was not any lower than that in the other groups. In addition, as the tasks lasted about 10-15 minutes, any short time of distraction may account for a considerable fraction of loss of the learning opportunities. Second, the custom-made post-tests were conducted in slightly different ways between the two proficiencies. For the beginning learners, the lexical test items were described in words and pictures, while for advanced learners these items were only described in words. The beginning learners who had received the teacher feedback in L1 may have been unfamiliar with the word definition, but their comprehension was aided by pictures. On the contrary, the advanced learners who had received the teacher feedback in L1 struggled to make sense of the definition in the TL before they could give an answer. Meanwhile, the word definitions used in the custom-made post-tests were familiar to the learners who had received the feedback in the TL and this may have added to their performance.

The ASR analysis of the test results across the two proficiency levels layered by the teacher use of L1 and the TL shows that there was significant difference between the advanced learners and the beginning learners receiving the teacher feedback in the TL. In the TL groups, the advanced learners were much more likely to produce targetlike answers and much less likely to produce no answer than the beginning learners. This result may reflect the beginning learners' familiarity with the teacher use of L1 when they received long explanations for their interlanguage gaps. As can be seen from the descriptive study of this thesis, the teachers tended to switch to L1 when giving feedback to low-level learners. As a result, in the experimental study, in addition to the meaning-focused tasks taking place totally in the TL, the teacher's long explanations for their linguistic problems are likelyto have been difficult to understand. Though the teacher's multi-move feedback assisted learner noticing of the targeted items, the beginning learners' cognitive resource may have been occupied with processing the meaning of the teacher feedback rather than the focused form (van Patten, 1996). The result reveals that even though the levels of noticing were similar across the four experimental groups, the test results varied widely. 


\subsubsection{The use of $L 1$ and the $T L$ in FonF and its impact on language development: Summary}

The analysis of this data set showed that the teacher use of L1 and the TL in FonF had impact on the learners' language development. It revealed that the teacher use of the TL in FonF were significantly more likely to lead to learning the targeted linguistic items than the use of L1. In contrast, when receiving the teacher feedback in L1, the learners were much more likely to produce non-targetlike answers or even no answer at all to the test questions. This finding was different from the widely observed claim that L1 should be used when long grammatical and lexical explanations are given. The result suggests that the use of L1 in FonF may save time and effort, but it does not facilitate learning as effectively as the use of the TL.

Further analysis exploring how the use of L1 and the TL to produce feedback influences learners' language development across the two proficiency levels showed that the use of L1 in FonF did not lead to more language development than the use of the TL in FonF at both proficiency levels. When the advanced learners received feedback in L1, they recalled the targeted linguistic items significantly less than when they received feedback in the TL. Meanwhile, the beginning learners who received feedback in the TL tended to recall a similar number of the targeted linguistic items with those who received feedback in L1. This finding refutes the long-held beliefs in FonF research that the use of L1 to give long explanations about grammar and vocabulary for low-level learners will help tham better than the use of the TL.

\subsection{Summary}

The experimental study aims to answer the question about whether teacher use of L1 in FonF leads to more learner uptake, noticing and language development. The research design involves 43 participants at two proficiency levels participating in a lab study individually on two consecutive days. On the first day, they did three one-on-one interactive tasks with the research as the interlocutor. On the following day, they performed custom-made post-tests based on the targeted linguistic items addressed in the tasks. After the custom-made post-tests, they participated in SR and FQ sessions to watch video clips about the interactive tasks and talk about what they had thought during the tasks. 
The results show that when the learners received teacher feedback in L1, they produced significantly less uptake (both successful and unsuccessful) and more no uptake than when they received feedback in the TL. This is also the case across the proficiency levels. The results suggest that teacher use of L1 in FonF does not lead to feedback more than the TL. In fact, it is even suggested that teacher use of the TL is more likely to lead to learners' output production than L1. The results also suggest that learners' proficiency levels are not associated with learner uptake despite the language (that is, L1 and the TL) of FonF. This study also explored the learners' note-taking or "camouflaged uptake" (Farrokhi \& Gholami, 2007) during the interactive tasks and it found that the use of L1 led to more note-taking than the use of the TL; however, further analysis shows that the learners' note-taking was not associated with their production of uptake.

Investigation into the relationship between teacher use of L1 and the TL in FonF and learner noticing show that when the learners received feedback in L1, they did not report significantly more noticing than when feedback was in the TL. This result suggests that teacher use of L1 in FonF does not lead to more noticing than the use of the TL. However, as the FFEs in this study were explicit and contained more than one feedback, the learners were more likely to notice the targeted linguistic items than when FFEs were implicit and simple. Thus, it was understandable that the noticing levels were near maximum and hence similar across the two groups of FonF language (that is, L1 and the TL) and the two proficiency levels.

The results of the custom-made post-tests showed that the learners who received feedback in the TL produced significantly more targetlike answers in the custom-made post-tests than those who received feedback in L1. This suggests that teacher use of L1 does not lead to more language development than the TL. In fact, it suggests that teacher use of the TL leads to more language development than L1. The results also showed that the learners' proficiency levels were not associated with the custom-made post-tests despite the teachers' use of L1 and the TL in FonF.

In summary, the findings in this study refute two widely observed claims in SLA research. First, they refute the claim that L1 should be used for long and complex explanations of grammar and vocabulary (e.g. Gill, 2005; Turnbull \& Arnett, 2002) by giving evidence that teacher use of the TL in FonF is more facilitative of learning than 
L1. It reconfirms the results of the descriptive study which showed that teacher use of L1 led to more no uptake than the TL. Second, the findings in this study also refute the claim about the need to use L1 when giving feedback to low-level learners (e.g. Gill, 2005) by providing evidence that learners' proficiency levels had little association with learning despite the FonF language (that is, L1 and the TL). 


\section{Chapter 10: Conclusion}

This chapter presents the summary of this thesis, the contributions to FonF research, the implications for FonF instruction, and limitations and suggestions for further research.

\subsection{Summary}

This study addresses the issue of teacher use of L1 and the TL in FonF and its impact on learner uptake, noticing and language development. The research involves two studies: an observational study and an experimental study.

The observational study investigated the occurrence of FonF and learner uptake in a foreign language setting where teachers and learners share L1. The results confirm the occurrence of FonF and learner uptake in this setting. The study also examined the use of L1 and the TL in FonF across the characteristics of FonF. When the teachers engaged in complex vocabulary or morphosyntax focused FFEs and provided feedback explicitly using provide or elicit, they typically resorted to L1. In simpler FFEs which focused on other linguistic features for which feedback was provided implicitly, they chose to use the TL more frequently. This finding confirmed the widely observed practice in the language classroom of teachers resorting to L1 when giving explicit, long and complex explanations about grammar and vocabulary. Thirdly, this descriptive study also found an association between the teacher use of L1 and the TL in FonF and learner uptake. When the teachers used the TL to give feedback, the learners were more likely to produce repair. In contrast, when the teachers use L1 to give feedback, the learners tend to produce no uptake more often than when the teachers used the TL. Throughout the observational study, it was also found that there was a wide variation in the amount of FonF, characteristics of FonF and learner uptake. This variation was attributed to the teachers' individual differences and the different courses they teach.

The experimental study addressed the question of the relationship between the teacher use of L1 and the TL and learner uptake, noticing and language development. The study had three stages: interactive tasks, and custom-made post-tests, and stimulated recall (SR) and focused question (FQ) sessions. In the first phase, the learners individually performed interactive tasks one-on-one with the researcher as the interlocutor. They received FonF with a focus on vocabulary or morphosyntax and the interlocutor 
provided feedback explicitly using provide or elicit in complex FFEs. These characteristics of FFEs were chosen because they reflect the typical characteristics of FFEs in which the teachers resorted to the L1 in the observational study. On the following day, the learners performed custom-made post-tests based on FFEs that had taken place in the interactive tasks performed on the previous day. This phase provided data about language development. After the post-tests, they participated in an SR and FQ session in which they first watched the video clips of the interactive tasks they had performed and then talked about what had happened and what they had thought during the tasks. From this phase, data about learner noticing was collected. The results revealed that across the beginnning and advanced classes, the teacher use of L1 did not lead to more uptake, noticing and language development than the use of the TL. On the contrary, TL use in FonF led to more repair, more targetlike test results and less no uptake than L1 use.

\subsection{Contributions and implications}

This research sheds light on a feature of FonF about which little has previously been known: the language of FonF (that is, L1 or the TL). The results have theoretical implications for SLA and FonF research, and practical implications for guiding teachers in the pedagogical choices they make concerning use of FonF in their classrooms.

\subsubsection{Contributions}

This research has contributed to SLA research in three main areas: through the issues it has addressed; the research design and statistical tools it has adopted; and the findings it has produced. The research contributes to the study of FonF by investigating FonF in a somewhat neglected setting in the FonF literature, namely that of the EFL classrooms in which teachers and learners share L1 and in which, the language of FonF shifts between L1 and the TL. This is a setting which Borg (2005) argues is more representative of the global language classroom than the ESL setting typical of many studies in this area. And yet few FonF studies have been conducted in this setting, and none has examined a practice which has been widely observed in this setting of teachers switching between L1 and the TL in FonF (e.g. Farrokhi \& Gholami, 2007). Studies in this area have to date explored the use of L1 and the TL in class talk without a specific focus on teacher- 
learner interaction in FonF or on the impact of the language of FonF on uptake and learning. Both of these issues were addressed in this study.

In terms of research design and the statistical tools adopted in the study, it has three advantages over other studies in the field. Firstly, the present research combines a descriptive study and an experimental study. Teacher use of L1 and the TL in an EFL setting has long been controversial (see Turnbull \& Arnett, 2002) partly because most arguments for and against this practice are drawn from observational studies where there is a wide range of internal and external factors which may have influenced the relationship between teacher use of L1 and the TL and learning (e.g. de la Campa \& Nassaji, 2009). To address this problem, the present research first involved a descriptive study to obtain a detailed description of teacher use of L1 and the TL in FonF in an EFL setting and learners' responses to this practice through their production of uptake, and this then informed the design of the experimental study. The combination of the observational study and an experimental study in the present research, therefore, not only resulted in a description of the practice but also identified the relationship between this practice and learning.

Secondly, in addition to the use of uptake as an index for learning, other indexes such as learner noticing recorded through SR ad FQ sessions and learners' language development measured by custom-made post-tests were combined so that learners' language learning could be reported in a comprehensive way (see Mackey, 2006). Thirdly, various statistical tools were used to explore the complex relationships between many different variables involving this research. In addition to the use of chi-square tests to explore the differences in teacher use of L1 and the TL in FonF across the teachers, any significant differences were further partitioned by the use of adjusted standardized residuals (ASRs) to discover how much each variable contributed to the differences found in the chi-square tests (Siegel \& Castellan, 1988). To investigate the difference between mean scores of two proficiency groups, one-way ANOVA were performed. The effect size was also reported by the use of odds ratios to find out the power of the effect (Larsen-Hall, 2010). When being jointly used to analyse the data, these statistical tools help revealing prominent issues in the data, from which reliable and valid interpretation for the research results could be made. 
Overall, the findings from the present research add to the literature of SLA research in four ways. First, the current study points out that theuse of L1 and the TL in FonF is associated with the amount of learner uptake and uptake types. Evidence from the research shows that input in L1 does not induce more learner uptake than input in the TL, and input in L1 leads to more no uptake and less of other types of uptake (including repair and needs-repair) than input in the TL. When learners receive input in the TL, they are more likely to incorporate it to produce pushed output than when they receive input in L1.

Secondly, the evidence shows that input in L1 does not lead to more noticing than input in the TL. This finding has refuted the common claim that L1 should be used so that learners could notice their interlanguage gaps more easily (Clanfield \& Foord, 2003; Gabrielatos, 2001; Gill, 2005). Thirdly, and consistent with the points above, evidence shows that input in L1 does not lead to more language development that input in the TL. On the contrary, there is evidence that input in the TL induces more learner uptake (both successful and unsuccessful) and language development than input in L1.

Thirdly, this study has also refuted the claim that learners' proficiency levels are a factor that should be included when the choice of L1 and the TL for input is made in order to insure comprehensibility of input. Evidence shows that learners' proficiency has little association with learner uptake, noticing and language development, despite the language (that is, L1 or the TL) of input in FonF.

Finally, this research has identified weaknesses the operationalisation of uptake as a measure of learning from FFEs where comprehension-based learner problems are concerned, especially in vocabulary-focused feedback. Pre-emptive FonF triggered by learners' comprehension problems has been treated in the same way with other types of FonF in FonF research to date. But the present study shows that this type of FonF is more likely to lead to learners' production of acknowledge if the learner's turn is a receptive retrieval. In addition, the comprehension-based problems may also lead to learners' use of new vocabulary items before understanding their meanings, which is not considered in the construct of uptake. 


\subsubsection{Implications for teaching}

As the EFL setting addressed in the present study is common, the results of this study can be generalised. This study is important in a number of ways for language teaching in EFL settings where teachers and learners share the mother tongue since it sheds light on what has been myths to many L1 teachers of English for such a long time, including the effectiveness of the teacher use of L1 when giving feedback, the need to use L1 in low-level classes, and the relationship between learners' note-taking practice and learning. As a result, the implications could be integrated into teacher training programs designed for L1 teachers of English and administrative policies of EFL schools and centres.

First, the research findings do not support teachers' long-held beliefs about the value of L1 use in FonF. Evidence shows that the use of L1 in giving feedback is not more effective than the use of the TL in facilitating learning. Learners who receive feedback in L1 are more likely to make no response while learners who receive feedback in the TL are more responsive and productive. Also, the use of L1 in FonF does not help learners to notice targeted linguistic forms more often than they would through the use of the TL. This study also shows that feedback in L1 does not help learners in recalling targeted linguistic items more effectively than feedback in the TL. In fact, there is evidence that opportunities for language development increase when feedback is provided in the TL. As a result, the research partly bursts the first myth about the role of L1 in giving feedback on lexical and morphosyntactic items, as this research points out that feedback in the TL is more helpful that in L1 in learners' production of targeted language items and their performance of tests.

Secondly, the study provides evidence that the use of L1 in FonF does not always help low-level learners to learn better than the use of the TL. In the study, learners at both the advanced level and the beginning level were more likely to be silent when receiving feedback in L1 than in the TL. Evidence also shows no higher level of noticing and language development when learners at both levels receiving feedback in L1 in comparison with feedback in the TL. In fact, learners receiving feedback in the TL at both levels are more likely to outperform those receiving feedback in L1. The second myth about the need to use L1 in giving feedback for low-level learners is therefore exploded as the research shows that the teacher use of the TL in giving feedback benefits learners more than the use of L1 despite their proficiency levels. 
Another aspect of the EFL language classroom that mystifies L1 teachers of English is the role of learners' note-taking practice in learning. The findings of this research reveal that the teacher use of L1 in giving feedback leads to more note-taking than the use of the TL, but note-taking does not lead to more learner uptake. In other words, whether learners make notes about the feedback they receive from teachers, they do not produce significantly more of the targeted language items.

The implications mentioned above may contribute to teacher training programs designed for EFL teachers and to administrative regulations at EFL schools and centres as these implications can serve as the rationale for the teacher use of the TL in giving feedback or explanations about linguistic items. Recommendations could be made to L1 teachers of English that their use of the TL in giving feedback and explanations about linguistic items are more helpful for learners. Through the teacher training programs for EFL teachers, these recommendations could be integrated into curriculums. Administrative policies at EFL schools and centres can also consider regulations regarding teacher use of the TL in their everyday teaching practice.

\subsection{Limitations and further research}

This section presents the limitations of this research study and further research suggested from the procedures and the findings of this study.

\subsubsection{Limitations}

A number of limitations in the research need to be acknowledged. First, in the observational study, due to time constraints, I was unable to collect data concerning the teachers' beliefs and attitudes toward use of L1 and the TL in FonF. Although after the observations, casual talks with the teachers were held and some notes about their viewpoints on the issue were taken, a more systematic research approach to investigating emic perspective (for example, through SR) is desirable.

Secondly, the sample size of the descriptive study was not ideal since it involved only six teachers and 12 class observations at two private English language centres in one city in Vietnam out of hundreds of language centres of this type all over the country. 
Though many of these other institutions are likely to provide similar types of courses, a larger-scale research study covering a wider geographical area can provide a more panoramic picture of the research issues.

Another limitation is potential interference in the data collection process for the observational study from the presence of the researcher and recording equipment in he classrooms. Despite the fact that the "observer paradox" is inevitable in such research, a number of measures were taken to minimize the intrusiveness of the observations and the classes were unaware of the purpose of the research (see 4.2.4.).

In addition, in the experimental study, since the FonF in use was explicit, the levels of learner noticing were near maximum across the experimental groups and hence, were not different from each other. Further research is desirable to explore the impact of teacher use of L1 and the TL and FonF including implicit types of FonF.

Finally, in the experimental study, as the learners were volunteers, they were usually well motivated and confident learners and so their performance was likely to be at a higher level than learners in typical classroom settings. However, this "halo effect" limitation is inherent in this type of research.

\subsubsection{Further research}

While addressing the research questions on the teacher use of L1 and TL in FonF and its impact on learner uptake, noticing and language development, this research also encountered some issues in the research procedure.

From the research design, the conditions of the experimental study require that L1 and the TL were used separately to measure their effects on learning. In reality, teachers in EFL classes may combine L1 and the TL when giving feedback by switching from one language to another. Further research on teachers' code-switching in FonF can be carried out using this data set to explore this aspect of teacher use of L1 and the TL in FonF.

During the research procedure, also in the experimental study, due to time constraints, only immediate post-tests were used in the lab study which reflects the immediate effect of the use of L1 anf the TL in FonF on learning. As pointed out by Loewen (2005), 
delayed post-tests are desirable to explore the long-term effect of this variable on learning. Further research, therefore, could be designed to include delayed post-tests to verify the long-term impact of the use of $\mathrm{L} 1$ and the TL in FonF on learning.

Another issue in the research procedure that can be considered in future research is how the wide range of the teacher variables should be addressed. In this research, many statistical tools were used to reveal a significant difference in the use of L1 and the TL across the teachers, but since the difference was too large and most of the variables were not controlled, the statistical tools could hardly help to justify the trends and significance of the data. The justification for the difference was, therefore, mainly speculative based on some basic personal facts collected from the teachers. Further research could be carried out by another approach to data collection using in-depth interviews with the teachers. The interpretation of the data can be presented in a case study of each of the teachers so that the justification for their classroom practice can be firmly established.

\subsection{Conclusion}

The descriptive study of this research explores the teacher practice of using L1 and the $\mathrm{TL}$ in FonF in the intact EFL classroom in Vietnam. The results reveal from the occurrence of FonF and learner uptake that learning takes place in the EFL classroom where teachers and learners share L1, and that teachers are more likely to resort to L1 in FonF when the targeted linguistic items are lexical or morphosyntactic, or when the input in the forms of negative evidence is given explicitly. The results also suggest that there is limited evidence that input provided in L1 in intact EFL classes during FonF induces more pushed output from learners. This finding has been confirmed in the experimental study of the research.

The experimental study addresses the relationship between the teacher use of L1 and the TL in FonF and three indexes of learning: uptake, noticing and language development. The research results show that when input in the forms of negative evidence is given in the TL it induces more pushed output from learners than when it is given in L1. In addition, input in the TL leads to more learner noticing than input in L1. Finally, the findings from this research suggest that input in the TL is more likely to lead to 
language development than input in L1. This research, therefore, provides support for teacher use of the TL in FonF to facilitate learning of the targeted linguistic items. 


\section{LIST OF REFERENCES}

Abbott, G. (1992). Development, education, and English language teaching. ELT Journal, 46(2), 172-179.

Adams, R. (2003). L2 output, reformulation and noticing: Implications for IL development. Language teaching research, 7(3), 347-376.

Adams, R. (2007). Do second language learners benefit from interacting with each other? In A. Mackey (Ed.), Conversational interaction in second language acquisition (pp. 29-51). Oxford: Oxford University Press.

Al-Nofaie, H. (2010). The attitude of teachers and students towards using Arabic in EFL classrooms in Saudi public schools - a case study. Novitas-ROYAL (Research on Youth and Language), 4 (1), 64-95.

Alcon-Soler, E. (2009). Focus on form, learner uptake and subsequent lexical gains in learners' oral production. International Review of Applied Linguistics, 47, 347365 .

Alderson, J. C., \& Hamp-Lyons, L. (1996). TOEFL preparation courses: A study of washback. Language Testing, 13, 280 - 297.

Alegría de la Colina, A., \& del Pilar García Mayo, M. (2009). Oral interaction in taskbased EFL learning: The use of the L1 as a cognitive tool. International Journal of Educational Research, 47, 325-345.

Allwright, R. (1984). The importance of interaction in classroom language learning. Applied Linguistics, 5(2), 156-171.

Anton, M., \& DiCamilla, F. J. (1999). Socio-cognitive functions of L1 collaborative interaction in the L2 classroom. The Modern Language Journal, 83(2), 233-247.

Atkins, A. (2001). Sinclair and Coulthard's 'IRF' model in a one-to-one classroom: An analysis. Retrieved from http://www.birmingham.ac.uk/Documents/collegeartslaw/cels/essays/csdp/Atkins4.pdf.

Atkinson, D. (1987). The mother tongue in the classroom: A neglected resource. ELT Journal, 41(4), 241-247.

Atkinson, D. (1993). Teaching monolingual classes. Harlow, Essex: Longman Group UK Limited.

Auerbach, E. R. (1993). Reexamining English only in the ESL classroom. TESOL Quarterly, 27(1), 9-32. 
Austrade (Australian Trade Commission) (2010). International student data. Retreived from http://www.austrade.gov.au/Export/Export-

Markets/Industries/Education/International-Student-Data.

Bailey, K. M. (1985). Classroom-centred research on language teaching and leaming. In M. Celce-Murcia (Ed.), Beyond basics. issues and research in TESOL (pp.96121). Rowley, Mass.: Newbury House.

Bao, D. (2007). Enhancing the language learning process for reticent learners of Vietnamese and of English in Vietnam. In B. Tomlinson (Ed.), Language acquisition and development: Studies of learners of first and other languages (pp. 205-224). London: Continuum.

Barkhuizen, G. P. (2002). Language-in-education policy: Students' perceptions of the status and role of Xhosa and English. System, 30(4), 499-515.

Basturkmen, H., Loewen, S., \& Ellis, R. (2004). Teachers' stated beliefs about incidental focus on form and their classroom practices. Applied Linguistics, 25(2), 243-272.

Bitchener, J. (2004). The relationship between the negotiation of meaning and language learning: A longitudinal study. Language Awareness, 13(2), 81-95.

Borg, S. (2005). Teacher cognition in language teaching. In K. Johnson (Ed.), Expertise in second language learning and teaching (pp. 190-209). New York: Palgrave Macmillan.

Brosh, H. (1996). Perceived characteristics of the effective language teacher. Foreign Language Annals, 29(2), 125-138.

Butzkamm, W. (1978). The role of the mother tongue in the teaching of foreign languages: Development in the 1970s. Etudes de Linguistique Appliquee, 31, 162-168.

Carroll, S., \& Swain, M. (1993). Explicit and implicit negative feedback: An empirical study of the learning of linguistic generalizations. Studies in Second Language Acquisition, 15, 357-386.

Chau, E. (2007). Learners' use of their first language in ESL classroom interactions. TESOL in Context, 16(2), 11-18.

Chau, H. (2009). Balancing Grammar and Communication in EFL Teaching: A Study of Teachers' Beliefs about Grammar Instruction and Error Correction. Paper presented at the Asian EFL Conference, Busan, Korea 10-11 April. Retrieved from http://www.asian-efl-journal.com/2009-Chau.php 
Chaudron, C. (1977). A descriptive model of discourse in the corrective treatment of learners' errors. Language Learning, 21(1), 29-46.

Cheetham, C., Albery, D., Eales, F., Barker, H., Comyns-Carr, J., Moor, P., \&

Cunningham, S. (2002). Cutting Edge. New York: Pearson Longman.

Cheng, L. (2005). Changing language teaching through language testing: A washback study. Cambridge: Cambridge University Press.

Cheng, L., Watanabe, Y., \& Curtis, A. (Eds.). (2004). Washback in Language Testing: Research Contexts and Methods. Mahwah: N.J.: Laurence Erlbaum \& Associates.

Clanfield, L., \& Foord, D. (2003). Using L1 in the classroom: In defense of L1 in the classroom secondary and adult. Humanising Language Teaching, 5(1). Retrieved from http://www.hltmag.co.uk/jan03/mart2.htm

Cohen, L., Manion, L., \& Morrison, K. (2004). Research methods in education. London $\&$ New York: RoutledgeFalmer Taylor \& Francis Group.

Cook, V. (2001). Using the first language in the classroom. The Canadian Modern Language Review, 57(3), 402-423.

Crawford, J. (2004). Language choices in the foreign language classroom: Target language or the learners' first language? RELC Journal, 35(1), 5-20.

Crystal, D. (2008). A dictionary of linguistics and phonetics. Malden, MA: Oxford Blackwell Publishing.

Cullen, R. (1998). Teacher talk and the classroom context. ELT Journal, 52(3), 179187.

Cullen, R. (2002). Supportive teacher talk: The importance of the F-move. ELT Journal, $56(2), 117-127$.

Cummins, J. (2009). Multilingualism in the English-language clasrooms: Pedagogical considerations. TESOL Quarterly, 43(2), 317-321.

de la Campa, J. C., \& Nassaji, H. (2009). The amount, purpose, and reasons for using L1 in L2 classrooms. Foreign Language Annals, 42(4), 742-759.

Do, H. T. (2006). The role of English in Vietnam's foreign language policy: A brief history. Paper presented at the 19th Annual EA Education Conference, Perth, Australia, 14-16 September.

Doughty, C., \& Varela, E. (1998). Communicative focus on form. In C. Doughty \& J. Williams (Eds.), Focus on form in classroom: Second language acquisition (pp. 115-138). New York: Cambridge University Press. 
Doughty, C., \& Williams, J. (1998). Pedagogical choices in focus on form. In C. Doughty \& J. Williams (Eds.), Focus on form in classroom: Second language acquisition (pp. 197-261). New York: Cambridge University Press.

Duff, P. A., \& Polio, C. G. (1990). How much foreign language is there in the foreign language classroom? The Modern Language Journal, 74(2), 154-166.

Egi, T. (2004). Verbal reports, noticing, and SLA research. Language Awareness, 13(4), 243-264.

Egi, T. (2010). Uptake, modified output, and learner perceptions of recasts: Learner responses as language awareness. The Modern Language Journal, 94(1), 1-21.

Ellis, E. M. (2007). Discourses of L1 and bilingual teaching in adult ESL. TESOL in Context, 16(2), 5-10.

Ellis, R. (1984). Classroom second language development. Oxford: Pergamon.

Ellis, R. (1990). Instructed second language acquisition. Oxford: Blackwell.

Ellis, R. (2001). Introduction: Investigating form-focused instruction. Language Learning, 51(1), 1-46.

Ellis, R. (2007). The different effects of corrective feedback on two grammatical structures. In A. Mackey (Ed.), Conversational interaction in second language acquisition (pp. 339-360). Oxford: Oxford University Press.

Ellis, R. (2008). The study of second language acquisition. Oxford: Oxford University Press.

Ellis, R., Basturkmen, H., \& Loewen, S. (2001a). Learner uptake in communicative ESL lessons. Language Learning, 51(2), 281-318.

Ellis, R., Basturkmen, H., \& Loewen, S. (2001b). Preemptive focus on form in the ESL classroom. TESOL Quarterly, 35(3), 407-432.

Ellis, R., Basturkmen, H., \& Loewen, S. (2002). Doing focus-on-form. System, 30, 419432.

Ellis, R., Loewen, S., \& Erlam, R. (2006). Implicit and explicit corrective feedback and the acquisition of L2 grammar. Studies in Second Language Acquisition, 28, 339-368.

Ellis, R., Tanaka, Y., \& Yamazaki, A. (1994). Classroom interaction, comprehension, and the acquisition of L2 word meanings. Language Learning, 44(3), 449-491.

Farrokhi, F., Ansarin, A. A., \& Mohammadnia, Z. (2008). Preemptive focus on form: Teachers' practices across proficiencies. The Linguistics Journal, 3(2), 7-31.

Farrokhi, F., \& Gholami, J. (2007). Reactive and preemptive language related episodes and uptake in an EFL class. Asian EFL Journal, 9(2), 58-92. 
Ferrer, V. (2005a). The mother tongue in the classroom: Cross-linguistic comparisons, noticing and explicit knowledge. Retrieved 19 July, 2007, from http://www.teachenglishworldwide.com/Articles/Ferrer_mother\%20tongue\%20i n\%20the\%20classroom.pdf

Ferrer, V. (2005b). Using the mother tongue to promote noticing: Translation as a way of scaffolding learner language. Retrieved 19 June, 2007, from http://www.teachenglishworldwide.com/Articles/Ferrer mother\%20tongue\%20t o\%20promote\%20noticing.pdf

Forman, R. (2007). Bilingual teaching in the Thai EFL context: One teacher's practice. TESOL in Context, 16(2), 19-24.

Franklin, C. E. M. (1990). Teaching in the target language: Problems and prospects. Language Learning Journal, 2, 20-24.

Fujii, A., \& Mackey, A. (2009). Interactional feedback in learner-learner interactions in a task-based EFL classroom. International Review of Applied Linguistics, 47, 267-301.

Gabrielatos, C. (2001). L1 use in ELT: Not a skeleton, but a bone of contention. TESOL Greece Newsletter, 70, 6-9.

Gass, S. M. (1997). Input, interaction and the second language learner. Mahwah, NJ: Lawrence Erlbaum.

Gass, S. M., \& Mackey, A. (2000). Stimulated recall methodology in second language research. Mahwah: NJ: Lawrence Erlbaum Associates, Publishers.

Gass, S. M., Mackey, A., \& Pica, T. (1998). The role of input and interaction in second language acquisition: Introduction to the special issue. The Modern Language Journal, 82(3), 299-307.

Gass, S. M., Mackey, A., \& Ross-Feldman, L. (2005). Task-based interactions in classroom and laboratory settings. Language Learning, 55(4), 575-611.

Gill, S. (2005). The L1 use in the L2 classroom. Humanising Language Teaching, 7(5). Retrieved from http://www.hltmag.co.uk/sep05/mart03.htm

Hadfield, J. (1984). Harrap's communication games. London: Harrap Ltd.

Harbord, J. (1992). The use of the mother tongue in the classroom. ELT Journal 46(4), 350-355.

Hill, L. A., \& Mallet, D. (1972). Cartoons for students of English. London: Oxford University Press.

Holmes, J. (2008). An introduction to sociolinguistics (3rd ed.). Harlow: Pearson Education Limited. 
IIE (Institute of International Education) (2010). U.S. higher education fairs in Asia. Retrieved from http://www.iiehongkong.org/ufair/spring\%202010/hanoi.htm.

Iwashita, N. (2001). The effect of learner proficiency on interactional moves and modified output in nonnative-nonnative interaction in Japanese as a foreign language. System, 29, 267-287.

Izumi, S. (2002). Output, input enhancement, and the noticing hypothesis: An experimental study of ESL relativization. Studies in Second Language Acquisition, 24(541-577).

Izumi, S. (2003). Comprehension and production processes in second language learning: In search of the psycholinguistic rationale of the output hypothesis. Applied Linguistics, 24(2), 168-196.

Izumi, S., Bigelow, M., Fujiwara, M., \& Fearnow, S. (1999). Testing the output hypothesis: Effects of output on noticing and second language acquisition. Studies in Second Language Acquisition, 21, 421-452.

Jenkins, S. (2010). Monolingualism: An uncongenial policy for Saudi Arabia's lowlevel learners. ETL Journal, ELT Journal Advance Access.

Jeon, K. S. (2007). Interaction-driven L2 learning: Characterizing linguistic development. In A. Mackey (Ed.), Conversational interaction in second language acquisition (pp. 379-406). Oxford: Oxford University Press.

Kern, R. G. (1994). The role of mental translation in second language reading. Studies in Second Language Acquisition, 16(4), 441-461.

Kharma, N. N., \& Hajjaj, A. H. (1989). Use of the mother tongue in the ESL classroom. International Review of Applied Linguistics, 27(3), 223-235.

Kim, H., \& Mathes, G. (2001). Explicit vs implicit corrective feedback. The Korea TESOL Journal, 4, 1-15.

Krashen, S. D. (1980). The Input hypothesis. Georgetown University Round Table on Languages and Linguistics, 168-180.

Krashen, S. D. (1985). The input hypothesis: Issues and implications. New York: Longman.

Krashen, S. D., \& Terrell, T. D. (1983). The natural approach: Language acquisition in the classroom. Hayward, CA: Alemany Press.

Kumaravadivelu, B. (1994). The postmethod condition: (E)merging strategies for second/foreign language teaching TESOL Quarterly, 28(1), 27-49.

Kumaravadivelu, B. (2001). Toward a postmethod pedagogy. TESOL Quarterly, 35(4), 537-560. 
Kumaravadivelu, B. (2003). Beyond methods: Macrostrategies for language teaching. New Haven, London: Yale University Press.

Lapkin, S., Swain, M., \& Smith, M. (2002). Reformulation and the learning of French pronominal verbs in a Canadian French immersion context. The Modern Language Journal, 86(4), 485-507.

Larsen-Freeman, D. (1999). On the appropriateness of language teaching methods in language and development. Paper presented at The Fourth International Conference on Language and Development, Hanoi.

Larsen-Freeman, D. (2007). Redefining grammar in contextualizing communicative competence. In J. Liu (Ed.), English language teaching in China: New approaches, perspectives and standards (pp. 42-54). London, New York: Continuum.

Larsen-Freeman, D., \& Long, M. H. (1991). An introduction to second language acquisition research. New York: Longman Inc.

Larsen-Hall, J. (2010). A guide to doing statistics in second language research using SPSS. New York ; London: Routledge.

Le, V. C. (1999). Language and Vietnamese pedagogical contexts Paper presented at The Fourth International Conference on Language and Development, Hanoi, Vietnam, 13-15 October.

Le, V. C., \& Barnard, R. (2008). A survey of Vietnamese EAP teacher's beliefs about grammar teaching. Paper presented at The 13th International Conference on English in Southeast Asia, Singapore: National Institute of Education, Nanyang Technological University, 4-6 December.

Leeser, M. J. (2004). Learner proficiency and focus on form during collaborative dialogue. Language Teaching Research, 8(1), 55-81.

Lewis, M., \& McCook, F. (2002). Cultures of teaching: Voices from Vietnam. ELT Journal, 56(2), 146-153.

Lightbrown, P. M., \& Spada, N. (1990). Focus-on-form and corrective feedback in communicative language teaching: Effects on second language learning. Studies in Second Language Acquisition, 12, 429-448.

Liu, D., Ahn, G.-S., Baek, K.-S., \& Han, N.-O. (2004). South Korean high school English teachers' code switching: Questions and challenges in the drive for maximal use of English in teaching. TESOL Quarterly, 38(4), 605-638.

Loewen, S. (2003). Variations in the frequency and characteristics of incidental focus on form. Language Teaching Research, 7(3), 315-345. 
Loewen, S. (2004a). The occurrence and characteristics of student-initiated focus-onform. Paper presented at The Independent Learning Conference 2003, Japan.

Loewen, S. (2004b). Uptake in incidental focus on form in meaning-focused ESL lessons. Language Learning, 54(1), 153-188.

Loewen, S. (2005). Incidental focus on form and second language learning. Studies in Second Language Acquisition, 27, 361-386.

Loewen, S., \& Nabei, T. (2007). Measuring the effects of oral corrective feedback on L2 knowledge. In A. Mackey (Ed.), Conversational interaction in second language acquisition (pp. 361-378). Oxford: Oxford University Press.

Loewen, S., \& Philp, J. (2006). Recasts in the adult English L2 classroom: Characteristics, explicitness, and effectiveness. The Modern Language Journal, 90(4), 536-556.

Long, M. H. (1983). Native speaker/non-native speaker conversation and the negotiation of meaning. Applied Linguistics, 37(3), 271-283.

Long, M. H. (1988). Focus on form: A design feature in language teaching methodology. Paper presented at the National Foreign Language Center, European Cultural Foundation Conference on Empirical Research on Second Language Learning in Institutional Settings, Bellagio, Italy, 20-24 June.

Long, M. H. (1991). Focus on form: A design feature in language teaching methodology. In K. de Bot, R. Ginsberg \& C. Kramsch (Eds.), Foreign language research in cross-cultural perspective (pp. 39-52). Amsterdam: John Benjamins.

Long, M. H. (1996). The role of the linguistic environment in second language acquisition. In W. C. Ritchie \& T. K. Bhatia (Eds.), Handbook of second language acquisition. San Diego: Academic Press.

Long, M. H., Inagaki, S., \& Ortega, L. (1998). The role of implicit negative feedback in SLA: Models and recasts in Japanese and Spanish. The Modern Language Journal, 82(3), 357-371.

Long, M. H., \& Robinson, P. (1998). Focus on form: Theory, research and practice. In C. Doughty \& J. Williams (Eds.), Focus on form in classroom second language acquisition (pp. 15-41). Cambridge: Cambridge University Press.

Lyster, R. (1998). Negotiation of form, recasts and explicit correction in relation to error types and learner repair in immersion classrooms. Language Learning, 48(2), 183-218. 
Lyster, R. (2002). Negotiation in immersion teacher-student interaction. International Journal of Educational Research, 37, 237-253.

Lyster, R. (2004). Differential effects of prompts and recasts in form-focused instruction. Studies in Second Language Acquisition, 26, 339-432.

Lyster, R., \& Ranta, L. (1997). Corrective feedback and learner uptake. Studies in Second Language Acquisition, 20, 37-66.

Macaro, E. (1995). Target language use in Italy. Language Learning Journal(11), 5254.

Macaro, E. (2000). Issues in target language teaching. In K. Field (Ed.), Issues in modern foreign language teaching (pp. 171-189). London: Routledge.

Macaro, E. (2001). Analysing student teachers' codeswitching in foreign language classrooms: Theories and decision making. The Modern Language Journal, 85(4), 531-548.

Macaro, E. (2005). Codeswitching in the L2 classroom: A communication and learning strategy. In E. Llurda (Ed.), Non-native language teachers: Perceptions, challenges and contributions to the profession. New York: Springer.

Macaro, E. (2009). Teacher use of codeswitching in the second language classroom: Exploring optimal use. In M. Turnbull \& J. Dailey-O'Cain (Eds.), First language use in second and foreign language learning. Bristol, UK ; Buffalo [N.Y.] Multilingual Matters.

Mackey, A. (1999). Input, interaction, and second language development: An empirical study of question formation in ESL. Studies in Second Language Acquisition, $21,557-587$.

Mackey, A. (2006). Feedback, noticing and instructed second language learning. Applied Linguistics, 27(3), 405-430.

Mackey, A., \& Oliver, R. (2002). Interactional feedback and children's L2 development. System, 30, 459-477.

Mackey, A., \& Philp, J. (1998). Conversational interaction and second language development: Recasts, responses, and red herrings? The Modern Language Journal, 82(3), 338-356.

Mackey, A., Polio, C. G., \& McDonough, K. (2004). The relationship between experience, education and teachers' use of incidental focus on form techniques. Language Teaching Research, 8, 301-327.

Mangubhai, F. (2005). What can EFL teachers learn from immersion language teaching? The Asian EFL Journal Quarterly, 7(4), 203-212. 
McDonough, K. (2005). Identifying the impact of negative feedback and learners' responses on ESL question development. Studies in Second Language Acquisition, 27, 79-103.

McDonough, K. (2007). Interactional feedback and the emergence of simple past activity verbs in L2 English. In A. Mackey (Ed.), Conversational interaction in second language acquisition (pp. 323-338). Oxford: Oxford University Press.

McDonough, K., \& Mackey, A. (2000). Communicative tasks, conversational interaction and linguistic form: An empirical study of Thai. Foreign Language Annals, 33(1), 82-92.

McDonough, K., \& Mackey, A. (2006). Responses to recasts: Repetitions, primed production, and linguistic development. Language Learning, 56(4), 693-720.

Medgyes, P. (1992). Native or non-native: Who's worth more? ELT Journal 46 (4), 340-349.

Medgyes, P. (1994). The non-native teacher (First edition ed.). Hong Kong: Macmillan Publishers.

Mercer, N. (2001). Language for teaching a language. In C. N. Candlin \& N. Mercer (Eds.), English language teaching in its social context: A reader (pp. 243-257). London and New York: Routledge.

Moore, D. S., \& McCabe, G. P. (2003). Introduction to the practice of statistics (3rd ed.). New York: W.H. Freeman and Co.

Mori, R. (2004). Staying-in-English rule revisited. System, 32, 225-236.

Muñoz, A. P., \& Álvarez, M. E. (2010). Washback of an oral assessment system in the EFL classroom. Language Testing, 27, 33 - 49.

Muranoi, H. (2000). Focus on form through interaction enhancement: Integrating formal instruction into a communicative task in EFL classrooms. Language Learning, 50(4), 617-673.

Nagata, N. (1993). Intelligent computer feedback for second language instruction. The Modern Language Journal, 77(3), 330-339.

Nagy, K., \& Robertson, D. (2009). Target language use in English classes in Hungarian primary schools. In M. Turnbull \& J. Dailey-O'Cain (Eds.), First language use in second and foreign language learning. Bristol, UK; Buffalo [N.Y.]: Multilingual Matters.

Nation, I. S. P. (1997). L1 and L2 use in the classroom: A systematic approach. TESL Reporter 30 (2), 19-27. 
Nation, I. S. P. (2001). Learning vocabulary in another language. Cambridge: Cambridge University Press.

Nation, I. S. P., \& Newton, J. (2008). Teaching ESL/EFL listening and speaking. New York: Routledge.

Norris, J. M., \& Ortega, L. (2000). Effectiveness of L2 Instruction: A research synthesis and quantitative meta-analysis. Language Learning, 50(3), 417-528.

Nunan, D. (2003). The impact of English as a global language on educational policies and practices in the Asian-Pacific region. TESOL Quarterly, 37(4), 589-612.

Oliver, R. (2000). Age differences in negotiation and feedback in classroom and pairwork. Language Learning, 50(1), 119-151.

Panova, I., \& Lyster, R. (2002). Patterns of corrective feedback and uptake in an adult ESL classroom. TESOL Quarterly, 36(4), 573-595.

Pham, H. H. (2007). Communicative language teaching: Unity within diversity. ELT Journal, 61(3), 193-201.

Phillipson, R. (1992). Linguistic imperialism. Oxford: Oxford University Press.

Philp, J. (2003). Constraints on 'noticing the gap': Nonnative speakers' noticing of recasts in NS-NNS interaction. Studies in Second Language Acquisition, 25, 99126.

Piasecka, K. (1988). The bilingual teacher in the DSL classroom. In S. Nicholls \& E. Hoadley-Maidment (Eds.), Current issues in teaching English as a second language to adults (pp. 97-103). London: Edward Arnold.

Polio, C. G., \& Auerbach, E. R. (1994). Comments on Elsa Roberts Auerbach's "Reexamining English Only in the ESL Classroom" TESOL Quarterly, 28(1), 153-161.

Polio, C. G., \& Duff, P. A. (1994a). Teachers' language use in university foreign classrooms: A qualitative analysis of English and target language alternation. The Modern Language Journal, 78(3), 313-326.

Polio, C. G., \& Duff, P. A. (1994b). Teachers' language use in university foreign language classrooms: A qualitative analysis of English and target language alternation. The Modern Language Journal, 78(3), 312-326.

Polio, C. G., Gass, S. M., \& Chapin, L. (2006). Using stimulated recall to investigate native speaker perceptions in native-non-native speaker interaction. Studies in Second Language Acquisition, 28(2), 237-267.

Prodromou, L. (1991). The good language teacher. English Teaching Forum, 29(2), 2-7. 
Prodromou, L. (2000). From mother tongue to other tongue. TESOL Greece Newsletter, 67.

Radwan, A. A. (2005). The effectiveness of explicit attention to form in language learning. System, 33, 68-87.

Rivers, W. M. (1981). Teaching foreign-language skills. Chicago: University of Chicago Press.

Rolin-Ianziti, J. (2002). Justifying selected uses of the learners first language in the foreign language classroom within communicative language teaching. Paper presented at the Setting the Agenda: Languages, Linguistics and Area Studies in Higher Education conference, Manchester, England, 24-26 June. Retrieved from http://www.llas.ac.uk/resources/paper/1428

Rosa, E. M., \& Leow, R. P. (2004). Awareness, different learning conditions, and second language development. Applied Psycholinguistics, 25, 269-292.

Ross-Feldman, L. (2007). Interaction in the L2 classroom : Does gender influence learning opportunities? In A. Mackey (Ed.), Conversational interaction in second language acquisition: A series of empirical studies (pp. 53-81). Oxford: Oxford University Press.

Schmidt, K. (1995). Use of Japanese in the EFL classroom: Which way to go? ETAPS Journal.

Schmidt, R. W. (1990). The role of consciousness in second language learning. Applied Linguistics, 11, 129-158.

Schmidt, R. W. (2001). Attention. In P. Robinson (Ed.), Cognition and Second Language Instruction (pp. 3-32). Cambridge: Cambridge University Press.

Schweers, C. W., Jr. (1999). Using L1 in the L2 classroom. English Teaching Forum, $37(2)$.

Seliger, H., \& Shohamy, E. (1989). Second language research methods. Oxford: Oxford University Press.

Serdiukov, P., \& Tarnopolsky, O. (1999). EFL teachers' professional development: A concept, a model, and tools. 1999-00-00.

Sheen, Y. (2004). Corrective feedback and learner uptake in communicative classrooms across instructional settings. Language teaching research, 8(3), 263-300.

Sheen, Y. (2006). Exploring the relationship between characteristics of recasts and learner uptake Language teaching research, 10(4), 361-392.

Sheen, Y. (2007). The effects of corrective feedback, language aptitude, and learner attitudes on the acquisition of English articles. In A. Mackey (Ed.), 
Conversational interaction in second language acquisition (pp. 301-322). Oxford: Oxford University Press.

Siegel, S., \& Castellan, N. J., Jr. (1988). Nonparametric statistics for the behavioral sciences (2nd ed.). New York: McGraw-Hill.

Sinclair, J. M., \& Coulthard, R. M. (1975). Towards an analysis of discourse: The English used by teachers and pupils. Oxford: Oxford University Press.

Skehan, P. (1998). Task-based instruction. Annual Review of Applied Linguistics, 18, 268-286.

Soars, L. \& J., \& Sayer, M. (2003). New Headway. Oxford: Oxford University Press.

Swain, M. (1985). Communicative competence: Some roles of comprehensible input and comprehensible output in its developments. In S. M. Gass \& C. G. Madden (Eds.), Input in second language acquisition (pp. 235-253). Rowley, MA: Newbury House.

Swain, M. (1995). Three functions of output in second language learning. In G. Cook \& B. Seidlhofer (Eds.), Principle and practice in applied linguistics: Studies in honour of H. Widdowson (pp. 125-144). New York: Oxford University Press.

Swain, M. (2005). The output hypothesis: Theory and research. In E. Hinkel (Ed.), Handbook of research in second language teaching and learning (pp. 470-483). Mahwah, N.J.: L. Erlbaum Associates.

Swain, M., \& Lapkin, S. (1989). Canadian immersion and adult second language teaching: What's the connection? The Modern Language Journal, 73(2), 150159.

Swain, M., \& Lapkin, S. (2000). Task-based second language learning: The uses of the first language. Language Teaching Research, 4(3), 251-274.

Swain, M., \& Lapkin, S. (2002). Talking it through: Two French immersion learners' response to reformulation. International Journal of Educational Research, 37, 285-304.

Tan, Z. (2007). Questioning in Chinese university EL classrooms: What lies beyond it? RELC Journal, 38(1), 87-103.

Thornbury, S. (2006). An A-Z of ELT. Oxford: Macmillan Publishers Limited.

Tracedreyer, n.d. Using a student's first language for learning in the second language classroom. Viewed 21 October, 2010, http://www.brighthub.com/education/k12/articles/6033.aspx 
Truong, M. H. H. (2004). Issues in EFL teacher professional development at a private university in Vietnam. Unpublished research fellowship paper. Singapore: SEAMEO Regional Language Centre.

Tsang, W. K. (2004a). Feedback and uptake in teacher-student interaction: An analysis of 18 English lessons in Hong Kong secondary classrooms. RELC Journal, 35(2), 187-209.

Tsang, W. K. (2004b). Teachers' personal practical knowledge and interactive decisions. Language Teaching Research, 8(2), 163-198.

Turnbull, M., \& Arnett, K. (2002). Teachers' uses of the target and first languages in second and foreign language classrooms. Annual Review of Applied Linguistics, 22, 204-218.

Turnbull, M., \& Dailey-O'Cain, J. (2009). First language use in second and foreign language learning. Bristol, Great Britain: Multilingual Matters.

University of Cambridge. Teacher resources YLE. Retrieved 20 October, 2008, from http://www.cambridgeesol.org/resources/teacher/yle.html

Ur, P. (1981). Discussions that work: Task-centered fluency practice. New York: Cambridge University Press.

Utsumi, L., \& Doan, T. N. H. (2009). Trends in teaching and learning English in Vietnam: Implications for the future Retrieved from http://daotaoquocte.edu.vn/eng/coe/conference2009/9.Anh.pdf

van Lier, L. (1998). The relationship between consciousness, interaction and language learning. Language Awareness, 7(2\&3), 128-145.

van Patten, B. (1989). Can learners attend to form and content while processing input? Hispanic, 72, 409-418.

van Patten, B. (1990). Attending to form and content in the input. Studies in Second Language Acquisition, 12, 287-301.

van Patten, B. (1996). Input processing and grammar instruction in second language acquisition. Norwood: NJ: Ablex.

Vygotsky, L. S. (1962). Thought and language. Cambridge, MA: MIT Press.

Wang, W., \& Wen, Q. (2002). L1 use in the L2 composing process: An exploratory study of 16 Chinese EFL writers. Journal of Second Language Writing, 11(3), 225-246.

Webster, D. (1977). Guess what? New York: Macmillan. 
Weschler, R. (1997). Uses of Japanese (L1) in the English classroom: Introducing the functional-translation method. The Internet TESL Journal, 3(11). Retrieved from http://iteslj.org/Articles/Weschler-UsingL1.html

White, C. J. (1996). Note-taking strategies and traces of cognition in language learning. RELC Journal, 27(1), 89-102.

White, L. (1989). Linguistic Universals, Markedness and Learnability: Comparing Two Different Approaches. Second Language Research, 5(2), 127-140.

White, L. (1991). Adverb Placement in Second Language Acquisition: Some Effects of Positive and Negative Evidence in the Classroom. Second Language Research, $7(2), 133-161$.

Williams, J. (1999). Learner-generated attention to form. Language Learning, 49(4), 583-625.

Williams, J. (2001). The effectiveness of spontaneous attention to form. System, 29, 325-340.

Williams, J. (2005). Form-focused instruction. In E. Hinkel (Ed.), Handbook of research in second language teaching and learning (pp. 671-691). Mahwah, N.J: L. Erlbaum Associates. 


\section{APPENDIXES}

\section{APPENDIX 1: ABBREVIATIONS}

ASR Adjusted Standardized Residual

CF Corrective Feedback

CLT Communicative Language Teaching

EFL English as a Foreign Language

ESL English as a Second Language

FFE Form-Focused Episode

FonF Focus on Form

FQ Focused Question

IELTS International English Language Testing System

L1 First Language

NNS Non-native Speaker

NS Native Speaker

SLA Second Language Acquisition

SR Stimulated Recall

TL Target Language

TOEFL Test of English as a Foreign Language

TOEIC Test of English for International Communication 
I am doing a mini-survey for the feasibility study of my research. Please answer the following questions as detailedly as you can.

\section{FOR VIETNAMESE TEACHERS:}

1. Do you use Vietnamese while teaching English? If no, please go to Question 2. If yes, please go to Question 3.

2. a. Why not?

b. How do you cope with class situations in which learners have problems with understanding targeted linguistic items despite your explanations in the TL?

3. a. Please list some typical class situations in which you resort to L1.

b. How often do you use L1 in the class?

\section{FOR NATIVE-SPEAKER-OF-ENGLISH TEACHERS}

1. Can you speak your learners' mother tongue (Vietnamese) at all? Have you ever tried to learn it? Do you think that knowing your learners' mother tongue (Vietnamese) is an advantage for your job?

2. If you can speak Vietnamese, are you going to use it in your teaching job? If yes, in what class situations are you going to use it? If no, why not? 
APENDIX 3: PARTICIPANT'S PERSONAL INFORMATION - DESCRIPTIVE STUDY

VICTORIA UNIVERSITY OF WELLINGTON
Te Whare Wananga o te Upoko o te Ika a Maui

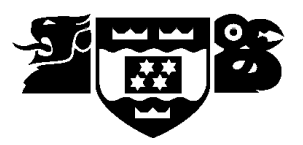

TEACHER PARTICIPANT'S BACKGROUND INFORMATION

Name:

Age: $\quad$ Gender:

Years of working as an EFL teacher:

Highest qualification:

Major:

Qualification in progress (if any):

Major: 


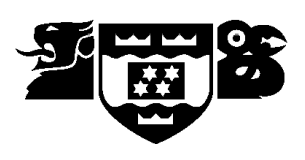

\section{LEARNER PARTICIPANT'S BACKGROUND INFORMATION}

Name:

Class:

$\begin{array}{llll}\text { Age group: } & 15-19 & 20-30 & 30-40 \quad \text { Over } 40\end{array}$

Gender: $\quad$ Male $\quad$ Female

Contact phone number:

(optional)

Years of learning English:

$$
\text { under } 2 \text { years } 2-5 \text { years more than } 5 \text { years }
$$

Job:

Do you know any language other than English and Vietnamese?

$$
\text { Yes No }
$$

If yes, how good are you at it?

$$
\text { Very good Fair Limited }
$$

How would you rate your level of overall motivation to learn English as a foreign language?

extremely high high moderate weak extremely weak 


\section{APPENDIX 4: PARTICIPANT INFORMATION SHEET AND CONSENT FORM - DESCRIPTIVE STUDY}

PARTICIPANT INFORMATION SHEET - ENGLISH VERSION

VICTORIA UNIVERSITY OF WELLINGTON

Te Whare Wananga o te Upoko o te Ika a Maui

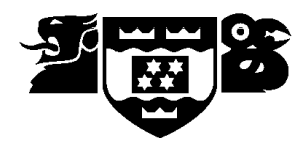

\section{INFORMATION FOR PARTICIPANTS}

\section{About the project}

The project I am carrying out focuses on the nature of conversational interaction taking place in English-as-a-foreign-language (EFL) classes in Vietnam. In this part of the project, I will describe some aspects of conversational interaction as it takes place in intact EFL classes.

We would like you to cooperate with us as participants. All the information from you will be acknowledged and will be kept confidential. The observations as well as other research data collecting activities are absolutely not for any judgmental purposes.

\section{Aims of the project}

In this part of the project, I will observe and record some EFL classes to collect data on conversational interaction. After that, I will invite the students and the teachers to fill up questionnaires focusing on the researched aspects of conversational interaction. Some students and teachers will be asked to participate in some group interviews to expand ideas on the features of interest deriving from the questionnaires. The data will be analyzed so that a descriptive report on some aspects of conversational interaction can be made.

I will give you a summary of the result of the research and will hold a workshop if asked by the institutions.

\section{Ethics and confidentiality}


The ethical guidelines subscribed to by social scientists internationally will be observed as well as the specific guidelines of Victoria University's Human Ethics Committee.

In terms of personal information, we recognise the importance of personal confidentiality in the Vietnamese culture. The recordings and other information we collect from you will be used only for research, publications and presentations based on this research. We may play short excerpts from the tapes in professional contexts such as seminars, but only if we are sure that no one will recognise you.

All tapes and other information collected as part of this project will be stored securely. No one other than authorised researchers will have access to this information.

Dr

Phone:

Fax:

Email:

\section{Jonathan}

$0-4-463$

$0-4-463$
Newton

5622

5604

Website:

jonathan.newton@vuw.ac.nz http://www.vuw.ac.nz/lals/staff/jonathan-newton/newton.aspx

Room 418, Von Zedlitz Building, Kelburn Pde, Kelburn Campus

Dr

Rebecca

Adams

Phone:

0-4-463

5625

Fax:

0-4-463

5604

Email:

rebecca.adams@vuw.ac.nz

Room 403, Von Zedlitz Building, Kelburn Pde, Kelburn Campus

\section{Researcher}

Truong Hong Hue Minh

PhD Student

Phone: 0-4-463-8029

Email: minh.truong@vuw.ac.nz

Room: 410, Von Zedlitz Building, Kelburn Pde, Kelburn Campus.

\section{November 2007}




\section{VICTORIA UNIVERSITY OF WELLINGTON}

Te Whare Wananga o te Upoko o te Ika a Maui

\section{5)}

THÔNG TIN DÀNH CHO NHŨ்NG NGƯỜI THAM GIA

\section{Thông tin chung về dụ án}

Dự án tôi đang thực hiện tập trung nghiên cứu việc tương tác trong đối thoại trong giờ học ngoại ngữ tiếng Anh ở Việt Nam. Trong phần này của nghiên cứu, tôi sẽ mô tả một số khía cạnh của tương tác trong đối thoại khi nó diễn ra trong các lớp học nguyên trạng.

Chúng tôi mong muốn được các bạn hợp tác. Tất cả các thông tin từ phía các bạn sẽ được ghi nhận và tuyệt đối giữ bí mật. Việc dự giờ cũng như các hoạt động thu thập dữ liệu nghiên cứu khác của chúng tôi hoàn toàn không nhằm mục đích đánh giá hay chấm điểm.

\section{Mục đích của dự án}

Trong phần này của dự án, tôi sẽ dự giờ và ghi âm một số lớp ngoại ngữ tiếng Anh để thu thập dữ liệu về tương tác trong giao tiếp. Sau đó, tôi sẽ mời một số giáo viên điền vào bảng câu hỏi về một số khía cạnh cần nghiên cứu trong tương tác trong giao tiếp. Một số học viên và giáo viên sẽ được mời tham gia các cuộc phỏng vấn theo nhóm để thảo luận mở rộng về các khía cạnh đáng quan tâm nảy sinh từ các bảng câu hỏi. Dữ liệu sẽ được phân tích để có thể đưa ra một báo cáo mô tả một số khía cạnh của tương tác trong giao tiếp.

Tôi sẽ cung cấp cho các bạn một tóm tắt kết quả nghiên cứu và có thể sẽ tổ chức một buổi báo cáo nếu trung tâm của bạn có yêu cầu.

\section{Qui định về đạo đức nghiên cúu và tính bảo mật}

Các qui tắc hướng dẫn về đạo đức nghiên cứu được các nhà nghiên cứu khoa học xã hội tuân thủ sẽ được áp dụng cùng với các hướng dẫn riêng của Hội đồng Đạo đức trong nghiên cứu về con người của trường Đại học Victoria.

Nói về các thông tin cá nhân, chúng tôi nhận thấy rõ tầm quan trọng của việc bảo mật thông tin cá nhân trong văn hóa Việt nam. Các đoạn băng ghi âm và các thông tin khác 
mà chúng tôi thu thập được từ các bạn sẽ chỉ được dùng cho việc nghiên cứu, xuất bản và báo cáo dựa trên nghiên cứu này. Chúng tôi có thể cho phát những đoạn trích ngắn từ các băng ghi âm này trong các tình huống mang tính chuyên môn như seminar, nhưng chỉ khi chúng tôi tin chắc rằng không ai có thể nhận ra các bạn trong các đoạn băng đó.

Tất cả các đoạn băng ghi âm và các thông tin khác được thu thập trong dự án này sẽ được bảo quản nghiêm ngặt. Không ai khác ngoài các nhà nghiên cứu có đủ thẩm quyền được phép truy cập các thông tin này.

\section{Các giảng viên hướng dẫn}

Dr

$$
\text { Jonathan }
$$

Newton

Phone:

Fax:

Email:

Website: http://www.vuw.ac.nz/lals/staff/jonathan-newton/newton.aspx

Room 418, Von Zedlitz Building, Kelburn Pde, Kelburn Campus

Dr

Rebecca

Adams

Phone:

$0-4-463$

5625

Fax:

$0-4-463$

5604

Email:

rebecca.adams@vuw.ac.nz

Room 403, Von Zedlitz Building, Kelburn Pde, Kelburn Campus

\section{Nghiên cứu sinh}

Trương Hồng Huệ Minh

Phone: 0-4-463-8029

Email: minh.truong@vuw.ac.nz

Room: 410, Von Zedlitz Building, Kelburn Pde, Kelburn Campus.

\section{November 2007}




\section{CONSENT FORM}

\section{VICTORIA UNIVERSITY OF WELLINGTON \\ Te Whare Wananga o te Upoko o te Ika a Maui}

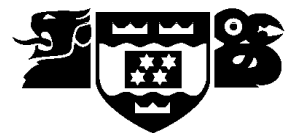

\section{CONSENT FORM}

Tôi đã hiểu rõ mục đích của nghiên cứu này. Tôi đã có cơ hội để hỏi các câu hỏi có liên quan và đã hài lòng với những câu trả lời mà nghiên cứu sinh này cung cấp. Tôi hiểu rằng các câu trả lời và những thông tin mà tôi cung cấp sẽ được giữ bí mật và chỉ những người có thẩm quyền trong nghiên cứu này mới được sử dụng và chỉ sử dụng cho mục đích nghiên cứu. Tôi cho phép các thông tin mà tôi cung cấp được sử dụng cho các mục đích có liên quan đến nghiên cứu về ngôn ngữ.

I have understood the aims of this research project. I have had an opportunity to ask questions and have them answered to my satisfaction. I understand that any information I provide will be kept confidential to the approved researchers and will be used for research purposes only. I give permission for the information I provide to be used for linguistic research purposes.

Ngày (Date):

Xin điền họ tên đầy đủ. (Please print full name)

Xin vui lòng ghi địa chỉ hoặc email nếu bạn muốn tôi gửi các thông tin phản hồi cho bạn theo địa chỉ thư hay email.

Write your address or e-mail address if you would like me to send feedback to you by mail or by e-mail. 


\title{
APPENDIX 5: PARTICIPANT INFORMATION SHEET AND CONSENT FORM - EXPERIMENTAL STUDY
}

PARTICIPANT INFORMATION SHEET - ENGLISH VERSION

\author{
VICTORIA UNIVERSITY OF WELLINGTON \\ Te Whare Wananga o te Upoko o te Ika a Maui
}

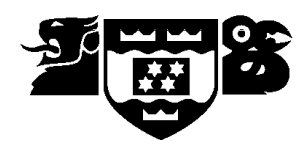

\section{INFORMATION FOR LEARNER PARTICIPANTS}

\begin{abstract}
About the project
This project examines the nature of conversational interaction in English-as-a-foreignlanguage (EFL) classes in Vietnam. In this part of the project, I will explore the effectiveness of conversational interaction as it takes place between Vietnamese teachers of English and Vietnamese learners.
\end{abstract}

I would like to invite you to participate in this project by taking part in a short interactive activity, a number of small tests and a short talk about what you learn from the interactive activity. These activities will be recorded for analysis. Your participation will involve approximately 30 minutes.

\section{Aims of the project}

In this part of the project, I will conduct some interactive activities between teachers and students to collect data on conversational interaction. After that, I will invite the students to do a few small oral tests focusing on the researched aspects of conversational interaction. The students will also be asked to participate in a short talk about what they learned from the interactive tasks. The data will be analysed so that a report on the effectiveness of conversational interaction can be made.

This part of the project is beneficial not only for the Vietnamese teachers of English and the Vietnamese learners but also for policy makers and teacher educators in making decisions related to conversational interaction in an English classroom. 
I will give you a summary of the result of the research and will hold a workshop if asked by the institutions.

\section{Ethics and confidentiality}

The ethical guidelines subscribed to by social scientists internationally will be observed as well as the specific guidelines of Victoria University’s Human Ethics Committee.

In terms of personal information, we recognise the importance of personal confidentiality in the Vietnamese culture. The recordings and other information we collect from you will be used only for research, publications and presentations based on this research. We may play short excerpts from the tapes in professional contexts such as seminars, but only if we are sure that no one will recognise you.

All tapes and other information collected as part of this project will be stored securely. No one other than authorised researchers will have access to this information.

Your participation in this study is voluntary and you are free to decline without giving any reason. You may also withdraw from the research at any time during data collection without explanation. The collected data will be destroyed after your withdrawal.

If you have any questions or would like to receive further information about the project, please contact me at minh.truong@ vuw.ac.nz or my supervisors, Dr Jonathan Newton at Jonathan.Newton@vuw.ac.nz or Dr Rebecca Adams at Rebecca.Adams@vuw.ac.nz, School of Linguistics and Applied Language Studies, Victoria University of Wellington, New Zealand.

Thank you for your cooperation.

Truong Hong Hue Minh

Signed:

\section{October 2008}




\section{VICTORIA UNIVERSITY OF WELLINGTON \\ Te Whare Wananga o te Upoko o te Ika a Maui

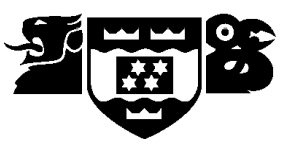 \\ THÔNG TIN DÀNH CHO CÁC HỌC VIÊN THAM GIA}

\section{Thông tin chung về dụ án}

Dự án tôi đang thực hiện tập trung nghiên cứu việc tương tác trong đối thoại trong giờ học ngoại ngữ tiếng Anh ở Việt Nam. Trong phần này của nghiên cứu, tôi sẽ xem xét tính hiệu quả của tương tác trong đối thoại giữa giảng viên tiếng Anh người Việt nam và học viên người Việt nam.

Chúng tôi mong muốn được các bạn hợp tác. Tất cả các thông tin từ phía các bạn sẽ được ghi nhận và tuyệt đối giữ bí mật. Các hoạt động thu thập dữ liệu nghiên cứu khác của chúng tôi hoàn toàn không nhằm mục đích đánh giá hay chấm điểm.

\section{Mục đích của dự án}

Trong phần này của dự án, tôi sẽ mời một sô học viên và giảng viên tham gia một hoạt động giao tiếp ngắn, sau đo các học viên sẽ được mời tham gia một bài kiểm tra nói ngắn và một buổi nói chuyện ngắn về các nội dung thu thập được từ bài học.. Dũ liệu sẽ được phân tích để có thể đưa ra một báo cáo mô tả một số khía cạnh về tính hiệu quả của tương tác trong giao tiếp.

Nghiên cứu này không chỉ có lợi cho giảng viên tiếng Anh người Việt nam và học viên Việt nam mà còn có lợi cho các nhà hoạt định chương trình giảng dạy và các tổi chức đào tạo giảng viện trong việc đưa ra các quyết định có liên quan đến giao tiếp tương tác trong giờ học.

Tôi sẽ cung cấp cho các bạn một tóm tắt kết quả nghiên cứu và có thể sẽ tổ chức một buổi báo cáo nếu trung tâm của bạn có yêu cầu.

\section{Qui định về đạo đức nghiên cứu và tính bảo mật}

Các qui tắc hướng dẫn về đạo đức nghiên cứu được các nhà nghiên cứu khoa học xã hội tuân thủ sẽ được áp dụng cùng với các hướng dẫn riêng của Hội đồng Đạo đức trong nghiên cứu về con người của trường Đại học Victoria. 
Nói về các thông tin cá nhân, chúng tôi nhận thấy rõ tầm quan trọng của việc bảo mật thông tin cá nhân trong văn hóa Việt nam. Các đoạn băng ghi âm và các thông tin khác mà chúng tôi thu thập được từ các bạn sẽ chỉ được dùng cho việc nghiên cứu, xuất bản và báo cáo dựa trên nghiên cứu này. Chúng tôi có thể cho phát những đoạn trích ngắn từ các băng ghi âm này trong các tình huống mang tính chuyên môn như seminar, nhưng chỉ khi chúng tôi tin chắc rằng không ai có thể nhận ra các bạn trong các đoạn băng đó.

Tất cả các đoạn băng ghi âm và các thông tin khác được thu thập trong dự án này sẽ được bảo quản nghiêm ngặt. Không ai khác ngoài các nhà nghiên cứu có đủ thẩm quyền được phép truy cập các thông tin này.

Trân trọng cám ơn.

Trương Hồng Huệ Minh

\section{October 2008}




\section{VICTORIA UNIVERSITY OF WELLINGTON \\ Te Whare Wananga o te Upoko o te Ika a Maui \\ CONSENT TO PARTICIPATION IN RESEARCH}

This project examines the nature of conversational interaction in English-as-a-foreignlanguage (EFL) classes in Vietnam and is conducted by researcher Truong Hong Hue

Minh, School of Linguistics and Applied Language Studies, Victoria University of Wellington, New Zealand

Please tick the following boxes if you agree with the statements:

I have been given and have understood an explanation of this research project.

I have had the opportunity to ask questions and have had them answered to my satisfaction.

I understand that I may withdraw myself from this project at any time during data collection without having to give reasons.

I understand that any information I provide will be confidential. The results of the research will not use my name, and no opinions will be attributed to me in any way that will identify me. I understand that access to the research data will be restricted to the researcher and his supervisors and all collected data will be destroyed five years after the end of the project.

I agree to take part in this research.

I agree to take part in an interactive activity.

I agree to take part in a number of small tests. 
I agree to take part in a short talk with the researcher about what I learn from the interactive activity.

Signed:

Date:

Name of participant

I would like to receive a summary of the results of the research when it is completed. My email address is: 


\section{XÁC NHậN ĐỒNG Ý THAM GIA ĐỀ ÁN NGHIÊN CÚU}

Đề án này nghiên cứu bản chất của việc giao tiếp giữa giáo viên và học viên trong lớp học ngoại ngữ tiếng Anh tại Việt nam và được thực hiện bởi nghiên cứu sinh Trương Hồng Huệ Minh, Khoa Ngôn Ngữ Học và Nghiên Cứu Ứng Dụng Ngôn Ngữ, Đại học Victoria of Wellington, New Zealand.

Làm ơn đánh dấu vào các ô vuông sau nếu bạn đồng ý tham gia cùng chúng tôi:

Tôi đã được giải thích và đã hiểu về đề án này.

Tôi đã được nêu thắc mắc và được giải đáp thỏa mãn các thắc mắc

Tôi biết rằng tôi được phép rút lui khỏi dự án bất kỳ lúc nào trong quá trình tham gia mà không cần phải giải thích gì cả.

Tôi biết rằng các thông tin tôi cung cấp sẽ được giữ bí mật. Kết quả nghiên cứu sẽ không sử dụng tên tôi và không điều gì trong kết quả đề án có thể khiến người khác nhận ra tôi. Tôi hiểu rằng việc tiếp xúc với các dữ liệu tôi cung cấp chỉ hạn chế cho người nghiên cứu và hai giáo sư hướng dẫn và các dữ liệu này sẽ được hủy trong vòng 5 năm sau khi kết thúc dự án.

Tôi đồng ý tham gia đề án này.

Tôi đồng ý tham gia buổi học giao tiếp.

Tôi đồng ý tham gia một bài kiểm tra nhỏ.

Tôi đồng ý tham gia một buổi nói chuyện ngắn với nghiên cứu sinh về buổi học giao tiếp vừa rồi.

Ký tên:

Ngày:

Tên người tham gia: 
Tôi muốn nhận được một bản tóm tắt kết quả nghiên cứu khi đề án này hoàn thành. Địa chỉ email của tôi là: 


\begin{tabular}{ll}
\hline Symbol & Meaning \\
\hline Sx & Student \\
Sxx & Another student \\
Ss & Many students \\
T & Teacher \\
R & Researcher \\
Bold & Emphasised word(s) \\
Italics & Utterances in Vietnamese \\
$()$. & Short pause \\
$(\ldots)$ & Long pause \\
. & Falling intonation \\
$?$ & Rising intonation \\
/ / & Phonetic transcription \\
$($ ) & English translation of the Vietnamese utterances \\
[ ] & More information about the context \\
xxx & Indistinct utterances \\
\hline
\end{tabular}

CODING LEARNERS IN THE EXPERIMENTAL STUDY

AV20
A: $\quad$ Advanced level
$\mathrm{V}$ : receiving feedback in Vietnamese
20: $\quad$ order

BE11 B: Beginning level

E: receiving feedback in English

11: order 
APPENDIX 7: INTERACTIVE TASKS FOR BEGINNING LEARNERS EXPERIMENTAL STUDY

TASK 1: JIGSAW TASK - WHERE ARE MY GLASSES? (Adapted from Hadfield, 1988)

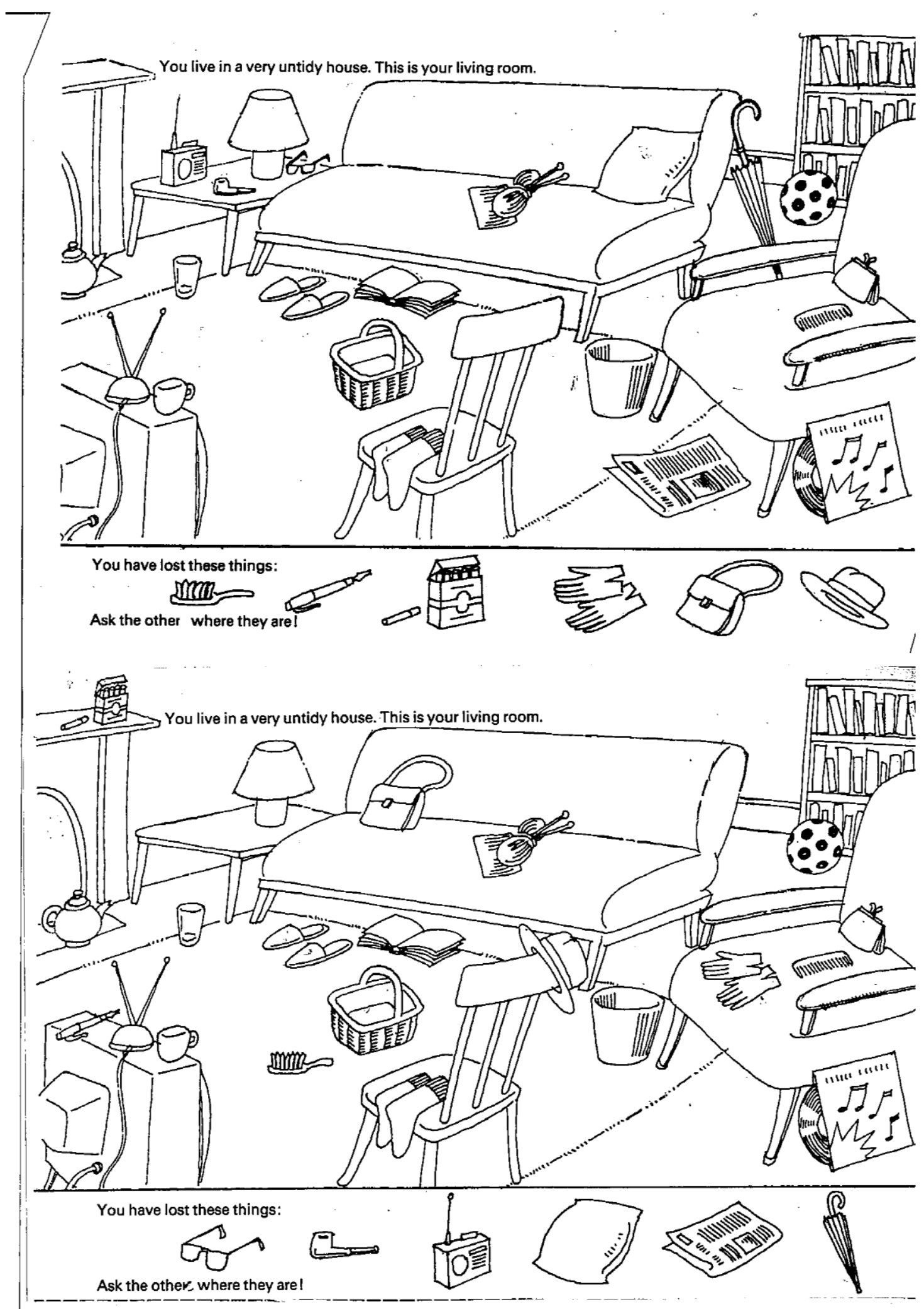




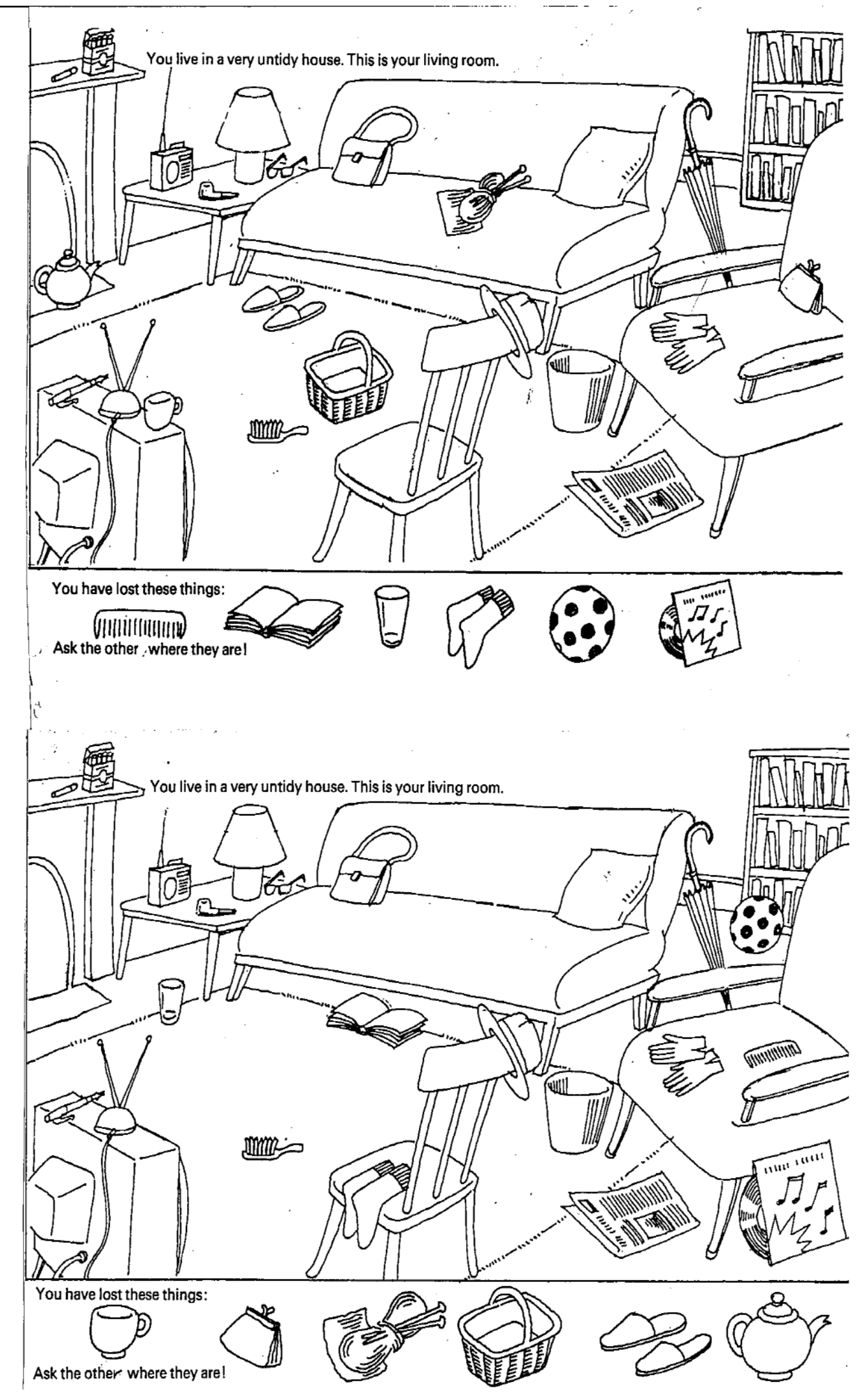


TASK 2: DESCRIBING THE PICTURE: WHAT HAS HAPPENED (Adapted from Webster, 1977)

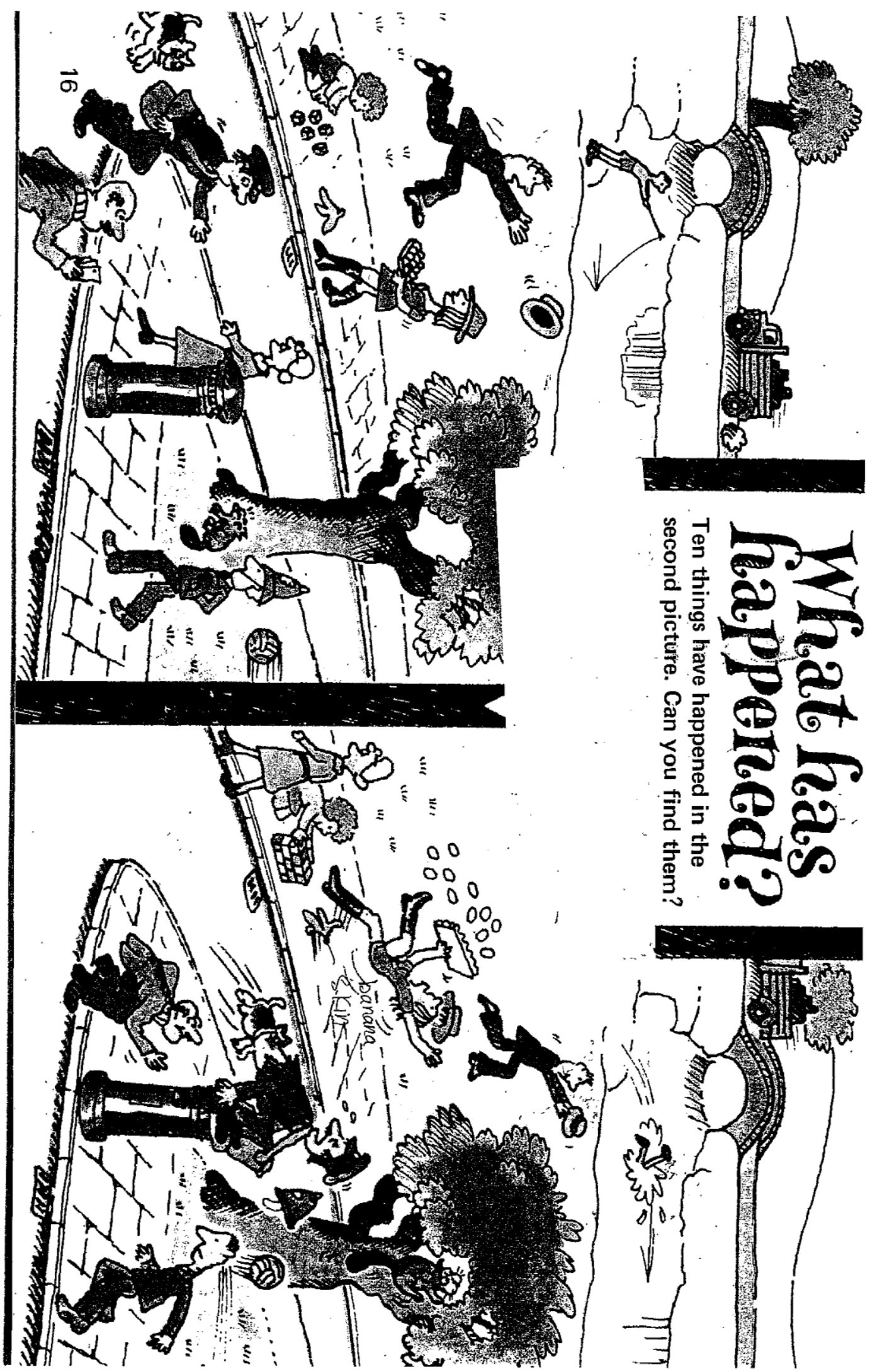



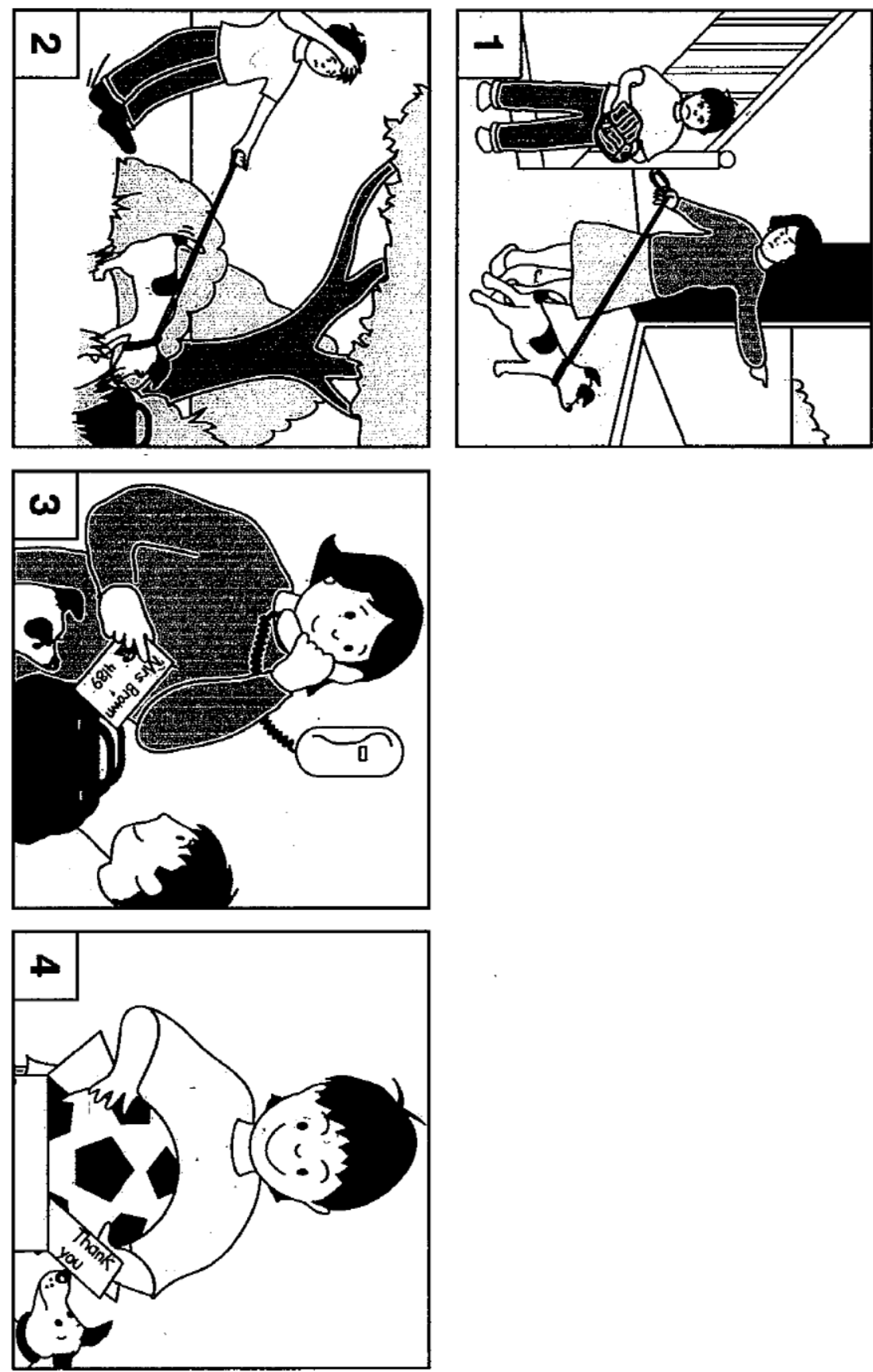
APPENDIX 8: INTERACTIVE TASKS FOR ADVANCED LEARNERS EXPERIMENTAL STUDY

TASK 1: JIGSAW TASK - KITCHEN TASK (adapted from Ross-Feldman, 2007)

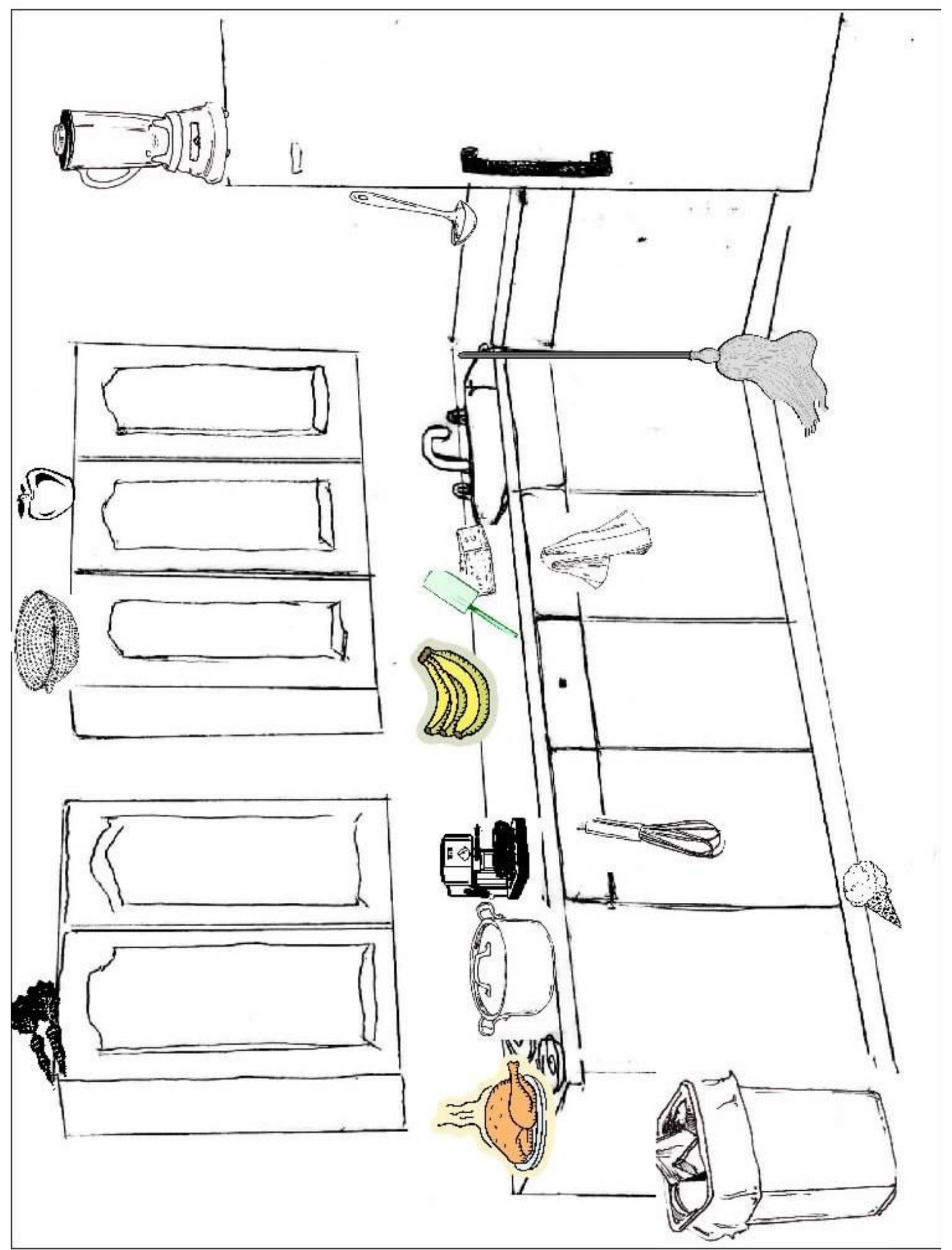




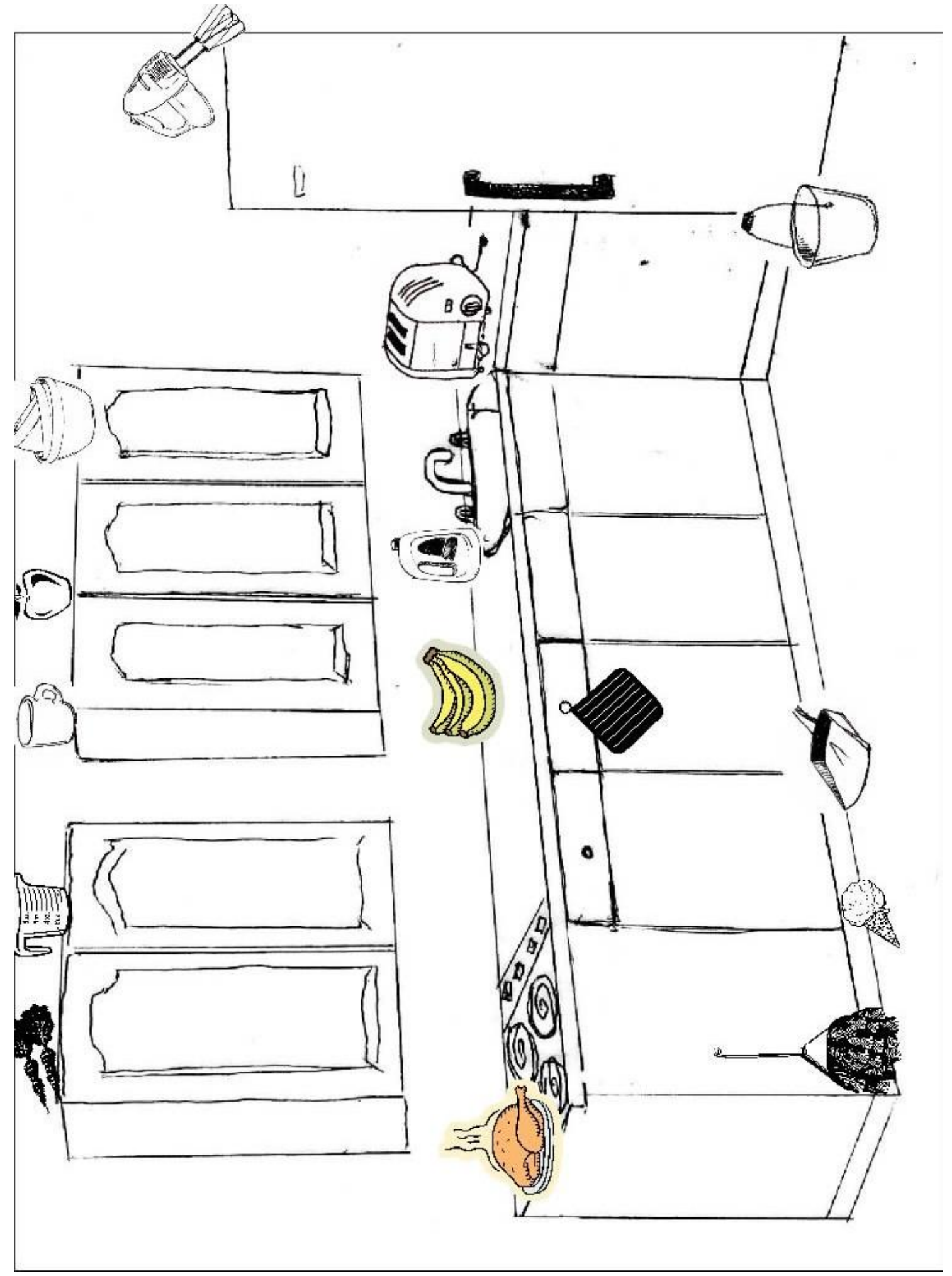




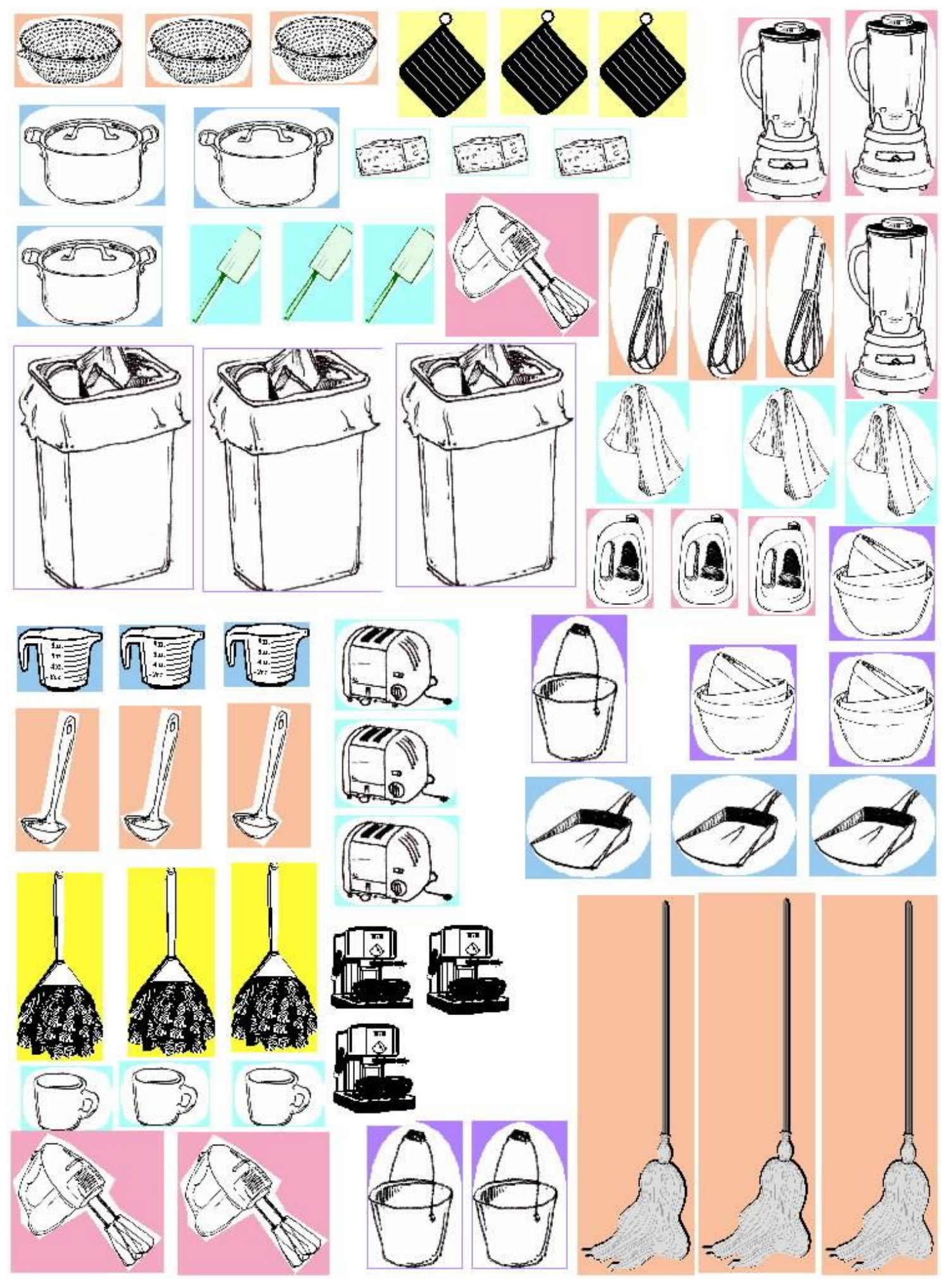


TASK 2: GUESSING FROM THE PICTURE: WHAT HAS HAPPENED (Adapted from Hill \& Mallet, 1972)

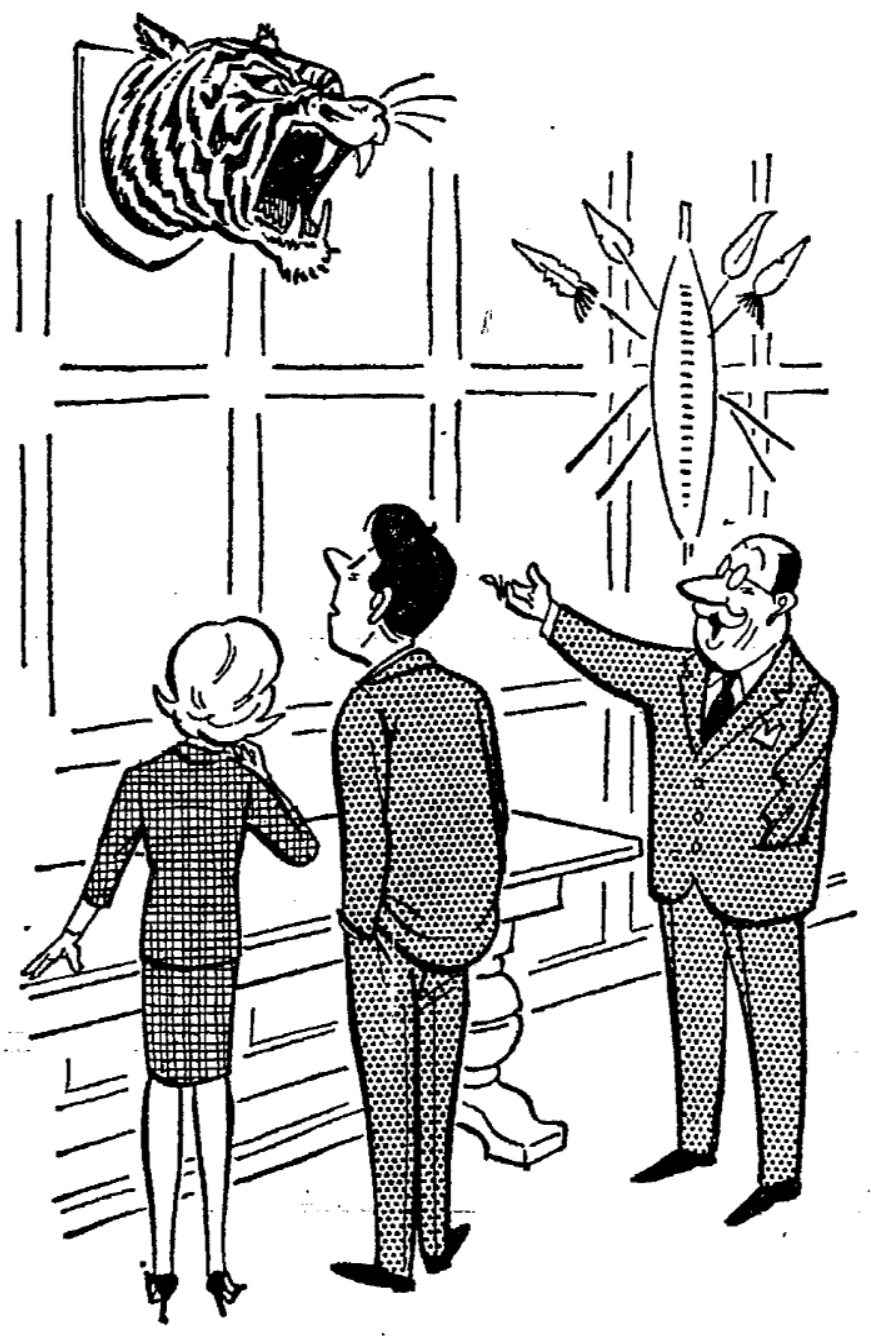

'At first he was so tame that he used to eat out of my hand.' 


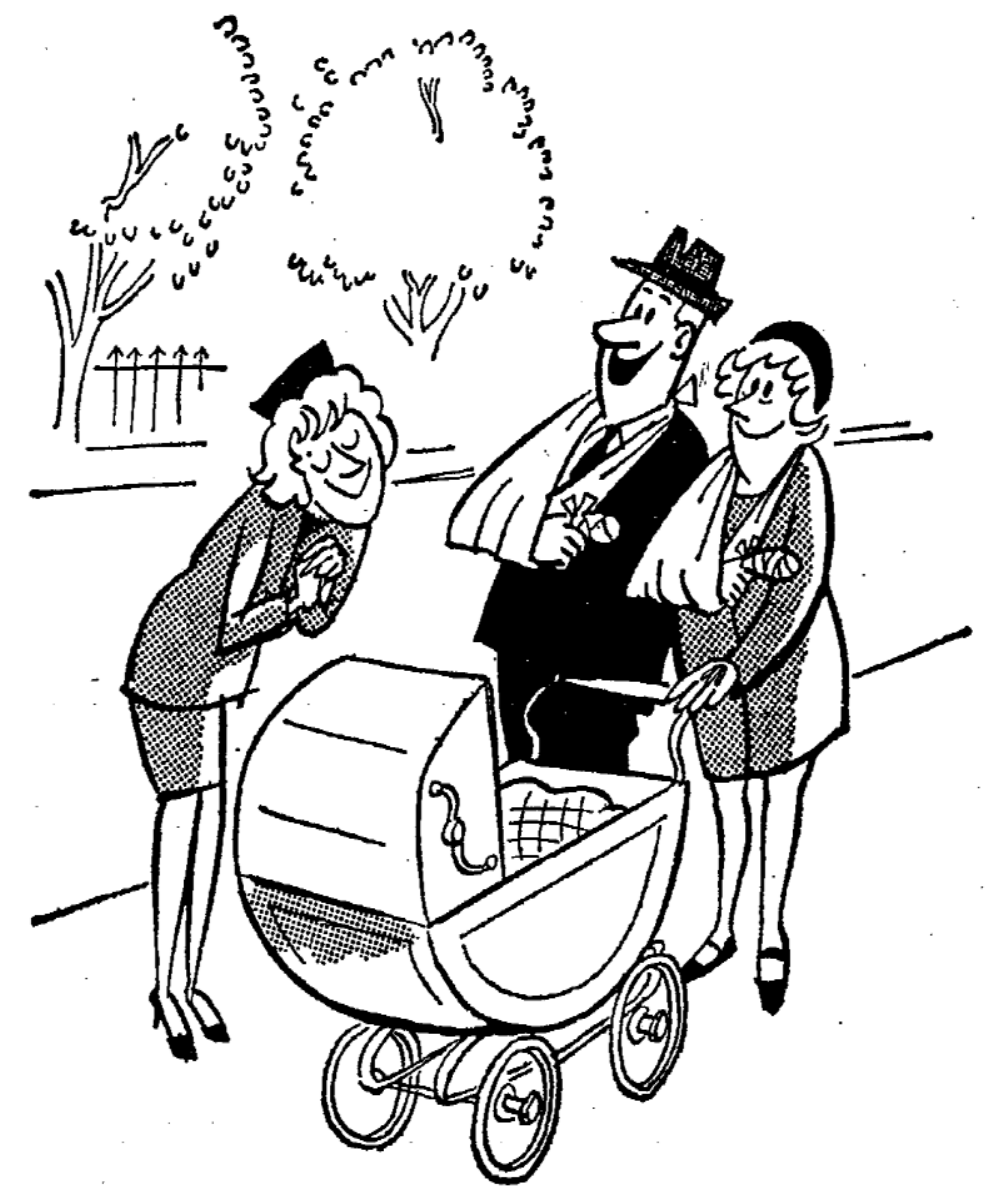

Yesterday we discovered that he has got a tooth now.' 
TASK 3: STORY-TELLING (Adapted from Ur, 1981)
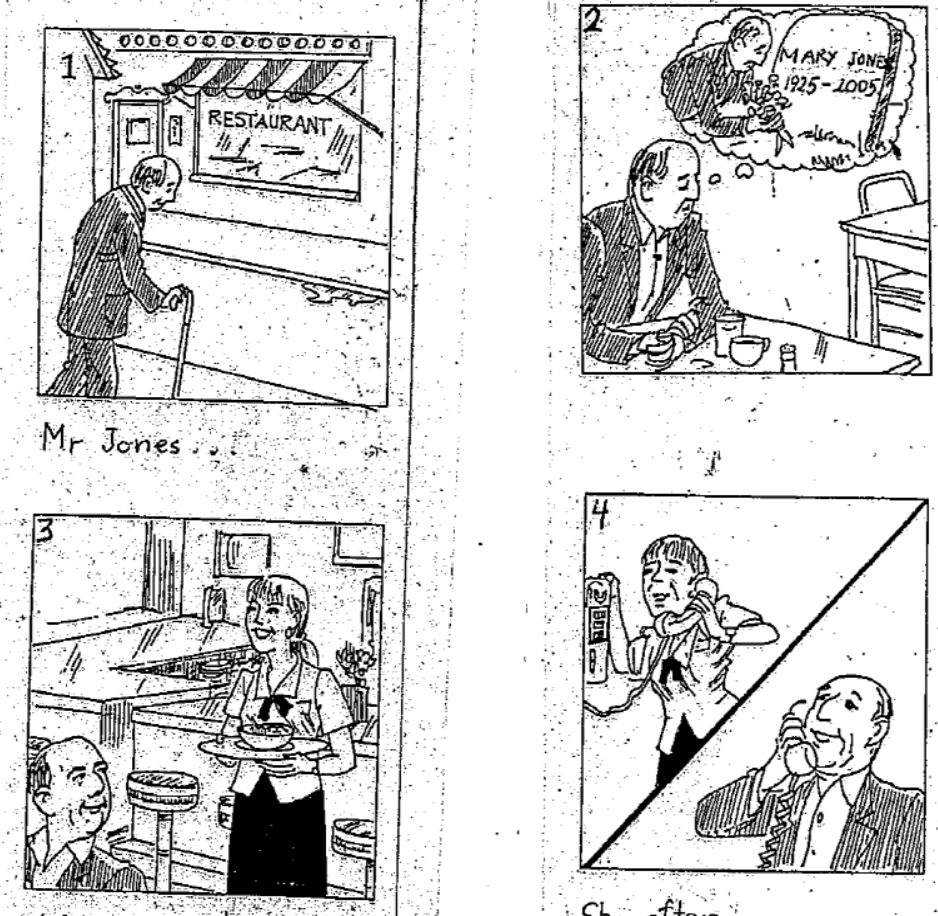

After sometime...

She often

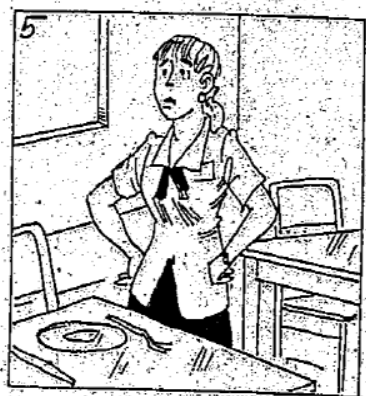

One day.
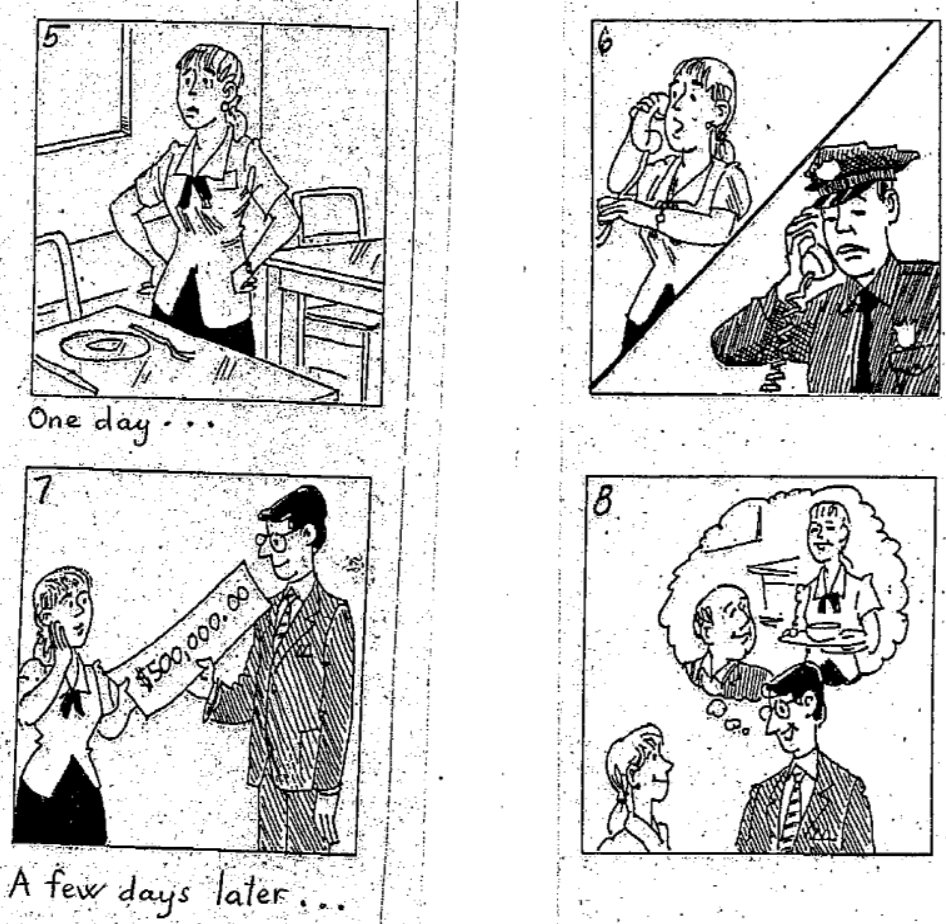


\section{APPENDIX 9: SAMPLE FFES FROM A BEGINNING CLASS - DESCRIPTIVE STUDY}

\section{Episode 01 B2}

Sx: How do you feel before an important exam?

Sxx: I... I feel nervous /'ne-v3s/ before an important exam.

T: uhm, you feel nervous /'n3:-v3s/

Sxx: /n3:-v3s/

T: before an important exam, ok.

Sx: an important exam

T: $\quad$ yep

\section{Episode 02 B2}

Sx: very /he/ to speak in front of a lot of... a lot people, I feel em... /'em-ba-ras/

T: embarrassed /em-'ba-r3st/, embarrassed /em-'ba-r3st/ yeah, right

Sx: embarrassed /em-'ba-r3st/

T: right, ok.

\section{Episode 03 B2}

Sx: yeah, and when I can't remember someone's name, I feel very embarrassed... embarrassed... I feel very embarrassed when xxx.

And I feel /'w3-ring/ when I ...lose my /'we-lis/

T: wallet/'wolit/

Sx: /'wolit/

T: $\quad$ say /'wolit/, yeah.

\section{Episode 04 B2}

T: $\quad$ You feel worried when you lose your wallet.(.)

Why do you feel worried when you lose your wallet?

Thanh, why do you feel...?

Sx: I... I... I have a lots of mo... uhm... important /im'post3nt/ information in my wallet.

T: uhm, so you mean you keep a lot of important things in your wallet.

Sx: yeah, keep a lot of important things 
T: that's why

\section{Episode 05 B2}

Sx: $\quad$ I ...I feel ...uhm, I feel...uhm... I feel /'ska:red/ ... /s'ka:-red/ when I ...if I see...

Sxx: /'ske3d/

Sx: a big spider

T: uhm, you say you feel scared /ske3d/

T + Ss: /ske3d/

T: uhuh

Sx: /ske3d/ if I see a big spider

T: uhuh

Sx: a big spider

\section{Episode 06 B2}

Sx: I feel worry ...before an important exam.

T: $\quad$ you feel? you feel? before an important exam.

Sx: worry

T: $\quad$ worried, uhuh. Usually, people feel nervous

\section{Episode 07 B2}

Sx: I feel quite angry when I miss the $/ \mathrm{j} 3 /$ train ... my train

Sxx: miss the $/ \mathrm{j} 3 /$ train $/ \operatorname{tran} /$

T: $\quad$ miss the train /th3 trein/, huh?

Sx: $\quad$ yes, so quite...

T: angry

Sx: quite angry

\section{Episode 08 B2}

T: yeah, you feel angry when you miss the train

Sx: angry himself

T: ah, angry with yourself

Sx: uhuh [students laugh]

T: because you get up late or something like this.

\section{Episode 09 B2}


Sx: what time did you go to bed last night?

Sxx: oh, before nine, I /'lef3n/ really tired

T: oh, I felt

Sx: I felt... I felt really tired

T: $\quad$ really tired. Right.

\section{Episode 10 B2}

Sx: oh, your hand feels cold /kou/... feels /kous/

T: $\quad$ cold /kould/

Sx: /kould/ 


\section{APPENDIX 10: SAMPLE FFES FROM AN ADVANCED CLASS - DESCRIPTIVE STUDY}

\section{Episode 01 A3}

T: Has any of your friends or family gone to live in a foreign country?

Sx: My aunt has gone to Canada because her husband live there.

T: $\quad$ Her husband lives there. Uhm. (.)

Fred, you've got any relatives or acquaintances or friends who have gone to live in a foreign country?

\section{Episode 02 A3}

Sx: I know one person.

When he cames, he's a British or somewhere in Europe.

She come to Vietnam and live here in about 8 years

T: $\quad$ she has lived here for 8 years

Sx: $\quad$ yes, for 8 years.

\section{Episode 03 A3}

Sx: He works for...

T: $\quad$ she or he?

Sx: $\mathrm{He}$

T: $\quad \mathrm{He}$

\section{Episode 04 A3}

Sx: He work for a company, energy, solar energy

T: He works for a solar energy company

Sx: yeah

\section{Episode 05 A3}

Sx: the life in Vietnam is maybe very different from the life in their country because you see the traffic here is terrible. He says me that it's terrible, so he must go...

T: he told you that

Sx: yes

\section{Episode 06 A3}


T: traffic in Vietnam is terrible

Sx: $\quad$ so he don't use any motorbike or even he knows go to work by bus he just...

T: he doesn't go to work by bus, he doesn't use a motorbike,

Sx: yes

\section{Episode 07 A3}

Sx: I think maybe a big problem is for food.

People eat something like spaghetti or pizzas and they can't eat the Vietnamese food.

T: cannot eat Vietnamese food.

Sx: yeah

\section{Episode 08 A3}

Sx: I miss rolling food

T: do you mean spring rolls? Spring rolls?

Sx: yes,

T: $\quad$ ram ấy hả? (Do you mean spring rolls?)

Sx: no

T: bánh tráng cuốn thịt heo ấy hả? (Do you mean pork rolls?)

Sx: $\quad d a($ yes)

[Students and teacher laugh]

\section{Episode 09 A3}

Sx: that food, how to say. It's made of wheat, also it's made of ...

T: noodle? What kind of noodles?

Sx: $\quad$ mắm cái (a special kind of fishsauce)

T: bún mắm (noodles with special fishsauce), noodles with fish sauce

Sx: yes

[students and teacher laugh]

\section{Episode 10 A3}

Sx: Kate miss her country

T: yeah, Kate misses his country

Ss: yeah 


\section{- 268 -}




\section{APPENDIX 11: SAMPLE FFES, SUBSEQUENT TEST ITEMS AND STIMULATED RECALL WITH BEGINNING STUDENTS OF L1 GROUP - EXPERIMENTAL STUDY}

\section{Episode 01 BV10}

\section{FFE from interactive tasks}

BV10: where is my book?

$\mathrm{R}$ : $\quad$ your book is on the floor, next to the slippers

BV10: yes, on the floor

$\mathrm{R}$ : $\quad$ next to the slippers

BV10: next to slippers [

R: you know what slippers are?

BV10: uhm...

R: $\quad$ slippers la doi dep mang trong nha (slippers are footwear you often wear in the house).

BV10: yes.

$\mathrm{R}$ : $\quad$ so the book is on the floor, next to the slippers.

\section{Test item}

R: how do you call a pair of footwear you wear inside the house?

[points at the slippers in the picture]

BV10: this is ... (.)

SR: [translated] I didn't know the word 'slippers'.

I couldn't understand if you just spoke English.

I learnt that word, but I couldn't remember.

\section{Episode 02 BV10}

\section{FFE from interactive tasks}

BV10: on the floor?

$\mathrm{R}$ : you know the floor?

BV10: no 
R: floor la san nha do. [points at the floor]

BV10: ah, yes.

\section{Test item}

R: how do you call this part of the house? [points at the floor]

BV10: this ... this ...floor

SR: [translated] I had known the word 'floor' before, but how come I couldn't remember it then. I was not too nervous. I didn't remember the words I had known maybe because I didn't use them often enough.

\section{Episode 03 BV10}

\section{FFE from interactive tasks}

BV10: where is my ball?

$\mathrm{R}$ : $\quad$ your ball is on the floor, next to the bookcase

BV10: on the floor, next to the book...

$\mathrm{R}$ : bookcase. You know what a bookcase is? (.)

Bookcase la cai gia de sach do (Book case is a piece of furniture with shelves to put books on).

BV10: yes.

\section{Test item}

R: how do you call a piece of furniture with shelves to put books on?

BV10: shelf book

SR: I learnt the word 'bookcase' here. I only knew the word 'shelf book' [sic] before that.

\section{Episode 04 BV10}

\section{FFE from interactive tasks}

$\mathrm{R}$ : have you seen my cushion anywhere? 
BV10: my cushion

R: you know what cushion means?

BV10: no

R: cushion la cai goi dem nguoi ta dat tren ghe de ngoi cho em do (cushion is like a pillow, a soft bag of cloth to cushion on a sofa for example).

BV10: yes, I have seen it on the sofa beside the umbrella.

\section{Test item}

R: how do you call a soft bag of cloth to sit on a sofa for example?

[points at the cushion in a picture]

BV10: uhm (.) I don't know. I don't remember.

SR: [translated] I learnt the word 'cushion' from your Vietnamese explanation.

\section{Episodes 05 BV10}

\section{FFE from interactive tasks}

$\mathrm{R}$ : The CD is on the floor, next to the armchair.

BV10: next to the armchair. [puts the CD next to the chair]

R: no, that one is not an armchair. You know 'armchair'?

BV10: armchair (points at a chair)

R: $\quad$ khong phai, do la ghe thuong, cai nay moi la armchair ne (no, that is a chair.

This is an armchair). Co cho de 'arms' do, ghe banh do. (An armchair has space to rest your arms)

BV10: yes, ok.

\section{Test items}

R: How do you call this kind of seats? [points at an armchair]

BV10: chair... an chair

SR: [translated] I understood the word 'armchair'.

Episodes 06 BV10

FFE from interactive tasks 
$\mathrm{R}: \quad$ have you seen my pipe anywhere?

BV10: /pai/

R: $\quad$ pipe

BV10: pipe

$\mathrm{R}$ : you know what a pipe is?

BV10: no, I don't know.

R: no la do dung de hut thuoc, co mot cho nhoi thuoc vao de hut (it is an implement for smoking. It has a small bowl at the end and people put tobacco in to smoke). Cai tau thuoc do [gives Vietnamese translation].

BV10: yes, ok. It's on the desk

\section{Test items}

R: how do you call a tool which has a small bowl at one end to put tobacco in for smoking? [points at the pipe in a picture]

BV10: it's smoke.

SR: [translated] I learnt the word 'pipe' but I couldn't remember it for the test.

\section{Episode 07 BV10}

\section{FFE from interactive tasks}

BV10: 'tat' la chu gi? (what is 'tat' in English?)

R: $\quad$ 'socks'

BV10: sock

$\mathrm{R}$ : doi tat la socks ( a pair of them is socks)

BV10: socks. where are socks?

\section{Test item}

R: how do you call the pair of things covering your feet.

You often wear them before wearing shoes? [points at the socks in a picture]

BV10: the /su:/

SR: [learner did not report any noticing of this item] 


\section{Episode 08 BV10}

\section{FFE from interactive tasks}

BV10: he gets... he have... he has get a hat ... your hat.... his hat.

R: $\quad$ em khong the noi (you cannot say) 'he has get', boi vi 'has get' o thi HTHT phai la 'has or have + QKPT' (because for Present Perfect, you need have or has + PP).

BV10: got... gotten

R: chu 'bat duoc, chup duoc' la chu 'catch' (the word 'bat duoc, chup duoc' is 'catch'.)

BV10: catch, he has catch his hat

R: $\quad$ qkpt la chu 'caught. (its PP form is 'caught')

BV10: caught. He has caught his hat.

\section{Test item}

R: $\quad$ Please listen to these sentences and tell me if they are grammatically correct:

He has catch his hat.

BV10: has catch his hat. wrong. catched... caught. 'He has caught his hat'

SR: [translated] I learnt the word 'catch'. Also I used the wrong form of this word in this tense.

I didn't have enough vocabulary to express myself.

I used the wrong tense, Present Simple instead of Present Perfect.

I knew it right when you corrected me.

\section{Episode 09 BV10}

\section{FFE from interactive tasks}

BV10: old woman has across

R: $\quad$ has crossed, khong phai across (not across). 'has crossed'

BV10: has crossed

R: $\quad$ dong tu 'crossed', con across la gioi tu 
(crossed is a verb while across is just a preposition)

BV10: has crossed the /rau/

$\mathrm{R}: \quad$ the road

BV10: the road.

\section{Test item}

R: Please listen to these sentences and tell me if they are grammatically correct: the woman has across the road. Right or wrong?

BV10: Right

SR: [translated] I mistook the word 'across' for 'cross'.

\section{Episode 10 BV10}

\section{FFE from interactive tasks}

BV10: the dog found a bag. Then he took dog go home.

$\mathrm{R}$ : he took the dog?

BV10: the dog go home

R: and what?

BV10: and the bag go home

R: $\quad$ he took the bag home, chu khong phai la go home (not go home).

Khong noi la (do not say) took the dog go home, 'took the dog home' thoi (just say) 'dua con cho ve nha' ('take the dog home').

BV10: yes.

\section{Test item}

R: Please listen to this sentence and tell me if it is structurally correct: 'he took the dog go home'. Right or wrong?

BV10: wrong. He has taken the dog go home.

SR: [translated] I was wrong to say 'take the dog go home' and I knew it right when you corrected me. 


\section{APPENDIX 12: SAMPLE FFES, SUBSEQUENT TEST ITEMS AND STIMULATED RECALL WITH ADVANCED STUDENTS OF L1 GROUP - EXPERIMENTAL STUDY}

\section{Episode 01 AV20}

\section{FFE from interactive tasks}

AV20: can I have this one?

$\mathrm{R}$ : what is this one?

AV20: this... uhm... a mixer

R: $\quad$ a food-blender, cai nay la cai binh xay sinh to, de xay nhuyen thuc pham (this is a food blender. It is used to blend food, making it smooth) food-blender, khong phai mixer (not a mixer)

AV20: yes. (.)

\section{Test item:}

R: how do you call a machine in the kitchen that you use when you want to make food become smoothly mixed?

AV20: blend... blender.

SR: [translated] I learnt the word 'food-blender'.

The words were not new, but the compound noun was new.

\section{Episode 02 AV20}

\section{FFE from interactive tasks}

$\mathrm{R}: \quad$ can I borrow your mug, please?

AV20: mug. yes (.) mug.

$\mathrm{R}$ : you know what a mug is?

AV20: mug, uhm

R: $\quad$ mug

AV20: this one? [points at a kitchen towel]

R: Khong, cai nay la mug ne (no, this one is a mug). Cai nay goi la cai coc vai [gives the Vietnamese equivalent of the word "mug"]. 
No khong phai la 'cup', no cao hon va co thanh day

(it is not a cup, it is taller and thicker).

Nguoi ta goi no la mug (It is called 'mug') (.)

You know that word?

AV20: no [tries to write down and R helps with spelling].

$\mathrm{R}$ : could I borrow your mug, please?

AV20: sure, here you are.

\section{Test item:}

R: How do you call a drinking vessel which is very much like a cup, but taller and thicker?

AV20: $\mathrm{a} / \mathrm{m}^{\wedge} \mathrm{t} /$

SR: [translated] I learnt the word 'mug'.

\section{Episode 03 AV20}

\section{FFE from interactive tasks}

AV20: Could I borrow you the waste basket?

R: $\quad$ khi ma con noi 'basket' no la cai dang nhu cai gio ma co cac lo o tren, con cai nay no la cai bin ('Basket' is not an enclosed container, but a bin is).

Day la cai thung rac chu khong phai gio rac

(so it is a 'waste bin', not a 'waste basket').

Day goi la 'rubbish bin' hay la 'waste bin'.

(So call it 'rubbish bin' or 'waste bin'.)

AV20: (.)

\section{Test item:}

R: how do you call an enclosed container in the kitchen or in the house that you often contain rubbish?

AV20: rubbish bin

SR: [translated] I learnt the difference between basket and bin. 


\section{Episode 04 \& 05 AV20}

\section{FFE from interactive tasks}

R: can I borrow your egg-beater, please?

AV20: yes (gives the $\mathrm{R}$ a whisk)

$\mathrm{R}$ : cai nay khong phai egg-beater (this one is not an egg-beater)

Khi ma noi egg-beater la nguoi ta noi cai may danh trung

(an egg-beater refers to a machine used to beat eggs).

Con cai nay la do danh bang tay

(This is an tool for beating eggs by hand), no goi la whisk (it is called 'whisk')

AV20: [tries to write the word down and $\mathrm{R}$ helps with spelling].

$\mathrm{R}$ : $\quad$ con cai nay moi la egg-beater (and this is an egg-beater)

AV20: [gives the picture of the egg-beater to R]

\section{Test items:}

R: how do you call a machine you use when you want to stir or mix things like eggs or oil or flour together so that you can make a cake for example?

AV20: I'm sorry, I can't remember.

R: How do you call an implement in the kitchen also used to mix food, but you use your hands to do that?

AV20: Oh, (.) uhm

SR: [translated] I learnt the words 'egg-beaters' and 'whisk', couldn't remember though.

\section{Episode 06 AV20}

\section{FFE from interactive tasks}

AV20: I want to borrow this one but I don't... [laughs]

$\mathrm{R}$ : this is a mop, cai cay chui nha. Cay dai co mieng vai o mot dau (a mop. It is a long stick with a piece of absorbent cloth at one end). 
AV20: [tries to write the word down and R gives help with spelling].

\section{Test item:}

R: How do you call a long stick with a piece of cloth attached to one end and you use it to clean, to wipe the floor?

AV20: uhm... mop

SR: [translated] I learnt the word 'mop'.

\section{Episode 07 AV20}

\section{FFE from interactive tasks}

R: Can I borrow your pot holder please?

AV20: can you spell?

R: pot holder

AV20: [tries to write the word down and R helps]. This one?

R: $\quad$ dung roi, no la pot holder, la cai mieng nhac do nong trong bep [gives explanation in Vietnamese]

AV20: (.)

\section{Test item:}

R: How do you call a piece of thick cloth that you use when you want to handle hot things in the kitchen?

AV20: pot holder.

SR: [translated] I learnt the word 'pot holder'. Too many new words [sighs].

\section{Episode 08 A V20}

\section{FFE from interactive tasks}

R: $\quad$ you know 'tame'?

AV20: uhm, tame ... (.) 
R: tu "tame" la mot tinh tu de chi cac con vat sau khi o chung voi nguoi da tro nen rat than thien, khong so nguoi (the word 'tame' is an adjective which is used to describe a wild animal after living with humans for some time, it becomes very friendly).

Tu nay co nghia la dan [gives Vietnamese equivalent].

AV20: yes.

\section{Test item:}

R: How do you describe a wild animal which after living with humans for some time becomes very friendly and close to humans?

AV20: tame

SR: [translated] I learnt the word 'tame'. At first, I thought it meant 'angry'.

\section{Episode 09 AV20}

\section{FFE from interactive tasks}

AV20: he ate his hand and that man cut the tiger's head to decorate his house.

R: Cai nay la em doan thoi. Nhu trong truong hop nay, em noi 'co le la con ho nay da an canh tay ong $t a^{\prime}$ (This is your guess. So, in this case, you may say 'the tiger might have eaten his arm').

AV20: (.)

R: $\quad$ neu em rat la chac thi con noi la (if you are very sure, you may say) 'the tiger must have eaten his arm'.

AV20: (.)

\section{Test item:}

R: $\quad$ Please look at this picture and make a guess on what has happened to these two people.

AV20: The baby might have bitten them.

SR: [translated] I learnt how to use the structures 'might have' and 'must have'. 


\section{Episode 10 AV20}

FFE from interactive tasks

$\mathrm{R}: \quad$ how do you call a man whose wife died?

AV20: he's a /wis-dou/

R: widow? Widows la chi phu nu (widows are for women), ok?

Khi ma goi la widow la goa phu.[gives the Vietnamese equivalent of "widow”]

Con ong nay la dan ong goa vo thi nguoi ta goi la...? (a woman whose husband died is called a widow. A man whose wife died is called ...?

(.) widower.

AV20: widower.

\section{Test item:}

R: how do you call a man whose wife died?

AV20: a widower

SR: [translated] I learnt the word 'widower'. 


\section{APPENDIX 13: SAMPLE FFES, SUBSEQUENT TEST ITEMS AND STIMULATED RECALL WITH BEGINNING STUDENTS OF TL GROUP - EXPERIMENTAL STUDY}

\section{Episode 01 BE12}

\section{FFE from interactive tasks}

BE12: where...where is glasses in living room?

$\mathrm{R}$ : where are my glasses? because 'glasses' is always plural.

So you have to say 'where are my glasses?'

BE12: yes. where are my glasses?

\section{Test item}

$\mathrm{R}$ : Listen to these sentences and tell me if they are grammatically right or wrong:

Where is my glasses? Right or wrong?

BE12: wrong. "Where are my glasses?"

SR: [translated] I should say "where are my glasses?", not "where is glasses?". I understood you right then.

\section{Episode 02 BE12}

\section{FFE from interactive tasks}

$\mathrm{R}: \quad$ where is my cup?

BE12: my cup. yes, your cup is in the TV

$\mathrm{R}: \quad$ in or on?

BE12: on the TV

\section{Test item}

$\mathrm{R}$ : Look at the picture and tell me if this sentence is right or wrong:

'The cup is in the TV'.

BE12: on, not in.

SR: [translated] I mistook the word 'on' for 'in'. "on the TV', not 'in the TV'. 
I recognized it right when you corrected me.

\section{Episode 03 BE12}

\section{FFE from interactive tasks}

$\mathrm{R}$ : where is my purse?

BE12: purse?

$\mathrm{R}: \quad$ purse. Do you know what a purse is?

BE12: No, I don't know.

$\mathrm{R}$ : purse is a small bag for ladies they often put their small things in like money, lipsticks or things like that. Very small bag. [points at the purse in the picture]

BE12: (.) it's on the chair.

\section{Test item}

R: how do you call a small bag women often use to put money and their small things? [points at the purse in the picture]

BE12: uhm... (.)

SR: [translated] I didn't understand immediately your explanation about the word 'purse' in English. I just picked it up after some time thinking it over.

\section{Episode 04 BE12}

\section{FFE from interactive tasks}

BE12: ah, it is in the sofa... in the chair.

$\mathrm{R}$ : in or on?

BE12: on the chair

$\mathrm{R}$ : uhm. Is this a chair?

BE12: yes

$\mathrm{R}$ : this one is not a chair. This one is a chair and this one is an armchair.

BE12: armchair

\section{Test item}


R: How do you call a seat with a back and this part? [points at an armchair in the picture]

BE12: armchair

SR: [translated] I learnt the word "armchair" then.

\section{Episode 05 BE12}

\section{FFE from interactive tasks}

BE12: where is my newspaper?

$\mathrm{R}$ : your newspaper is on the floor, under the armchair.

BE12: under the armchair [not sure where to mark in the picture].

R: $\quad$ you know 'under'?

BE12: 'dang sau' (it means 'behind')

R: no, under means beneath, here [points under the armchair in the picture].

BE12: yes [still looking]

R: what does 'floor' mean?

BE12: 'cai ngan' (a drawer)

$\mathrm{R}$ : no, the floor is here [points at the floor]

BE12: ohhh, yes. [marks the correct place in the picture].

\section{Test item}

R: how do you call this part of the house? [points at the floor in the picture]

BE12: floor

SR: [translated] I mistook the word 'floor' for 'armchair'. The word 'floor' was new to me then.

\section{Episodes 06 \& 07 BE12}

FFE from interactive tasks

$\mathrm{R}: \quad$ where are my slippers?

BE12: slipper... slipper... 
R: $\quad$ you know 'slippers'? What are slippers? (.)

slippers are the footwear, you wear inside the house, ok?

These are slippers [points at the slippers in the picture].

BE12: yes. It is on the floor and under the sofa.

R: $\quad$ very good, but you know they are plural, so you cannot say 'it is'.

BE12: they are.

\section{Test items}

R: how do you call a pair of footwear used inside the house?

[points at the slippers in the picture]

BE12: uhm... (.)

R: Look at the picture and listen to me: 'The slippers is on the floor, near the book.'. Right or wrong?

BE12: yes, it's right.

SR: [translated] 'slippers' was also new. Many other words! All new!

\section{Episode 08 BE12}

\section{FFE from interactive tasks}

$\mathrm{R}$ : where is my basket?

BE12: basket? uhm.. say again.

R: $\quad$ you know basket? This is a basket, a container made of bamboo or plastic used to contain things like fruit [points at the basket].

BE12: basket [tries to write the word down and R helps with spelling]. It is on the floor between the chair and the TV.

\section{Test item}

R: how do you call a container made of flexible materials like plastic or bamboo, used to contain things like fruits? [points at the basket in the picture]

BE12: /bei-kit/ 
SR: [translated] I knew the word 'basket', but I forgot. That word was not totally new, but I rarely used it, that's why I couldn't remember.

\section{Episode 09 BE12}

\section{FFE from interactive tasks}

BE12: The man has the dog... 'can' la chi he? (how to say 'can'?)

R: $\quad$ you remember? 'to bite'

BE12: bite

$\mathrm{R}: \quad$ and PP form is bitten

BE12: yes. The man has bitten... has the dog bite by him.

$\mathrm{R}: \quad$ the dog has?

BE12: has bite the man

R: has bitten, not 'bite'. You need to use PP form here.

BE12: has bit

\section{Test item}

R: The dog has bite the man. Right or wrong?

BE12: uhm, it's wrong. The man has the dog bite by... [laughs]

SR: [translated] I made mistakes with PP form of 'bite' for the tense. I knew all about the tense. I think I made so many mistakes because I never used it in speaking. When speaking, I couldn't avoid making mistakes.

\section{Episode 10 BE12}

\section{FFE from interactive tasks}

BE12: the girl has crossing the street.

$\mathrm{R}$ : $\quad$ has crossed, not crossing

BE12: crossed

\section{Test item}

$\mathrm{R}$ : the girl has crossing the street. Right or wrong? 
BE12: (.) right.

SR: [translated] I was wrong when using 'crossing', not 'crossed'. I rarely used this structure, so it was hard to do it correctly. 


\section{APPENDIX 14: SAMPLE FFES, SUBSEQUENT TEST ITEMS AND STIMULATED RECALL WITH ADVANCED STUDENTS OF TL GROUP - EXPERIMENTAL STUDY}

\section{Episode 01 AE14}

\section{FFE from interactive tasks}

AE14: can I borrow you a (.) a /'pa-kit/

$\mathrm{R}$ : basket? That one is not a basket, it is a rubbish bin

AE14: yes

$\mathrm{R}$ : you dump rubbish in it. A basket is not an enclosed container. This one is.

AE14: yes.

\section{Test item}

R: How do you call an enclosed container in the kitchen that you use for dumping rubbish?

AE14: a /pin/

SR: [translated] I learnt the word 'bin'. I learnt to differentiate a bin and a basket here.

\section{Episode 02 AE14}

\section{FFE from interactive tasks}

$\mathrm{R}$ : can I borrow your toaster, please?

AE14: toaster

R: you know a toaster?

AE14: yes, but now I don't see.

$\mathrm{R}$ : where is the toaster in your picture? Can you show me? [learner points at the oven] You say here?

This one is an oven. It is for cooking and this is a roasted chicken.

You know what a toaster is?

AE14: toaster?

$\mathrm{R}$ : $\quad$ toaster is a piece of kitchen equipment that you use to toast bread slices.

It makes bread slices hot, crunchy and brown, and this is a toaster. (.) 
AE14: yes. (...)

\section{Test item}

R: how do you call a machine in the kitchen that you use to make bread slices crunchy, hot and brown?

AE14: a... a oven

SR: [translated] I mistook the word 'oven' for 'toaster'. After you explained, I thought that it was the oven. I recognized my misunderstanding right after you corrected me though.

\section{Episode 03 AE14}

\section{FFE from interactive tasks}

AE14: Can I ask what is this? [points at the food-blender]

$\mathrm{R}$ : $\quad$ this is a food blender.

AE14: food-blender.

R: $\quad$ ok, you use it to blend food, to make food well-mixed and smooth.

AE14: can I borrow you a food blender?

\section{Test item}

R: how do you call a machine in the kitchen that you use to mix food, to make food become smooth?

AE14: a /wis-t3/

SR: [translated] I didn't know that word in English before then. I stopped for a long time, I wanted to ask, but I hesitated.

\section{Episode 04 AE14}

\section{FFE from interactive tasks}

AE14: how about this? [points at the picture of a whisk]

$\mathrm{R}: \quad$ this one is a whisk. 
AE14: whisk. How to spell?

R: whisk, w-h-i-s-k. This is a bundle of wires attached to a handle and you use it to stir liquid like oil or you mix oil or flour or eggs together to make a cake for example. A whisk.

AE14: a whisk. Can I borrow you a whisk?

\section{Test item}

R: how do you call a piece of equipment in the kitchen that you use to mix things?

It is a bundle of metal wires attached to a short handle and you use it to stir food like eggs, oil or flour by hand to make a cake for example?

AE14: a handle? (.)

SR: [translated] I didn't pick up the word 'whisk' then. I just understand it now when I am watching this video clip.

\section{Episode 05 AE14}

\section{FFE from interactive tasks}

$\mathrm{R}$ : Could you lend me a measuring cup, please?

AE14: a cup?

$\mathrm{R}$ : a measuring cup

AE14: measuring cup? is this? [points at a mug]

$\mathrm{R}$ : this one is not a cup. It is a mug. You know a mug?

AE14: [tries to write the word down and R helps]

R: A mug is taller and thicker than a cup and you use it to drink tea or coffee or any liquid like water. ok? This is a mug.

AE14: and is it ok? (points at a measuring cup)

$\mathrm{R}$ : yes, this one is a measuring cup. You use this cup to measure things in the kitchen like flour or milk or other things.

AE14: yes, I understand.

\section{Test item}

R: How do you call a container for drinking which is thicker, taller and heavier than a cup, often used for drinking tea or coffee? 
AE14: a... (.)

SR: [translated] there were two cups. After you explained, I learnt the word 'mug', but I couldn't remember.

\section{Episode 06 AE14}

\section{FFE from interactive tasks}

AE14: can I borrow you a spoon?

$\mathrm{R}$ : this one is not a spoon. It is long-handled with a very deep scoop at the end and you use it to convey food from a pot or a pan into to a bowl. We call it a ladle.

AE14: ladle. [tries to write the word down and R helps] Can I borrow you a ladle?

\section{Test item}

R: how do you call a big, long-handled spoon that you use to convey food from a pot or pan to a plate or bowl for example?

AE14: it's like a spoon, but not a spoon [laughs]

SR: [translated] I didn't know the word 'ladle' before then. I understood what you explained right then.

\section{Episode 07 AE14}

\section{FFE from interactive tasks}

AE14: so tame? what does it mean?

$\mathrm{R}$ : tame is an adjective used to describe a wild animal that lives with humans for some time and becomes very friendly, very close to humans.

AE14: (.)

\section{Test item}

R: how do you describe a wild animal which after living with humans for some time becomes very friendly and close to humans?

AE14: uhm /'tei-m3/ 
SR: [translated] This word was new to me.

\section{Episode 08 AE14}

\section{FFE from interactive tasks}

R: can you guess what has happened to this man that he lost his arm?

AE14: perhaps the tiger has beaten

R: eaten his arm

AE14: yes.

R: This is just a guess. If you are very sure about what has happened, say 'must have done something' and if you are not so sure, say 'might have done something', ok?

AE14: the tiger has tied... may be tied

R: might have been

AE14: might have been tied

\section{Test item}

R: [shows a picture] Please make a guess on what these two people have done.

AE14: I saw there was an accident. The woman might have called an ambulance.

SR: [translated] I had learnt this structure before, but I had never practised using it in speaking before.

\section{Episode 09 AE14}

\section{FFE from interactive tasks}

AE14: this man's wife is dead.

R: $\quad$ she was dead, ok? How do you call a man whose wife is dead?

AE14: (...)

$\mathrm{R}$ : a man whose wife died is called a widower.

AE14: widower 


\section{Test item}

R: how do you call a man whose wife died?

AE14: uhm (.) a /'wi-d3m-m3/

SR: [translated] in the second picture, I learnt the word 'widower'. I had just known the word 'widow' only.

\section{Episode 10 AE14}

\section{FFE from interactive tasks}

AE14: But one day, the waitress didn't see Mr Jones to the restaurant, so she call for a policeman.

$\mathrm{R}$ : called the police, not call for

AE14: call the police to find him.

\section{Test item}

R: Please listen to this sentence and tell me if it is grammatically correct:

'The waitress called for the police when seeing that the man didn't come to the restaurant that day'.

AE14: uhm, correct.

SR: [learner did not report any noticing of this item] 